\title{
CARACTERIZACIÓN SINÓPTICA DE LOS PROCESOS CONVECTIVOS EN EL INTERIOR DEL NORDESTE PENINSULAR
}

Nota técnica 3 de AEMET

\author{
Evelio Álvarez Lamata \\ Francisco Espejo Gil \\ Francisco José Cortés Rabinad \\ Cristina Lafragüeta Pérez \\ Roberto Serrano Notivoli
}
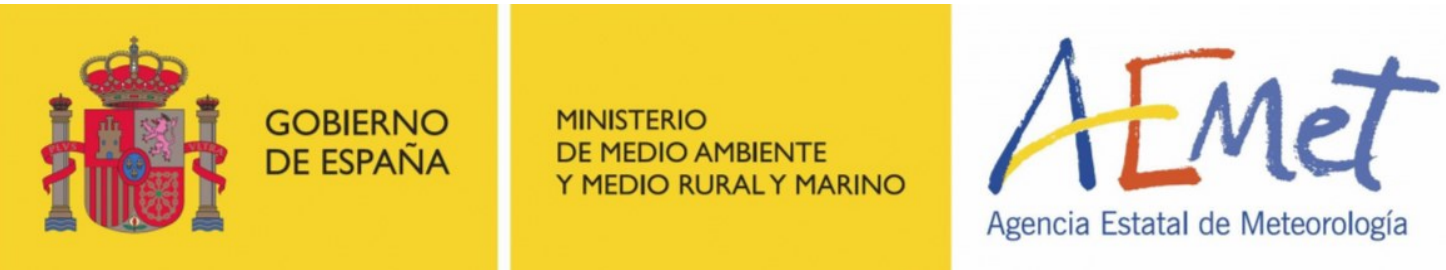


\section{$\approx$ datos}

Aviso Legal: los contenidos de esta publicación podrán ser reutilizados, citando la fuente y la fecha, en su caso, de la última actualización

Edita:

(c) Ministerio de Medio Ambiente, y Medio Rural y Marino

Agencia Estatal de Meteorología

Madrid, 2011

Catálogo de Publicaciones de la Administración General del Estado: https://cpage.mpr.gob.es/

NIPO: 784-11-008-8

https://doi.org/10.31978/784-11-008-8

Agencia Estatal de Meteorología (AEMET)

C/ Leonardo Prieto Castro, 8

28040 Madrid

http://www.aemet.es/

@Aemet_Esp 


\title{
CARACTERIZACIÓN SINÓPTICA DE LOS PROCESOS CONVECTIVOS EN EL INTERIOR DEL NORDESTE PENINSULAR
}

Nota técnica 3 de AEMET

\author{
Evelio Álvarez Lamata ${ }^{(1)}$ \\ Francisco Espejo Gil ${ }^{(1)}$ \\ Francisco José Cortés Rabinad ${ }^{(2)}$ \\ Cristina Lafragüeta Pérez ${ }^{(3)}$ \\ Roberto Serrano Notivoli ${ }^{(3)}$
}

(1) AEMET

(2) Sodemasa

(3) Universidad de Zaragoza 


\section{Agradecimientos}

Los autores agradecen a Francisco Martín León, Jefe del Área de Técnicas y Aplicaciones para la Predicción (A.T.A.P.) de AEMET, la revisión general de la obra. Con su concienzudo esfuerzo se ha mejorado, aclarado y enriquecido el contenido de la misma. Asimismo, gracias a Carlos Santos Burguete, del Área de Aplicaciones de AEMET, por su colaboración esencial para el procesado de los campos numéricos con Metview y especialmente con GRIB_API. También ha sido muy importante la colaboración de Samuel Buisán Sanz y José Luis Collado Aceituno para la instalación y uso de Metview en la D.T. de AEMET en Aragón. Gracias también a Francisco Pérez Puebla, del Área de Operación de las Redes de Observación, por la información aportada sobre la red de detección de descargas y sus trabajos previos de estadísticas ceráunicas a nivel nacional. Por último, gracias al Delegado Territorial de AEMET en Aragón, Amadeo Uriel González, por el apoyo y la comprensión que siempre ha mostrado durante la larga y compleja realización de este trabajo. 


\section{ÎNDICE}

1. Introducción ...................................................................................................

1.1. Justificación y objetivos del trabajo ............................................................ 1

1.2. Aspectos geográficos del área de estudio .................................................. 2

1.2.1. Unidades morfoestructurales ............................................................. 3

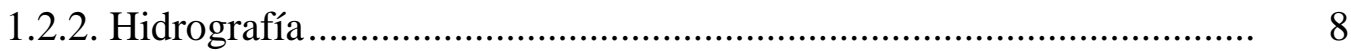

1.2.3. Caracterización climática....................................................................... 9

1.2.4. Organización territorial..................................................................... 16

2. Climatología de la convección........................................................................ 19

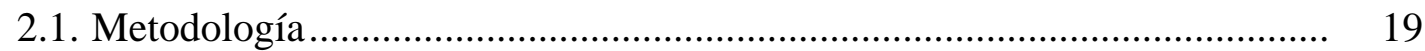

2.2. Actividad eléctrica ............................................................................. 24

2.2.1.Promedios de descargas eléctricas ................................................ 24

2.2.2.Promedios de días de tormenta .......................................................... 34

2.3. Precipitación .............................................................................................. 40

3. Clasificación sinóptica ..................................................................................... 45

3.1. Datos y metodología ................................................................................... 45

3.1.1. Criterios de clasificación ................................................................... 45

3.1.2. Origen de los datos ................................................................ 48

3.2. Justificación y procedimiento de la clasificación ....................................... 50

3.3. Descripción de los tipos de situaciones ....................................................... 52

3.3.1. Situaciones de masa de aire (Tipo 1) ................................................. 52

3.3.2. Situaciones del sur (Tipo 2) ............................................................ 55

3.3.3. Situaciones del suroeste con difluencia (Tipo 3) ............................... 58

3.3.4. Situaciones del suroeste sin difluencia (Tipo 4) ............................... 62

3.3.5. Situaciones del oeste (Tipo 5)..................................................... 65

3.3.6. Situaciones depresionarias entrantes (Tipo 6) ................................. 68

3.3.7. Situaciones depresionarias rebasadas (Tipo 7) .................................. 71

3.3.8. Situaciones de ondas largas del noroeste (Tipo 8)............................ 75

3.3.9. Situaciones de oclusiones a vaguadas rebasadas (Tipo 9) .................. 77

3.4. Distribución temporal .............................................................................. 80

4. Estudio de la relación entre precipitación y actividad eléctrica ......................... 83

4.1. Medidas de correlación ............................................................................. 83

4.1.1. Correlación mensual ..................................................................... 85 
4.1.2. Correlación por situaciones ............................................................. 86

4.1.3. Correlación geográfica .................................................................. 89

4.2. Medidas de asociación ............................................................................ 92

4.2.1.Asociación mensual ............................................................................. 95

4.2.2.Asociación por situaciones .............................................................. 96

4.2.3.Asociación geográfica ...................................................................... 97

5. Sistematización de las causas de los procesos convectivos ............................... 101

5.1. Metodología _................................................................................................. 101

5.1.1. Del modelo .................................................................................. 101

5.1.2. Del análisis estadístico ..................................................................... 103

5.2. Atribución general de causas .................................................................. 104

5.3. Atribución de causas para cada tipo sinóptico .......................................... 109

5.3.1. Situaciones de masa de aire (Tipo 1) .............................................. 110

5.3.2. Situaciones del sur (Tipo 2) ........................................................... 111

5.3.3. Situaciones del suroeste con difluencia (Tipo 3) .............................. 111

5.3.4. Situaciones del suroeste sin difluencia (Tipo 4) .............................. 112

5.3.5. Situaciones del oeste (Tipo 5)...................................................... 112

5.3.6. Situaciones depresionarias entrantes (Tipo 6) ................................. 113

5.3.7. Situaciones depresionarias rebasadas (Tipo 7) ................................. 114

5.3.8. Situaciones de ondas largas del noroeste (Tipo 8)........................... 114

5.3.9. Situaciones de oclusiones a vaguadas rebasadas (Tipo 9) .................. 115

6. Casos de estudio ......................................................................................... 119

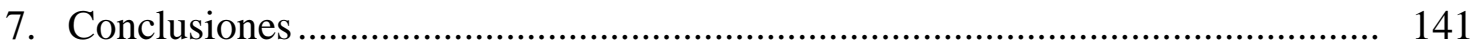

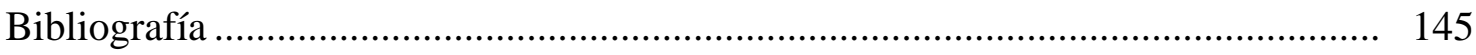

Glosario de abreviaturas y unidades ............................................................... 149 


\section{INTRODUCCIÓN}

\subsection{Justificaciốn y objetivos del trabajo}

Uno de los elementos más significativos de la meteorología y la climatología del interior del nordeste de la Península Ibérica es la actividad convectiva. La configuración de este territorio como un pasillo a caballo entre dos masas marítimas diferenciadas, el Atlántico y el Mediterráneo (Mapa 1.1), bordeada por sistemas montañosos en su mayor parte de importancia y con un relieve que facilita el calentamiento del aire y la convergencia de los vientos de su interior con los periféricos, de influencia marítima, aporta muchos ingredientes para que los fenómenos convectivos, como por ejemplo los rayos, se generen y desarrollen con más frecuencia e intensidad que en cualquier otro punto de la Península y se sitúe entre las zonas más propensas del continente europeo a la convección atmosférica (Imagen 1.1).

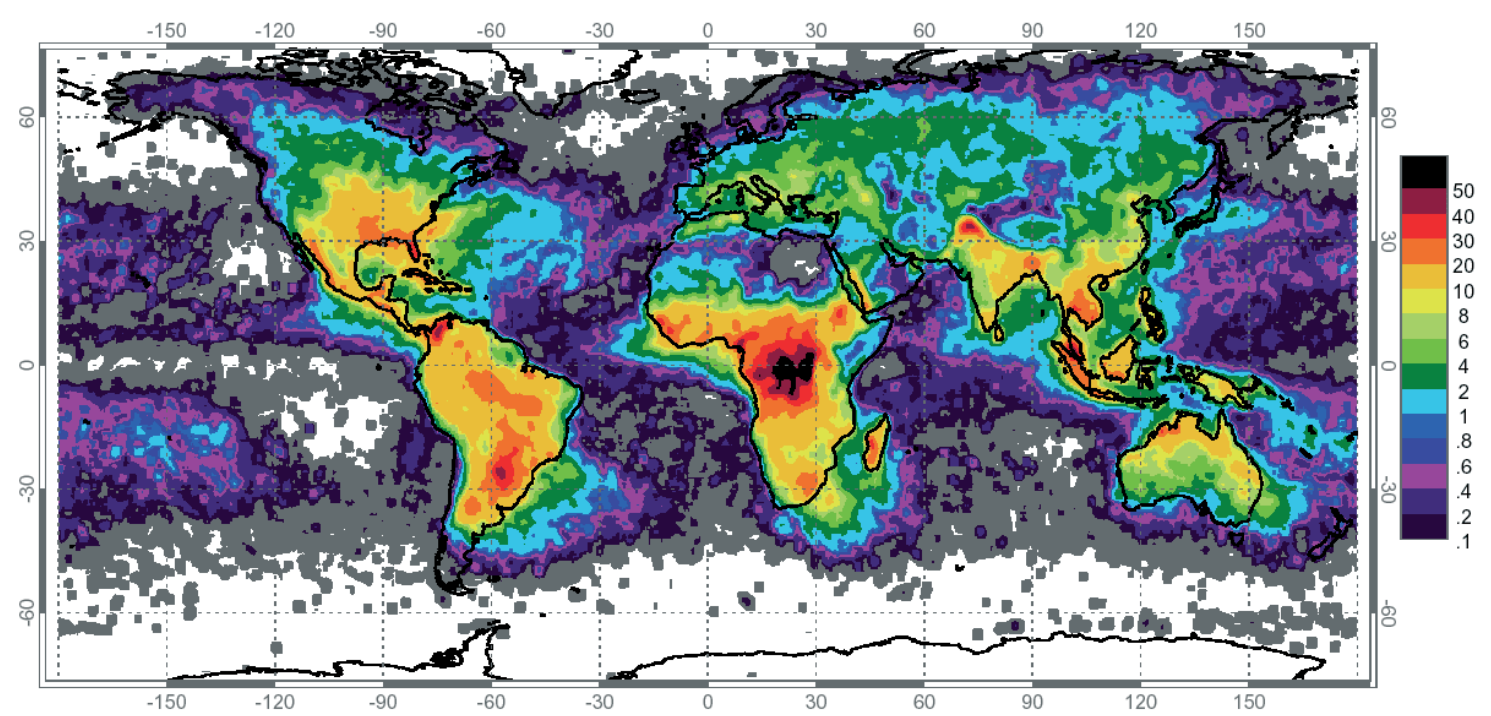

Imagen 1.1. Climatología mundial de número de descargas eléctricas por $\mathrm{km}^{2}$ para el periodo 1995-2003. (Fuente: NASA).

Este trabajo continúa y completa una línea de investigación sobre la convección, su climatología y sus causas del entonces Centro Meteorológico Territorial en Aragón, La Rioja y Navarra, que directa o indirectamente se ha reflejado en distintos trabajos, contribuciones a congresos y publicaciones (ÁlVAREZ, 2000; ÁlVAREZ, 2001; ESPEJO Y ÁlVAREZ, 2007; ÁlVAREZ ET AL., 2009; BUISÁN ET AL., 2009; BuISÁN Y ESPEJO, 2009). Esta línea de investigación se complementa con otra que tiene un gran interés en el estudio de los incendios forestales originados por rayo (ÁlvAREZ ET AL., 2005; ÁlVAREZ Y CORTÉS, 2007; LAFRAGÜETA ET AL., 2009) y con una tercera que estudia otras manifestaciones de la convección y del tiempo severo (RIOSALIDO ET AL., 1998; EsPejo y SANZ, 2001; CONESA, 2003; CONESA, 2004; REQUENA Y ESPEJO, 2007; ESPEJO, 2007).

En otras unidades de la Agencia Estatal de Meteorología, la climatología de la convección, a través de la actividad ceráunica, se ha tratado a nivel nacional en diferentes estudios y trabajos (PÉREZ Y ZANCAJO, 2008; PÉREZ Y ZANCAJO, 2010). 
Como resultado de todo el trabajo desarrollado en la Delegación en Aragón de la Agencia Estatal de Meteorología (AEMET), buena parte de él en colaboración con el Gobierno de Aragón, se ha generado una gran cantidad de información y una cierta especialización en el tema de la convección. Esta nota técnica pretende sintetizar todo ese trabajo realizando los siguientes objetivos:

- Realizar una climatología detallada de la actividad eléctrica, número de descargas que alcanzan el suelo y días de tormenta, para el área de estudio y el semestre cálido (1 de abril-30 de septiembre).

- Realizar una climatología de la precipitación para la misma área y periodo, investigando la relación entre actividad eléctrica y precipitación.

- Llevar a cabo una clasificación sinóptica de los tipos de circulación en el semestre cálido y estudiar la precipitación, las descargas y la probabilidad de tormentas por zonas y cada tipo de situación.

- Investigar los factores sinópticos y mesoescalares más favorecedores de la convección en general y para cada tipo de situación sinóptica.

- Analizar cada una de las situaciones a través de casos de estudio seleccionados.

En definitiva, este trabajo pretende describir la actividad convectiva en el periodo en el que es más significativa en el área de estudio —el semestre cálido—, sistematizar los distintos tipos de situación que la producen y relacionarla con la mayor o menor probabilidad espacial de aparición de convección en el área de estudio, así como aumentar el conocimiento sobre las causas y factores que juegan un papel más destacado para la activación de la convección según cada tipo de situación, con el fin último de mejorar la predecibilidad de estos fenómenos en el área.

En cuanto a la manera de llevarlo a cabo, se pretende hacer un estudio con una doble perspectiva. Por un lado se intenta hacer una nota técnica "al uso", un producto que sea útil para la operatividad de la predicción en AEMET. Por el otro, también se intenta dar a esta obra una dimensión de estudio climatológico de elementos que no siempre aparecen en las climatologías habituales, o que se hacen a partir de otros medios. La climatología de descargas y de días de tormenta a partir de la red de detección de descargas eléctricas, la investigación de sus características y causas, y de la relación entre situaciones sinópticas y convección hacen que, además de un producto útil para la predicción, esta nota intente, modestamente, al aportar información novedosa para el estudio de un elemento del clima de primordial importancia en el ámbito geográfico al que se refiere: la convección.

\subsection{Aspectos geográficos del ấrea de estudio}

El área de estudio (Mapas 1.1 y 1.2), abarca el nordeste de la Península Ibérica, comprendiendo las CC. AA. de Aragón, Navarra, La Rioja, País Vasco, el nordeste de Castilla-La Mancha, la franja occidental de Cataluña, la mitad norte de la Comunidad Valenciana, y la provincia de Soria en Castilla y León. 


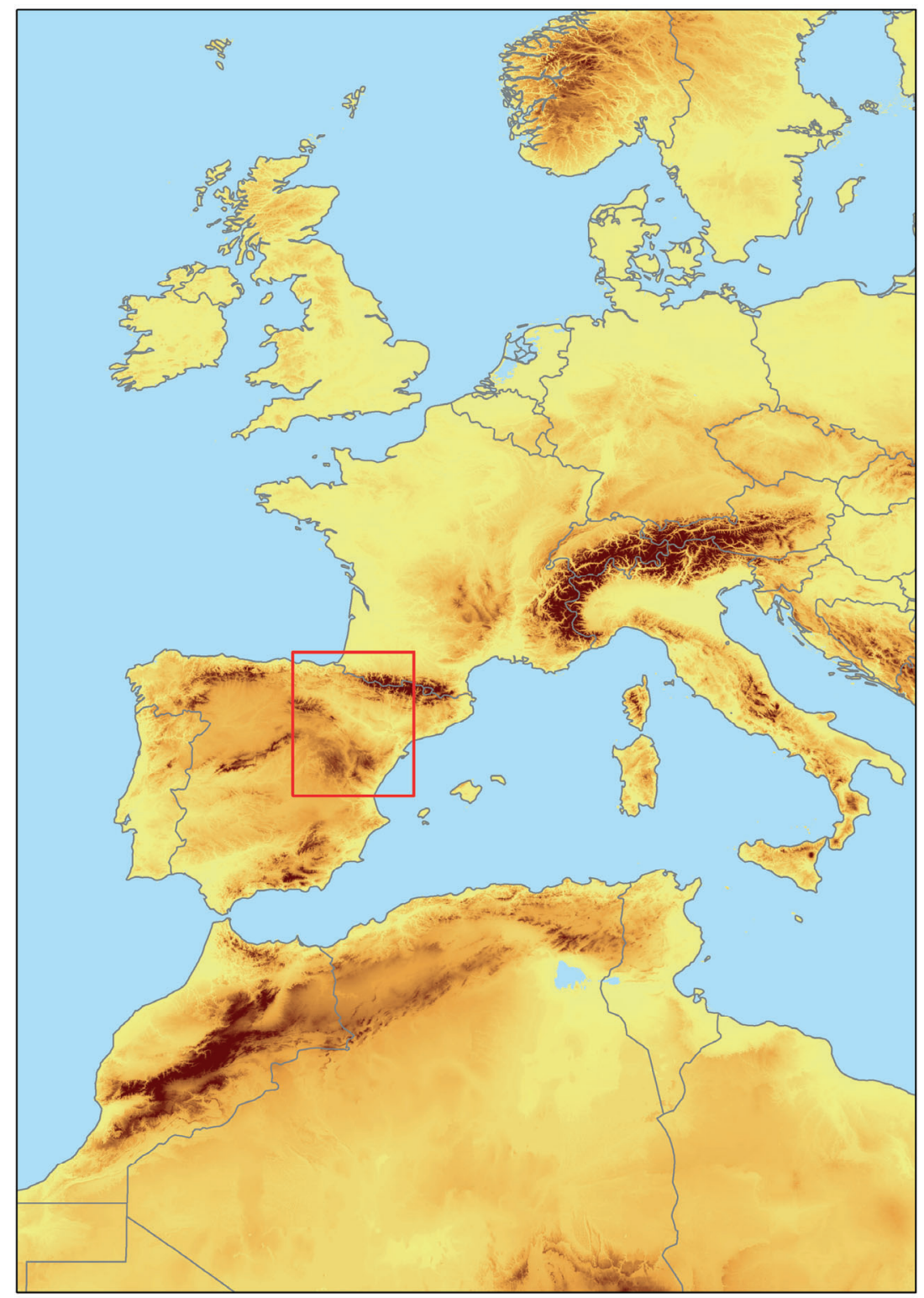

Mapa 1.1. Situación del área de estudio en el contexto regional.

\subsubsection{Unidades morfoestructurales}

Se pueden distinguir varias unidades del relieve en el área de estudio: los Montes Vascos, los Pirineos, el Sistema Ibérico, la Meseta, separada en la norte y la sur por el Sistema Central y la Cordillera Costero-Catalana. El centro está ocupado por la depresión del Ebro. Las llanuras litorales tienen muy poco desarrollo en las costas españolas, no así en la francesa, cuya extensión ocupa el extremo norte del área de estudio (Imágenes 1.2 y 1.3).

Los Pirineos constituyen una importante barrera montañosa de $435 \mathrm{~km}$ de longitud que forma el istmo de la península Ibérica entre el golfo de Vizcaya y el cabo de Creus. El sector central aragonés es el que ocupa las mayores altitudes (Aneto: $3404 \mathrm{~m}$; Posets: 3375 m; Monte Perdido: 3355 m; Vignemale: $3298 \mathrm{~m}$ ) perdiendo progresivamente altura hacia los márgenes navarro y catalán. La red fluvial compartimenta fuertemente 
el relieve dado que su disposición norte-sur es transversal a las estructuras pirenaicas, alineadas principalmente de oeste a este.

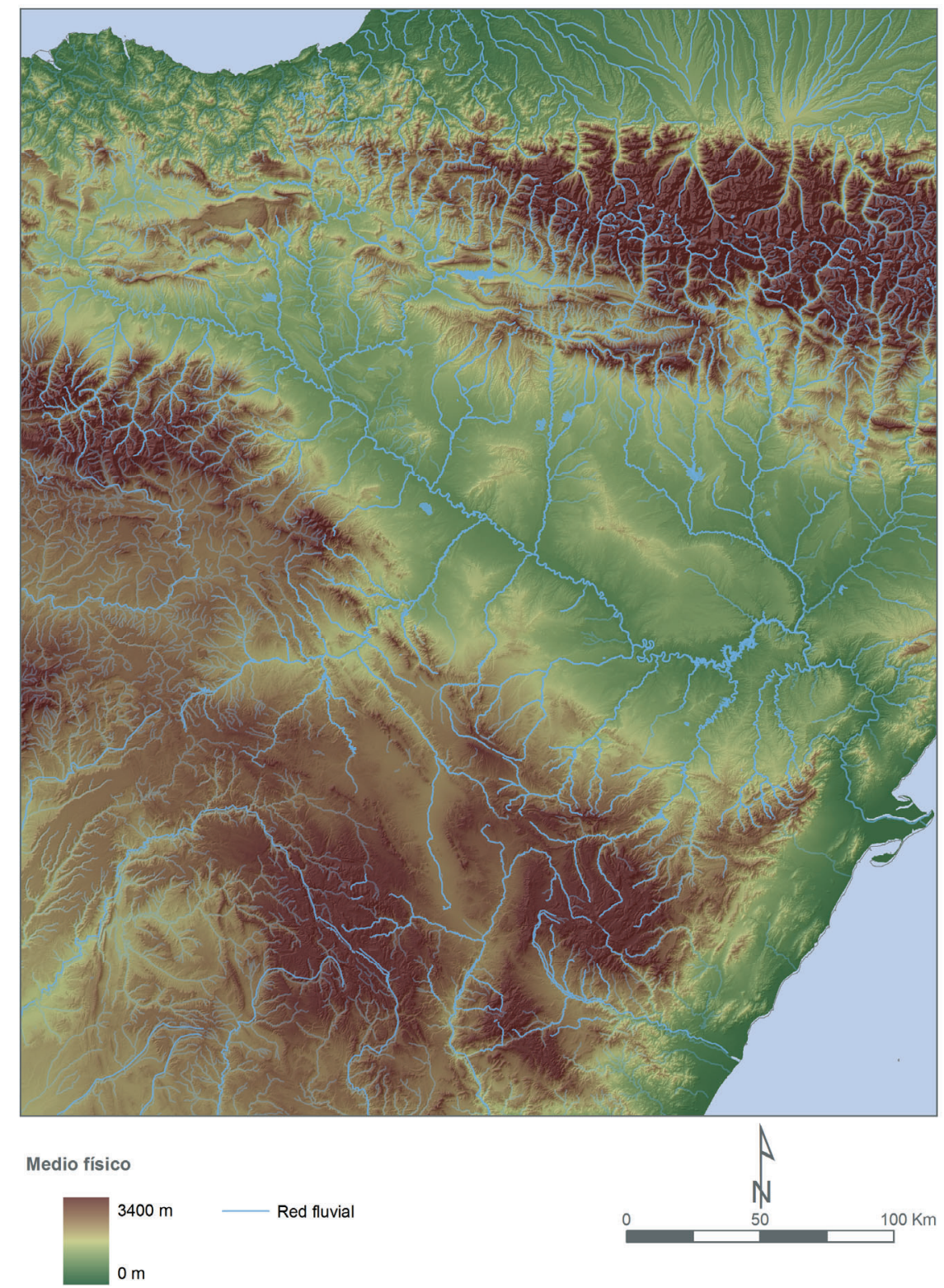

Mapa 1.2. Mapa físico de la zona de estudio.

Desde el punto de vista geomorfológico, se pueden distinguir cuatro unidades del relieve en la cordillera pirenaica, a las que se hace alusión en esta obra: el Pirineo Axial, las Sierras Interiores, el Sector Medio Pirenaico y las Sierras Exteriores.

Las zonas más altas de los Pirineos suelen coincidir con el núcleo más antiguo y resistente de la cadena, sobreelevado por el plegamiento alpino, y constituye el denominado Pirineo Axial. Está formado por materiales paleozoicos como granitos, pizarras o cuarcitas. Presenta una gran continuidad espacial en el Pirineo central (macizos de Maladeta, Perdiguero, Posets; Parzán y Punta Suelza; Vignemale, macizos de Panticosa, Balaitús y Anayet) y es mucho más disperso al oeste (Astún, valle de Guarrinza y, en Navarra, las más bajas sierras de Oroz-Betelu y macizos de Quinto Real y Cinco Villas). 
Las Sierras Interiores forman el cordal que constituye el espinazo continuo de la cadena, y están formadas por materiales sobre todo cretácicos (calizas y dolomías). Suponen un escalón altitudinal inferior con respecto al Pirineo Axial. La cota de los $3000 \mathrm{~m}$ sólo se ve superada en el caso del Monte Perdido. A esta unidad pertenecen topónimos como las sierras de Abodi, Ori y Larra, en Navarra; Sierra Bernera, Collarada, Peña Telera, Tendeñera, Cotiella o el Turbón, en Aragón, además del mencionado Monte Perdido.

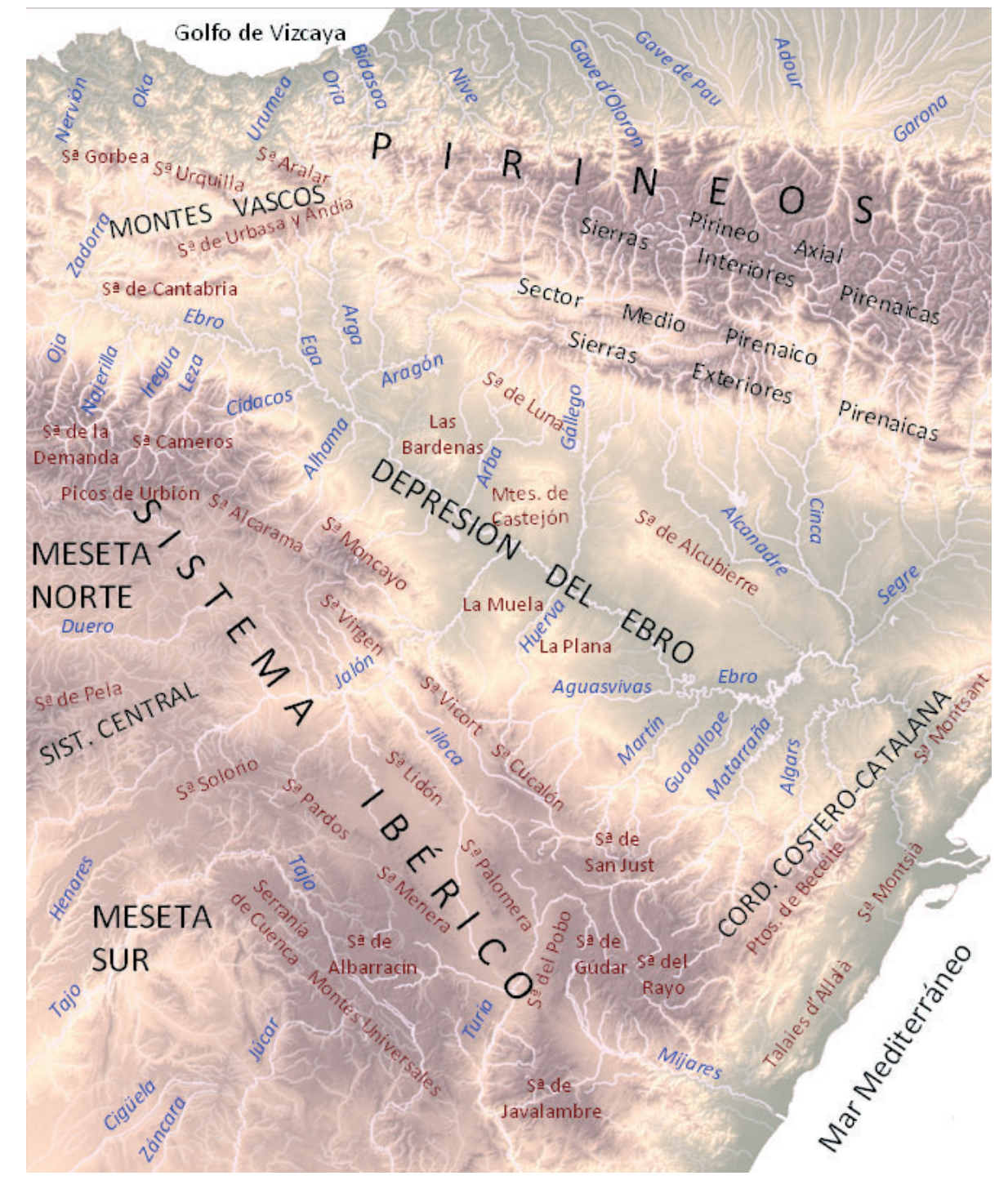

Imagen 1.2. Unidades del relieve del área de estudio y referencias toponímicas.

Más al sur se encuentra el Sector Medio Pirenaico, que es una unidad muy heterogénea formada por depresiones como la de Pamplona, la Canal de Berdún, la Val Ancha y la de Aínsa y por sierras que difícilmente superan los $1800 \mathrm{~m}$ de altitud (Gongolatz, San Juan de la Peña, Santa Liestra, Sis, etc.). Los materiales que la forman son de origen eoceno y oligoceno: areniscas, molasas, margas, etc. A medio camino entre el Sector Medio Pirenaico y las Sierras Interiores (normalmente incluidas en la primera unidad) se encuentra la subunidad del flysch eoceno, que incluye zonas como los montes de Areta, La Garcipollera o Sobrepuerto. 
El sector más meridional de los Pirineos forma la unidad de las Sierras Exteriores, en ocasiones denominada "Prepirineo". Se trata de calizas cretácicas con orientación esteoeste con altitudes máximas entre 1500 y $2000 \mathrm{~m}$. Entre ellas están la sierra de Cantabria al sur de Álava, sierras como Lóquiz, Izco y Leyre en Navarra y otras como Santo Domingo, Loarre, Guara y Montsec en Aragón.

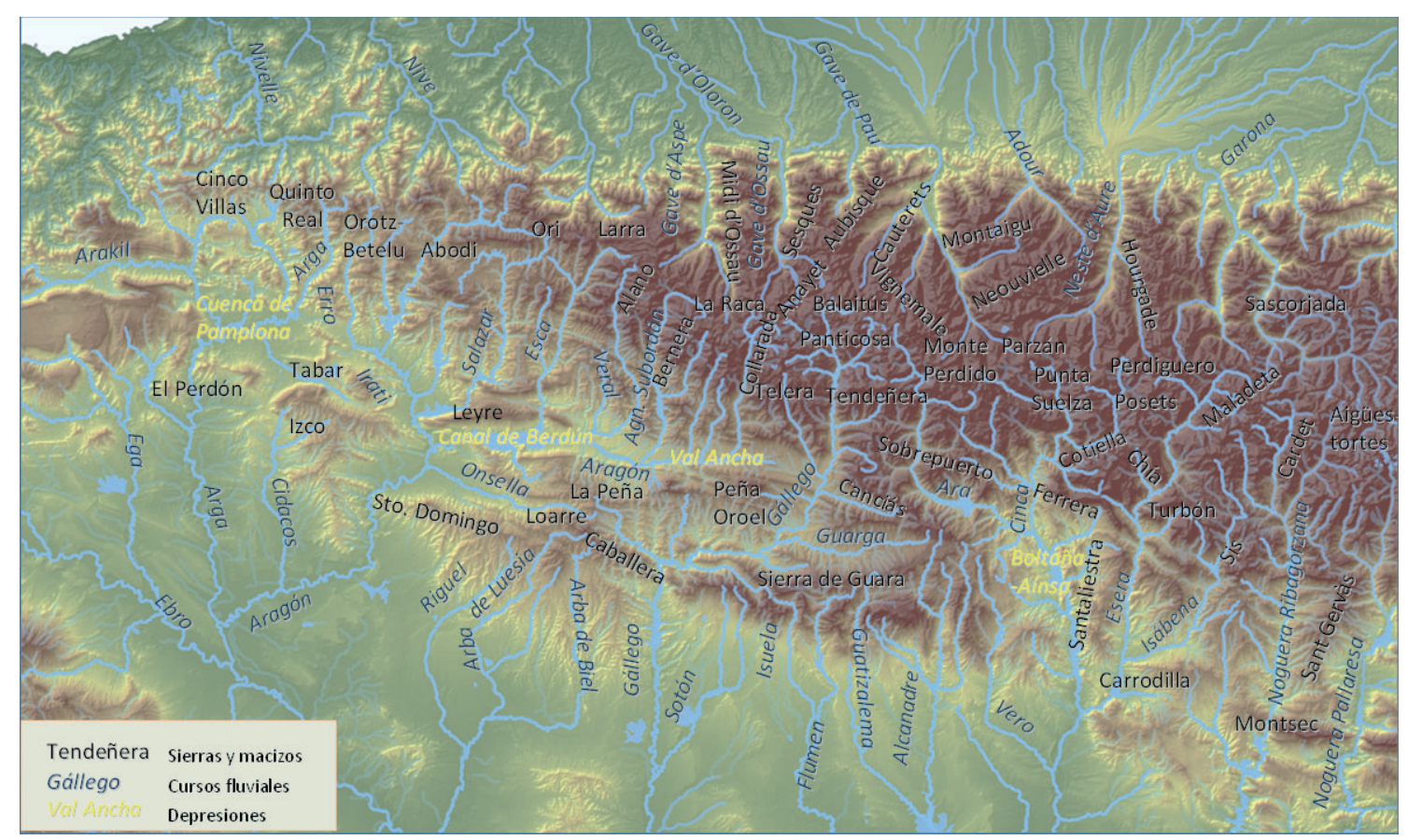

Imagen 1.3. Referencias toponímicas de la cadena pirenaica.

La depresión del Ebro es una amplia fosa tectónica, limitada al norte por los Pirineos, al sur por la Cordillera Ibérica y al este por la Cordillera Costero-Catalana. Está recorrida longitudinalmente por el río Ebro, que recoge los afluentes procedentes de las unidades montañosas. Las máximas cotas topográficas aparecen en las plataformas estructurales o muelas del sector central (sierra de Alcubierre, $811 \mathrm{~m}$ ) y en los relieves conglomeráticos del borde de cuenca, como Los Mallos de Riglos (1 $235 \mathrm{~m})$. En el Eoceno la cuenca pasó a ser endorreica recibiendo continuos aportes continentales en un ambiente de abanicos aluviales. En las zonas centrales domina una sedimentación fundamentalmente evaporítica (yesos) y rocas carbonatadas (margas y calizas), que son los bancos calcáreos que forman en la actualidad la estructura de relieves dominantes de la parte central de la depresión (las Muelas). A finales del Terciario la cuenca pasa a ser exorreica y la instalación del Ebro y sus afluentes modelan el paisaje actual. Los glacis y terrazas fluviales recubren parcialmente los fondos de los valles (PEÑA, 2004).

El Sistema Ibérico alcanza una longitud cercana a los $400 \mathrm{~km}$ y una anchura de unos $120 \mathrm{~km}$. Se trata de un sistema montañoso heterogéneo, discontinuo y dotado de una orientación diagonal que hará que sirva de enlace entre la Cordillera Cantábrica, el Sistema Central, la Cordillera Costero-Catalana y los Sistemas Béticos. Este papel para compartimentar el relieve le otorga una importancia elevadísima de cara al forzamiento de los flujos en los niveles bajos de la atmósfera, facilitando convergencias que tienen un papel muy importante de cara a la convección. Por este mismo motivo, las cabeceras de los principales colectores hidrográficos del norte de la Península (Ebro, Duero, Tajo, Júcar) se sitúan en su ámbito o en las articulaciones de la cordillera con otros sistemas montañosos. 
Se pueden diferenciar una serie de unidades de relieve. La más occidental, en contacto con los Montes Vasco-Cantábricos, es la de los bloques noroccidentales, que incluyen los montes de Burgos, Soria, La Rioja y termina en el Moncayo. Están formados por materiales más antiguos y resistentes y constituyen, en el Moncayo y en la sierra de la Demanda, los puntos más altos de la cadena, que superan los $2200 \mathrm{~m}$. En un ambiente mucho más mediterráneo se localiza la Ibérica del sur de Soria y la de las provincias de Guadalajara, Zaragoza, Cuenca y Teruel. En ella se distinguen dos ramas, una más occidental, la castellana, y otra más oriental, la aragonesa, separadas por una depresión intraibérica por la que discurren el Jiloca y el Turia. Los materiales que las forman varían de oeste (más antiguos y resistentes: cuarcitas, pizarras, etc.) a este (calizas cretácicas y jurásicas). La parte norte de la rama castellana es discontinua y de poca altitud, y supone poco más que el reborde de la Meseta. Su parte sur tiene mucha más entidad, e incluye los Montes Universales y la sierra de Albarracín, con altitudes máximas del orden de 1800 m y constituye una divisoria hidrográfica de primer orden. La rama aragonesa tiene asimismo dos sectores muy diferenciados: el sector paleozoico, esencialmente correspondiente con la Ibérica zaragozana: una serie discontinua de bloques elevados como las sierras de la Virgen o de Vicort, con altitudes máximas que rondan los 1500 m, y el sector del Maestrazgo y Gúdar-Javalambre. Este último está formado por afloramientos calizos con altitudes máximas del orden de $2000 \mathrm{~m}$, muy arrasadas durante el Mioceno, por lo que su aspecto, más que el de una montaña singular elevada, es el de una zona alta y relativamente llana: la llamada superficie de erosión fundamental.

La Meseta es una elevada altiplanicie de 600-800 m de altitud que ocupa el $45 \%$ de la Península, compuesta por un conjunto de terrenos elevados donde aflora el zócalo paleozoico (oeste y zonas montañosas) y de terrenos llanos de forma aplanada (zonas con sedimentos de la Era Terciaria). La Submeseta norte tiene unos $800 \mathrm{~m}$ de altitud y es más elevada que la sur. Forma la llamada altiplanicie del Duero y da lugar a una llanura en la que aparecen los páramos, que es esencialmente la zona de la Meseta comprendida en el área de estudio, con el aspecto de terrenos elevados y pedregosos.

Los Montes Vascos son sierras mesozoicas con origen en el movimiento orogénico alpino. Sus altitudes no son muy elevadas (en torno a los $1400 \mathrm{~m}$ ) con predominio de las formaciones calcáreas muy erosionadas que ofrecen un paisaje típico de simas, grutas y dolinas o paisaje suaves modelados por la acción erosiva. Enlazan al oeste con el Sistema Cantábrico y al este con los Pirineos. Alcanza en Aitxuri (1551 m) y Gorbea (1 $482 \mathrm{~m}$ ) sus máximas altitudes. Forma la unidad del relieve que separa el litoral cantábrico de la cuenca del Ebro y está completamente comprendida en el área de estudio, perteneciendo a ellas los relieves del País Vasco y otros de Navarra como las sierras de Urbasa y Andía. Forman un eslabón montañoso discontinuo entre la Cordillera Cantábrica y los Pirineos, con menor altitud, lo que supone que la influencia atlántica penetre más al sur, hasta la totalidad de la Ibérica riojana y el Moncayo.

Por último, la Cordillera Costero-Catalana es una cordillera litoral que enlaza la Cordillera Ibérica con los Pirineos, bordeando por el este la depresión del Ebro. Se apoya sobre el basamento hercínico de la Península, aunque su cobertera es mesozoica. Sus altitudes no llegan a los 1400 m y dentro del área de estudio están los puertos de Beceite, entre Teruel y Castellón, las sierras de Montsant y Cavalls en Tarragona, y otros relieves de menor entidad y aún más próximos al Mediterráneo como Las Talaies d’Allalà o la sierra de Montsià. 


\subsubsection{Hidrografía}

El área de estudio comprende todo el sector medio y bajo de la cuenca del Ebro, las cabeceras de la cuenca del Duero, Tajo y Guadiana, el sector este de la cuenca norte, las cabeceras del Júcar y el Guadalaviar-Turia, así como una mínima parte de la cuenca del Pirineo Oriental (cuencas internas de Cataluña).

En la cuenca del Ebro, el río Ebro como colector principal se acomoda al esquema morfológico del conjunto: dos cordilleras, la Ibérica y los Pirineos, convergentes en el noroeste dejando entre sí a la depresión del Ebro. Cerca del Mediterráneo el río corta transversalmente la Cadena Costero-Catalana. La citada red fluvial principal tiene una longitud de unos $13000 \mathrm{~km}$ (910,5 km en el cauce principal). En conjunto muestra una forma de "espina de pez" aunque se encuentran diversas configuraciones en los diferentes sectores de la cuenca. En este sentido destaca el marcado paralelismo de los ríos riojanos recogidos perpendicularmente por el Ebro, generándose una red de tipo subparalelo. Lo mismo ocurre en el sector oriental de la cuenca del Aragón, o con los afluentes de la margen derecha del Jalón. En otras áreas la red muestra una tipología dendrítica. Son los casos de los ríos del conjunto Cinca-Segre, los de la cuenca del Aragón antes de Sangüesa (Navarra), la cuenca del Arba, la del Nela o, en la margen derecha, las cabeceras aragonesas de los ríos Aguas Vivas, Martín y Guadalope.

El Ebro es uno de los ríos mediterráneos con menos variabilidad interanual de entre los de la Península Ibérica. Los acuíferos situados en zonas calizas afectan al régimen de caudales suavizándolo, lo que resulta especialmente evidente en los ríos aragoneses de la margen derecha del Ebro. Los afluentes cantábricos y pirenaicos del Ebro, en el sector occidental hasta la cuenca del Irati, muestran un régimen esencialmente pluvial oceánico. Se observa influencia de la retención nival en el Nela y en el Irati, por lo que en estos casos se habla de un régimen pluvionival oceánico. Por la margen derecha del Ebro, los ríos del noroeste reciben influencias oceánicas, aunque con cierta retención nival en sus cabeceras que define un régimen pluvionival oceánico. Más hacia el sureste desaparece la influencia atlántica y se acentúa la mediterránea con marcado carácter continentalizado, además de desaparecer la retención nival como hecho significativo. Se trata, por lo tanto, de un régimen pluvial mediterráneo, claramente equinoccial en el caso de los ríos más orientales: Guadalope, Matarraña, Algás, Canaleta. (CHE, 2005).

El río Duero es el cauce principal de la red de drenaje de su cuenca, con una longitud de $572 \mathrm{~km}$ en territorio español, desde las Fuentes del Duero en Duruelo (Soria) hasta la frontera con Portugal. El tramo inicial de $73 \mathrm{~km}$ recorre los escarpados valles de la Cordillera Ibérica, donde el mesozoico cubre el núcleo paleozoico que asoma en superficie por los montes del nacimiento, en el macizo de los Picos de Urbión. La pendiente media de este tramo de cabecera, desde las Fuentes del Duero hasta la ciudad de Soria, es de $14,8 \mathrm{~m} / \mathrm{km}$. Desde Soria hasta la frontera portuguesa recorre suelos blandos formados por sedimentos terciarios a lo largo de $499 \mathrm{~km}$, con una pendiente media de $1 \mathrm{~m} / \mathrm{km}$. (CH DuERo, 2005). La zona perteneciente a la cuenca del Duero en el área de estudio comprende fundamentalmente la zona de la provincia de Soria que no vierte sus aguas al Ebro.

De la cuenca norte, el área de estudio abarca la zona oriental de la misma, gestionada por la Confederación Hidrográfica del Cantábrico, y abarca las cuencas de los ríos Bidasoa, Urumea, Oria, Deva y Nervión, además de las de otros cursos menores que 
desembocan directamente en el mar. Se trata de ríos de recorrido corto, pero con mucho desnivel y relativamente mucho caudal.

El río Tajo nace en los Montes Universales, enmarcados en el sector occidental de la Cordillera Ibérica en la provincia de Teruel. Su recorrido hasta su desembocadura en la costa portuguesa atlántica es de $1000 \mathrm{~km}$. Pertenecen al área de estudio estas zonas de la cabecera del Tajo y de algunos de sus afluentes, como el Cuervo o el Gallo. También en la Cordillera Ibérica nace el río Júcar, que atraviesa la comunidad valenciana para desembocar en el Mediterráneo. En este sistema montañoso no solo se produce el nacimiento del río principal de la demarcación, que a su vez da nombre a esta, sino que en él también nacen los ríos Turia y Mijares. Los tres ríos proporcionan conjuntamente el 80 \% de la escorrentía media de la demarcación (CHJ, 2007), y todas sus cabeceras están dentro del área de estudio.

\subsubsection{Caracterización climática}

El resultado de la compleja disposición del relieve y de la encrucijada de influencias marítimas de distinto origen, así como el papel de las masas continentales y la elevada altitud otorga al área de estudio una variabilidad climática del área de estudio (Imagen 1.4).

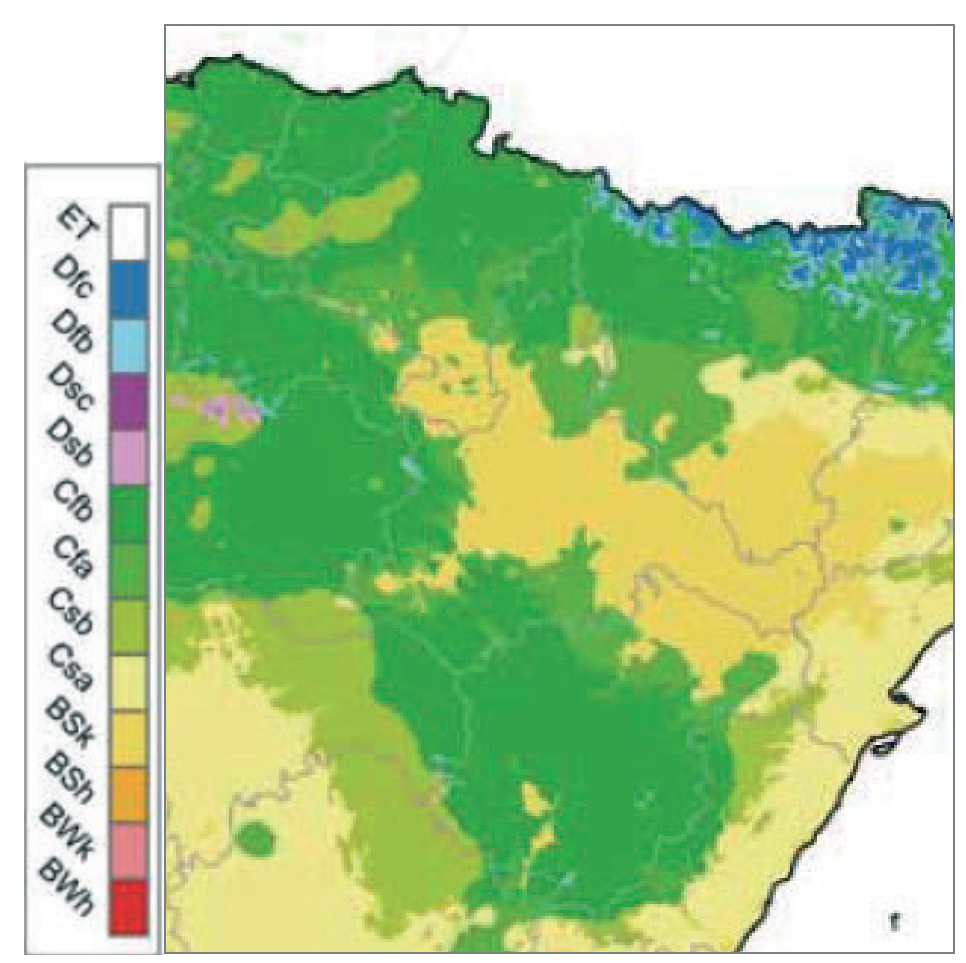

Imagen 1.4. Caracterización climática (Köppen) del área de estudio. (Fuente: AEMET-IM, 2011).

Esta variabilidad climática se concreta del siguiente modo, según Köppen (Imagen 1.2): clima polar de tundra (ET) en las zonas aisladas más altas de los Pirineos. En el piso alpino de los Pirineos el clima es frío sin estación seca y verano fresco (Dfc) y en las zonas más bajas de la alta montaña pirenaica, así como en los puntos más altos de la Ibérica (Moncayo, Demanda, Gúdar y Javalambre), el clima es frío sin estación seca y verano templado (Dfb). El resto del ámbito pirenaico (en sentido amplio), así como la 
fachada cantábrica y todo el Sistema Ibérico tiene un clima, según esta clasificación, templado sin estación seca y verano templado (Cfb). En los somontanos pirenaicos e ibéricos (dentro de la cuenca del Ebro y Júcar) domina un clima templado sin estación seca y verano caluroso (Cfa). Por el contrario, el somontano ibérico de la cuenca del Tajo y Duero presenta un clima templado con verano seco y templado (Csb). La depresión del Ebro, así como el norte del litoral de Castellón y la porción de La Mancha comprendida en el área de estudio presentan un clima de estepa cálida (Bsh), mientras que el resto - las cuencas medias de Cinca y Segre, el litoral mediterráneo y La Alcarria - tienen un clima templado con verano seco y caluroso (Csa), el típicamente mediterráneo. En definitiva, llama la atención que los climas Dfc, Dfb, Cfb y Cfa, que ocupan un porcentaje muy significativo del área de estudio, llevan todos el descriptor "sin estación seca”, lo que en parte revela la importancia de los fenómenos convectivos en la misma.

El mapa de temperaturas medias para el periodo 1971-2000 (Mapa 1.3) marca una gradación por altitud, así como una influencia importante de las masas de agua atlántica y mediterránea. La temperatura media para toda el área de estudio es de $12,2{ }^{\circ} \mathrm{C}$.

Las zonas con temperaturas más cálidas se encuentran, por una parte, en el centro de la depresión del Ebro siguiendo el curso fluvial principal, y por otra parte, en toda la costa mediterránea desde el delta del Ebro hasta la provincia de Valencia, donde las temperaturas medias alcanzan en la costa valores superiores a los $17^{\circ} \mathrm{C}$.

En la cuenca del Ebro los valores van disminuyendo a medida que disminuye la distancia a los somontanos pirenaico e ibérico, habiendo en este último una progresión más suave ya que las altitudes no son muy elevadas. Se distinguen temperaturas por debajo de los $8{ }^{\circ} \mathrm{C}$ en las sierras de Gúdar y Javalambre, e igualmente en Albarracín, en todas ellas la altitud no supera los 2000 metros más que en puntos concretos. En el somontano pirenaico el cambio es más brusco. En la primera barrera que conforman las Sierras Exteriores del Pirineo las temperaturas descienden, pero de una manera mucho más acusada en las Sierras Interiores y el Pirineo axial, especialmente en la parte aragonesa, donde se encuentran las mayores alturas (superiores a $3000 \mathrm{~m}$ ). En estas altitudes los valores medios pueden llegar a los $3{ }^{\circ} \mathrm{C}$, siendo habituales valores negativos fuera del periodo estival.

La montaña cantábrica tiene unas temperaturas mucho más suavizadas por el efecto de cercanía al mar. Los valores medios oscilan en torno a los $12-13{ }^{\circ} \mathrm{C}$, aunque en las zonas costeras del País Vasco es frecuente alcanzar los $15^{\circ} \mathrm{C}$. Estas temperaturas van disminuyendo hacia el sur hasta La Rioja, donde se mantienen altas en el entorno del valle del Ebro, y disminuyen bruscamente en la sierra de la Demanda hasta llegar a valores inferiores a los $5{ }^{\circ} \mathrm{C}$.

En la Meseta se alcanzan valores medios cercanos a los $10^{\circ} \mathrm{C}$ en la provincia de Soria, y a medida que disminuye la latitud (y la altitud), se observan en la Comunidad de Castilla la Mancha, ya en el tramo medio del Tajo, temperaturas medias en torno a los $11^{\circ} \mathrm{C}$. 


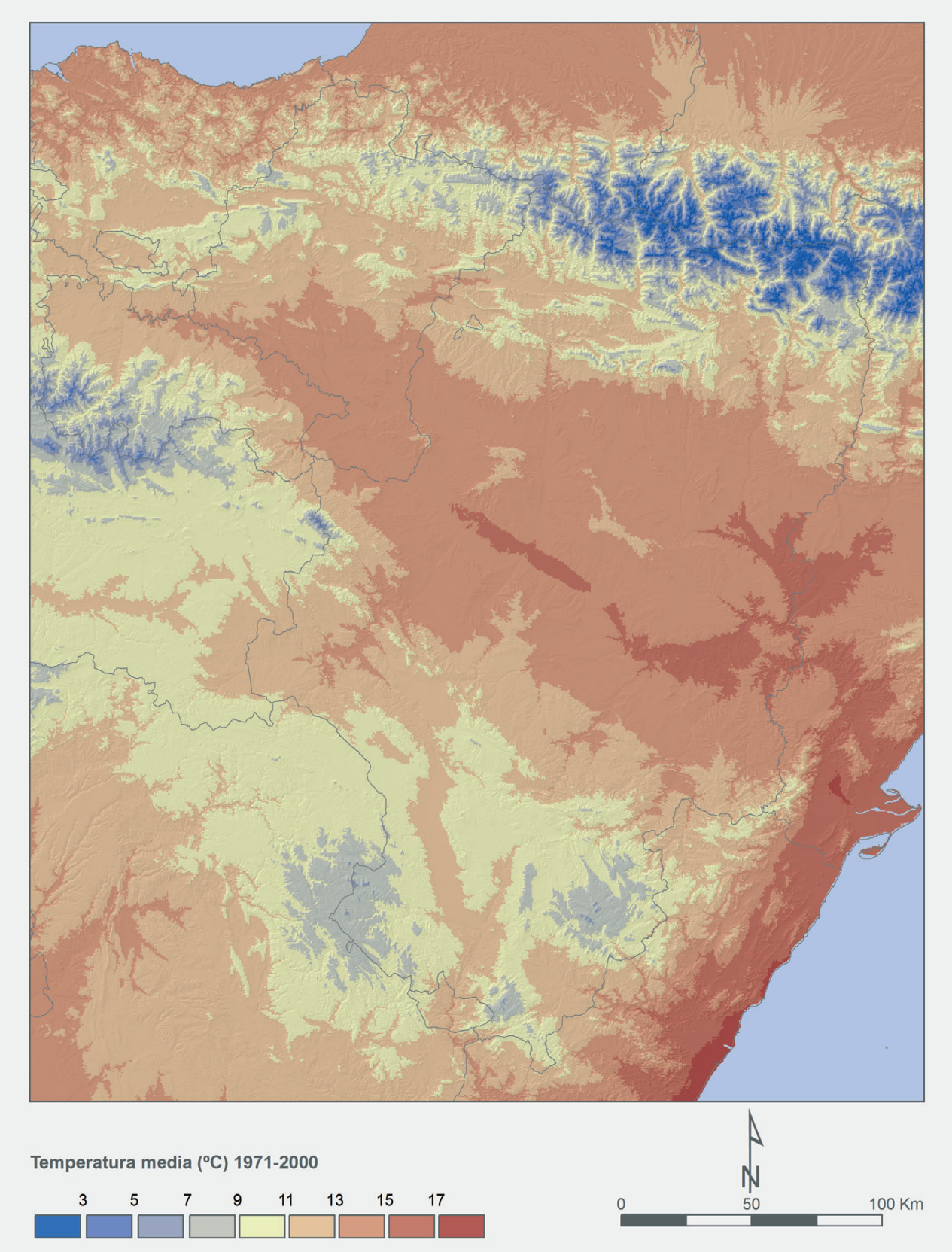

Mapa 1.3. Temperatura media anual en el área de estudio. (Elaboración propia).

El mapa de medias anuales de precipitación para el periodo 1971-2000 (Mapa 1.4) muestra varios tramos de precipitación bien diferenciados. El primero de ellos corresponde a aquellas zonas con menos de $400 \mathrm{~mm}$ anuales. Se trata principalmente del centro de la depresión del Ebro, el corredor del Jiloca en Teruel y otros puntos más localizados en zonas llanas. El resto de las zonas llanas, tanto de la depresión del Ebro, como de la Meseta o la totalidad de la Ibérica aragonesa y castellana, salvo el macizo del Moncayo, y las sierras de Albarracín, Javalambre y Gúdar, reciben menos de $600 \mathrm{~mm}$ anuales de precipitación.

Un segundo tramo responde al gradiente altitudinal que se da en la Cordillera Ibérica (riojana y las mencionadas sierras y macizos de la castellano-aragonesa), y de manera más acusada en el somontano pirenaico, donde los valores oscilan entre los 800 y los 
1000 mm anuales. Esta precipitación está muy relacionada con el progresivo aumento de altitud, y se refleja más intensamente en zonas de alta rugosidad (variabilidad altitudinal inmediata). En el caso de la Ibérica más occidental, la escasa altitud de los Montes Vascos, como se ha mencionado, favorece la penetración más al interior de la influencia atlántica, que redunda en mayores cantidades medias de precipitación, que en las sierras de la Demanda y el Moncayo llega a superar los $1200 \mathrm{~mm}$.

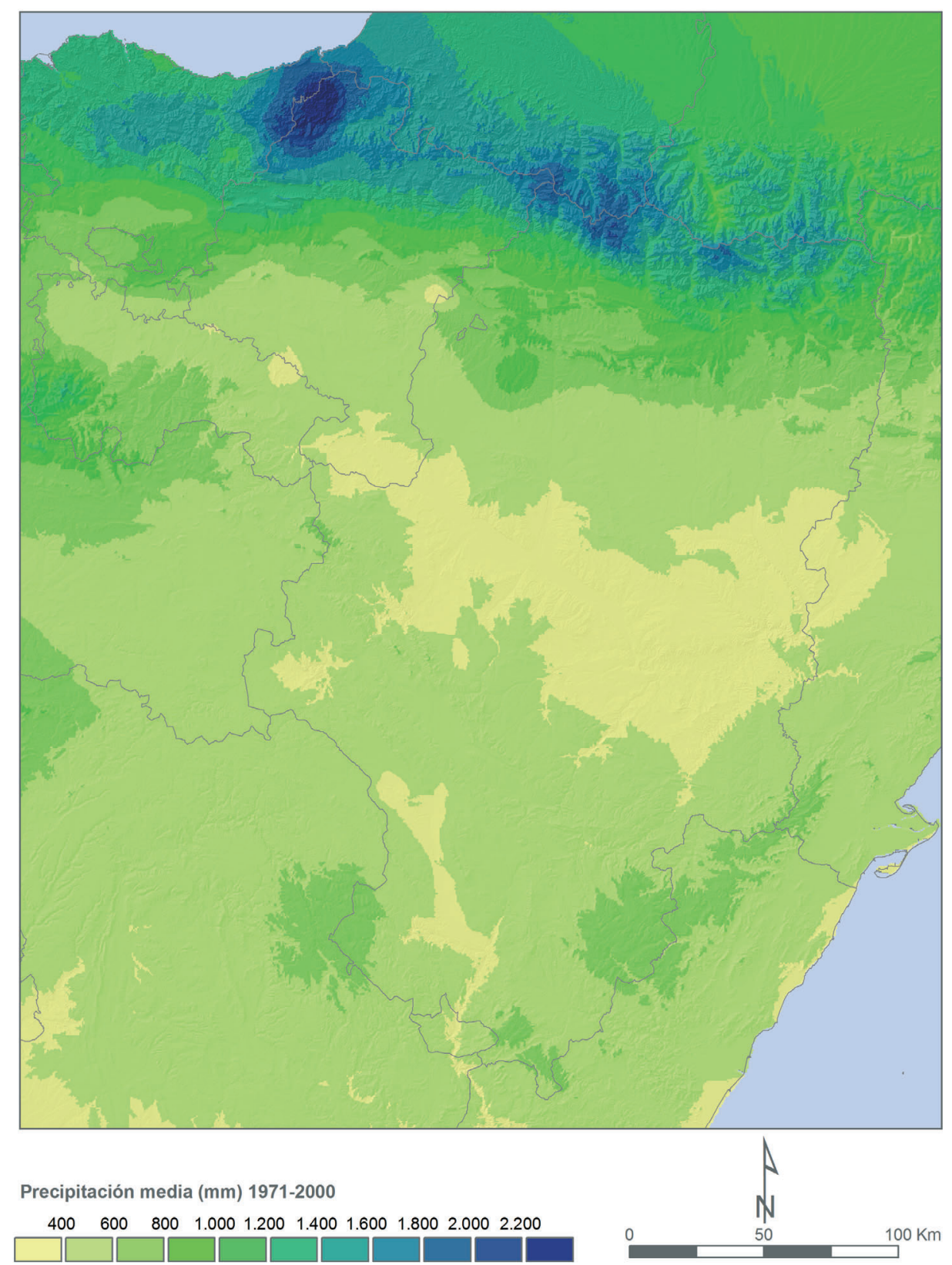

Mapa 1.4. Media de precipitación total anual en el área de estudio. (Elaboración propia).

La parte oeste aragonesa de las Sierras Interiores pirenaicas y del Pirineo axial, así como en las estribaciones de esta cordillera en Navarra, limitando ya con el golfo de Vizcaya, son las que más precipitación reciben en todo el área de estudio (CanfrancEstación $1860 \mathrm{~mm}$ anuales), dándose valores por encima de los $2200 \mathrm{~mm}$ en la articulación entre los macizos pirenaicos más occidentales y los Montes Vascos más 
orientales, especialmente en el entorno de la localidad navarra de Artikutza (2 $550 \mathrm{~mm}$ anuales). Aunque de escasa altitud, la ubicación de este relieve en el fondo del golfo de Vizcaya le confiere una disposición idónea para la recepción de todo tipo de flujos húmedos, incluso en situaciones de estabilidad atmosférica.

La vertiente francesa del Pirineo tiene una marcada influencia atlántica, pues los valores medios van disminuyendo desde el golfo de Vizcaya hacia el interior aunque la ausencia de relieves en sentido meridiano hace que este gradiente sea mucho más suave que en la vertiente española. Este patrón funciona en las zonas llanas y somontanos, ya que en las zonas más altas vuelve a dominar la variable altitud.

El Mapa 1.5 presenta la ubicación de puntos clave para la caracterización climática de la zona de estudio, alguna de cuyas características se van a discutir a continuación.

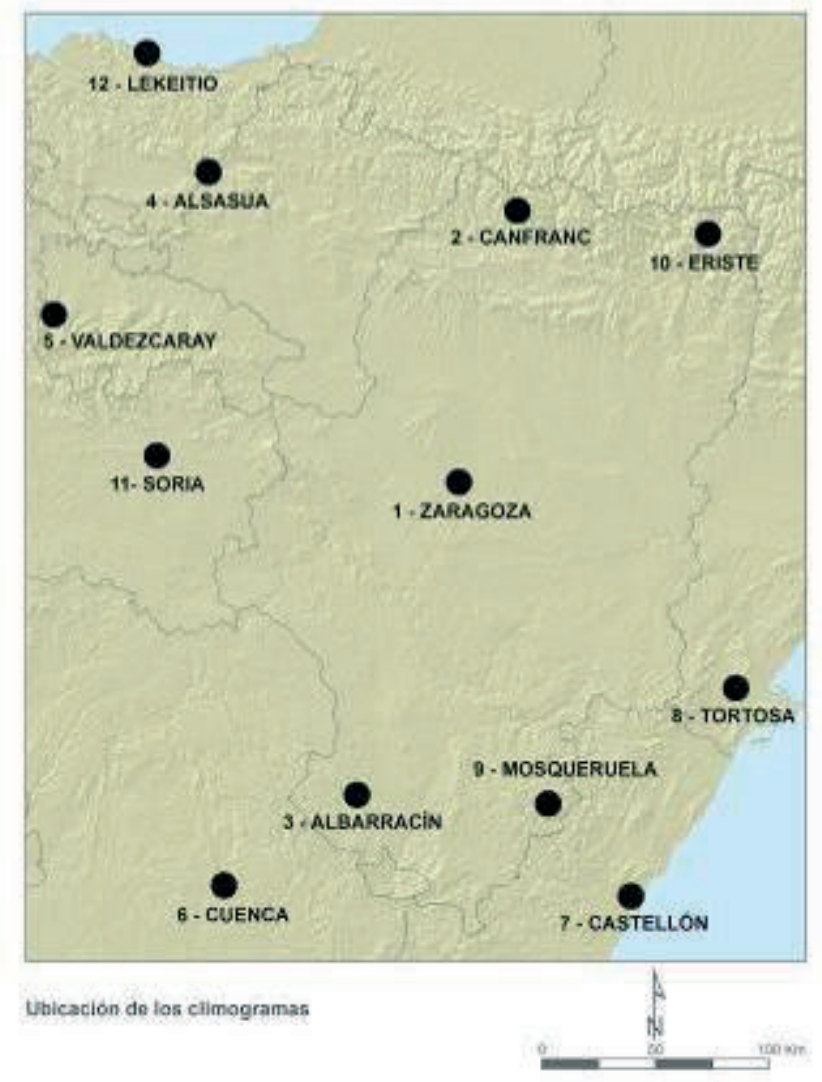

Mapa 1.5. Localización de los puntos correspondientes a los climogramas citados en el texto. 

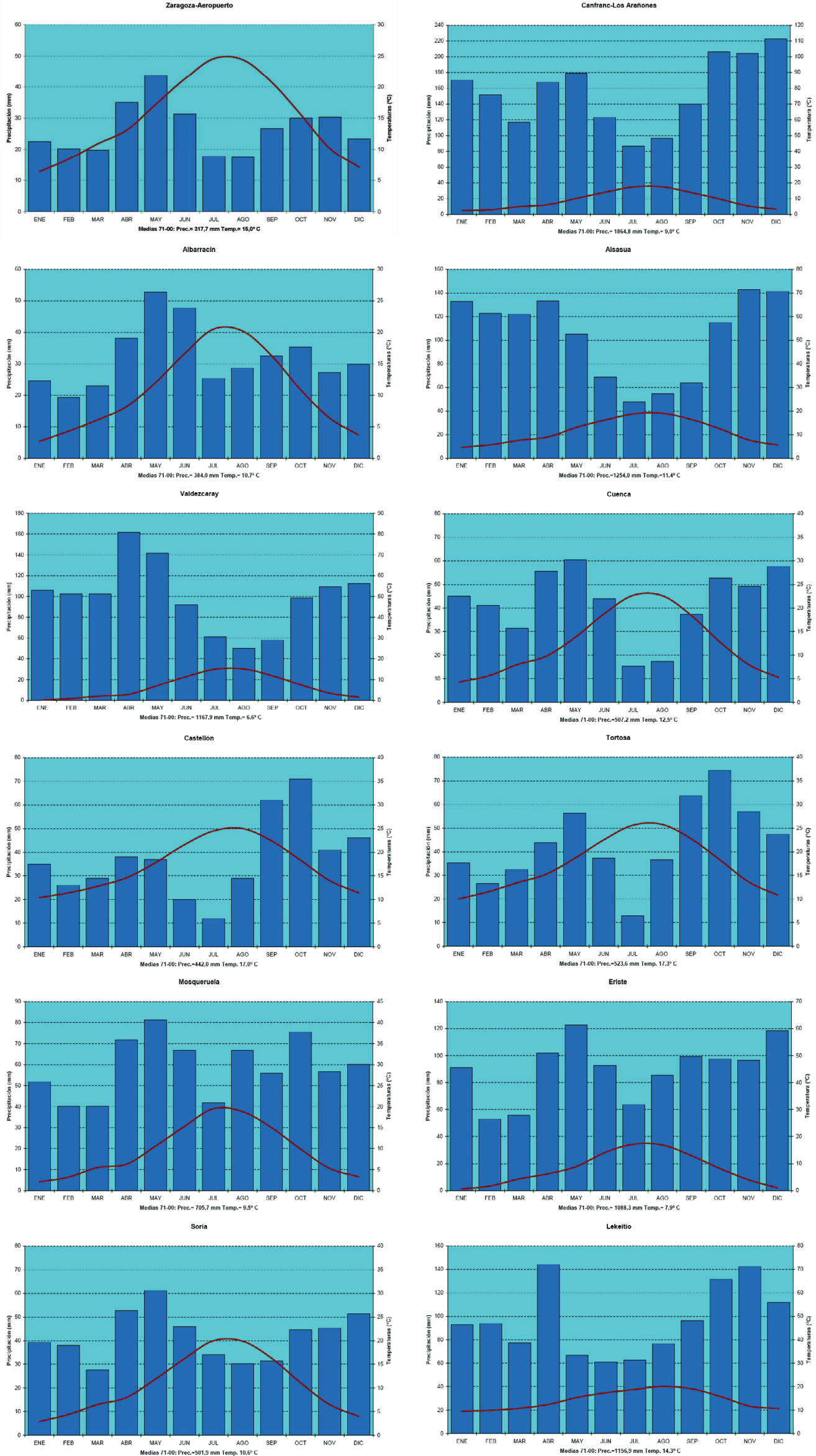

Imagen 1.5. Climogramas de distintos puntos del área de estudio. (Elaboración propia). 
La consideración conjunta de estos climogramas (Imagen 1.5), que pretenden representar la diversidad climática del área de estudio, permite identificar algunos factores clave. Desde el punto de vista de la temperatura media, como es lógico, la amplitud térmica es mayor en las zonas del interior que en las del litoral. Esta es máxima (superior a $15^{\circ} \mathrm{C}$ ) en la Meseta, la Ibérica y la depresión del Ebro. Por el contrario, los valores mínimos de amplitud térmica (poco menos de $10^{\circ} \mathrm{C}$ ) se da en la costa cantábrica. El Pirineo presenta un comportamiento, a este respecto, variado, entre las zonas occidentales y las orientales, reflejándose así también la mayor influencia atlántica o continental-mediterránea en cada caso.

En cuanto a la precipitación, al margen de las grandes diferencias cuantitativas ya comentadas, merece la pena comentar la diferente distribución estacional. Las áreas de influencia más atlántica (Canfranc, Alsasua) tienen un claro máximo invernal, con un máximo secundario en primavera. Las zonas con mayor influencia mediterránea (Tortosa, Castellón), un claro máximo otoñal. El resto de las zonas tienden a tener máximos en primavera, más claros en la depresión del Ebro (Zaragoza) o en zonas de la Ibérica occidental —en sentido amplio- (Valdezcaray, Soria, Albarracín). Las zonas montañosas más orientales en el área de estudio (Mosqueruela y Eriste) tienden a tener una distribución bastante homogénea de la precipitación, con mínimos en invierno y máximos en primavera y otoño, destacando el nada desdeñable peso relativo de la precipitación estival. Como se puede suponer, la convección juega un papel muy importante en este hecho. En este sentido, llama la atención la diferencia en la precipitación estival entre puntos de influencia ibérica bastante próximos, como Cuenca y Albarracín. En el segundo, la precipitación estival es apreciablemente mayor, revelando una mayor actividad convectiva al norte de los Montes Universales. En general, y pese a estar en un entorno indiscutiblemente mediterráneo en general, los mínimos estivales de precipitación son bastante relativos $\mathrm{y}$, en muchos casos, inexistentes.

Si se realiza un análisis específico de la distribución porcentual de la precipitación para el semestre cálido considerado en este estudio y para el verano en particular, estos hechos aparecen con aún más claridad.

La precipitación estival tiene un marcado máximo en la Ibérica turolense, donde se da más del $30 \%$ de la precipitación total anual, especialmente en su sector oriental (Mapa 1.6a). Aparecen máximos secundarios, de precipitación estival superior al 25 \% del total anual en la Ibérica riojana y en el sector más oriental del Pirineo considerado dentro del área de estudio. El porcentaje va disminuyendo tomando la forma de la depresión del Ebro, donde la precipitación estiva está entre el 20 y el $25 \%$ del total anual, y es ya mucho menor en las provincias de Soria, Guadalajara y Cuenca, así como en el noroeste de la zona de estudio, alcanzando valores mínimos de entre el 10 y el $15 \%$ en el somontano pirenaico navarro y en las depresiones interiores a los Montes Vascos, donde la precipitación es mucho más relevante en las demás estaciones.

Considerando la temporada de abril a septiembre tomada como referencia para el presente estudio (Mapa 1.6b), se puede observar que existen zonas con más del $65 \%$ de precipitación total anual en este periodo, que especialmente se encuentran en el sur de la provincia de Teruel, coincidiendo con las zonas elevadas de la Cordillera Ibérica. Aquellos territorios que están por debajo del 30 \% corresponden casi exactamente con 
la zona más lluviosa, al sur del golfo de Vizcaya, donde la regularidad de la precipitación minimiza el efecto concentrador de los meses estudiados.

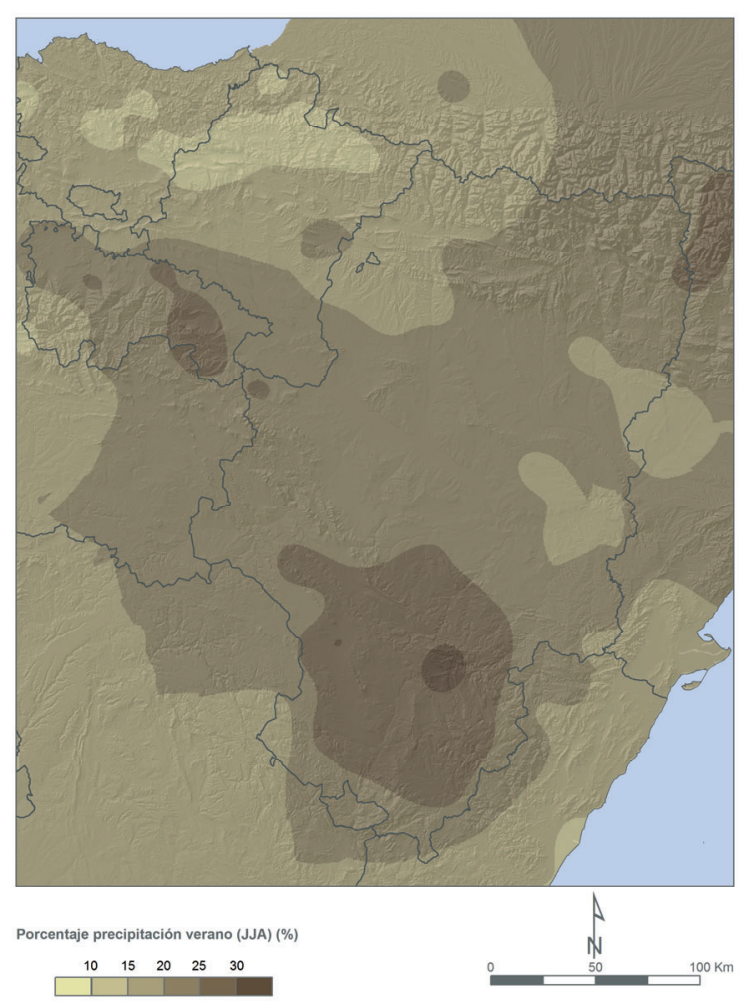

a. Porcentaje estival (JJA) de precipitación sobre el total anual.

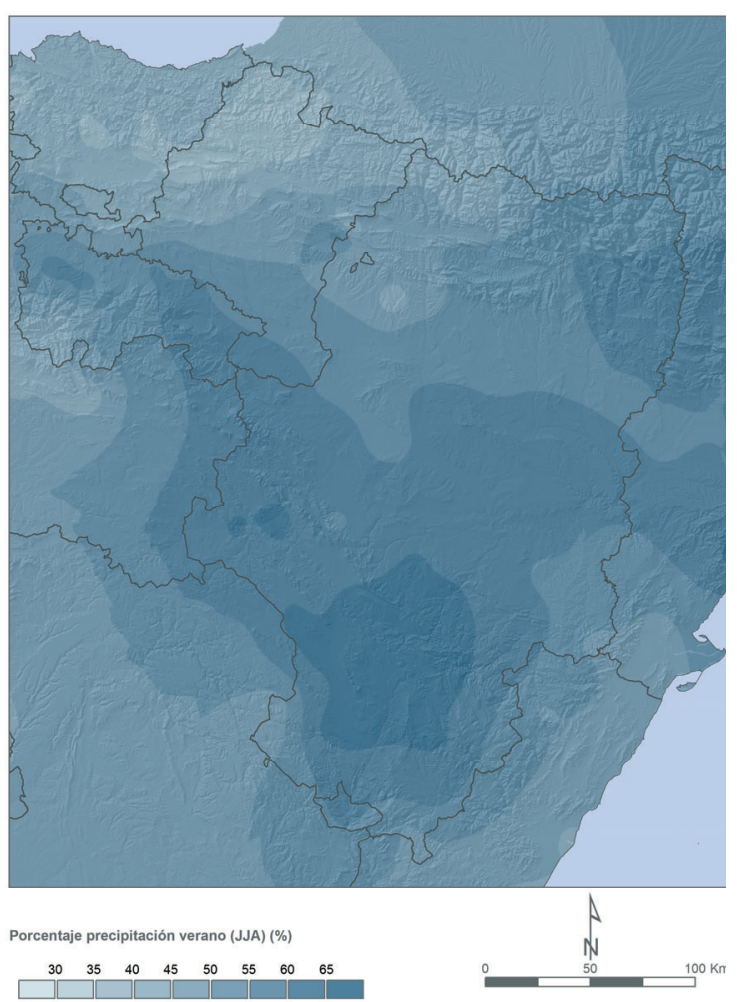

b. Porcentaje de precipitación de la temporada abril-septiembre sobre el total anual.

Mapa 1.6. Reparto estival y en la temporada considerada de la precipitación.

(Elaboración propia).

A modo de resumen, el clima de la zona estudiada en el nordeste de España se muestra variable, con una diferencia de temperaturas medias anuales de más de $15{ }^{\circ} \mathrm{C}$ en menos de $300 \mathrm{~km}$ de separación, y con precipitaciones anuales hasta 5 veces mayores en la vertiente cantábrica y zonas elevadas de los Pirineos respecto al centro de la depresión del Ebro. Es importante destacar para los objetivos del trabajo que la mayor parte de las situaciones de precipitación desde abril hasta septiembre respecto al total anual se dan en la zona oriental del Sistema Ibérico.

\subsubsection{Organización territorial}

El área de estudio abarca un territorio de gran variabilidad demográfica, que comprende territorios de diez comunidades autónomas españolas diferentes con un total de 2867 municipios (un 31,5 \% del total de España), así como el sur de las regiones francesas de Aquitaine y Midi-Pyrénées (con la totalidad de los departamentos de Pyrénées Atlantiques y Hautes-Pyrénées), aunque el estudio se va a centrar en la parte española. En números absolutos, la población total que en ella habita supera los siete millones de habitantes, aunque con una distribución muy irregular. A grandes rasgos (Imagen 1.6) la población se acumula en el litoral mediterráneo y cantábrico, en el interior del País Vasco y centro de Navarra, a lo largo del eje del Ebro hasta el área de Zaragoza, en el sur de Lérida y en el extremo oriental del área metropolitana de Madrid. El resto del 
territorio presenta un importante vacío poblacional, que en el área de la Ibérica llega a ser muy destacable. Precisamente, estas zonas con menor densidad de población coinciden con aquellas en las que se verá que la actividad de la convección es más relevante, lo que supone un factor importante de cara a que muchos de esos fenómenos pasen desapercibidos o tengan poca trascendencia fuera de la misma.

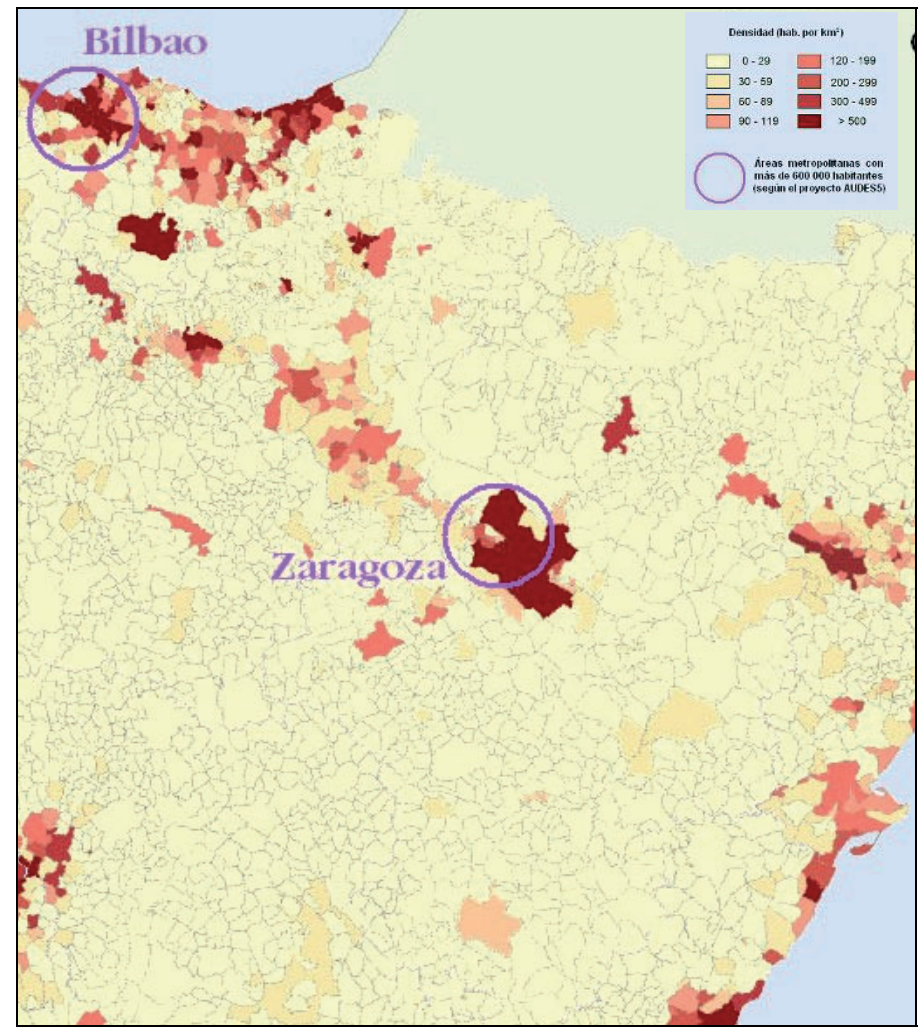

Imagen 1.6. Densidad de población por municipios en el área de estudio en 2008. (FREXEIRO, 2009). 



\section{CLIMATOLOGÍA DE LA CONVECCIÓN}

Se presentan a continuación una serie de climatologías y estadísticas que permiten la caracterización de la actividad convectiva en el área de estudio, a través del seguimiento exhaustivo de su evolución espacial y temporal.

\subsection{Metodología}

El estudio de los procesos convectivos, en el cuadrante definido por los meridianos $3^{\circ} \mathrm{W}$ y $1^{\circ} \mathrm{E}$ y los paralelos $43,5^{\circ} \mathrm{N}$ y $39,5^{\circ} \mathrm{N}$, tiene lugar a través del análisis de precipitación total y descargas eléctricas asociadas a cada uno de los 1281 días comprendidos entre los meses de abril y septiembre desde 2002 hasta 2008, aunque al no existir la misma disponibilidad de datos para las descargas eléctricas que para la precipitación, se han eliminado 150 días con datos insuficientes.

Los datos pluviométricos de base empleados en el proceso proceden de la red climatológica complementaria de AEMET. En total se consideran 1360280 datos brutos de precipitación relativos a unos 1000 observatorios, que varían según el mes y el año considerado en función de la completitud de sus registros mensuales.

La red de detección de descargas eléctricas en España se encuentra plenamente operativa desde principios de los noventa (PÉREZ, 2005). En ese momento, dicha red contaba con 14 equipos ALDF (Advanced Lightning Direction Finding), radiogoniómetros dotados de tecnología exclusivamente angular. La cooperación internacional establecida con Francia a mediados de los noventa supuso, por una parte, la ampliación del área de cobertura, principalmente en la parte nororiental de la Península Ibérica (golfo de Vizcaya y Pirineos), y por otra el aumento de la eficiencia y la precisión en la localización de los rayos, como consecuencia de la introducción de las primeras estaciones IMPACT (Improved Position Accuracy Technology), dotadas además con tecnología temporal GPS (Global Position System). Con el paso del tiempo, la sustitución de los radiogoniómetros españoles y franceses por estaciones IMPACT con tecnología combinada - angular y temporal— fue propiciando la mejora significativa de la precisión en la localización de las descargas, así como la capacitación para la detección de relámpagos (descargas que se producen en la atmósfera sin intervención de la superficie terrestre) y las diferentes descargas eléctricas simples constitutivas de cada rayo (de media 3 o 4) (PÉREZ, 2004). Dichos aspectos se han continuado mejorando a lo largo de la última década mediante la incorporación de nuevas estaciones a la red, fomentando la cooperación internacional con Francia y haciéndola extensiva a Portugal, y con nuevas tecnologías, empleadas recientemente en las Islas Canarias. 


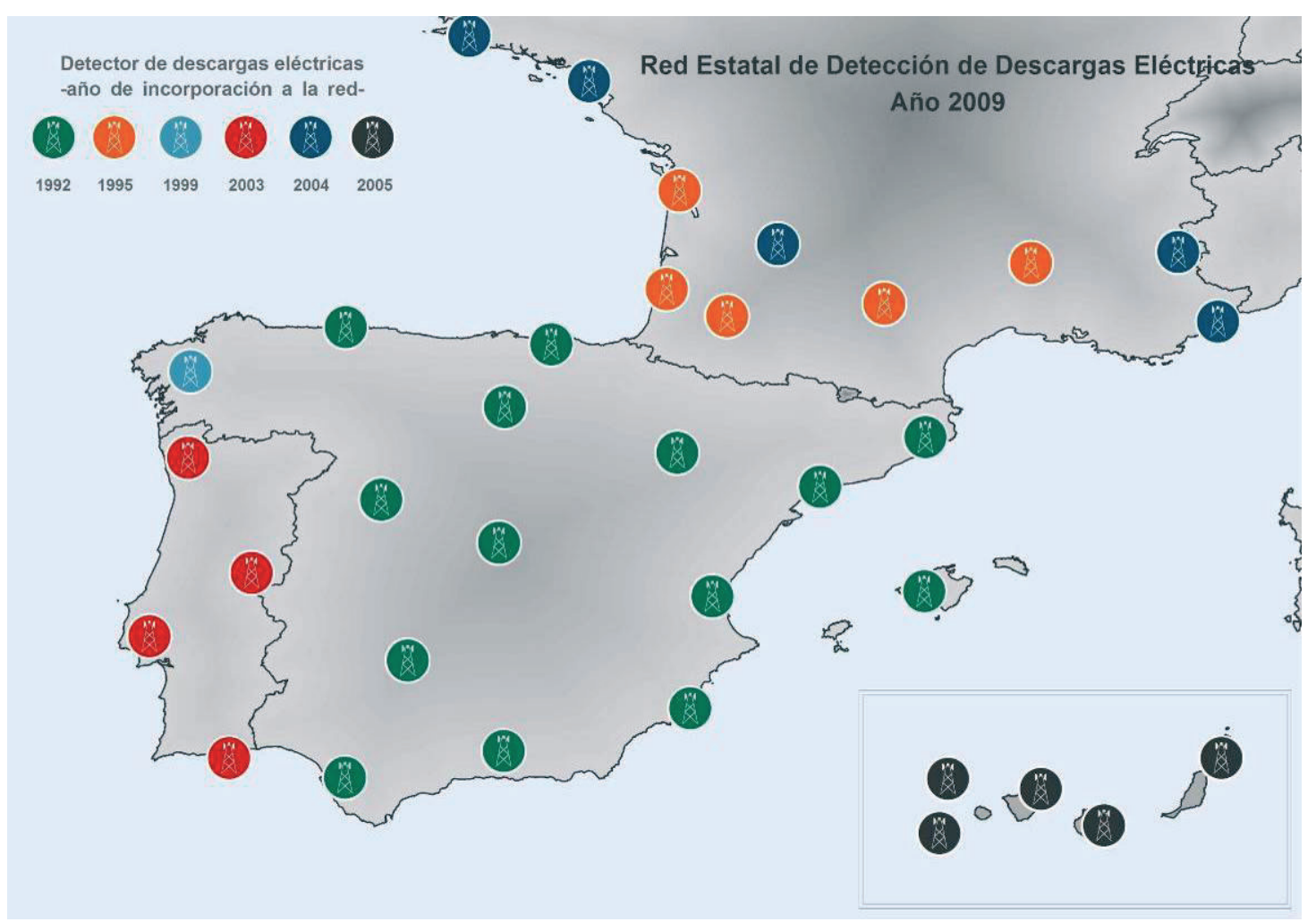

Imagen 2.1. Red de detección de descargas eléctricas de la AEMET en 2009, formada por los sensores propios y complementados por las redes vecinas de Francia y Portugal.

(Elaboración propia).

Atendiendo al periodo temporal que abarca este trabajo, las observaciones referentes a la actividad eléctrica proceden del registro efectuado por las 34 estaciones que, a día de hoy, configuran la red de radiodetección de descargas eléctricas en España, Francia y Portugal (Imagen 2.1). Pese a que, tal y como se ha apuntado anteriormente, dichas estaciones tienen capacidad para detectar las diferentes subdescargas que constituyen cada uno de los rayos, la metodología empleada en este trabajo considera a este último - el rayo - como unidad mínima de información; circunstancia que se ha de tener presente en relación a trabajos anteriores (PÉREZ Y ZANCAJO, 2008; PÉREZ Y ZANCAJO, 2010). Otro aspecto metodológico a considerar es la depuración aplicada a la base de datos con el fin de disminuir el error medio en la localización —espacial y temporal- de los rayos. Así, en relación al procedimiento de localización empleado por la tecnología angular de los equipos — triangulación esférica—, se aplican dos criterios espaciales (Imagen 2.2), además de un tercer criterio estadístico, $\mathrm{Chi}^{2}{ }^{\text {(STORCH Y }}$ ZWIERS, 1999), indicativo tanto de la calidad en la localización espacial como temporal, y cuyos valores de aceptabilidad oscilan entre el 0 y el 10; siendo óptimos por debajo de 3 (PÉREZ, 2009).

De acuerdo con lo anterior, un rayo se considera válido cuando se cumplen simultáneamente el siguiente conjunto de criterios:

1. Semieje mayor de la elipse de localización menor que $6 \mathrm{~km}$.

2. Semieje menor de la elipse de localización menor que $3 \mathrm{~km}$.

3. Valor del estadístico normalizado $\mathrm{Chi}^{2}$ menor que 10. 


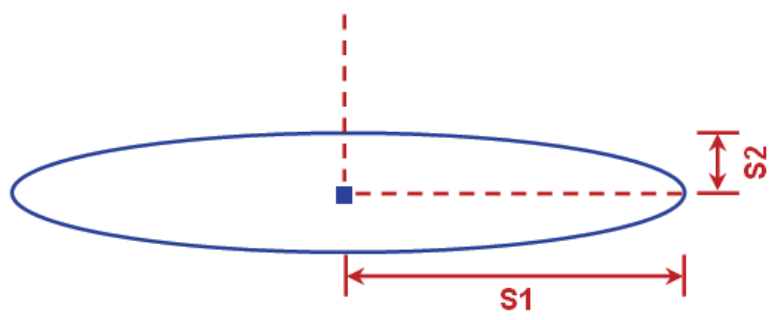

- Localización del rayo

S1- Semieje mayor de la elipse de localización (criterio de validez, $S 1<6 \mathrm{Km}$ )

s2- Semieje menor de la elipse de localización (criterio de validez, $\mathrm{s} 2<3 \mathrm{Km}$ )

Imagen 2.2. Criterios espaciales para la depuración de la base de datos de rayos.

La dificultad que entraña procesar el elevado volumen de información considerado, la circunstancia de que los observatorios pluviométricos seleccionados varían en función del mes y del año, así como el carácter puntual de las estimaciones proporcionadas por el modelo numérico de predicción, sugieren la reducción de los registros de descargas eléctricas y precipitación a una malla grid; de manera que la totalidad de los datos, independientemente de su origen (red climatológica complementaria de AEMET, red de radiodetección de descargas eléctricas en España, Francia y Portugal o modelo numérico de predicción HIRLAM $0.5^{\circ}$ ), hagan referencia a las mismas localizaciones geográficas. Dicho proceso de asimilación de datos se lleva a cabo en el caso de la precipitación con la ayuda de un Sistema de Información Geográfico (ArcGIS v.9.3), y en el caso de las descargas eléctricas a través de la estación de trabajo meteorológica McIDAS (Man Computer Interactive Data Access System v.2005B).

Tanto los registros de precipitación —procedentes de la red climatológica complementaria de AEMET - como las descargas eléctricas se reducen a una malla grid con tamaño de celda $0,5^{\circ}$ de latitud y longitud (el mismo que el modelo numérico empleado) y se emplean, una vez reducidos, para el establecimiento de las correlaciones entre ambos términos, en el análisis estadístico que relaciona las descargas con las variables derivadas del modelo numérico y en la representación cartográfica de los promedios de precipitación (Mapa 2.1). La representación cartográfica de los promedios de descargas eléctricas se lleva a cabo, sin embargo, a partir de los datos reducidos a una malla con un tamaño de celda inferior, de $0,2^{\circ}$ de latitud y longitud.

En el entorno SIG (Sistema de Información Geográfico), las técnicas de geoprocesamiento espacial permiten operar datos asignados a una localización geográfica (georreferenciados). De la misma manera que las técnicas de interpolación espacial permiten estimar, a partir de registros puntuales de las variables consideradas, el valor de estas mismas en cada uno de los puntos que configuran el área de estudio.

Los registros diarios de precipitación, procedentes de la red climatológica complementaria de AEMET, se interpolan según el método de inverso de la distancia (Inverse Distance Weighting, IDW), que estima el valor de la variable precipitación diaria en cualquier punto del área de estudio, como promedio ponderado de cada uno de los registros que configuran el conjunto de interpolación. El factor de ponderación es el inverso de la distancia; siendo los registros más próximos al punto considerado los que participan con un peso superior en la estimación (VICENTE, 2002). Posteriormente se 
realiza la reducción de estos valores interpolados de precipitación diaria a la malla grid de tamaño de celda $0,5^{\circ}$ de latitud y longitud mediante técnicas de geoprocesamiento espacial, de manera que la precipitación asignada a cada punto central de la celda corresponde al valor interpolado de precipitación en esa misma localización. Por último, se excluyen los 25 puntos de la cuadrícula que corresponden a ubicaciones fuera de territorio español, ya que los valores de precipitación resultantes de la interpolación no proceden de datos observados correspondientes a la base de datos climatológicos de AEMET, sino a artefactos del modelo espacial adoptado.

En este punto hay que destacar que la naturaleza de la variable precipitación, lógicamente, no discrimina entre precipitación convectiva o estratiforme. Será por ello siempre de modo indirecto que se inferirá el carácter convectivo, según la época del año, la zona o con relación con las descargas eléctricas, correlación y asociación que se estudia en los capítulos siguientes.
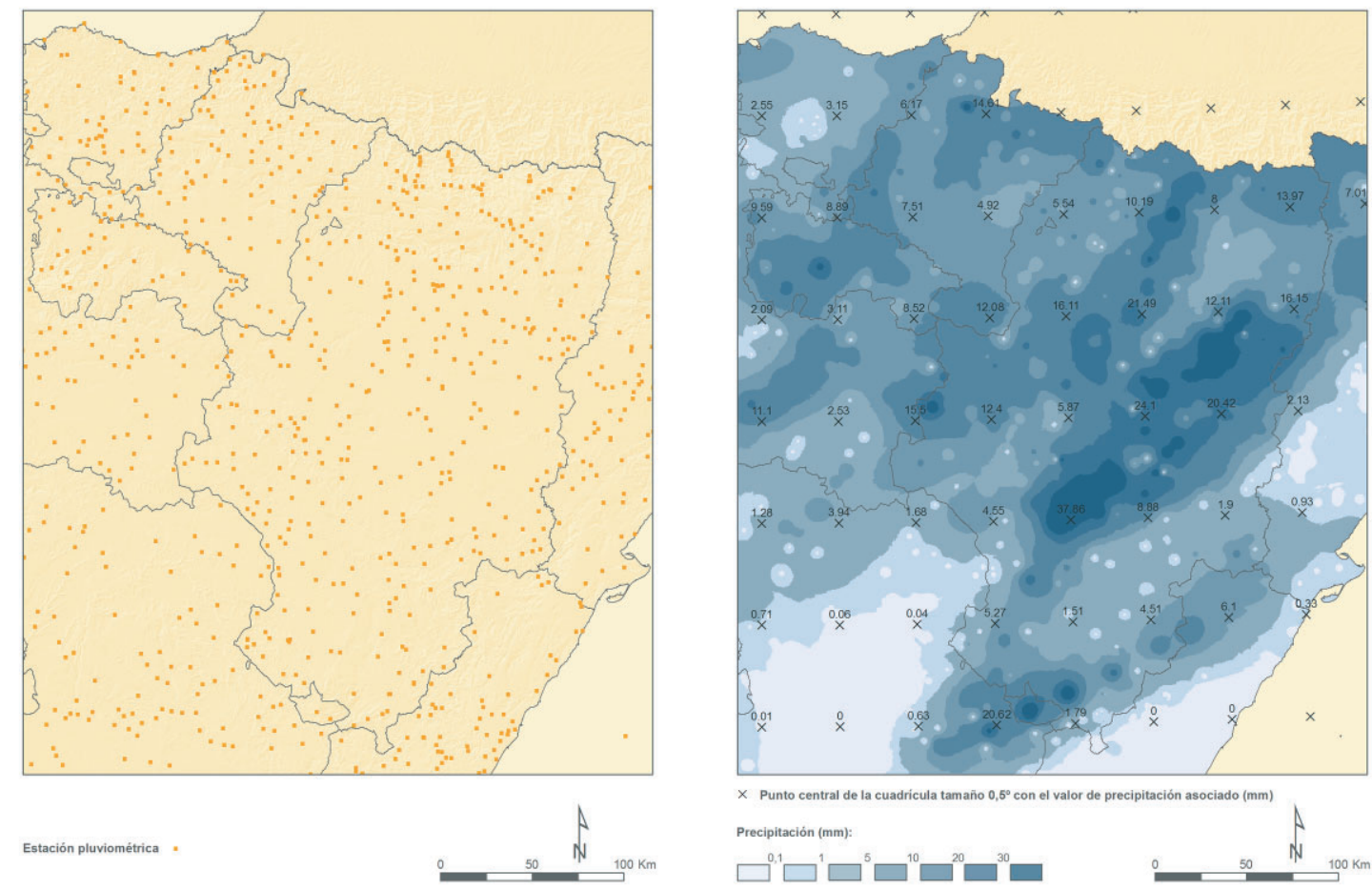

Mapa 2.1. Ejemplo de tratamiento de la información de precipitación.

Izquierda: imagen con los emplazamientos de los pluviómetros de la red climatológica complementaria de AEMET considerados para un día determinado.

Derecha: valor de precipitación asociado al punto central de cada una de las celdas de tamaño $0,5^{\circ}$ de latitud y longitud sobre la precipitación diaria de ese mismo día resultante del proceso de interpolación (método IDW).

(Elaboración propia).

Para la representación cartográfica de los promedios de precipitación, los registros diarios de precipitación reducidos a la malla grid de tamaño $0,5^{\circ}$ se interpolan según el método del krigeado simple (Simple Kriging), que estima el valor de la variable precipitación diaria para cada punto integrante del área de estudio como media ponderada de los valores asociados a los puntos centrales del grid dentro de la vecindad 
establecida. Los factores de ponderación aplicados, que proporcionan estimaciones no sesgadas y mínima varianza, se establecen a partir del análisis de correlación espacial entre los registros considerados (VICENTE ET AL., 2003).

Se emplea el mismo método de interpolación para representar cartográficamente la precipitación de los casos de estudio seleccionados, aunque en este caso dicho método se aplica directamente a los registros diarios de precipitación facilitados por la red climatológica complementaria de AEMET, ya que el objetivo en este caso es la visualización, y no la correlación o el tratamiento posterior de esta información.

Los registros de descargas eléctricas se trabajan bajo entorno McIDAS asociando las descargas eléctricas nube-tierra, detectadas en el área correspondiente a cada una de las celdas que configuran la malla de tamaño $0,2^{\circ}-0$ de $0,5^{\circ}$, según su finalidad- de latitud y longitud, al punto central de la misma. A partir de aquí, para cada celda se obtiene la densidad media de descargas como cociente entre el número de descargas asociadas a cada punto central de la cuadrícula y la superficie de esta, y el número de días de tormenta obtenido al calcular, para cada celda, la suma del número de días con rayos positivos y el número de días con rayos negativos, sustrayendo a este resultado el número de días en los que simultáneamente se registran rayos positivos y negativos.
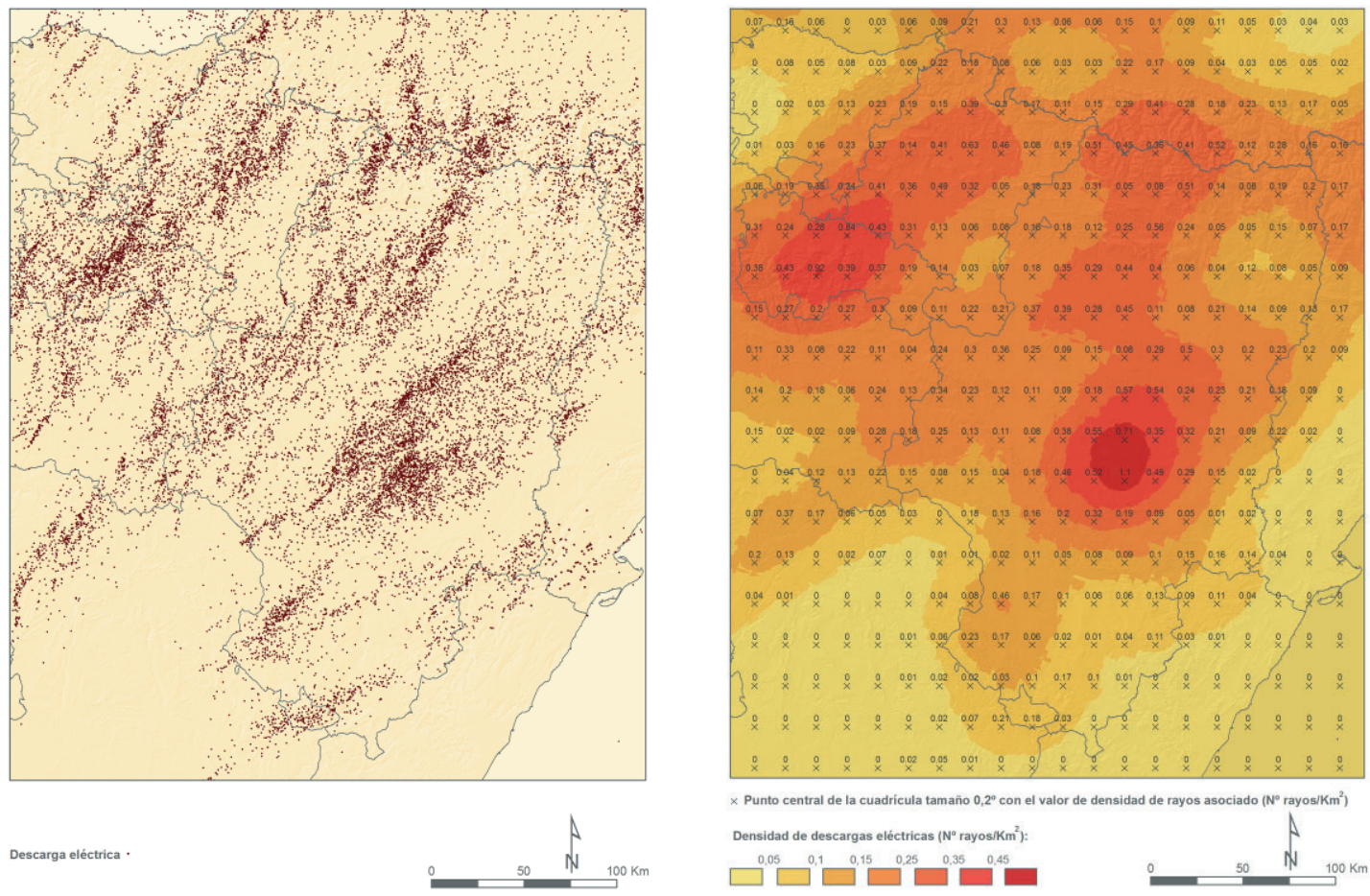

Mapa 2.2. Ejemplo de tratamiento de la información de descargas eléctricas.

Izquierda: imagen con las descargas eléctricas detectadas por las redes de radiodetección de descargas en España, Francia y Portugal para un día considerado.

Derecha: valor de la densidad de rayos para ese día asociada al punto central de cada una de las celdas de tamaño $0,2^{\circ}$ de latitud y longitud sobre la densidad de rayos resultante del proceso de interpolación (Krigeado Simple).

(Elaboración propia). 
La estimación de las densidades medias de rayos y el número medio de días de tormenta en cada punto del terreno, necesaria para la representación cartográfica de los promedios de descargas eléctricas y días de tormenta, se realiza mediante métodos de interpolación geoestadísticos (Mapa 2.2), en este caso el krigeado simple (Simple Kriging).

La Imagen 2.3 resume todo el proceso de tratamiento geoestadístico de la información de precipitación y de descargas eléctricas.

En los casos de estudio seleccionados en el Capítulo 5, la representación cartográfica de las descargas eléctricas se lleva mediante la representación puntual de su localización geográfica.

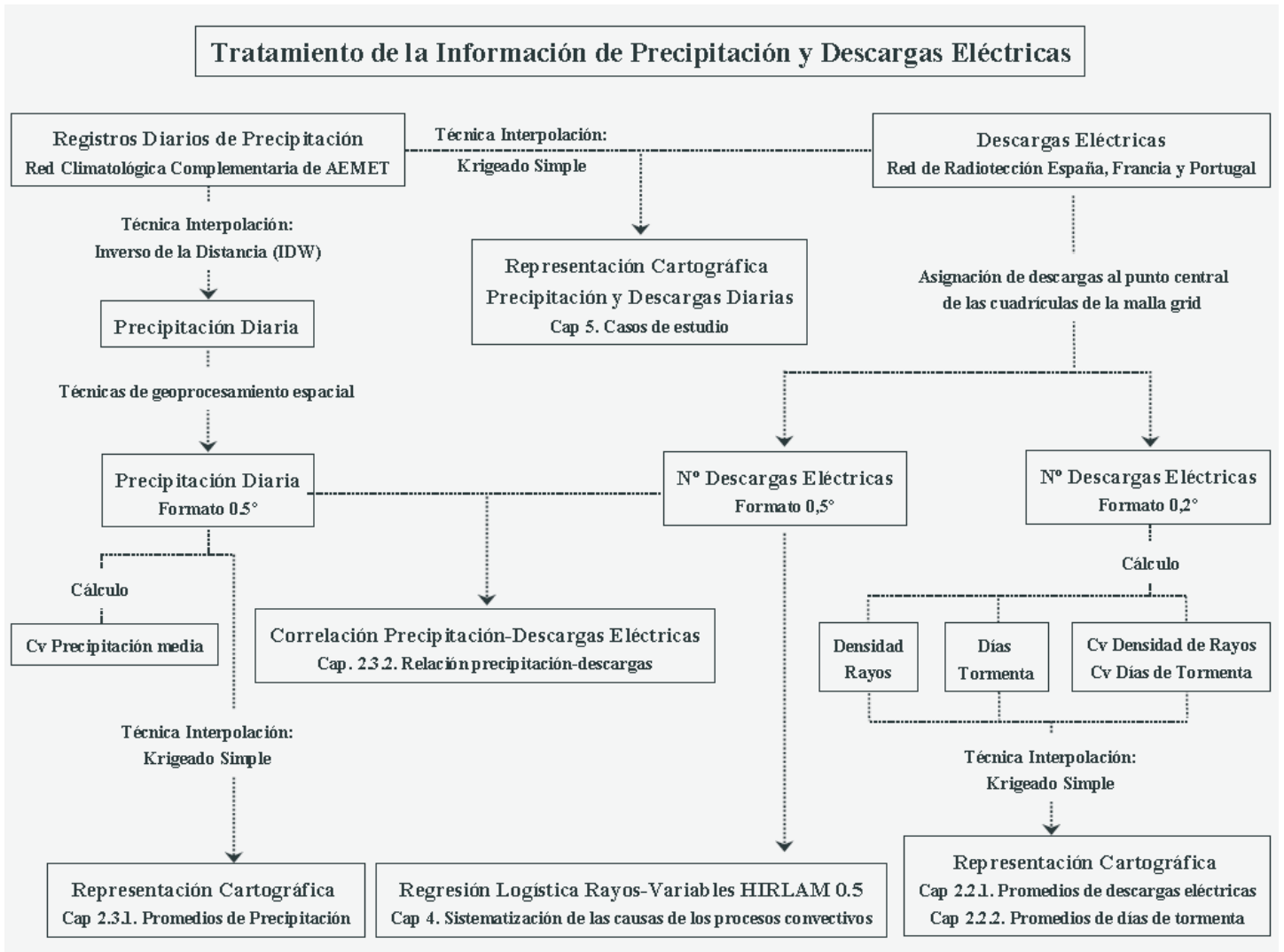

Imagen 2.3. Esquema explicativo del tratamiento de la información de precipitación y descargas eléctricas.

\subsection{Actividad eléctrica}

\subsubsection{Promedios de descargas eléctricas}

La densidad de rayos (descargas nube-tierra), tras la depuración de los datos y eliminando las subdescargas, tal y como se ha comentado anteriormente, presenta a grandes rasgos una buena correlación con los sistemas montañosos principales, los Pirineos y el Sistema Ibérico (Mapa 2.3). 


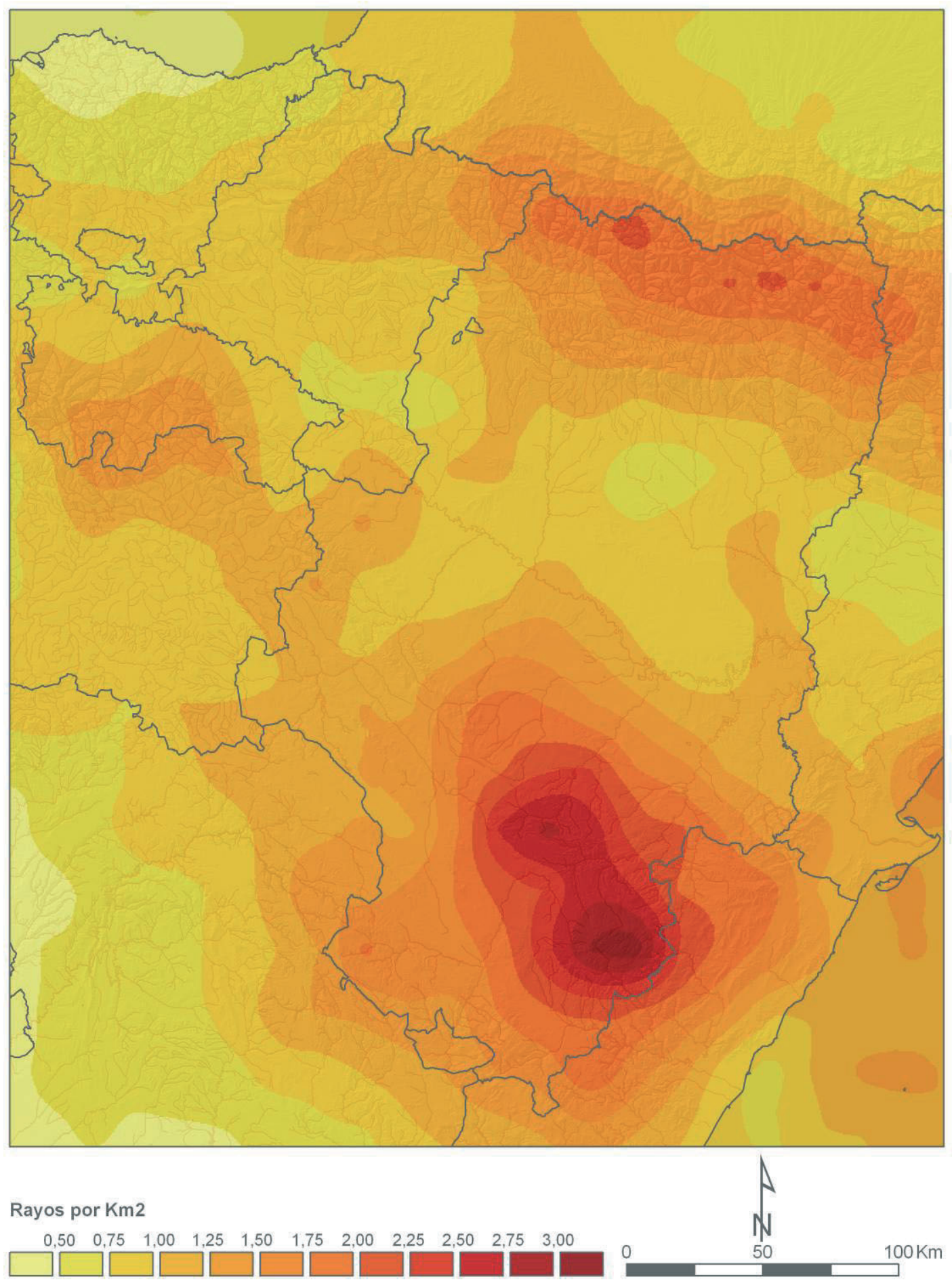

Mapa 2.3. Densidad de rayos para el periodo abr-sep entre 2002 y 2008. (Elaboración propia).

De forma más detallada la zona que, durante la temporada considerada, recibe más de una descarga por kilómetro cuadrado abarca la totalidad del Sistema Ibérico y sus piedemontes hacia la depresión del Ebro, específicamente en el valle del centro de La Rioja, el Somontano del Moncayo, los acampos al sur de Zaragoza (La Plana), Campo de Belchite, cuencas mineras y Bajo Aragón, zona en la que llega a rebasar al propio curso del Ebro y se prolonga por el Bajo Cinca. Esta zona abarca también la totalidad de la Cordillera Costero-Catalana y buena parte del litoral, desde la punta de Capicorb en 
Castellón hacia el norte. Asimismo, la zona con más de una descarga $/ \mathrm{km}^{2} /$ temporada comprende todo el ámbito pirenaico, con la excepción de la vertiente cantábrica de Navarra y la inclusión de la cuenca de Pamplona. Esta zona pirenaica se prolonga hacia el norte siguiendo, grosso modo, el curso de las gaves de Pau y Oloron. Al sur de los Pirineos la zona se prolonga, especialmente, por las zonas más montañosas de las Cinco Villas aragonesas (sierra de Luna y sierras de Erla y Las Pedrosas).

Las zonas que reciben más de dos descargas $/ \mathrm{km}^{2} /$ temporada abarcan en la Ibérica el área oriental de la Ibérica turolense y el Maestrazgo de Castellón. Comprende la sierra de Gúdar y todas sus ramificaciones, como las sierras de El Pobo, Lastra, La Cañada y las Dehesas, así como, más al noroeste, la sierra de Sant Just. En el Pirineo, las zonas con más de 2 descargas $/ \mathrm{km}^{2} /$ temporada se localizan en las sierras interiores del Pirineo y no presentan una gran continuidad espacial, habiendo un máximo occidental en Anayet-Peña Collarada-Peña Telera y varios puntos más orientales: La Solana, Cotiella y Turbón. La zona de 1,75 descargas $/ \mathrm{km}^{2} /$ temporada comprende, en general, toda el área de las sierras interiores del Pirineo oscense y parte del Pirineo Axial, con la notable excepción del macizo de la Maladeta. Salvo en el sector más occidental, esta zona de mayor actividad pirenaica no se prolonga al otro lado de la frontera sino que, al contrario, disminuye con rapidez. En Cataluña, esta área de máximos relativos termina en la sierra de Sant Gervás, entre Pont de Suert y La Pobla de Segur.

El máximo de toda el área de estudio, y seguramente de la Península Ibérica, superior a 3 descargas $/ \mathrm{km}^{2} /$ temporada, corresponde a la sierra de Gúdar, concretamente a una ramificación lateral de la anterior que reveladoramente lleva el topónimo de sierra del Rayo, entre los términos municipales de Mosqueruela, Fortanete y Cantavieja, en la provincia de Teruel. Por el contrario, las zonas con menor densidad de descargas, inferior a 1 descarga $/ \mathrm{km}^{2}$ y temporada, se dan en el litoral cantábrico, la margen izquierda de los tramos alto y medio de la depresión del Ebro, con la inclusión de los valles del Alhama en La Rioja y el Jalón en Aragón por la margen derecha, el litoral de la mitad sur de Castellón y, en general, la meseta castellana.

La evolución diurna de la convección se representa en las Imágenes 2.4a a 2.4h. Se han ordenado las cartografías trihorarias a partir de las $06 \mathrm{Z}$ para dotar de estructura lógica a la secuencia del calentamiento diurno, que ejerce un papel importante. Al amanecer (Imagen 2.4a) sólo hay cierta actividad tormentosa en el Mediterráneo, como consecuencia de la mayor temperatura relativa de la superficie del mar y del régimen de brisas. A partir de las $09 \mathrm{Z}$ (Imagen 2.4b) se empieza a manifestar el ciclo diurno de calentamiento y la actividad convectiva comienza a desarrollarse en varios puntos: el principal se sitúa entre el Pirineo navarro y aragonés occidental; por extensión y magnitud el segundo es el de Gúdar-Maestrazgo, y en una serie de puntos con menor extensión e intensidad: la sierra de Izco, en Navarra, Los Cameros, entre Soria y La Rioja, las sierras de Albarracín y Javalambre en Teruel y las sierras prelitorales de Les Talaies d'Allalà en Castellón. Durante las tres horas siguientes, de 12 a 15 Z, (Imagen 2.4c) la actividad tormentosa se distribuye claramente a lo largo de los sistemas montañosos, dibujando con claridad el arco orográfico que orla a la depresión del Ebro, el Sistema Central entre Soria y Guadalajara y la Cordillera Cantábrica más oriental al suroeste de Vizcaya. Los puntos con mayor densidad de descargas, y por lo tanto con más frecuencia e intensidad de fenómenos tormentosos en este intervalo, se localizan en la Ibérica riojana, el Pirineo centro-oriental y toda la Ibérica de Teruel especialmente su sector oriental, prolongándose hacia el Maestrazgo de Castellón. En este periodo 
comienzan a aparecer características diferentes, que serán más comunes durante las horas siguientes. Hasta este periodo, las densidades de descargas aparecen localizadas y concentradas, reflejando un escaso desplazamiento de los núcleos convectivos.

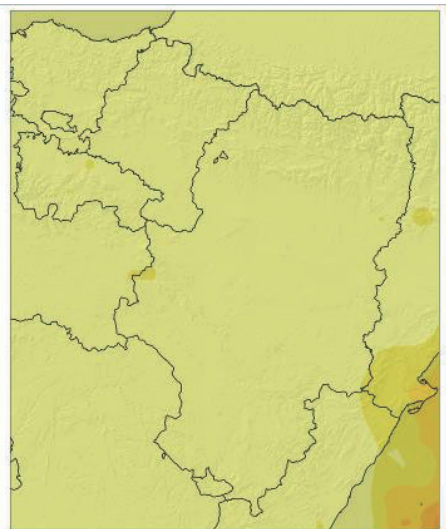

a) De 06 a $09 \mathrm{Z}$

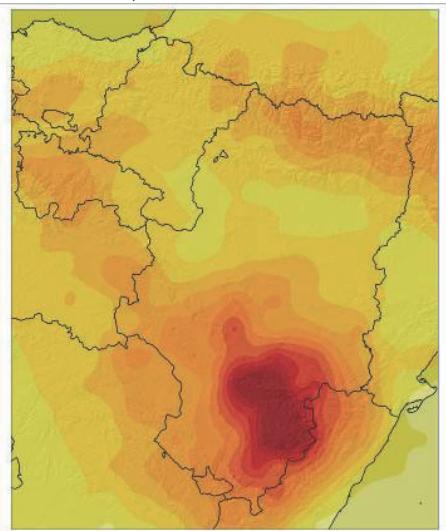

d) De 15 a $18 \mathrm{Z}$

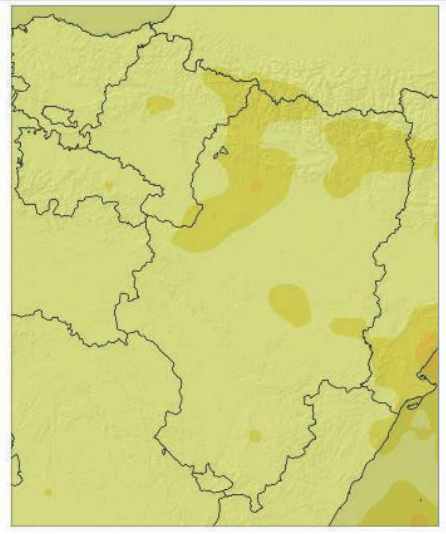

g) De 00 a $03 \mathrm{Z}$

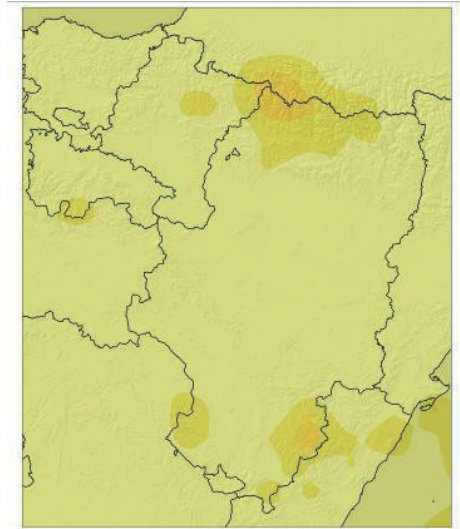

b) De 09 a $12 \mathrm{Z}$

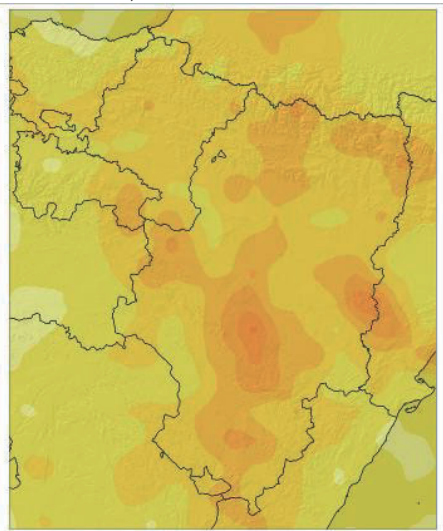

e) De 18 a $21 \mathrm{Z}$

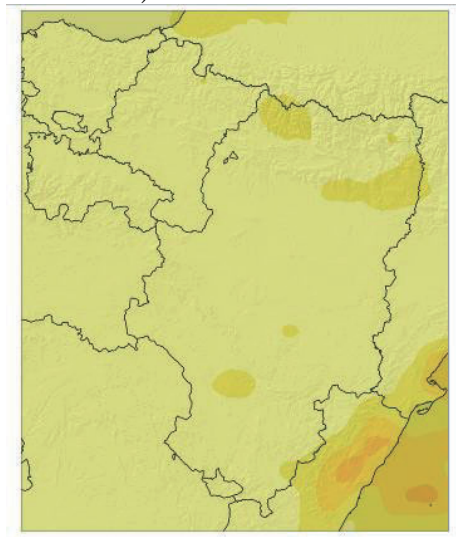

h) De 03 a $06 \mathrm{Z}$

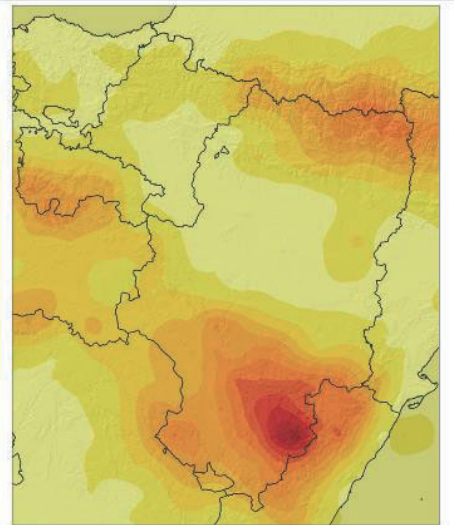

c) De 12 a $15 \mathrm{Z}$

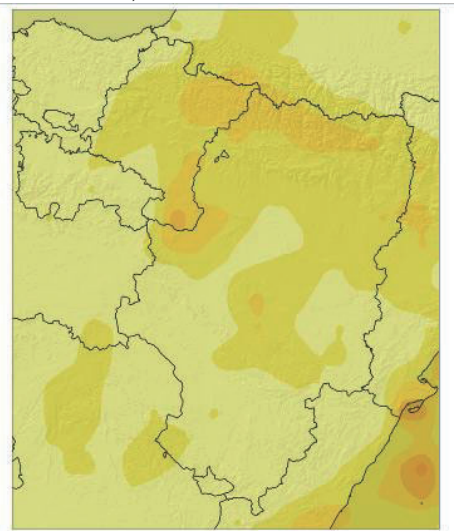

f) De 21 a 24 Z

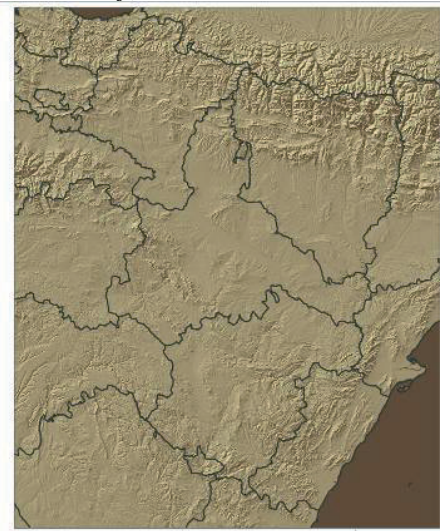

Rayos por Km2

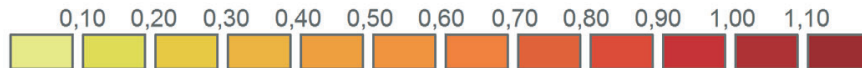

Imagen 2.4. Distribución trihoraria de las descargas $/ \mathrm{km}^{2} /$ temporada. (Elaboración propia).

En este periodo de primeras horas de la tarde sí que comienzan a aparecer estructuras alargadas en la densidad de descargas, como sobre toda La Rioja y la mitad occidental de Navarra o, con menor extensión y entidad, en el valle del Cinca. Es decir, los núcleos 
convectivos generados en la Ibérica Riojana (Picos de Urbión, sierra de la Demanda, Cameros) se propagan hacia el nordeste por la Ribera Alta, las sierras de Lóquiz, Urbasa, Andía y Aralar y la divisoria entre la cuenca del Ebro y la vertiente cantábrica de Navarra. Este desplazamiento de la actividad convectiva del suroeste al nordeste será una de las características principales de la convección en el nordeste peninsular y se produce con mayor claridad y a mayor escala en los intervalos temporales siguientes. Igualmente, el valle del Cinca, donde el régimen de brisas mediterráneo se ve reforzado por las brisas de valle debidas al calentamiento de los picos pirenaicos, favorece la convección en estas primeras horas de la tarde y se refleja en la mayor incidencia de las tormentas. No obstante, todos estos comentarios de detalle no deben enmascarar el hecho de que a primeras horas de la tarde la actividad tormentosa en las áreas de Gúdar y Maestrazgo es la máxima del área de estudio y alcanza ya niveles importantes tanto en esa zona como en el Pirineo centro-oriental.

La frecuencia e intensidad de las tormentas es, como cabría esperar, máxima durante la tarde (15-18 Z) (Imagen 2.4d). Se repite el patrón de máximos en las zonas montañosas del periodo anterior, con algunas modificaciones: hay una cierta disminución de la actividad en los Pirineos; dentro de mantenerse con una actividad elevada, el núcleo de la Ibérica riojana no aumenta en intensidad pero sí en extensión, abarcando prácticamente toda la montaña soriana y riojana, y el núcleo de Gúdar-Maestrazgo aumenta su extensión e intensidad y alcanza el máximo. Aparecen núcleos secundarios que antes no se podían individualizar en la Ibérica zaragozana y la característica principal de este periodo es la generalización de la traslación de los núcleos convectivos que se refleja en la prolongación en dirección SSW-NNE de las isolíneas de densidad, a través de corredores más o menos definidos: montaña de la Rioja Alta-Navarra centrooccidental, corredores del Jalón y del Huerva (en este periodo más importante este último), y el de Gúdar-Maestrazgo/Bajo Aragón/Cinca. El fin de la tarde y primeras horas de la noche (18-21 Z) (Imagen 2.4e) se refleja en un decaimiento general de la actividad convectiva y, o bien en la extinción de la generación de tormentas en los núcleos anteriormente más importantes en la Ibérica para dar paso únicamente a la propagación de los mismos hacia el área pirenaica (refuerzo de los corredores del Jalón y Huerva, prolongándose por el Gállego hacia el Pirineo), o bien en la aparición de nuevos núcleos de generación más tardía, que responden a otros procesos, como el del Bajo Ebro en Tarragona, o sobre el propio eje del río Ebro en La Ribera entre Aragón y Navarra. A primeras horas de la noche (21-24 Z) (Imagen 2.4f), los focos de la Ibérica cesan ya prácticamente su actividad y esta se mantiene bastante mermada en intensidad en los Pirineos, sobre todo en su sector más occidental, con cierta generación de convección sobre el Ebro en La Ribera y el sector central de la Depresión, que se prolongan en corredores hacia el Pirineo oscense occidental y oriental, respectivamente. Igualmente, aparecen tormentas justo sobre la costa mediterránea, producidas por las convergencias derivadas de la inversión del régimen de brisas. Durante el resto de la noche y la madrugada (Imágenes 2.4g y 2.4h) se van extinguiendo los focos pirenaicos y los del Ebro y solo se mantienen con una cierta intensidad los del litoral mediterráneo.

En las Imágenes $2.5 \mathrm{a}$ a $2.5 \mathrm{f}$ se representa el promedio de la densidad de descargas eléctricas para el área de estudio y cada uno de los seis meses de la temporada. Durante el mes de abril (Imagen 2.5a) esta es prácticamente irrelevante y responde más al patrón de tormentas dispersas asociadas al paso de sistemas de escala sinóptica. Esta tendencia se repite en mayo (Imagen 2.5b), aunque con mayores densidades y un patrón espacial que refleja la interacción del relieve con los sistemas frontales que refuerzan la 
convección. Así sucede en los sectores más occidentales de la Ibérica riojana, en las estribaciones de la Cordillera Cantábrica de Vizcaya y Álava, en el Pirineo occidental y sobre las muelas del sur de la depresión del Ebro, que interfieren con las perturbaciones del noroeste; con la Ibérica de Zaragoza, Guadalajara y Cuenca, así como con las sierras exteriores del Pirineo con las perturbaciones del suroeste y con el área del Maestrazgopuertos de Beceite con las perturbaciones mediterráneas del sureste. En junio (Imagen 2.5c) ya hay rasgos de un patrón "estival” de convección, con generación local sobre la Ibérica y los Pirineos de sistemas convectivos en el que se aprecia el funcionamiento de los corredores de tormentas riojano-navarro y, en Aragón, el que va de la Ibérica turolense occidental (Albarracín-Jiloca) hacia el Pirineo. El máximo de la actividad se produce en el Maestrazgo turolense, aunque la propagación de estos núcleos tiene menor alcance, lo que revela que en este mes los factores sinópticos de la circulación aún activa sobre el área de estudio juega un papel importante en la propagación de los núcleos convectivos con más influencia atlántica.

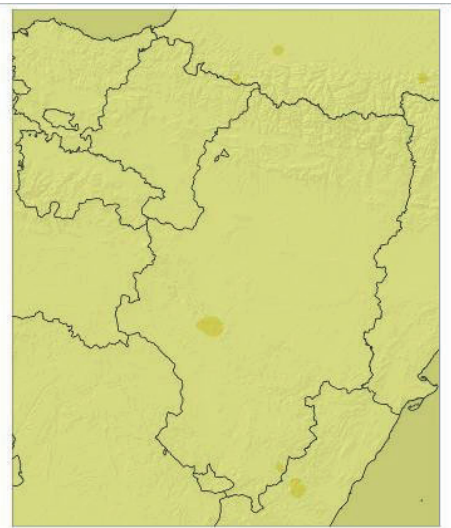

a) Abril

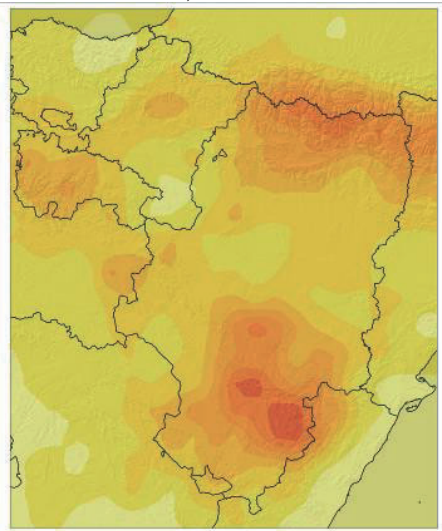

d) Julio

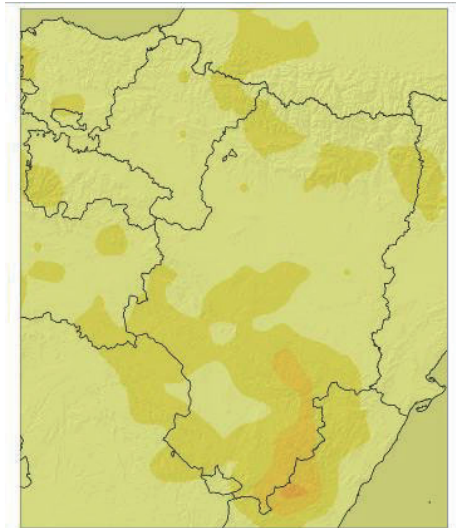

b) Mayo

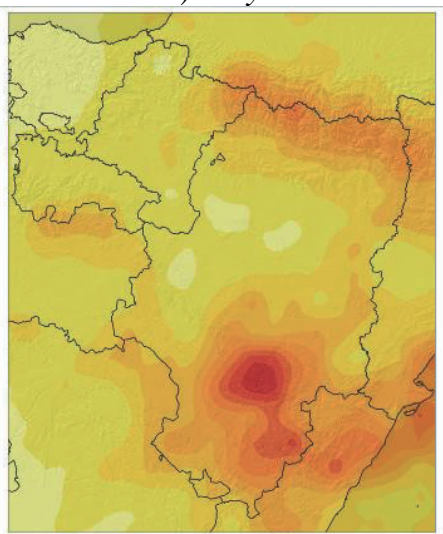

e) Agosto

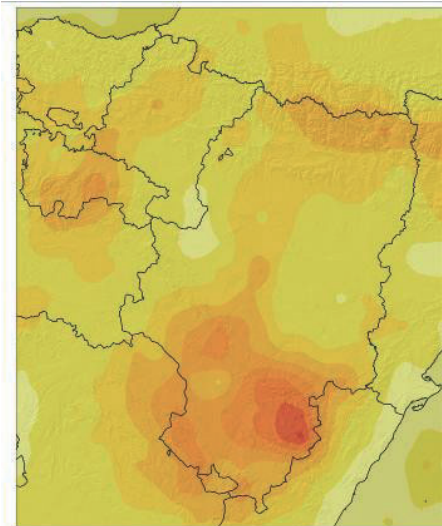

c) Junio

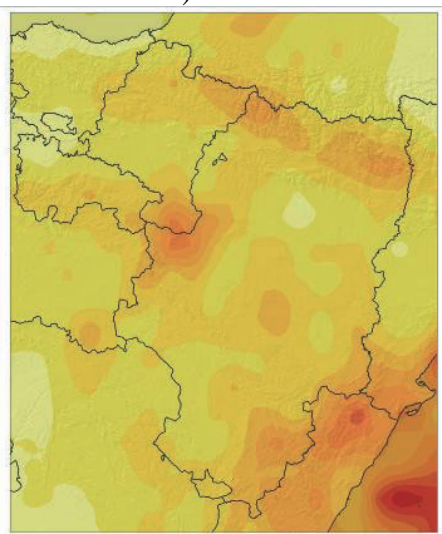

f) Septiembre

Rayos por Km2

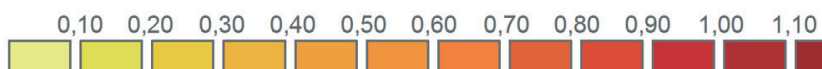

Imagen 2.5. Distribución mensual de las descargas $/ \mathrm{km}^{2} /$ temporada. (Elaboración propia).

Durante el mes de julio (Imagen 2.5d) se inicia un desplazamiento hacia el Mediterráneo de la actividad tormentosa que culminará en los dos meses siguientes. Tanto en los Pirineos como en la Ibérica la convección se focaliza en zonas más orientales, y el funcionamiento de los mencionados corredores occidentales pierde frecuencia y va adquiriendo una dirección más zonal y menos meridiana, lo que revela 
la alimentación de humedad y calor en niveles bajos proporcionada por los flujos mediterráneos procedentes de un mar cada vez más cálido. En el mes de agosto (Imagen 2.5e) llama la atención que el máximo de la actividad no se localiza sobre el núcleo de Gúdar-Maestrazgo, sino un poco más al norte, en el ámbito de la sierra de Sant Just y las cuencas mineras de Teruel, en localizaciones más abiertas a las entradas de flujos marítimos en superficie a través del Ebro. Se definen corredores desde esa zona hacia el Pirineo a lo largo del Cinca y desde el máximo secundario de Gúdar-Maestrazgo hacia la zona litoral, que presenta una actividad convectiva durante este mes mucho mayor que en cualquiera de los anteriores. En el sector noroeste del área de estudio se aprecia una cierta disminución de la actividad, aunque el núcleo de la Ibérica riojana aparece ahora con los máximos desplazados sobre la provincia de Soria y, en general, se aprecia indirectamente que estos núcleos son mucho más estáticos. Este proceso de deriva de la actividad convectiva hacia el Mediterráneo culmina en septiembre (Imagen 2.5f), cuando los máximos de actividad se sitúan bien sobre el litoral, bien directamente sobre la superficie del mar. Se dibuja una línea de máximos a lo largo del Ebro que llega a sus valores más altos sobre el piedemonte del Moncayo, donde se produce la convergencia de los flujos mediterráneos que ascienden el curso del Ebro con las descendencias de los valles laterales conforme se va estrechando la depresión del Ebro. Parte de estas tormentas se generan más al sur, en la cuenca alta del Jalón y se reactivan e intensifican sobre la Ibérica zaragozana, y parte de esta actividad continúa a lo largo de las Cinco Villas hasta terminar en el Pirineo occidental aragonés. Otra parte de la actividad que se genera sobre el litoral mediterráneo remonta el curso del Ebro y del Cinca y termina en la Ribagorza.

Hasta ahora se ha estudiado la evolución de la convección según las medias mensuales y según las medias trihorarias para todo el periodo. La matriz de medias de densidades de descargas eléctricas por meses y por intervalos trihorarios (Imagen 2.6) aporta una visión global de la evolución de la convección en el área de estudio y completa y enriquece lo ya comentado, que se puede resumir en los siguientes puntos clave:

- Durante el mes de abril apenas influye el ciclo diurno de calentamiento sobre la actividad convectiva, cuyo origen es posiblemente sinóptico y la actividad es muy escasa, en cualquier caso.

- En el mes de mayo, la actividad tormentosa que se produce es claramente vespertina, apareciendo a partir de las $12 \mathrm{Z}$ y decayendo rápidamente después de las $18 \mathrm{Z}$. Se produce fundamentalmente al sur del Ebro, destacando con claridad la divisoria entre Teruel y Castellón como línea de máximos.

- En junio ya comienza a producirse actividad durante la mañana en el Pirineo occidental aragonés y sobre la sierra de Gúdar. A partir del mediodía solar, esta actividad es muy destacable ya en toda la provincia de Teruel, especialmente en su sector oriental, en la Ibérica de La Rioja y en el Pirineo aragonés oriental-Pirineo catalán occidental. Durante la tarde, se dibujan con claridad corredores de tormentas desde las zonas de formación en Urbión-Demanda hasta el Pirineo navarro y desde Albarracín-Ibérica zaragozana hasta el Pirineo occidental aragonés a lo largo del Gállego. Este corredor continúa activo a primeras horas de la noche.

- A partir de julio, la actividad tormentosa matinal se restringe al Pirineo navarro y aragonés occidental. A primeras horas de la tarde se focaliza claramente sobre todo el Pirineo aragonés y catalán occidental y en la zona de Gúdar-Maestrazgo. 


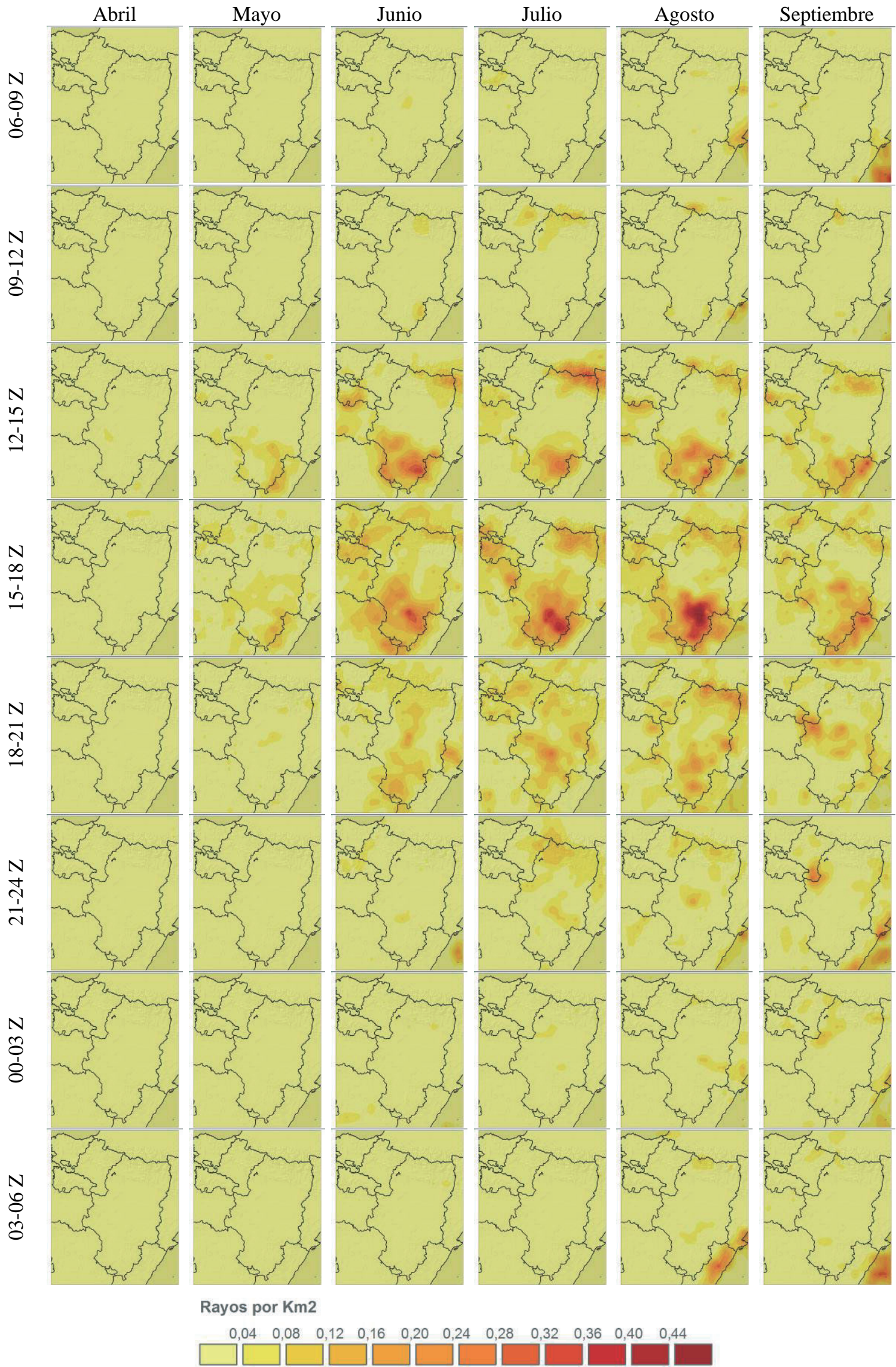

Imagen 2.6. Matriz de evolución mensual de la convección trihoraria. (Elaboración propia). 
La convección sobre el resto de la Ibérica (riojana, soriana y zaragozana) se inicia más tarde durante este mes, el funcionamiento de los corredores es evidente y la actividad se prolonga hasta primeras horas de la noche, especialmente sobre el Bajo Aragón y el área pirenaica.

- En agosto se mantiene el patrón del mes anterior en el interior del nordeste peninsular, pero aparece la importante novedad de una actividad tormentosa muy destacable por la noche y hasta primeras horas de la mañana sobre el litoral mediterráneo.

- En el mes de septiembre se mantiene la actividad puramente mediterránea, a la vez que va decayendo la actividad tormentosa sobre los sistemas montañosos, especialmente los más alejados del Mediterráneo. Durante la segunda mitad de la tarde y primeras horas de la noche la actividad se genera sobre el propio eje del Ebro.

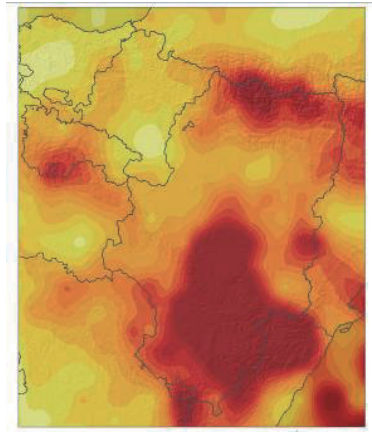

a) Temporada 2002

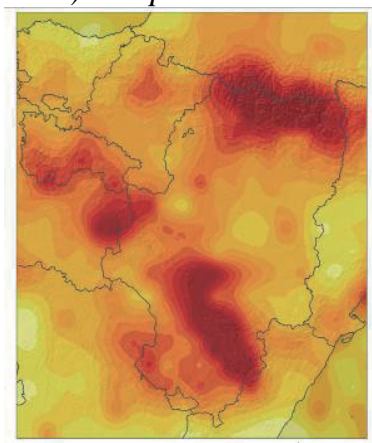

e) Temporada 2006

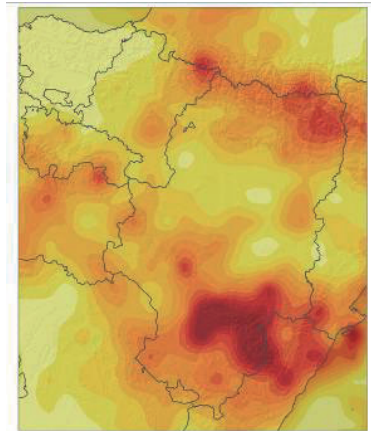

b) Temporada 2003

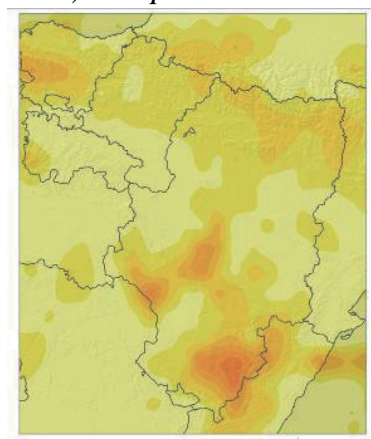

f) Temporada 2007

Rayos por Km2

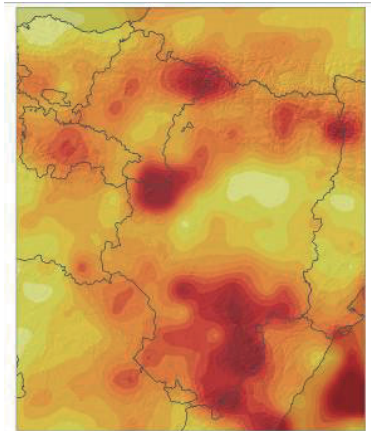

c) Temporada 2004

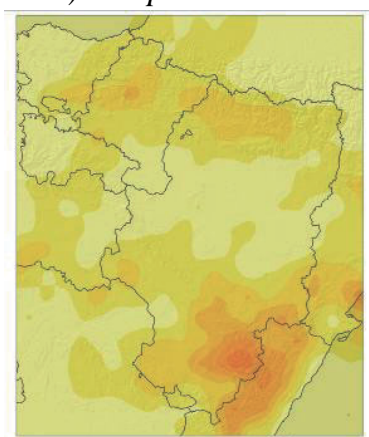

g) Temporada 2008

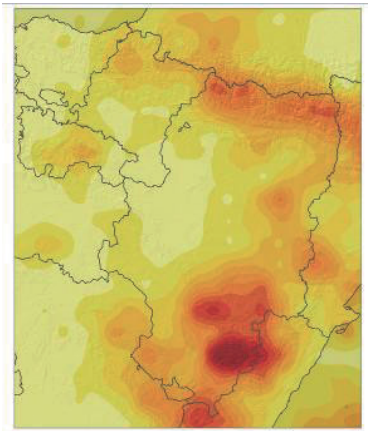

d) Temporada 2005

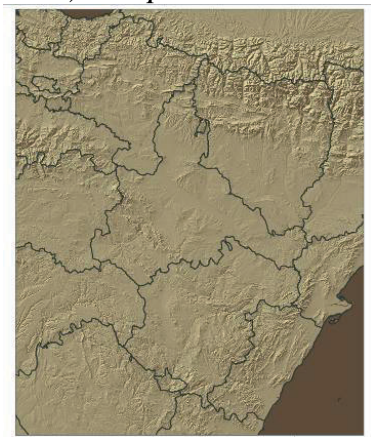

$\begin{array}{lllllllllll}0,50 & 0,75 & 1,00 & 1,25 & 1,50 & 1,75 & 2,00 & 2,25 & 2,50 & 2,75 & 3,00\end{array}$

Imagen 2.7. Densidades de descargas por temporada. (Elaboración propia).

Por último, se va a estudiar la dispersión de las descargas entre temporadas, es decir, si la presencia o ausencia de descargas en una zona entre temporadas es más o menos regular. Para ello, se utilizan las Imágenes 2.7a hasta 2.7g, que representan la densidad de descargas por temporada. A simple vista se aprecian diferencias significativas en actividad eléctrica entre temporadas y se podría deducir directamente qué zonas presentan mayor y menor frecuencia de descargas, y de ahí concluir la regularidad interanual del comportamiento de la actividad eléctrica sobre el área de estudio, pero es mejor hacerlo a través de un índice sintético y objetivo, como es el coeficiente de variación (STORCH Y ZWIERS, 1999). El coeficiente de variación, Cv, se define como el 
cociente entre la desviación estándar, sigma, y la media aritmética, $\bar{x}$, siempre que esta sea mayor que cero:

$$
C v=\frac{\sigma}{\bar{x}} \cdot 100
$$

De este modo, esta medida expresa porcentualmente la mayor o menor variabilidad de los valores de la variable, en este caso, la densidad de descargas eléctricas producidas por temporada con respecto a la media de todas ellas. La media se calcula en la rejilla de resolución $0,2^{\circ}$ (representada en el Mapa 2.3) y la desviación estándar de los valores en cada punto de rejilla para todas las temporadas consideradas. De ahí, se obtiene un valor de Cv para cada punto de rejilla, que se interpola espacialmente para resultar el Mapa 2.4 .

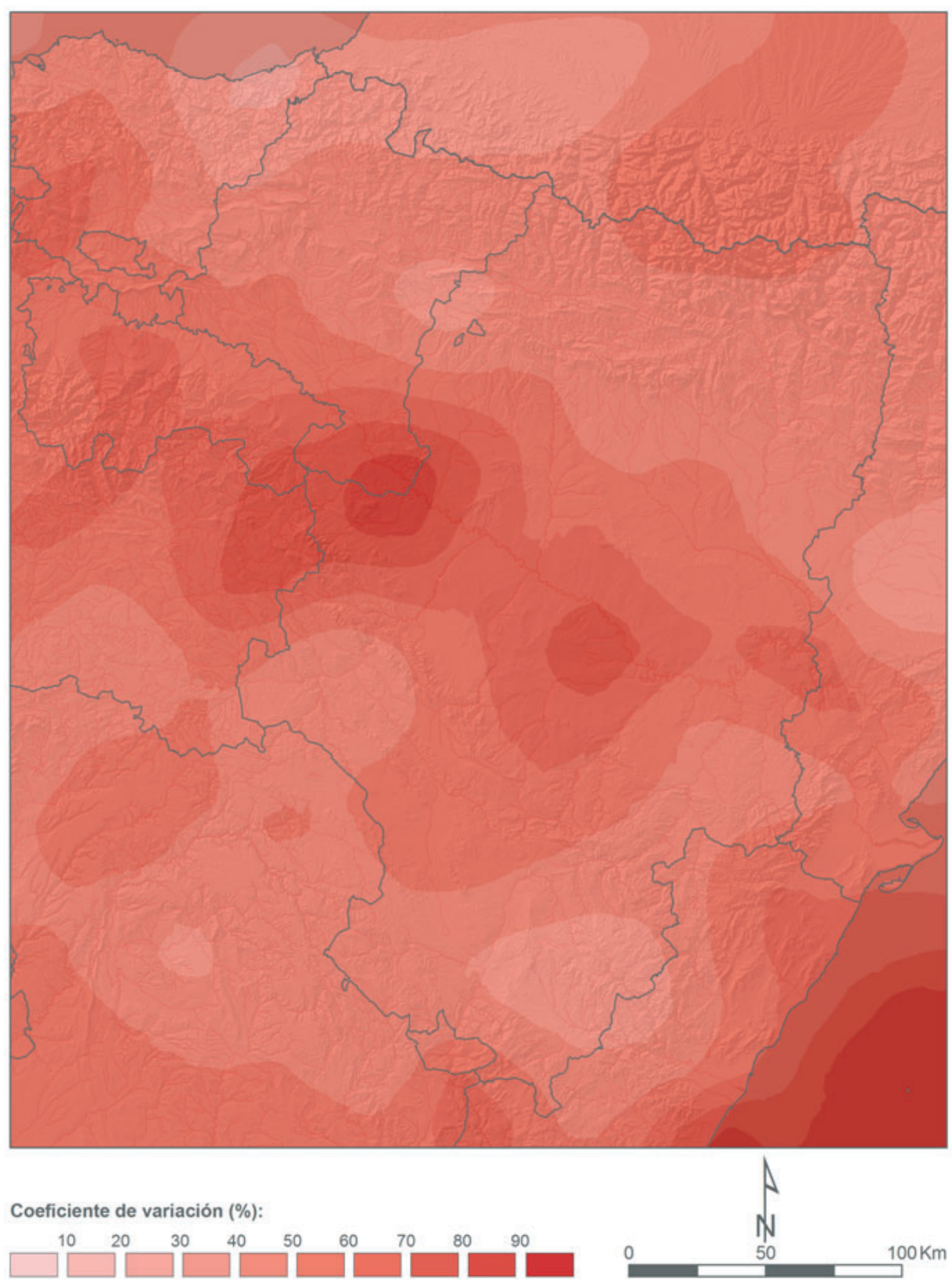

Mapa 2.4. Coeficiente de variación de la densidad de descargas eléctricas.

(Elaboración propia). 
El Mapa 2.4 revela características interesantes de la convección. Las áreas con Cv más bajo se encuentran en el litoral cantábrico oriental (con valores del orden del $10 \%$ ), que indica que la baja densidad de descargas que presenta esa zona es "normal" y esperable temporada tras temporada, y el área de Gúdar-Maestrazgo (con valores del orden del $20 \%$ ), que indica lo mismo pero en el sentido contrario: en ese caso, la alta densidad de descargas eléctricas de esa zona se presenta todas las temporadas con regularidad. Se identifican otras zonas de bajo Cv en el entorno prepirenaico de las sierras de La Peña y Leyre, entre Aragón y Navarra y en puntos de La Alcarria, así como en el centro-sur de Lérida. Mientras que en este último caso hay correspondencia con un mínimo relativo en la densidad de descargas, los otros dos más bien identifican áreas favorecedoras de la convección.

En el extremo opuesto, de zonas de alto coeficiente de variación de densidad de descargas entre temporadas, llama la atención la zona de máximos que aparece sobre el eje del Ebro, ligeramente desplazada hacia la margen derecha y el área sobre el Mediterráneo. El área de máximos sobre el Ebro identifica esencialmente a los corredores de tormentas desde la Ibérica (que aparecen incluso en el Alto Ebro). En el somontano del Moncayo, el Cv llega a ser del orden del $70 \%$, y los valores se mantienen en torno al 50-60 \% en todo el corredor del Ebro. Esta variación puede estar relacionada con causas sinópticas, es decir, con la presencia o ausencia de factores sinópticos que permiten el desplazamiento de los núcleos convectivos generados en la Ibérica desde el SSW hacia el NNE. Idéntica estructura aunque con menor magnitud se observa en el Pirineo central aragonés, propagándose por el departamento de Hautes Pyrénees. La variabilidad de las descargas sobre el Mediterráneo es la máxima del área de estudio, con valores superiores al $80 \%$, y probablemente se deba a la variación de los vientos dominantes y a otros posibles factores, como la diferente temperatura del agua del mar entre temporadas.

\subsubsection{Promedios de días de tormenta}

El proceso seguido para el conteo del número de días de tormenta en el área de estudio es menos variable con otros trabajos que en el caso del número de descargas, donde pueden aparecer variaciones según estudios por adoptar una metodología que cuente las subdescargas o no. En este caso, se cuentan por celda los días en los que ha habido por lo menos una descarga como "día de tormenta”.

La estructura general de la distribución de días de tormenta reproduce (Mapa 2.5) la configuración del relieve, con mínimos a lo largo de las costas, especialmente la vizcaína y la castellonense y máximos siguiendo las cadenas pirenaica e ibérica, con mínimos relativos en la depresión del Ebro.

Así, para toda el área de estudio, la temporada abril-septiembre, y el periodo 2002-2008, de promedio la zona con más días de tormenta, con más de treinta días de tormenta por temporada, es, en sentido amplio, el Pirineo aragonés y la zona considerada del catalán, salvo el valle de Arán. El máximo de más de treinta y cinco días se da en el Pirineo aragonés oriental, en una zona que va desde Sierra Tendeñera al oeste hasta la sierra de Sant Gervás, en Lérida, al este. Destaca que esta zona de máximos corresponde a las Sierras Interiores e incluso a la zona del flysch en este sector - la cuenca del Ara-, y no con el Pirineo Axial, que queda parapetado por esta primera zona que encuentra el flujo dominante del suroeste que transporta a la mayor parte de los núcleos convectivos. 
Llama también poderosamente la atención que la zona con máxima densidad de descargas, la Ibérica oriental turolense y su zona anexa en el Maestrazgo de Castellón, no es aquí un máximo absoluto, sino un máximo secundario, con más de treinta días de tormenta por temporada, equivalente a lo que se da en cualquier punto del Pirineo aragonés, lo cual da idea de la mayor intensidad de las tormentas en esta zona. Este máximo ibérico se extiende entre las sierras de Sant Just y la de Gúdar. El resto de la Ibérica de Teruel presenta más de veinticinco días de tormenta por temporada, salvo la sierra de Albarracín. El resto de la Ibérica queda comprendido en la zona de entre 20 y 25 días de tormenta por temporada, con dos máximos relativos de más de 25 días de tormenta/temporada entre Soria y La Rioja; uno más occidental que comprende las sierras de Alba, Rodadero, Camero Viejo, del Hayedo de Santiago y de la Hez y otro más oriental y localizado correspondiente con la sierra de Urbión.

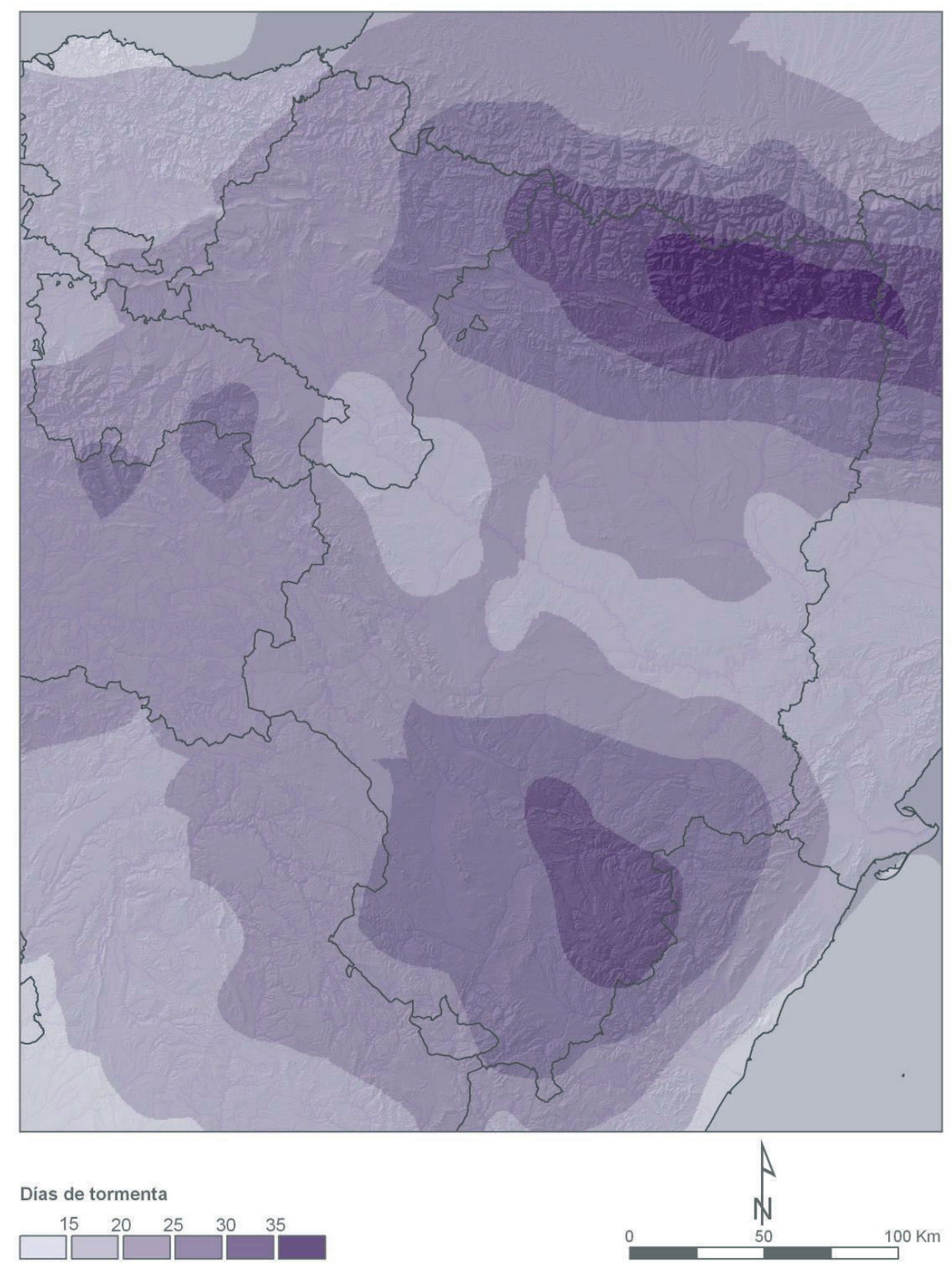

Mapa 2.5. Promedio de días de tormenta por temporada (abril-septiembre) para el periodo 2002-2008. (Elaboración propia). 
Casi todo el territorio de La Rioja y Navarra presenta más de veinte días de tormenta por temporada. El Pirineo navarro tiene más de veinticinco días de tormenta por temporada, como todo el Prepirineo aragonés y catalán (las Sierras Exteriores), así como la franja de los Pirineos franceses más próxima a la frontera. La zona del País Vasco que presenta más días de tormenta es el sureste de Álava — Sierra de Cantabria y estribaciones de Urbasa-, con más de veinte por temporada. El resto, salvo el mencionado litoral vizcaíno, queda comprendido en la zona de entre 15 y 20 días.

En la depresión del Ebro hay dos mínimos relativos de entre 15 y 20 días de tormenta por temporada; uno que comprende la Ribera Baja de Navarra, y las bajas Cinco Villas, la Ribera Alta y el Campo de Borja en Aragón, y otro que se prolonga a ambos lados del Ebro, con más desarrollo en la margen izquierda que en la derecha, aguas abajo de Zaragoza, que se amplía con las áreas bajas de las cuencas del Cinca y el Segre y por el resto de la Cataluña fuera del ámbito pirenaico. La estructura de estos mínimos en la depresión refleja muy bien los corredores de tormentas riojano-navarro y el que se establece en el centro de la depresión entre los relieves de La Muela y los Montes de Castejón. El corredor más occidental se prolonga hacia el norte de los Pirineos por las Landas.

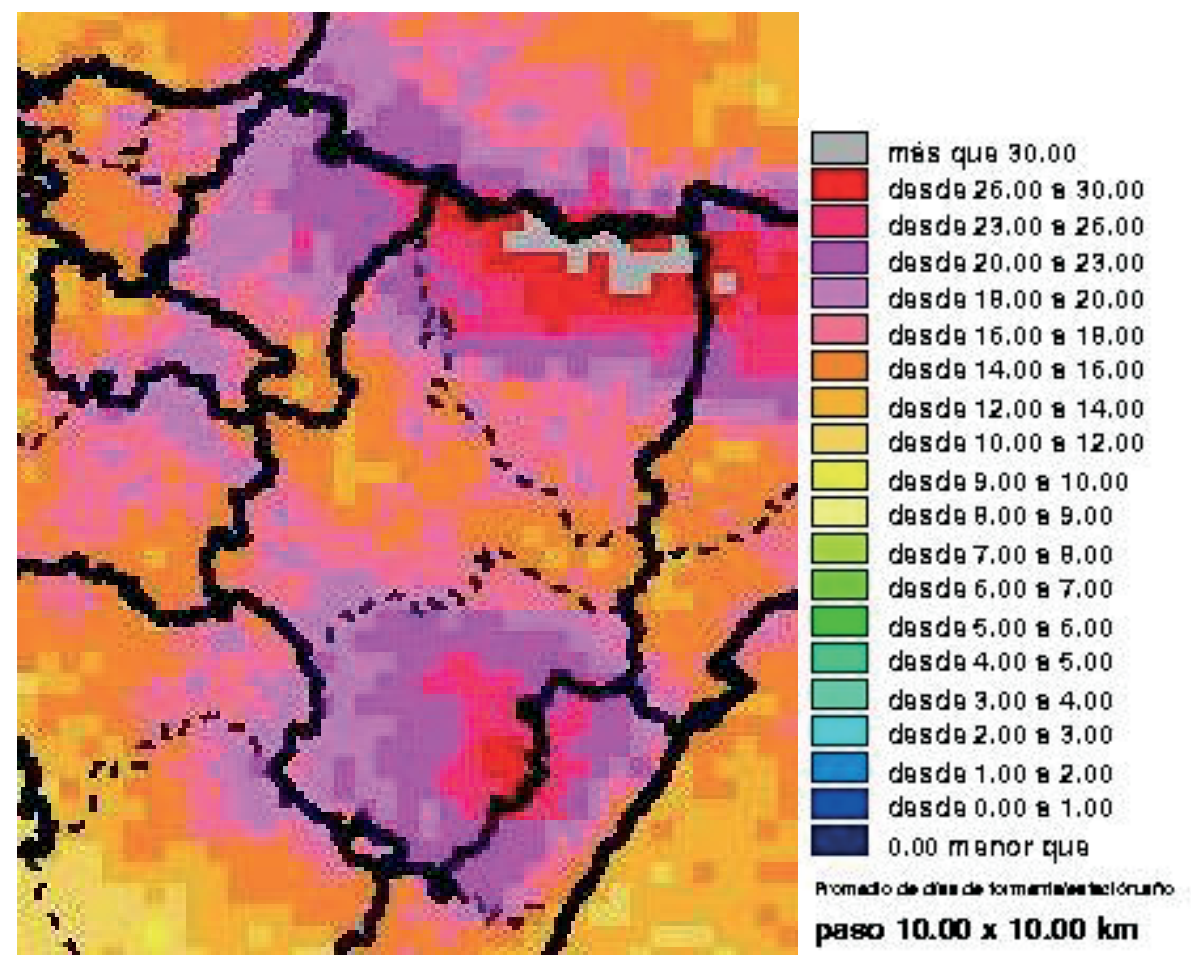

Imagen 2.8. Recorte, para el área de estudio de este trabajo, del mapa anual del número medio de días de tormenta 2000-2009. (PUEBLA Y ZANCAJO, 2010).

Al haber utilizado una metodología similar, esta descripción es compatible con los resultados obtenidos por PÉREZ Y ZANCAJO (2010) (Imagen 2.8), con la salvedad de que este último estudio considera el periodo 2000-2009 y todo el año, pero precisamente el no aparecer diferencias apreciables en el área de estudio objeto de esta nota justifica la representatividad de la temporada abril-septiembre con el fin del estudio de la convección. 
La distribución mensual media (Imagen 2.9) de los días de tormenta refleja —como es lógico - un patrón similar al de la evolución mensual de la densidad de descargas, es decir, un máximo en los meses puramente veraniegos y un desplazamiento de la zona con más actividad del área atlántica en primavera hacia el área mediterránea a finales de verano y otoño. No obstante, hay algunos otros matices que merecen la pena ser comentados.

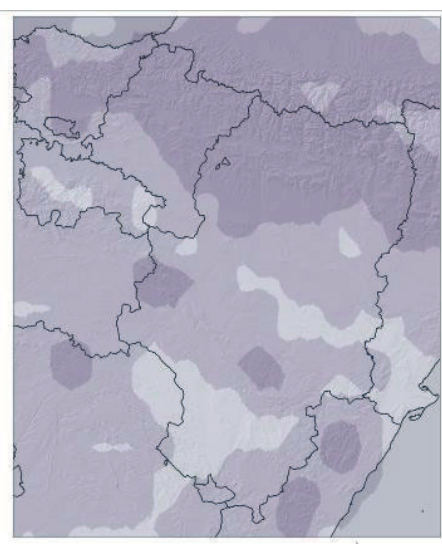

a) Abril

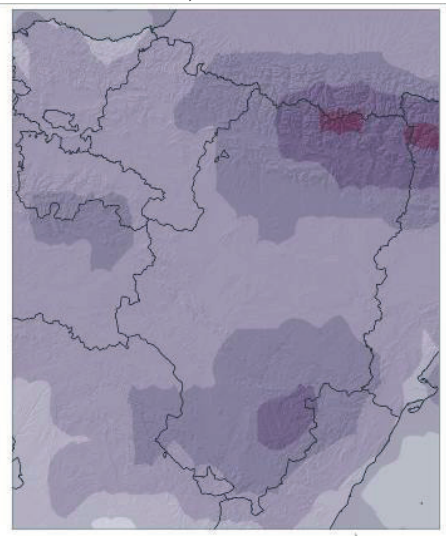

d) Julio

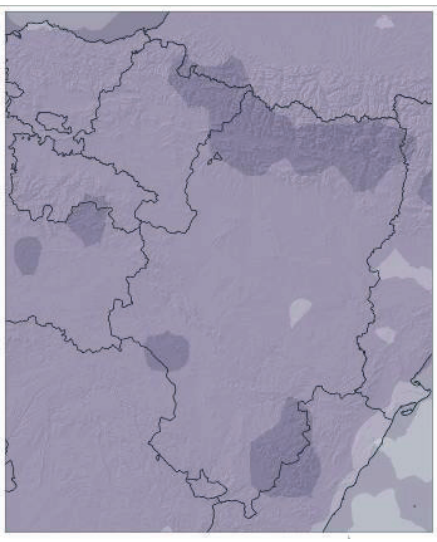

b) Mayo

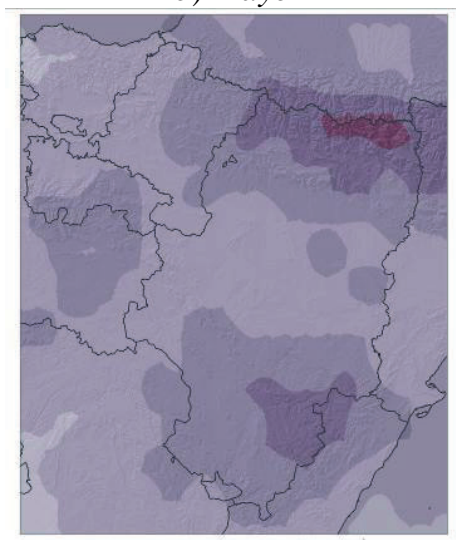

e) Agosto

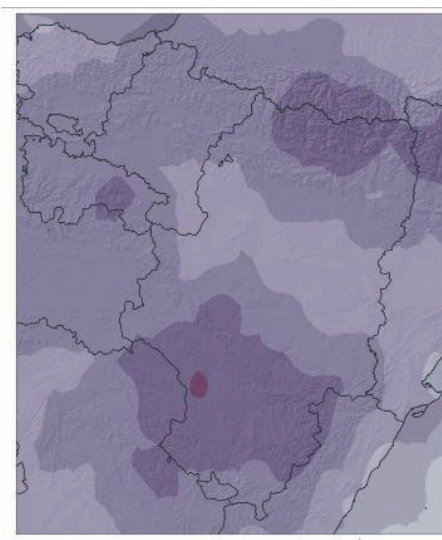

c) Junio

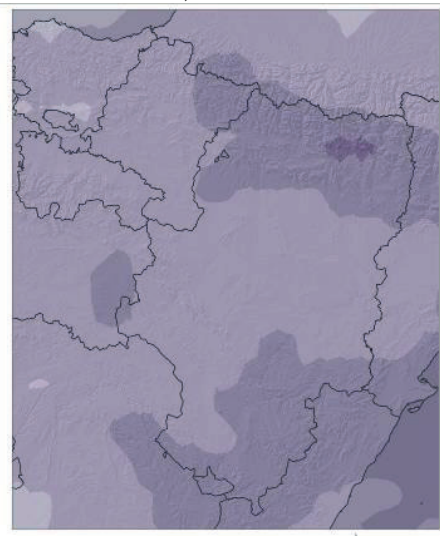

f) Septiembre Días de tormenta

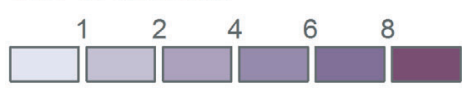

Imagen 2.9. Distribución mensual media de los días de tormenta. (Elaboración propia).

Desde el punto de vista del número de tormentas por mes, durante los meses primaverales, abril y mayo (Imágenes 2.9a y 2.9b), se aprecia un patrón que podría explicarse por el paso de perturbaciones sinópticas, de ahí que en abril la latitud sea un factor importante. En mayo la actividad aumenta en todo el territorio, muy bien distribuida como corresponde a las dimensiones de las perturbaciones que la producen, aunque hay un efecto más claro de aumento sobre los sistemas montañosos. Es decir, tanto por refuerzo de la intensidad de la convección de origen sinóptico como por la generación de las primeras tormentas locales, en mayo el número medio de días de tormenta en las zonas de montaña duplica al de las zonas llanas. En el mes de junio (Imagen 2.9c) el peso del factor orográfico se hace muy evidente y, dentro del contexto de un aumento general del número de días, aparecen máximos de más de 6 días al mes en el Pirineo aragonés centro-oriental, en la montaña de La Rioja Baja y, de forma muy 
destacada, en la Ibérica de Teruel, con un máximo de más de 8 días de tormenta al mes en las zonas más bien llanas y altas entre Teruel y Gallocanta (Llanos de Visiedo, sierras de Lidón y Palomera).

En julio y agosto (Imágenes 2.9d y 2.9e) las tormentas se comienzan a desplazar hacia el Mediterráneo y los máximos aparecen más concentrados en el Pirineo centro-oriental, en la Ibérica riojana occidental y en el área de Gúdar-Maestrazgo. En ambos meses, los máximos superiores a 8 días de tormenta al mes se dan entre los cursos pirenaicos del Gállego y el Noguera Pallaresa.

En septiembre (Imagen 2.9f) hay, como podía esperarse, más días de tormenta en las zonas de mayor influencia mediterránea, dentro de una disminución general del número de días, y el máximo de más de 6 días al mes se da en el Serrablo, en el interfluvio entre el Gállego y el Ara.

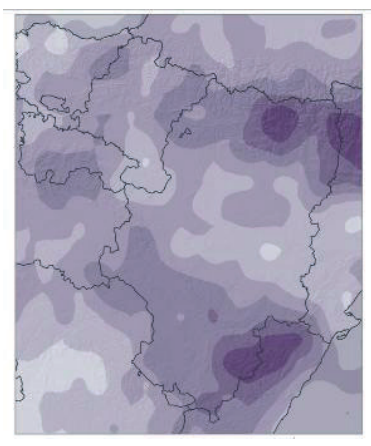

a) 2002

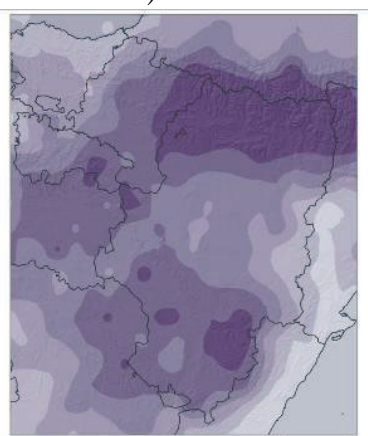

e) 2006

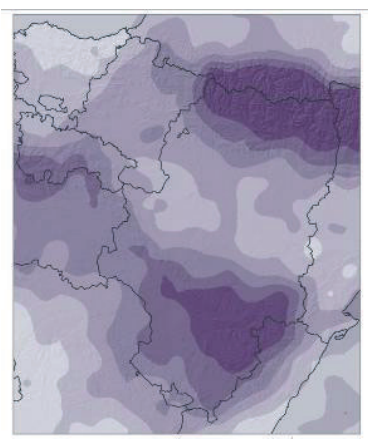

b) 2003

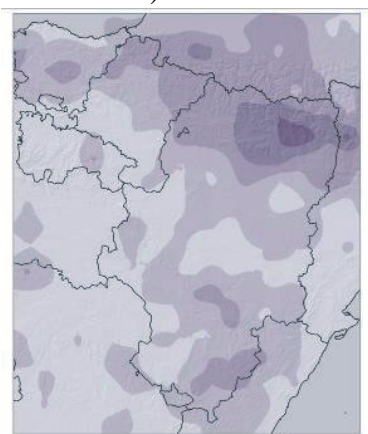

f) 2007

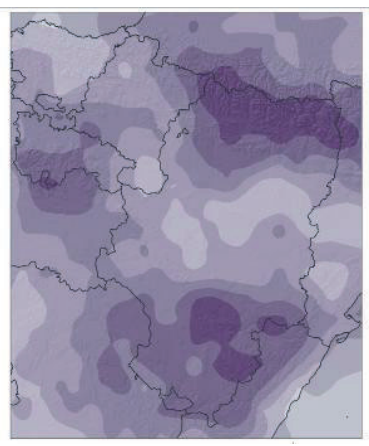

c) 2004

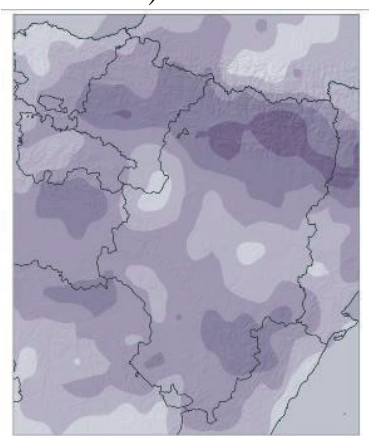

g) 2008

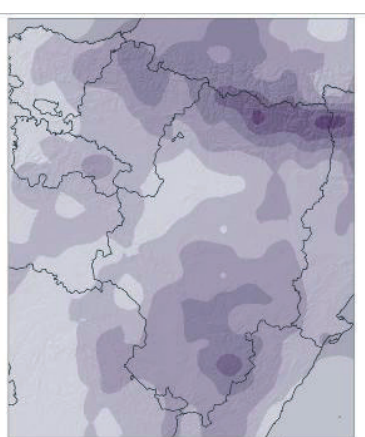

d) 2005

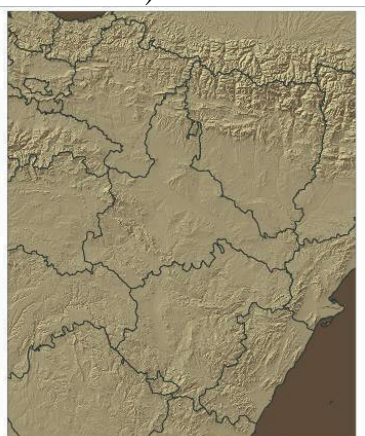

Días de tormenta

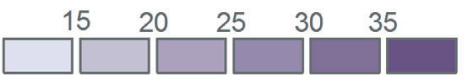

Imagen 2.10. Días de tormenta por temporada (abr-sep). (Elaboración propia).

La distribución de días de tormenta por temporada y su variación con respecto a la media se estudia de forma análoga a la evolución de la densidad de descargas por temporada. La Imagen 2.10 representa el número medio de días de tormenta por temporada, que, al igual que sucede con la Imagen 2.7 de la densidad de descargas, muestra variaciones apreciables en el territorio entre unas temporadas y otras en el número total y en la distribución de días de tormenta (más o menos relacionada con el relieve, más o menos relacionada con la influencia atlántica o mediterránea, más limitada al área pirenaica o extendida a la ibérica). Para sintetizar la información sobre la regularidad entre temporadas de la presencia o ausencia de tormentas en el área de 
estudio se recurre de nuevo al coeficiente de variación, en este caso del número de días de tormenta (Mapa 2.6).

La apariencia de este Mapa 2.6, por el contrario, tiene sensibles diferencias con el del Cv de la densidad de descargas por temporada (Mapa 2.4) y características particulares que interesa comentar.

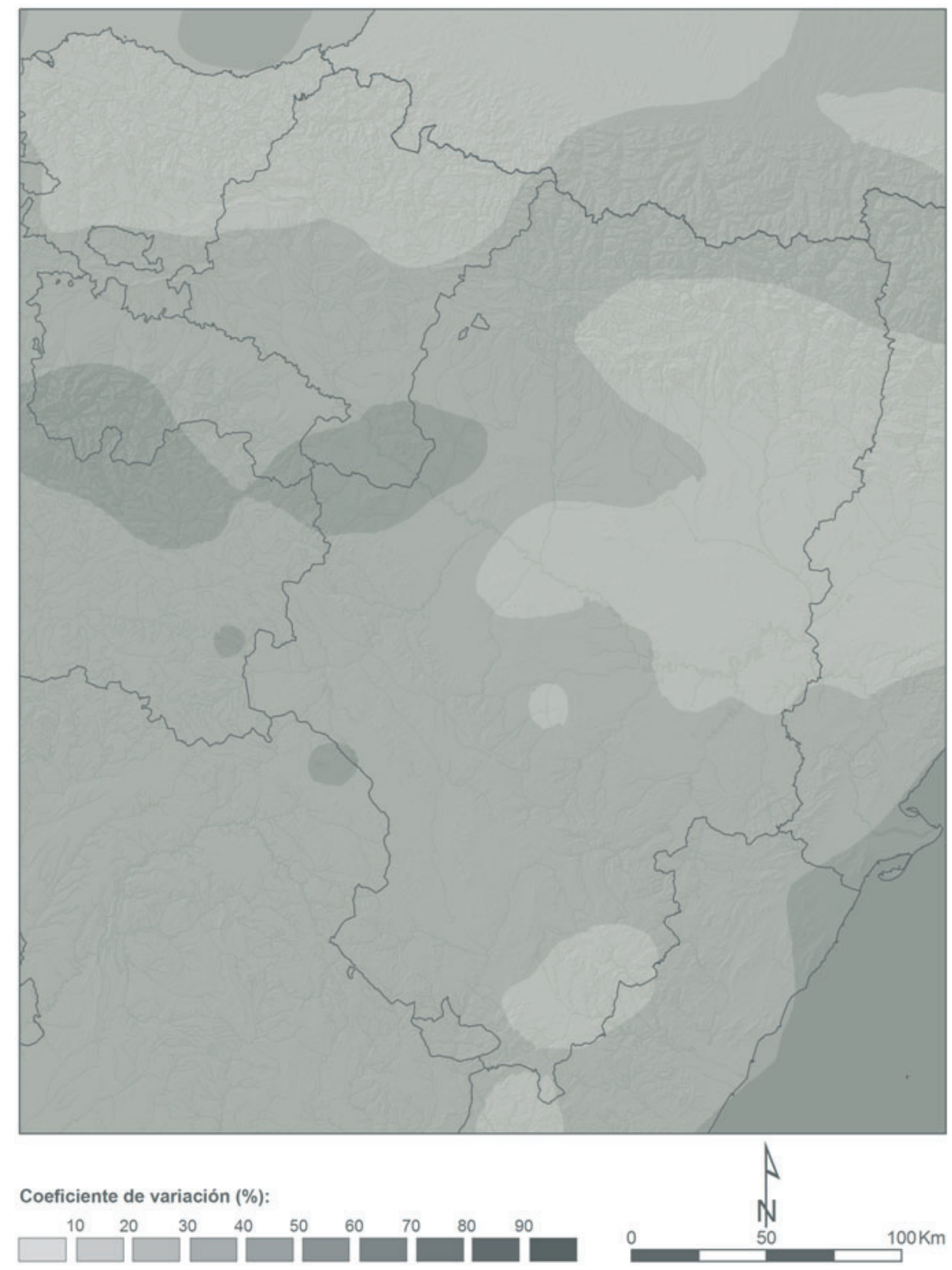

Mapa 2.6. Coeficiente de variación del número de días de tormenta por temporada.

(Elaboración propia).

En primer lugar, cuantitativamente los valores del Cv son menores para el caso de días de tormenta que para la densidad de número de rayos. Es decir, la presencia o ausencia de rayos es más regular que su densidad, que está más relacionada con la intensidad de las tormentas (e indirectamente, con su severidad) y por lo tanto con la variación de la 
magnitud de los factores que las causan. Cualitativamente, ambas cartografías coinciden en ofrecer valores mínimos en el área de influencia cantábrica y en la zona de GúdarMaestrazgo, en ambos casos por idénticas razones (regularidad de la ausencia y de la presencia, respectivamente, de fenómenos convectivos). Una diferencia importante, sin embargo, es que aparece una extensa zona de Cv mínimo que coincide básicamente con las cuencas del Cinca y el Segre más los Monegros y el área de Zaragoza, y que por tanto, el comportamiento de la actividad convectiva (en cuanto a su presencia y ausencia) es relativamente homogéneo entre temporadas. La variabilidad de los días de tormenta en el resto de la Ibérica de Aragón —-salvo el Moncayo-, la mitad occidental de la Depresión del Ebro y en Pirineo es moderada, y presenta máximos (del orden del $50 \%$ ) sobre el Mediterráneo, reflejo de los altos valores de $\mathrm{Cv}$ en la densidad de descargas, y, de modo muy interesante, en la Ibérica riojana y el Moncayo. Este hecho viene a ser otro factor a añadir a la hora de comentar las diferencias climáticas presentes entre la Ibérica occidental, con mayor influencia oceánica y continental mesetaria, y la oriental, de clara influencia mediterránea: mientras que en la segunda el factor tormentas tiene una presencia homogénea temporada tras temporada, en la primera este es más variable y depende de la climatología sinóptica de la temporada en cuestión.

\subsection{Precipitaciốn}

Una de las consecuencias más obvias de los procesos convectivos es la precipitación, por lo que su estudio, siquiera descriptivo en un trabajo de estas características, es obligatorio. Disponiendo, además, de datos sobre la actividad eléctrica, el análisis conjunto de ambos, que se llevará a cabo en el Capítulo 4, tiene sentido por cuanto, aunque no se consideran precipitaciones en forma de chubasco y por tanto de origen asimismo convectivo que no han llegado a presentar actividad eléctrica, se puede atribuir en una primera aproximación el peso de las precipitaciones convectivas sobre la precipitación total. Por otra parte, y como se ha comentado anteriormente, hay meses (los estrictamente primaverales) y zonas (especialmente el tercio norte del área de estudio) en el que el peso de la precipitación estratiforme es siempre mayoritario.

La distribución de las precipitaciones por temporada (abril a septiembre) refleja en mayor o menor medida la de la media analizada en la introducción: mayor precipitación en el Pirineo, especialmente en la zona central y el Pirineo navarro, y un segundo máximo en las estribaciones orientales de la Cordillera Ibérica. Sin embargo la distribución anual (Imagen 2.11 e Imagen 2.12) varía, siendo la temporada 2005 la más seca de todas ellas con una media territorial de 194,6 mm, y la más húmeda 2008 con 381,4 mm caídos, especialmente en el Pirineo central. Esta temporada 2008 supera a la media en un $38 \%$, seguida de la de 2002 con un 12,7 \%. El resto se acerca bastante a la media excepto la ya comentada de 2005 que representa solo 67,6 \% del valor promedio.

Las Imágenes 2.11a a 2.11g muestran los mapas correspondientes a la precipitación de temporada abril-septiembre en el rango de años considerado (2002-2008). El promedio de las temporadas consideradas se muestra en el Mapa 2.7. 


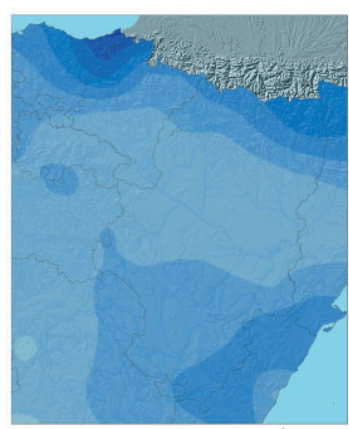

a) 2002

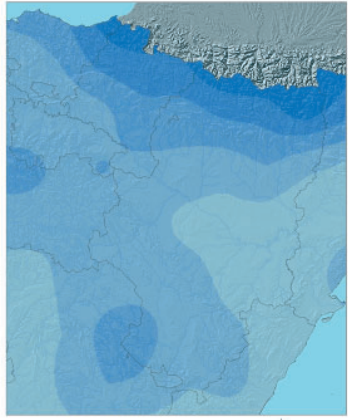

e) 2006

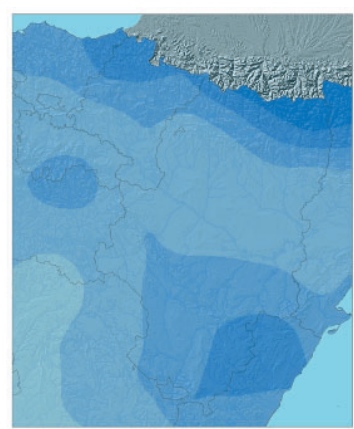

b) 2003

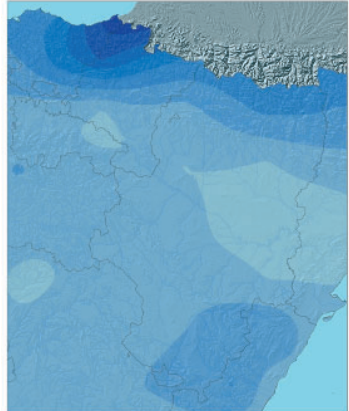

f) 2007

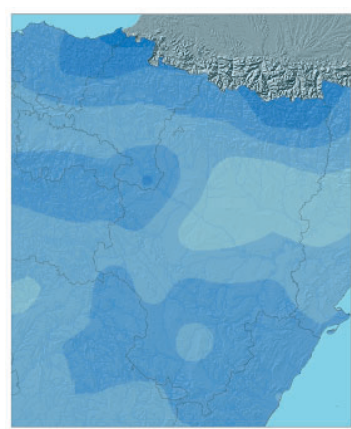

c) 2004

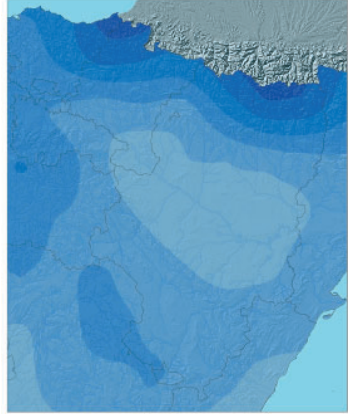

g) 2008

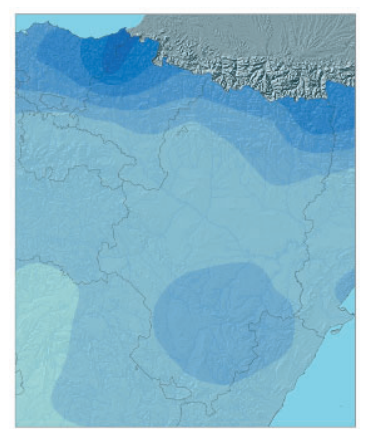

d) 2005

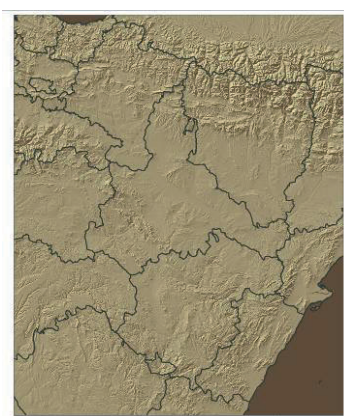

Precipitación por temporada $(\mathrm{mm})$

$\begin{array}{llllllllll}100 & 200 & 300 & 400 & 500 & 600 & 700 & 800 & 900 & 1.000\end{array}$

Imagen 2.11. Precipitación por temporadas (abr-sep). (Elaboración propia).

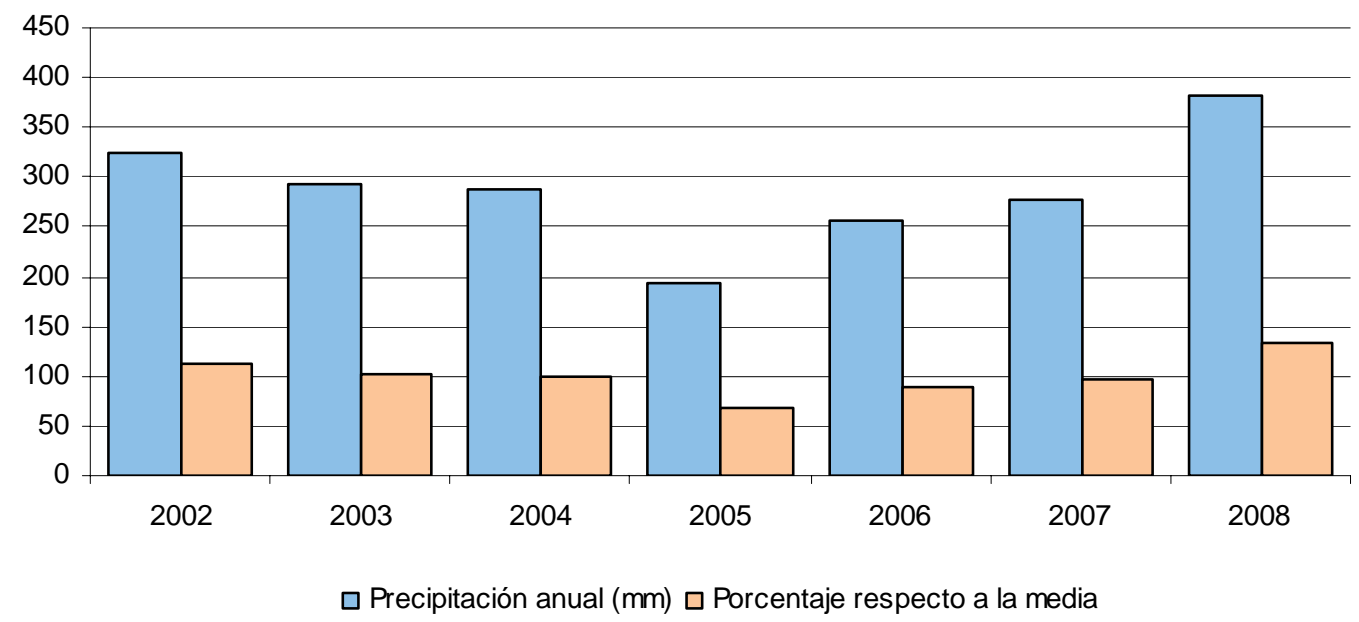

Imagen 2.12. Precipitación por temporada, en $\mathrm{mm}$, y porcentaje respecto a la media.

Tal y como se ha explicado en el Capítulo 1, la distribución de la precipitación es muy variable y, aunque la media del periodo considerado 2002-2008 sea de 287,7 mm por temporada para todo el territorio, presenta una gran variabilidad espacial (Mapa 2.7). Cuantitativamente, la zona con mayor acumulación media de precipitación en la temporada cálida, para el periodo de años considerado, es el extremo oriental de Guipúzcoa y la vertiente cantábrica de Navarra, con cantidades que superan los $600 \mathrm{~mm} / \mathrm{semestre}$, si bien en su mayor parte es precipitación estratiforme. Toda el área pirenaica queda por encima de los $400 \mathrm{~mm} / \mathrm{semestre}$ de media, con dos zonas que superan los $500 \mathrm{~mm}$ : una al oeste, orlando al máximo absoluto, que comprende buena 
parte de Guipúzcoa y la divisoria cántabro-ibérica de Navarra, y otra en el Pirineo central, que abarca desde la cabecera del Gállego hasta el valle de Arán, incorporando las zonas más altas del Sobrarbe y la Ribagorza. En términos relativos, la precipitación que cae durante el semestre cálido en el Pirineo central, supone del orden del $50 \%$ de la precipitación anual (Mapa 1.5b), buena parte de ella de origen convectivo, lo que revela el carácter mucho más mediterráneo de este sector pirenaico.

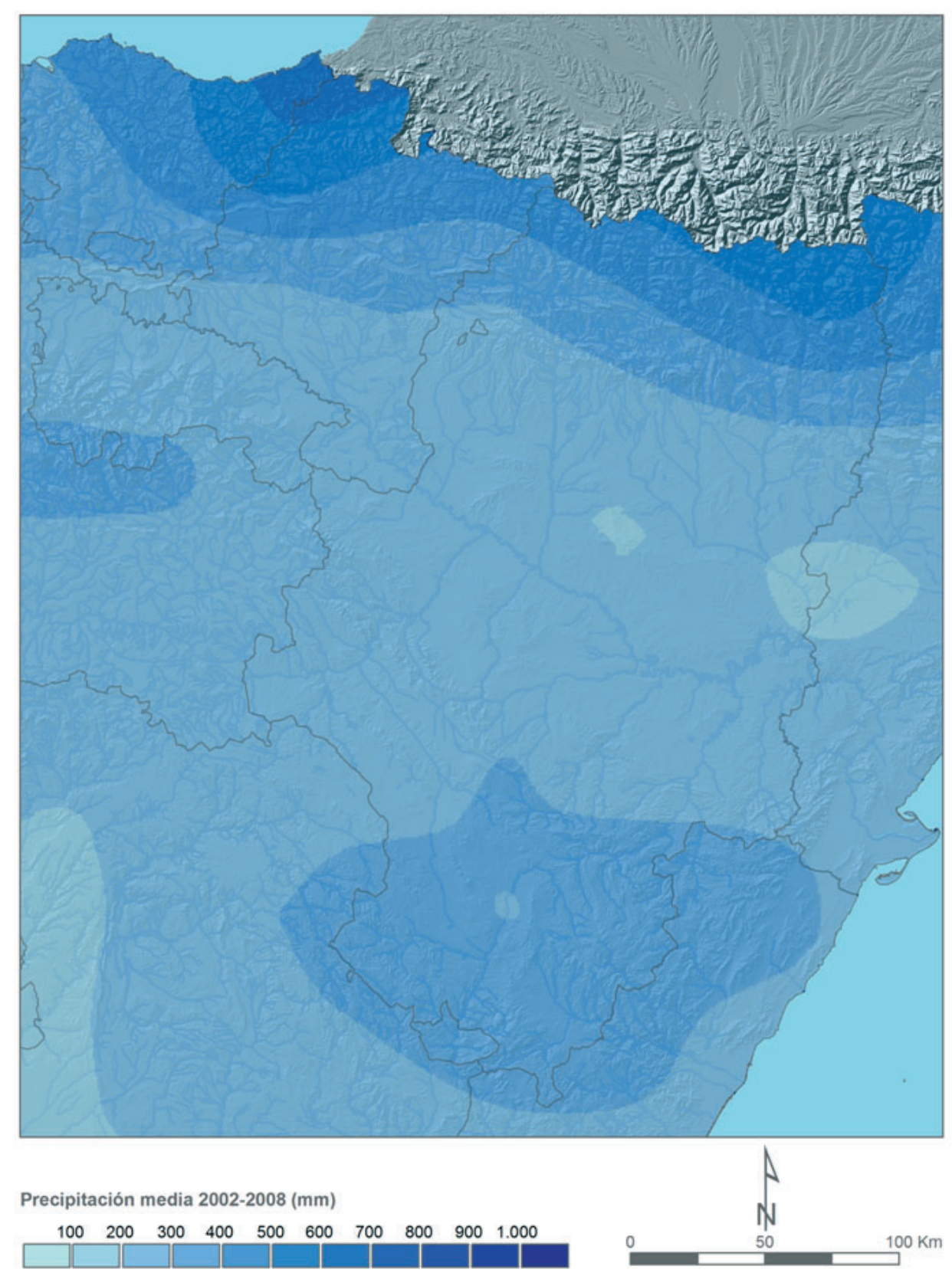

Mapa 2.7. Precipitación media por temporada para el periodo 2002-2008. (Elaboración propia).

En general, el cuarto septentrional del área de estudio recibe de media por temporada más de $300 \mathrm{~mm}$, así como la Ibérica riojano-soriana occidental y la Ibérica turolense, mientras que el resto del área (mayoritaria en superficie) queda comprendida entre las isoyetas de 200 y $300 \mathrm{~mm}$, salvo el interior manchego-alcarreño y puntos de la 
depresión del Ebro (áreas de Monegros y bajos Cinca y Segre), que reciben un promedio de menos de $200 \mathrm{~mm}$ por temporada. En términos relativos, la precipitación que recibe el sector aragonés y catalán de la depresión del Ebro y la Ibérica más oriental (del Moncayo hacia el Mediterráneo) supone igualmente más de la mitad de la precipitación media anual. En el caso de la Ibérica de Teruel (Mapa 1.5a) la precipitación (convectiva) estival (junio, julio y agosto) supone la tercera parte del total anual.

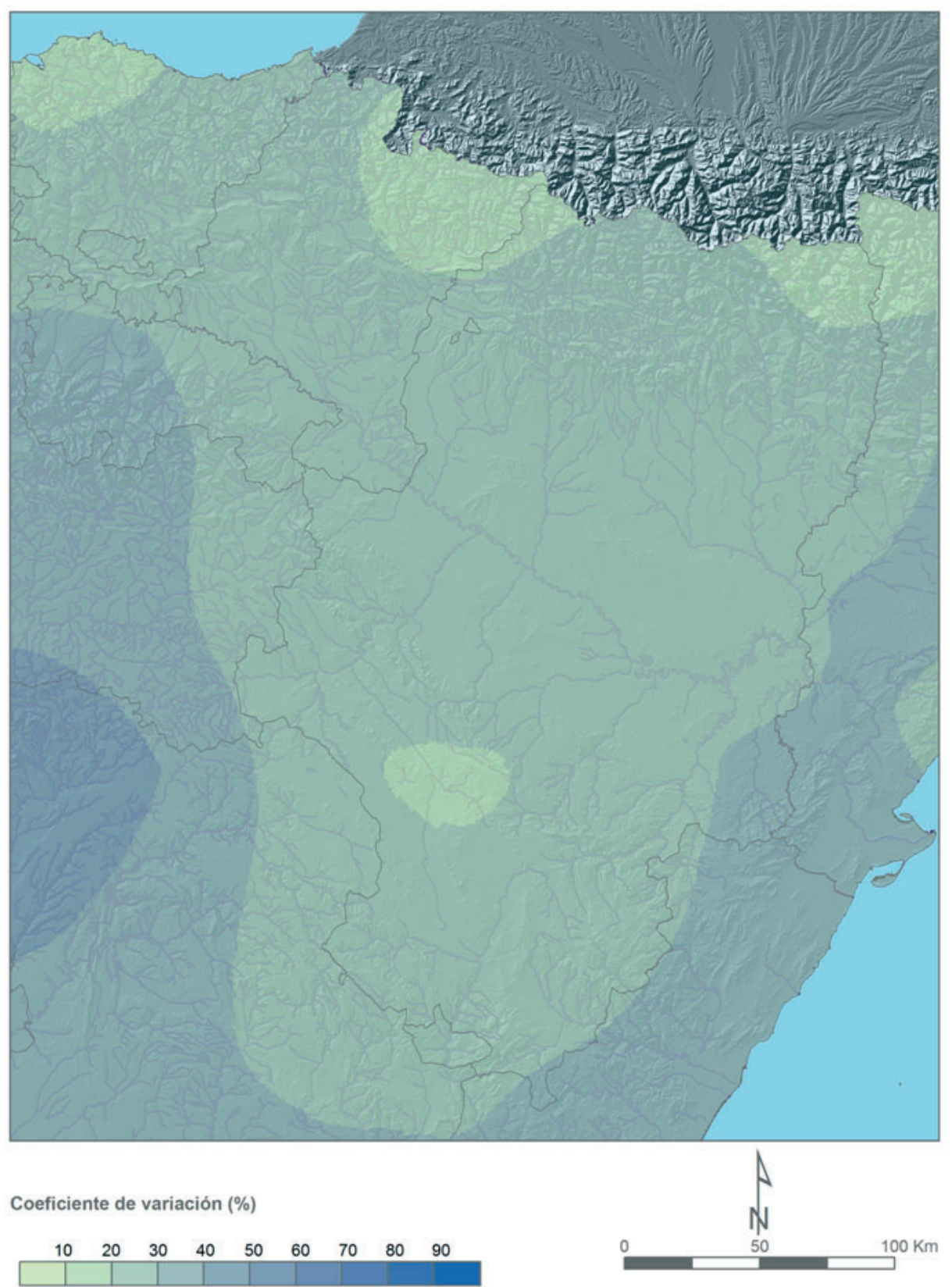

Mapa 2.8. Variabilidad interanual de la precipitación en el semestre cálido. (Elaboración propia).

Un estudio análogo a los anteriores sobre la variabilidad de la precipitación entre temporadas en el área de estudio arroja igualmente resultados interesantes (Mapa 2.8). En general, la variabilidad de la precipitación es bastante menor a la de los fenómenos 
puramente eléctricos (densidad de descargas - Mapa 2.5- y número de días de tormenta - Mapa 2.6-). El máximo, superior al 40 \% de Cv, aparece sobre el Sistema Central en Guadalajara y sobre el resto del área castellana (salvo la Serranía de Cuenca y los Montes Universales), la montaña de La Rioja occidental y el litoral mediterráneo es superior al $30 \%$. En el resto del área de estudio, salvo zonas aisladas que se enumeran a continuación, los valores de Cv oscilan entre el 20 y el $30 \%$. Las zonas con un comportamiento más homogéneo entre temporadas son la costa de Vizcaya, el Pirineo navarro, la Alta Ribagorza y el valle de Arán y, en la Ibérica, el tramo central de la cuenca del Jiloca.

De nuevo se aíslan las zonas de mayor influencia oceánica (con precipitaciones no siempre de tipo convectivo) que presentan un comportamiento más homogéneo del tiempo temporada tras temporada, de aquellas con una influencia mediterránea más clara que también presentan menor variabilidad por la presencia frecuente de fenómenos convectivos, que groseramente abarcan un sector inclinado desde los Montes Universales hasta el Pirineo central. El resto de las zonas presenta un comportamiento de la precipitación entre temporadas más variable. 


\section{ClaSIFICACIỐN SINỐPTICA}

Se realiza una clasificación sinóptica o de los “tipos de tiempo" que con más frecuencia afectan a la actividad convectiva en el área de estudio durante la época cálida. El punto de partida son los datos archivados, tanto de descargas y precipitación como de los archivos con la distribución espacial de las variables meteorológicas (campos meteorológicos) de cada jornada.

Como resultado del análisis se pueden atribuir frecuencias de ocurrencia a cada una de las configuraciones sinópticas resultantes, así como cuantificar la importancia de las mismas en términos de algunos de sus meteoros de tipo convectivo asociados.

\subsection{Datos y metodología}

De entre las muchas variables que pueden emplearse a efectos de establecer clasificaciones de tipos de tiempo una de las que más se encuentra en la literatura es el empleo de campos en el nivel de $500 \mathrm{hPa}$. Tienen la ventaja de que representan el estado de la atmósfera libre, sin la influencia de otros efectos condicionantes como puede ser la orografía, los tipos de suelo, etc. Por lo tanto, informan de los estados generales de la atmosfera media a los que en una fase posterior se le podrán ir añadiendo los efectos puramente locales.

\subsubsection{Criterios de clasificación}

Los campos fundamentales para la elaboración de una clasificación sinóptica son la dirección y la velocidad del viento, lo cual permite obtener información sobre la procedencia de las distintas masas de aire que afectan el área de estudio considerada (Mapa 3.1). En concreto, se analizan estas dos variables en el centro y en los vértices superior izquierdo e inferior derecho de un rectángulo definido en latitud por los paralelos $39,5^{\circ} \mathrm{N}$ y $43,5^{\circ} \mathrm{N}$ y en longitud por los meridianos $1^{\circ} \mathrm{E}$ y $3^{\circ} \mathrm{W}$ referidos al meridiano de Greenwich. Es decir, en los puntos A, B y C del mencionado mapa.

Los criterios clasificatorios fijados y el proceso iterativo utilizado han sido los siguientes:

- En primer lugar, si la velocidad del viento en el punto central del rectángulo es menor que $5 \mathrm{~m} / \mathrm{s}$ se considera que no existe advección significativa de las masas de aire procedentes de zonas limítrofes y por lo tanto los procesos convectivos se deberán a la masa de aire autóctona existente esa jornada sobre el área de interés. Por eso esta situación se denomina genéricamente con el nombre de "Situación de masa de aire", omitiendo el calificativo de "autóctona", de acuerdo a la nomenclatura léxica ampliamente adoptada entre los meteorólogos. Por tanto, esa situación, que suele presentarse con una frecuencia próxima al $10 \%$ de los casos, se considera con entidad propia diferente al resto de las situaciones que están asociadas a la llegada de masas de aire originadas en otras zonas.

- En el caso de que no se cumpla la anterior condición en el punto central, es decir, que la velocidad del viento en ese punto sea mayor que $5 \mathrm{~m} / \mathrm{s}$, se pasa a analizar 
separadamente los valores de la dirección del viento en la esquina superior derecha (latitud: $43,5^{\circ} \mathrm{N}$ y longitud: $3^{\circ} \mathrm{W}$ ) y en la esquina inferior izquierda: latitud: $39,5^{\circ} \mathrm{N}$ y longitud: $1^{\circ} \mathrm{E}$ ) que definen el área de estudio. Lógicamente las direcciones en ambos vértices no tienen por qué coincidir y al conjunto de combinaciones resultantes se les denominará con el nombre de "Situaciones sinópticas”.
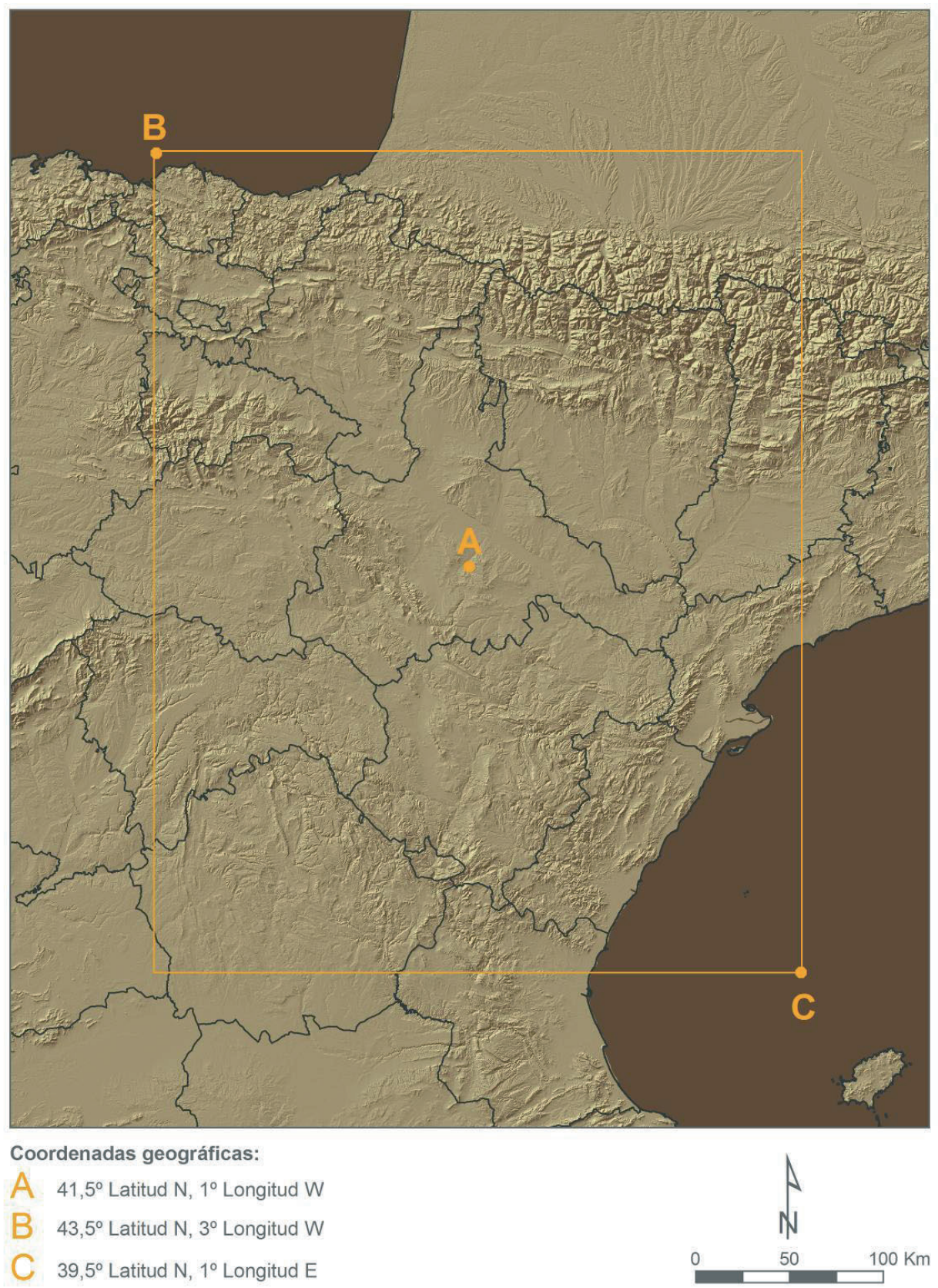

Mapa 3.1. Rectángulo que define el área de estudio y puntos a considerar para la clasificación sinóptica. (Elaboración propia).

Dado que la dirección del viento tiene un rango de $360^{\circ}$, con el fin de que el número de casos pueda ser manejable se divide la rosa de direcciones de procedencia del viento y se les asigna nombre de acuerdo al siguiente criterio: 
- Entre $30^{\circ}$ y $160^{\circ}$ : vientos del E.

- Entre $160^{\circ}$ y $200^{\circ}$ : vientos del S.

- Entre $200^{\circ}$ y $250^{\circ}$ : vientos del SW.

- Entre $250^{\circ}$ y $280^{\circ}$ : vientos del W.

- Entre $280^{\circ}$ y $360^{\circ}$, además de entre $0^{\circ}$ y $30^{\circ}$ : vientos del NW.

Esta clasificación ya fue utilizada con anterioridad en el trabajo Characterization of the evolution of convective processes in the Ebro Basin (NE Spain) (ESPEJO Y ÁlvAREZ, 2007). Surge de un análisis de las direcciones y sectores por los que transcurren las perturbaciones en el área de estudio como consecuencia de características sinópticas de las mismas, pero teniendo también en cuenta las particularidades orográficas que ejercen su influencia en niveles bajos.

Lógicamente, esta clasificación no se ajusta a la nomenclatura normalmente utilizada porque en este caso los intervalos utilizados no son de igual amplitud como, por ejemplo, en la rosa de ocho rumbos. No obstante, lo que la clasificación representa son sectores amplios por donde normalmente transcurren las perturbaciones que afectan al área de estudio dirigida por los flujos generales en la atmósfera media y que necesitan una explicación. Así por ejemplo, lo que aquí se considera NW participa también de los flujos de $\mathrm{N}$ e incluso del NNE, representando ambos flujos de masas procedentes de latitudes más frías. En los otros sectores se observan peculiaridades significativas, como en el caso del $\mathrm{E}$ que viene a representar todas las influencias mediterráneas o centroeuropeas. La procedencia $\mathrm{S}$ se asigna solamente a flujos muy meridianos de procedencia africana, diferenciándola de los flujos del SW tan frecuentes sobre la Península Ibérica en la época cálida del año. Finalmente el W representaría los flujos zonales de clara influencia atlántica.

En la Imagen 3.1 se puede observar la representación esquemática de los sectores de procedencia de los flujos con la nomenclatura asignada.

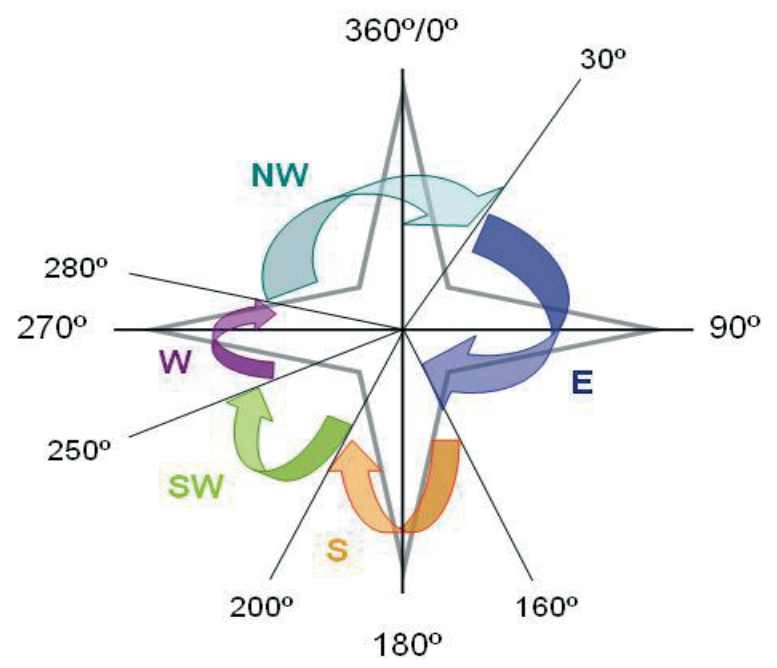

Imagen 3.1. Asignación de procedencia del flujo según los intervalos fijados en grados.

El proceso de clasificación se resume en la Imagen 3.2: 
- Si Velocidad $<5 \mathrm{~m} / \mathrm{s} \rightarrow$ Masa de aire

- Si Velocidad $>5 \mathrm{~m} / \mathrm{s} \rightarrow$ Sinóptica

- Según la procedencia del flujo (caso sinóptico):

$\mathrm{S}\left(160^{\circ}, 200^{\circ}\right]$

$\mathrm{SW}\left(200^{\circ}, 250^{\circ}\right]$

$\mathrm{W}\left(250^{\circ}, 280^{\circ}\right]$

$\mathrm{NW}\left(280^{\circ}, 360^{\circ}\right]$ y $\left[0^{\circ}, 30^{\circ}\right]$

$\mathrm{E}\left(30^{\circ}, 160^{\circ}\right]$

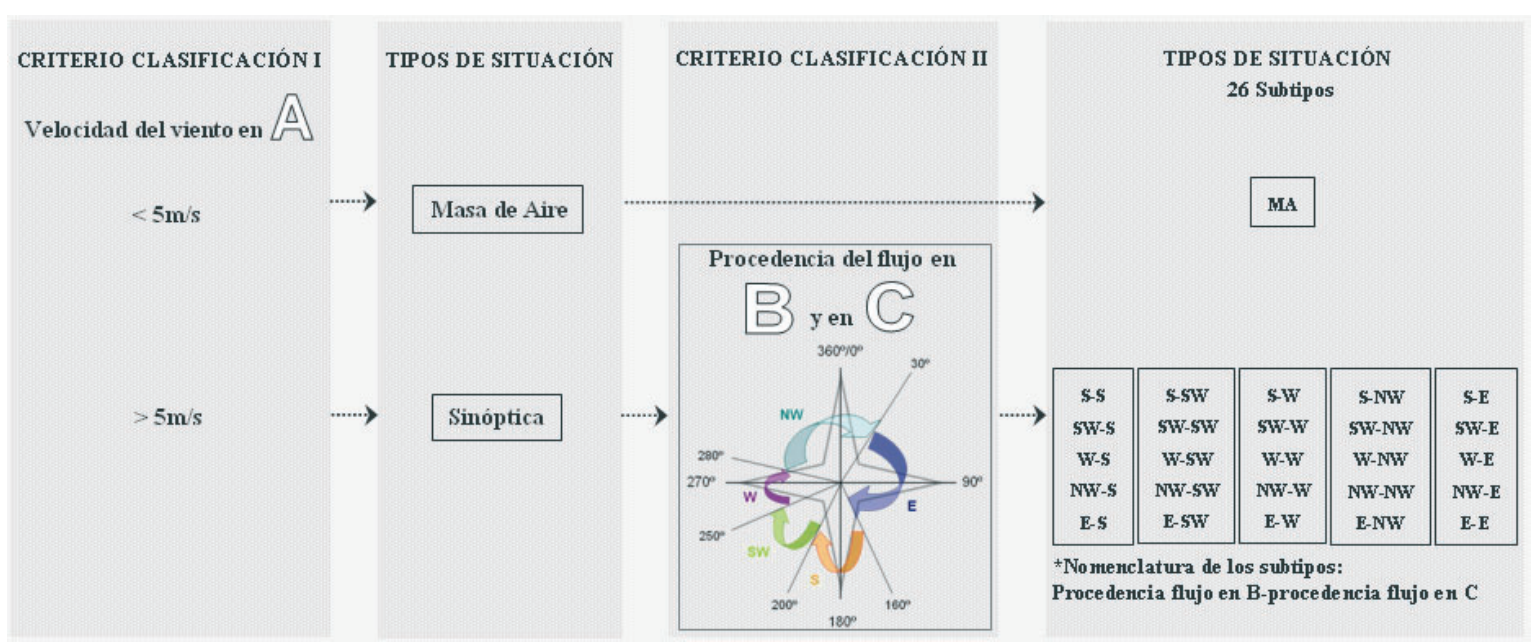

Imagen 3.2. Proceso de clasificación sinóptica a partir de los registros de la base datos.

\subsubsection{Origen de los datos}

Los datos sobre los valores del viento en los puntos considerados (A, B y C) provienen de la base de datos residente en la Delegación de AEMET en Aragón actualizada diariamente para la temporada considerada al predecir la probabilidad de tormentas en la zona como componente muy importante en la determinación del índice de riesgo de incendios forestales (ÁLVAREZ ET AL., 2005). Estos datos están en formato grid y pertenecen a la pasada de las $00 \mathrm{Z}$ horas del modelo HIRLAMirlam de resolución $0,5^{\circ}$. Con el fin de utilizar los valores que más se aproximen al periodo horario en el que la climatología de descargas del Capítulo 2 de esta obra indica que son más frecuentes las descargas eléctricas, se utilizan los valores del viento a las 15 horas solares (Predicción $\mathrm{H}+15$ de la pasada del modelo de las $00 \mathrm{Z}$ ) de ese día. Se utiliza este modelo y alcance de predicción para emplear la misma base de datos que en la segunda parte del estudio, que consta de un amplio conjunto de campos derivados que caracterizan la convección. Esta base de datos está disponible, almacenada y depurada como resultado del proceso automático de predicción operativa de la convección que en la época estival se realiza a diario para el área de estudio. De esta forma se le da homogeneidad al conjunto del trabajo.

Los datos en el centro y esquinas del área de interés son extraídos mediante los correspondientes programas en el entorno McIDAS, obteniéndose la clasificación que se muestra en la Tabla 3.1 en la que están diferenciados los tipos principales "Situación de masa de aire" y "Situaciones sinópticas". 
Mientras que el tipo de "Masa de aire" sólo agrupa las situaciones caracterizadas por vientos muy flojos en el centro del área de interés, el resto de las combinaciones entre vientos en el extremo noroeste y sureste del rectángulo considerado origina 25 configuraciones sinópticas distintas. Por lo tanto, cada día del periodo de estudio es asignado a uno y sólo uno de los 26 tipos sinópticos básicos obteniéndose un listado con los días integrantes de cada configuración. A partir de aquí puede obtenerse tanto la frecuencia relativa de cada configuración como los valores medios de los campos que definen ese día.

Tabla 3.1. Clasificación inicial en 26 subtipos de situaciones.

\begin{tabular}{|c|c|c|c|c|c|c|}
\hline $\begin{array}{c}\text { Punto C } \rightarrow \\
\text { Punto B } \downarrow\end{array}$ & MA & 2 & 3 & 4 & 5 & 6 \\
\hline 1 & 11 & S & SW & W & NW & E \\
MA & MA & & & & & \\
\hline 2 & & 22 & 23 & 24 & 25 & 26 \\
S & & S-S & S-SW & S-W & S-NW & S-E \\
\hline 3 & & 32 & 33 & 34 & 35 & 36 \\
SW & & SW-S & SW-SW & SW-W & SW-NW & SW-E \\
\hline 4 & & 42 & 43 & 44 & 45 & 46 \\
W & & W-S & W-SW & W-W & W-NW & W-E \\
\hline 5 & & 52 & 53 & 54 & 55 & 56 \\
NW & & NW-S & NW-SW & NW-W & NW-NW & NW-E \\
\hline 6 & & 61 & 63 & 64 & 65 & 66 \\
E & & E-S & E-SW & E-W & E-NW & E-E \\
\hline
\end{tabular}

En filas, dato de la esquina superior izquierda del área de estudio (punto B).

En columnas, dato de la esquina inferior derecha del área de estudio (punto C).

En cada celda, el subtipo definido por la procedencia del viento en los puntos B y C.

Los dos recuadros agrupados por contornos en negro mas anchos agrupan los subtipos "masa de aire" (subtipo 11) y "sinópticos" (el resto de subtipos).

Agrupación posterior de subtipos con características comunes en tipos identificados por el color.

La representación gráfica de los campos medios de cada configuración sinóptica se ha obtenido a partir de los campos del modelo HIRLAMdelo Hirlam 0.5 (HINR) para todos los días del periodo de estudio de la base de datos de productos de AEMET, para los campos de geopotencial, así como vientos asociados y temperatura en $500 \mathrm{hPa}$. Para una caracterización sinóptica adecuada y la visualización clara de las trayectorias seguidas por los sistemas determinantes del tiempo se ha ampliado el ámbito espacial de la representación a la ventana delimitada por los paralelos $26^{\circ} \mathrm{N}$ y $60^{\circ} \mathrm{N}$ y los meridianos $30^{\circ} \mathrm{W}$ y $20^{\circ} \mathrm{E}$, como se muestra en el ejemplo de la Imagen 3.3 que representa el patrón medio para una de estas configuraciones básicas.

Estas imágenes se generan con la aplicación Metview, creada en el Centro europeo de predicción a plazo medio para la representación gráfica de campos de modelos numéricos. La obtención de los valores promedio se obtiene con la aplicación paralela GRIB_API, a partir de los días componentes de cada situación característica, promediando los campos para cada punto de grid. 


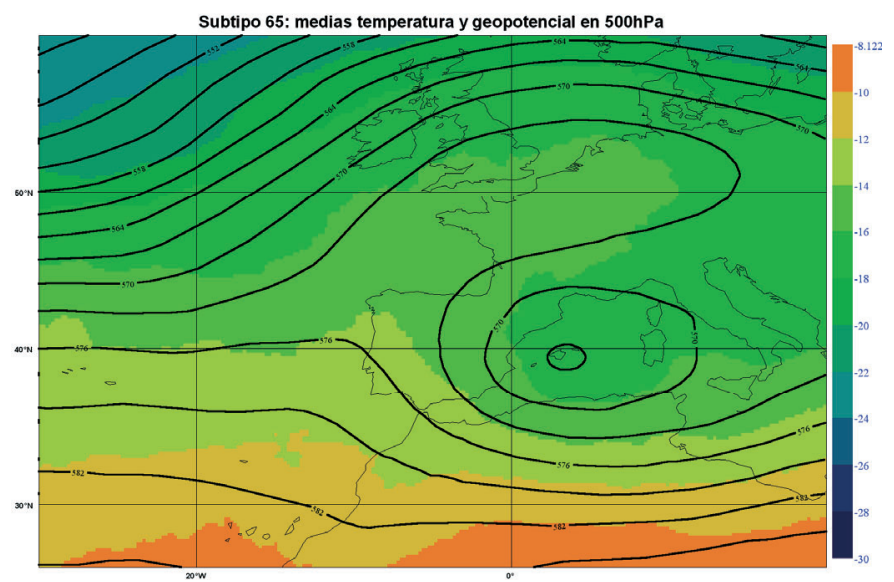

Imagen 3.3. Ejemplo de patrón medio de geopotencial, línea negra continua en mgp, y temperaturas en colores y en ${ }^{a} \mathrm{C}$, en el nivel de $500 \mathrm{hPa}$ para el Subtipo 65.

No obstante, un número de 26 situaciones características parece excesivo, sobre todo si se tiene en cuenta que se pretende conseguir un producto de utilidad operativa en la predicción diaria de la convección. Por ello, de ahora en adelante estas 26 situaciones características se denominarán subtipos, y se realizará una agrupación de las mismas en nueve tipos sinópticos principales. El resultado aparece en la Tabla 3.1, mediante la asignación del mismo color a aquellos subtipos con similitudes entre ellos.

\subsection{Justificaciốn y procedimiento de la clasificaciốn}

Como resumen de lo anterior queda la clasificación final mostrada en la Tabla 3.2, en la que ya se asignan a cada uno de los 9 tipos resultantes un nombre de situación con significado meteorológico y los subtipos que engloba, con objeto de poder analizarlos con detalle a continuación.

Tabla 3.2. Clasificación final de 9 tipos de situaciones al agrupar los 26 subtipos iniciales.

\begin{tabular}{|c|l|c|}
\hline $\begin{array}{c}\text { TIPO DE } \\
\text { SITUACIÓN }\end{array}$ & \multicolumn{1}{|c|}{ NOMBRE DE LA SITUACIÓN } & $\begin{array}{c}\text { SUBTIPOS QUE } \\
\text { ENGLOBA }\end{array}$ \\
\hline 1 & MASAS DE AIRE & 11 \\
\hline 2 & SITUACIONES DEL SUR & $22-32$ \\
\hline 3 & SITUACIONES DEL SW DIFLUYENTES & $23-24-34$ \\
\hline 4 & SITUACIONES DEL SW SIN DIFLUENCIA & $33-42-52-53$ \\
\hline 5 & SITUACIONES DEL W & $43-44$ \\
\hline 6 & SITUACIONES DEPRESIONARIAS ENTRANTES & $36-46-62-63$ \\
\hline 7 & SITUACIONES DEPRESIONARIAS REBASADAS & $26-56-64-65-66$ \\
\hline 8 & ONDAS LARGAS DEL NW & $45-54-55$ \\
\hline 9 & OCLUSIONES A VAGUADAS REBASADAS & $25-35$ \\
\hline
\end{tabular}


Además de las consideraciones de tipo operativo y práctico anteriormente indicadas, el reagrupamiento de los 26 subtipos en 9 tipos diferenciados se fundamenta en el análisis de la representación de los valores medios de los campos de geopotencial, temperatura y viento en $500 \mathrm{hPa}$ donde se observan similitudes muy significativas entre algunos de ellos, lo que va a permitir reagruparlos de una manera subjetiva pero rigurosa.

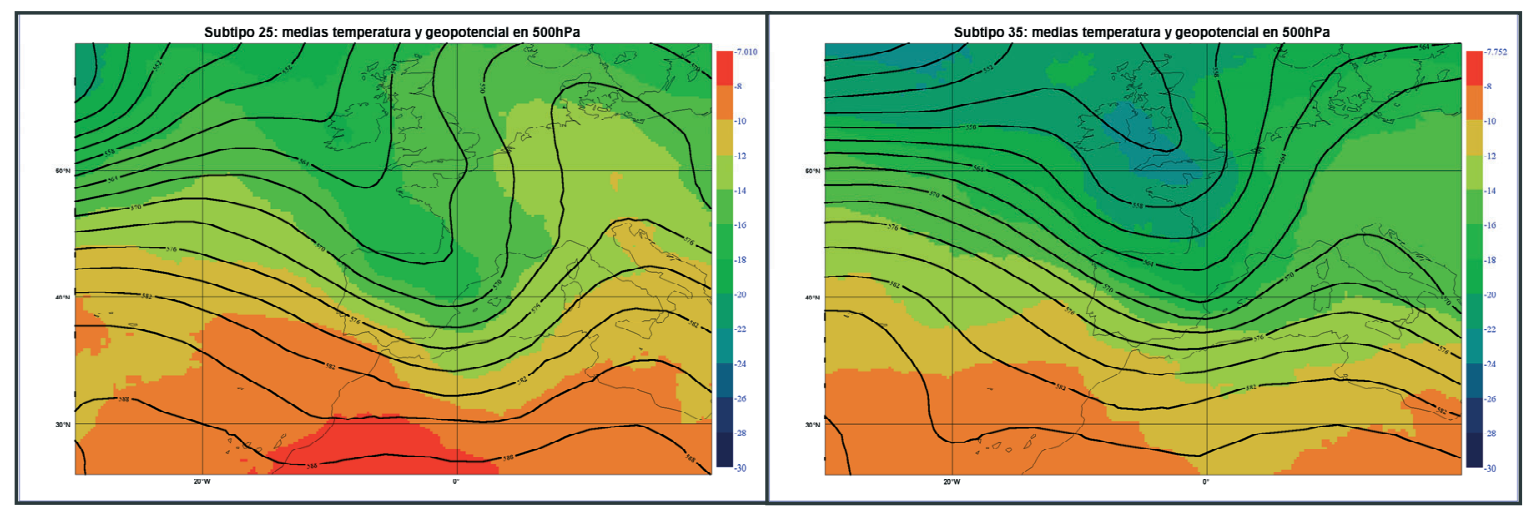

Imagen 3.3. Representación de los campos de $T$ (en colores y en ${ }^{\circ} \mathrm{C}$ ) y $\mathrm{Z}$ (en línea continua y en mgp) en 500 hPa para los Subtipos 25 (S-NW) y 35 (SW-NW).

En cada una de las imágenes presentadas pueden analizarse en $500 \mathrm{hPa}$, por una parte, los campos de geopotencial (línea continua en mgp) que a su vez reflejan las direcciones e intensidades de los campos de vientos, la potencia de los centros de presión y su distribución, las zonas de difluencia, etc. Asimismo se representan las temperaturas (coloreadas en ${ }^{\circ} \mathrm{C}$ ), y de ahí los gradientes térmicos, masas de aire, etc. No obstante, conjuntamente, aunque solo sea de una forma cualitativa y a nivel conceptual, también se pueden inferir otras propiedades como advecciones térmicas o dinámicas, acoplamientos positivos o negativos entre el campo térmico y el bárico, etc.

Algunas de las variables más características de los procesos convectivos, tales como el origen y dirección de traslación de las masas de aire o las advecciones del campo térmico por el vector viento son semejantes y solo varían en los valores numéricos. Por lo tanto, si se asume que el margen de incertidumbre es básicamente de tipo cuantitativo, se pueden reagrupar los dos subtipos de situaciones en una única situación compuesta por el conjunto de los días que componían los subtipos iniciales y a la que se puede volver a aplicar el proceso de cálculo de mapas medios. El resultado de estos cálculos se muestra en la Imagen 3.4.

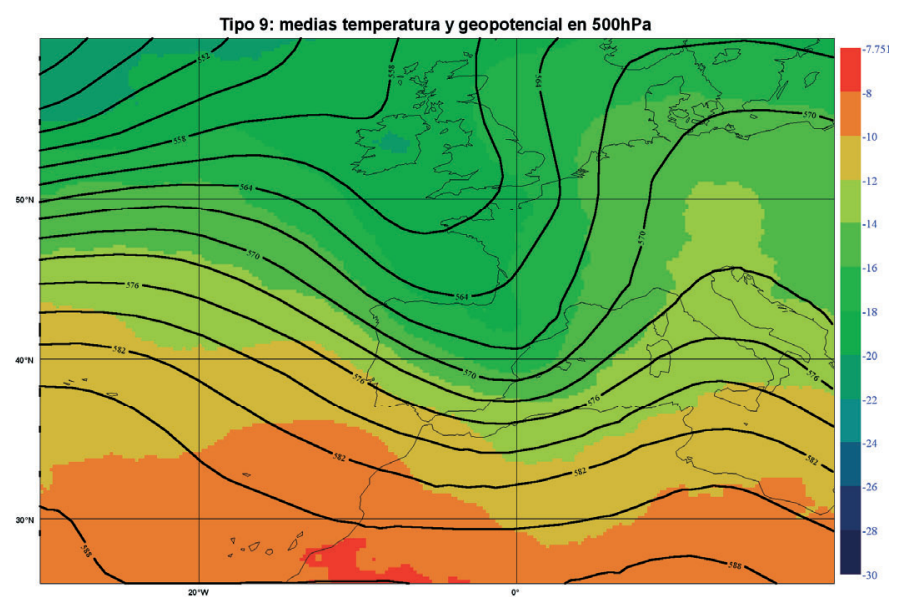

Imagen 3.4. Campos de T y Z en 500 hPa para el Tipo 9 (Oclusiones a vaguadas rebasadas). 
La elección de esta forma de clasificación sinóptica es muy simple pues no tiene en cuenta los efectos en niveles bajos a nivel regional o local y solo nos proporciona una clasificación según los niveles medios. A pesar de esta simplicidad los resultados del agrupamiento recogen razonablemente bien los principales patrones de las perturbaciones que afectan a la zona de estudio.

No obstante, una vez establecida esta clasificación de partida, los efectos locales son tenidos en cuenta, en especial en algunas situaciones particulares de cada tipo que se tratan al final del estudio y en las que se analizan los efectos determinados por las capas bajas, como pueden ser zonas de convergencia de distintas masas con humedad y temperaturas diferentes, fronteras térmicas, influencias orográficas sobre el flujo, etc.

\subsection{Descripciốn de los tipos de situaciones}

A continuación se van a mostrar, para cada uno de los tipos de situaciones, los valores medios de sus campos representativos así como los de los subtipos que lo constituyen, manteniendo la nomenclatura empleada en las anteriores tablas:

Los campos presentados en formato de mapa son:

a) la distribución media de las precipitaciones (mm);

b) promedio de los campos de $\mathrm{T}\left({ }^{\circ} \mathrm{C}\right)$ y $\mathrm{Z}$ (mgp) en el nivel de $500 \mathrm{hPa}$;

c) densidad media de rayos (número de descargas por $\mathrm{m}^{2}$ y día);

d) probabilidad media de tormentas (en tanto por ciento).

\subsubsection{Situaciones de masa de aire (Tipo 1)}

Como se ha explicado anteriormente, esta situación define aquellas situaciones meteorológicas caracterizadas por la ausencia de flujos de viento superiores a $5 \mathrm{~m} / \mathrm{s}$ en el nivel $500 \mathrm{hPa}$ en el centro del área de estudio, en las que se considera que la masa de aire residente sobre la zona tiene un carácter autóctono que hereda la historia de la temperie de los días anteriores.

Cuando se analizan individualmente los mapas dinámico-térmicos de los diferentes días que se dan estas circunstancias lógicamente se observan diferencias. De hecho esta es la situación que engloba situaciones más heterogéneas. El resultado del promedio de los mapas individuales se muestra en la Imagen 3.5 y llama la atención lo adecuadamente que representa la idea que se tiene de una situación de este tipo, en la que además de prácticamente ausencia de flujo, se dibuja una marcada dorsal anticiclónica con la isohipsa de $579 \mathrm{dmg}$ pasando por el centro de Francia y bloqueando el avance de los sistemas atmosféricos de origen atlántico, acompañada además de un campo térmico subsidente sin prácticamente gradiente y con la mayor parte de la Península Ibérica abarcada por valores relativamente cálidos entre $-12{ }^{\circ} \mathrm{C}$ y $-14{ }^{\circ} \mathrm{C}$.

Con esta ausencia de definición en los niveles medios de la atmósfera es lógico que sean los parámetros meteorológicos de las capas inferiores, como resumen de la memoria meteorológica reciente, los que a nivel local cuenten como causa del desarrollo de la convección al estar fuertemente influenciados por características superficiales orográficas como altitud, rugosidad, pendiente o exposición a los rayos solares dentro 
de la escala meso-gamma (extensiones superficiales de decenas de kilómetros y periodos de tiempo de horas), o la proximidad al mar y zonas de convergencia de vientos dentro la escala meso-beta (extensiones superficiales de centenares de kilómetros y periodos de tiempo de días) (ORLANSKI, 1975).
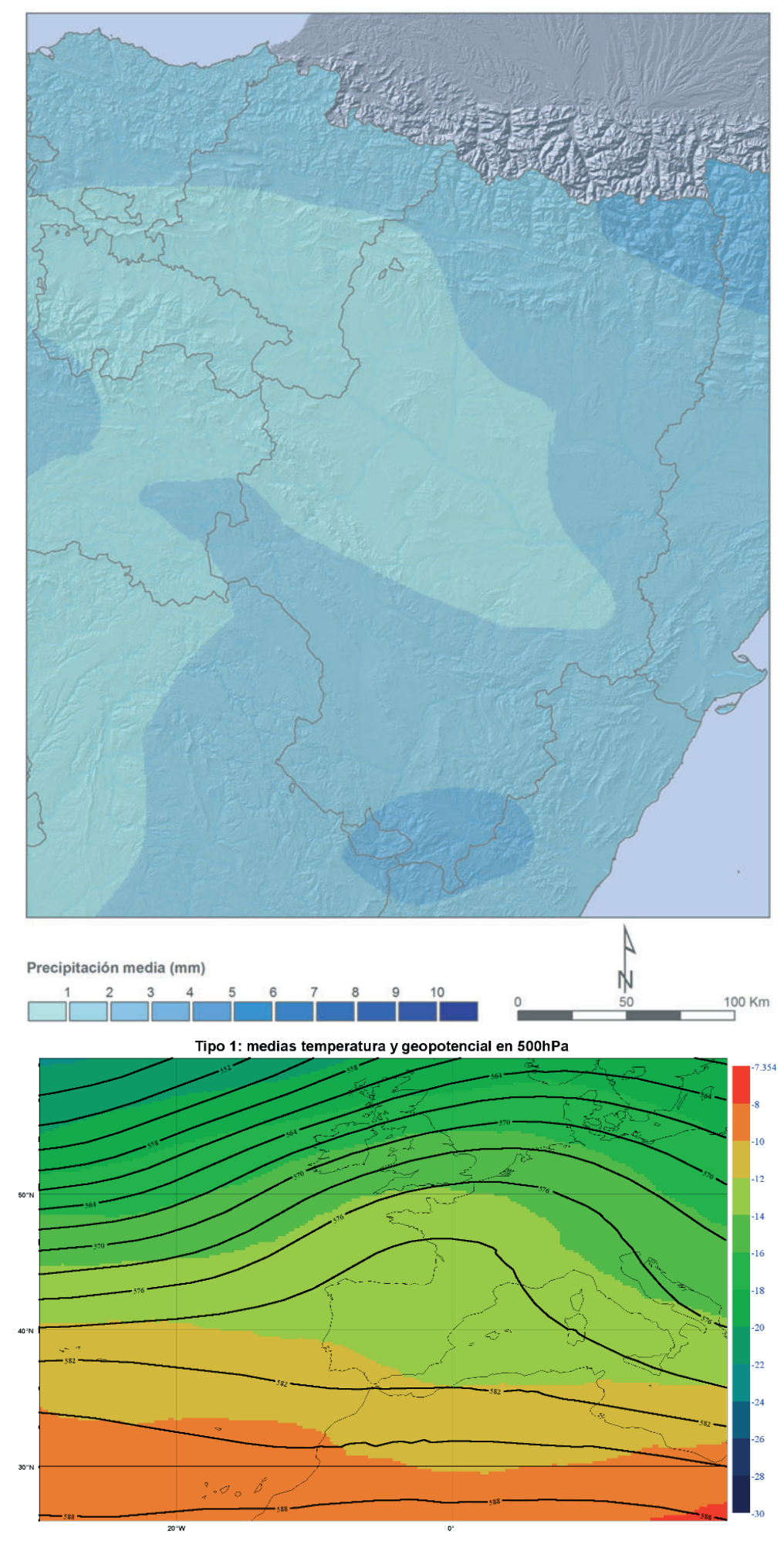

Imagen 3.5. Tipo 1, masa de aire. Mapa de distribución media de las precipitaciones (mapa superior) y promedio de los campos de $\mathrm{T}$ y $\mathrm{Z}$ en $500 \mathrm{hPa}$ (inferior). 


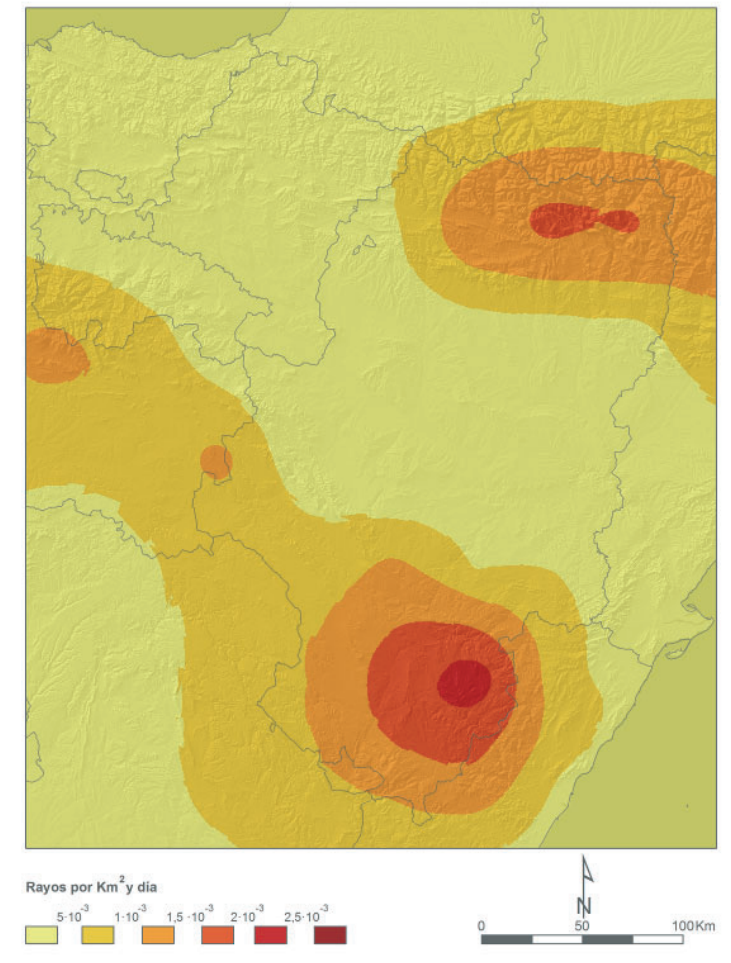

a. Densidad de rayos descargas eléctricas

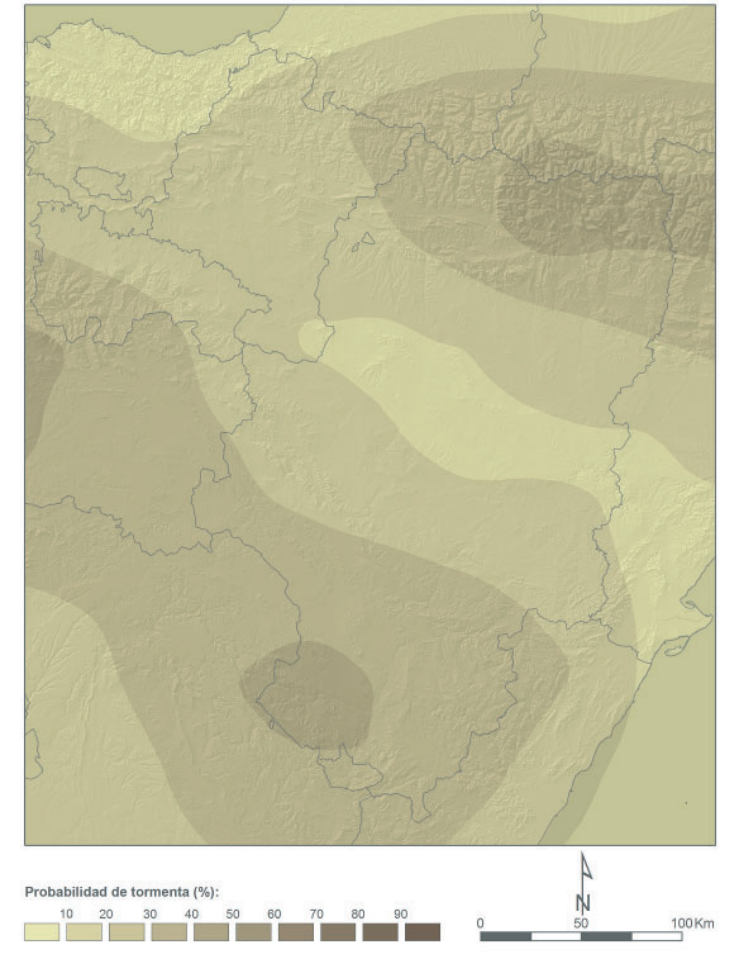

b. Probabilidad de tormentas

Mapa 3.1. Caracterización espacial de la convección en las situaciones de masa de aire (Tipo 1).

Es una situación en la que la convección nace, se desarrolla y muere prácticamente "in situ” con núcleos tormentosos poco importantes en cuanto a extensión pero que suelen quedarse anclados a los relieves escarpados o nacimientos de ríos y que dan nombre a lo que vulgarmente se viene conociendo como "nidos de tormentas", de los que el área de estudio posee abundantes ejemplos (en el Sistema Ibérico occidental: Picos de Urbión, sierras de la Demanda y Cebollera en las cercanías de la divisoria entre las cuencas del Duero y Ebro; en el Sistema Ibérico oriental: sierra de Albarracín, nacimiento de los ríos Tajo, Gallo o Júcar, sierras de Javalambre y Gúdar; en los Pirineos estos sistemas suelen quedar atrapados durante todo su ciclo de vida en las cuencas altas de los ríos de la vertiente sur de la cordillera). La persistencia de los sistemas tormentosos sobre un área reducida es lo que les da su carácter peligroso, más que su entidad propiamente. En el mapa de distribución de la precipitación se observa que aunque esta pueda presentarse en cualquier parte del territorio, es más probable en las zonas montañosas, y los máximos se producen en las sierras de la Ibérica oriental turolense y en el Pirineo central.

Los dos mapas que se presentan en los Mapas 3.1a y 3.1b (calculados según el procedimiento descrito en el Capítulo 2: climatología de la convección) corresponden sucesivamente a los valores medios de la densidad de descargas asociadas a este tipo de situaciones y a la probabilidad de ocurrencia de tormenta (determinada como el cociente relativo entre el número de días con tormenta en esa celda para esta situación y el número total de días que componen esta situación). Comparando entre la Imagen 3.5 (superior) y el Mapa 3.1 se puede apreciar las diferencias entre la precipitación 
convectiva, que aparece sobre el sur de la Ibérica y el Pirineo central, y la estratiforme, que corresponde a las precipitaciones del litoral cantábrico. Esta relación entre precipitación y convección se analiza más en detalle en el próximo epígrafe 3.3, donde se analizan expresamente las correlaciones entre precipitación y densidad de descargas. En estas situaciones de masa de aire la semejanza entre dichos patrones de distribución es muy alta.

\subsubsection{Situaciones del sur (Tipo 2)}

Esta constituida por los Subtipos 22 y 32 cuyos campos medios se muestran en la Imagen 3.6, que refleja cómo un flujo del sur puede advectar sobre la zona de estudio masas de aire que previamente han pasado sobre el norte del continente africano. Aunque esta característica es lo más llamativo, también se puede ver que ambos subtipos exhiben una marcada difluencia de las isohipsas sobre el nordeste peninsular (las curvas de Z constante se separan y se abren en forma de V), circunstancia que permite con cierta facilidad el desarrollo vertical de los sistemas nubosos, lo que se traduce en importantes consecuencias de intensificación de los fenómenos convectivos. En ambos subtipos el centro de bajas presiones se sitúa entre Lisboa y el cabo San Vicente, aunque presentan configuraciones diferentes.
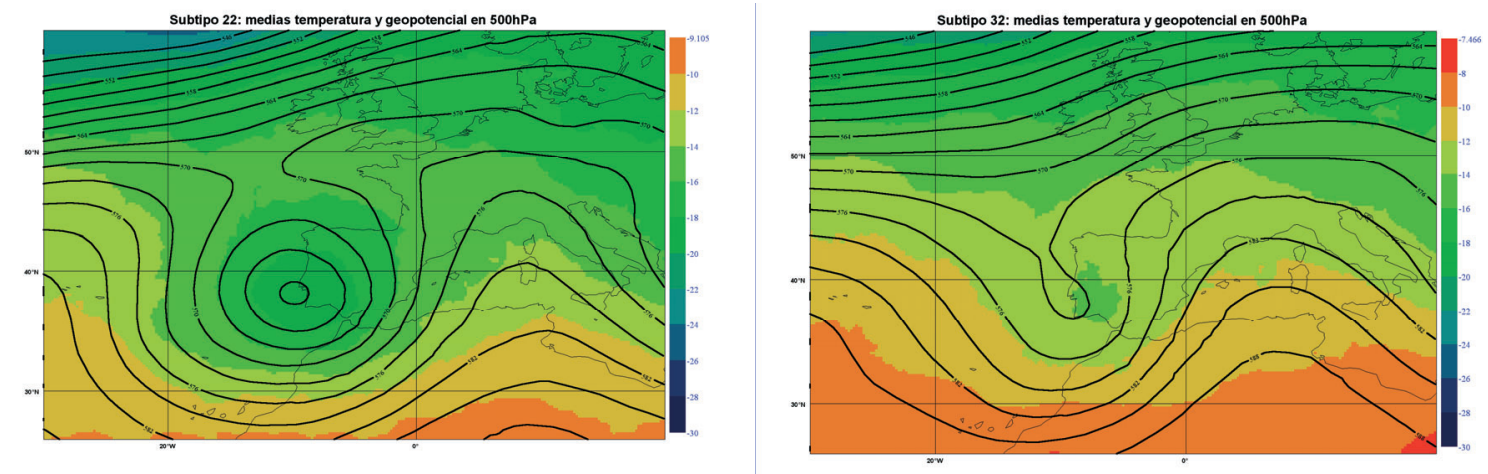

Imagen 3.6. Campos de Ty Z en 500 hPa para los Subtipos 22 (S-S) y 32 (SW-S) del Tipo 2 (situaciones del sur).

En el Subtipo 22 (S-S), la isohipsa central tiene valores muy bajos de $561 \mathrm{dmg}$, es cerrada y concéntrica con el campo de temperaturas que tiene valores centrales fríos de entre $-16{ }^{\circ} \mathrm{C}$ y $-18{ }^{\circ} \mathrm{C}$, lo que define la etapa de "estado maduro" de una depresión aislada en niveles altos (DANA), claramente desgajada de la circulación zonal del oeste, que circula sobre las Islas Británicas muy desplazada hacia las latitudes altas. Además, la marcada dorsal existente en la vertical sobre la línea que va del golfo de Marsella a Túnez indica un bloqueo en el avance de la DANA hacia el oeste, que determinará que la situación pueda prolongarse durante varios días. Durante este tiempo, y por el hecho de no encontrarse bajo el centro de bajas presiones, el área de estudio no queda fuera del alcance de la actividad convectiva. Bien al contrario, pues además de lo anteriormente indicado, también se halla en el sector de fuerte advección de vorticidad ciclónica por el viento de componente sur en la parte delantera del centro de bajas presiones con elevada intensidad, lo que determina que la zona afectada se extienda más hacia el norte.

Por el contrario, el Subtipo 32 (SW-S) muestra el periodo en el que la isohipsa de 573 dmg (que no es tan profunda como en el Subtipo 22), está comenzando a 
estrangularse para convertirse también en un núcleo aislado con un centro frío menos intenso, pero más adelantado, creando un entorno sinóptico que favorece los desarrollos convectivos.
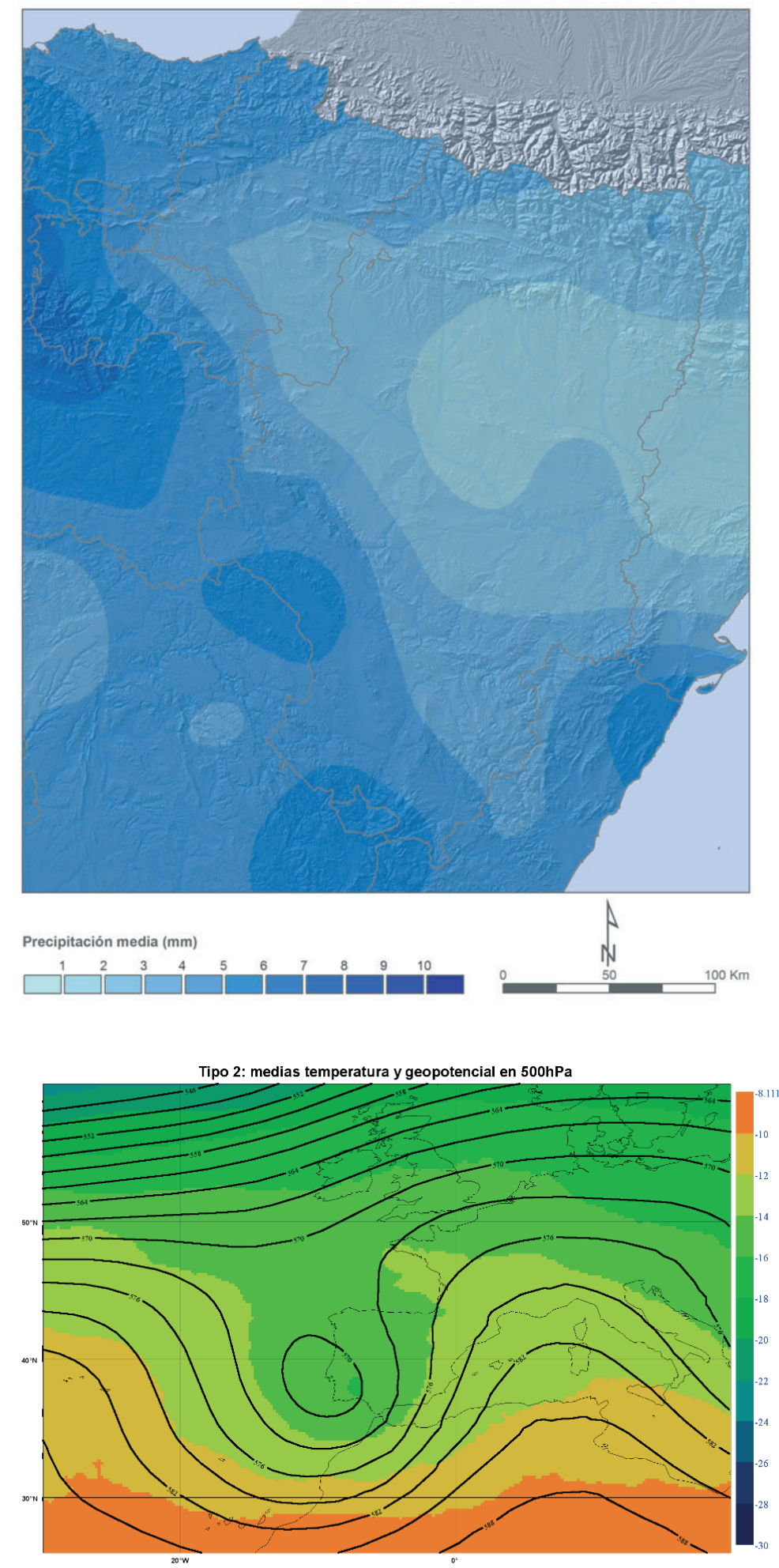

Imagen 3.7. Tipo 2, situación del sur: Mapa de distribución media de las precipitaciones (superior) y promedio de los campos de $\mathrm{T}$ y $\mathrm{Z}$ en $500 \mathrm{hPa}$ (inferior). 
Por lo tanto, puede representar una etapa anterior a la profundización que caracteriza el Subtipo 22, pero no necesariamente tiene por qué ocurrir así, sino que puede avanzar más rápidamente hacia el este si la corriente en chorro de niveles medios y altos que se encuentra sobre el mar de Alborán es capaz de erosionar la dorsal anticiclónica sobre el mar Mediterráneo. No obstante estas diferencias a nivel sinóptico (extensiones superficiales de miles de kilómetros y periodos de tiempo de varios días) sus efectos sobre el área de estudio no difieren esencialmente de los del Subtipo 22 pues tienen orígenes similares.

En la Imagen 3.7 se representa el efecto del reagrupamiento de ambos subtipos, donde la primera isohipsa cerrada es la de $570 \mathrm{dmg}$, mientras que sobre el área de estudio cruza la de $576 \mathrm{dmg}$ y, paralela a ella, la isoterma de $-14{ }^{\circ} \mathrm{C}$.

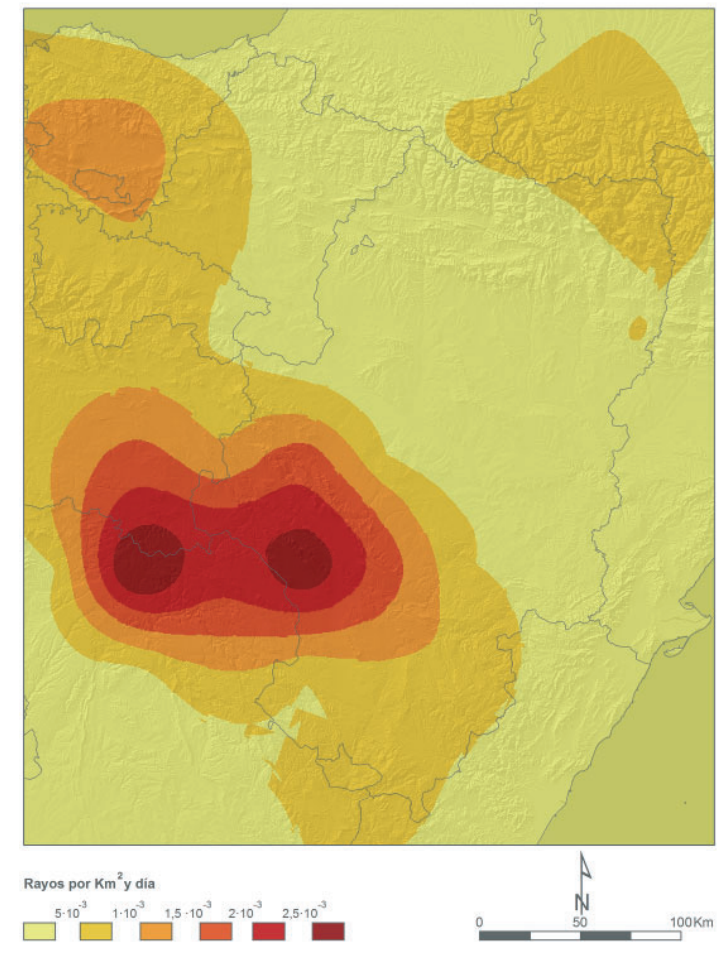

a. Densidad de rayos

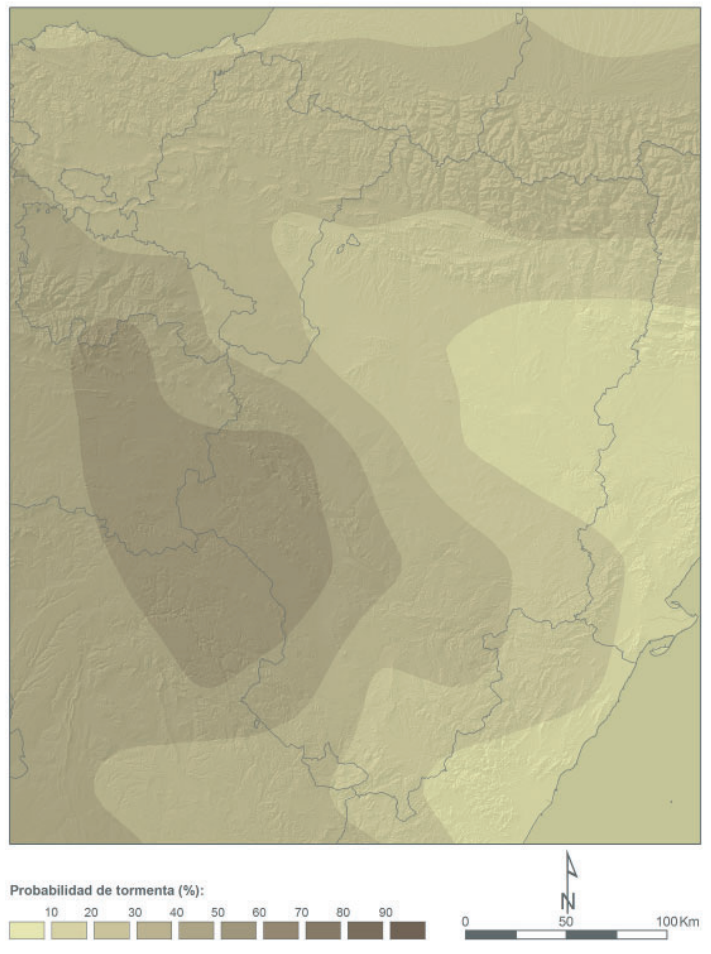

b. Probabilidad de tormentas

Mapa 3.2. Caracterización espacial de la convección en las situaciones del sur (Tipo 2).

Lógicamente, la fuerte componente dinámica en niveles medios es la característica determinante pero, si además se produce el acople con unos niveles bajos favorables a la convección desde el punto de vista térmico, la experiencia acumulada recuerda que los sistemas convectivos pueden adquirir dimensiones considerables con efectos muy importantes, en ocasiones subestimados por considerar que el centro de bajas presiones se encuentra "muy lejos". Por analogía con el caso de los sistemas frontales en las estaciones frías del año, a los sistemas nubosos presentes - con forma marcadamente lineal- que se trasladan rápidamente de sur a norte se les suelen llamar "bandas prefrontales" y se caracterizan por llevar asociado el efecto denominado "tren convectivo", consistente en el paso sucesivo y reiterado de las distintas células que constituyen la banda nubosa sobre las mismas zonas, con el consecuente efecto 
multiplicativo sobre la precipitación acumulada. En ocasiones esta precipitación viene acompañada de partículas de polvo en suspensión, recuerdo de su paso por zonas desérticas que, al ser arrastradas por la precipitación, la tiñen de color rojizo dando lugar a las denominadas "lluvias de sangre".

La distribución de la precipitación (Imagen 3.7) muestra el efecto de "precipitación orográfica” por la retención que se produce en los sistemas montañosos principales, con mayor intensidad en el caso del Sistema Ibérico debido a que recibe en primer lugar la acción de las masas nubosas. No obstante, en la mayor parte de los casos la situación posee suficiente potencia para mantener en el tiempo la renovación de las células que los constituyen a la par que los sistemas nubosos son dirigidos hacia el norte por el flujo rector, produciéndose intensificaciones locales como consecuencia de la interacción orográfica o de la posible recarga de humedad a su paso por cauces fluviales. Este efecto se produce también en el caso del río Ebro, que además se encarga de conducir la humedad de niveles bajos y origen mediterráneo a todo lo largo de valle, lo que explica que la precipitación acumulada registre valores relativamente altos en las cercanías del centro del valle, mientras que más al norte, en su margen derecha, disminuye su intensidad hasta que vuelve a reactivarse por realce orográfico en los Pirineos (sierras exteriores y cadena principal).

En el Mapa 3.2 se muestra la distribución de la importante actividad ceráunica, cuya zona de máxima concentración tiene lugar donde — desde el punto de vista dinámicoademás de difluencia, se produce un cambio de sentido — de ciclónico a anticiclónicoen las isohipsas de $500 \mathrm{hPa}$ afectando sobre todo a la zona de articulación entre los sistemas Ibérico y Central, en las provincias de Guadalajara, Soria, Cuenca, Teruel y Zaragoza y extendiéndose a las comunidades autónomas de La Rioja, Navarra y País Vasco. El mapa de probabilidad de ocurrencia de tormenta, aunque de forma más suave y extendida en el espacio, mantiene el patrón descrito anteriormente.

\subsubsection{Situaciones del suroeste con difluencia (Tipo 3)}

Está formada por el agrupamiento de los Subtipos 23, 24 y 34 mostrados en la Imagen 3.8.
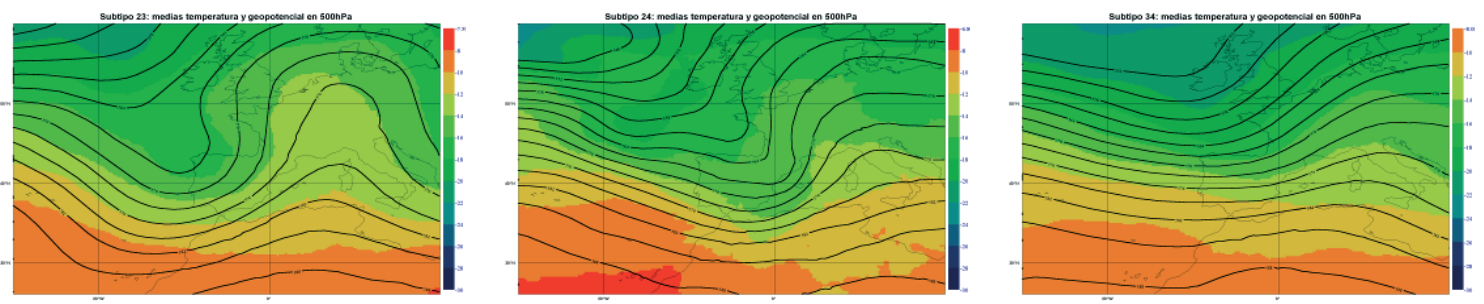

Imagen 3.8. Campos Z, T en 500 hPa de los Subtipos 23 (S-SW), 24 (S-W) y 34 (SW-W), que constituyen el Tipo 3 (situaciones del suroeste con difluencia).

Se caracteriza por la difluencia de las curvas de nivel sobre una superficie de geopotencial, representada por una apertura en forma de $\mathrm{V}$ en isohipsas que en principio eran paralelas. Tiene un efecto favorecedor de la convección al permitir la liberación de energía en la vertical ya que no se ve impedido el ascenso en los sistemas nubosos 
convectivos cuando disminuye la intensidad del viento por el propio efecto de separación de las isohipsas. Este efecto es particular y potencialmente adverso cuando se produce en la rama delantera de una vaguada (área de bajas presiones, no cerrada y con forma de U o V embebida en flujo general) marcada en los campos de geopotencial de los niveles medios y altos; concretamente en lo que se conoce como "zona de salida" de la corriente en chorro presente en dicha zona delantera. En los tres subtipos se encuentra en mayor o menor medida esta circunstancia.

El Subtipo 23 (S-SW) es el que mejor muestra la forma de una vaguada en U con su centro, no cerrado, frente a las costas gallegas y una clara difluencia en su rama delantera sobre el área de estudio mientras que el chorro de salida se dibuja desde el cabo San Vicente hasta las cercanías del golfo de Vizcaya. A su vez, la otra corriente en chorro responsable de la traslación hacia el oeste de todo el sistema (con su masa fría asociada) se sitúa sobre el océano Atlántico apuntando hacia el sureste entre la península Ibérica y Canarias, también la zona donde se aprecia mayor gradiente en la velocidad del viento determinado por la gran proximidad entre las isohipsas. Sobre el área de estudio, además de difluencia, esta configuración produce advección de vorticidad ciclónica (no se muestra), con alturas de geopotencial de $573 \mathrm{dmg}$ y temperaturas de $-14{ }^{\circ} \mathrm{C}$. La situación refleja los momentos de mayor actividad convectiva sobre el área de estudio.

El Subtipo 24 (S-W) representa una situación con la vaguada ya más desplazada hacia el oeste, pues el eje de la vaguada pasa sobre el golfo de Vizcaya y la desembocadura del Ebro. Asimismo, su forma ha adquirido un aspecto más parecido a una $\mathrm{V}$, con profundización de geopotenciales y la descarga fría ya alcanza al archipiélago balear, proceso típico del envejecimiento de tales sistemas, aunque se sigue observando difluencia en la rama de salida por lo que este subtipo se incluye en este Tipo 3. No obstante sobre la parte más occidental del área de estudio ya soplan flujos de componente oeste, lo que determina una menor severidad de los fenómenos tormentosos, como se verá más adelante.

Por el contrario, el Subtipo 34 (SW-W) representa una onda ciclónica larga, muy abierta, propia de sus primeros estadios cuando acaba de comenzar el proceso de profundización. Aunque muy ligera, también presenta una cierta difluencia en su zona delantera. Dentro de su seno suelen ir embebidos varios paquetes nubosos que, de forma consecutiva y rápida (debido al fuerte gradiente de geopotencial), van afectando al territorio aunque no con demasiada intensidad.

El efecto del agrupamiento da lugar a la configuración del Tipo 3 (situaciones del suroeste con zona difluente en la parte delantera de la vaguada) mostrada en la Imagen 3.9, con la isohipsa de $573 \mathrm{dmg}$ y la isoterma de $-14{ }^{\circ} \mathrm{C}$ pasando sobre el centro del valle del Ebro. Cuando esta situación se acopla positivamente con la de los niveles bajos da lugar a episodios convectivos altamente organizados que suelen interaccionar con la parte a barlovento de los relieves orográficos, produciendo importantes realces en las cantidades de precipitación, además de otros efectos propios de la convección severa como granizo, rachas fuertes de viento o incluso tornados. La propia difluencia hace que se puedan distinguir dos direcciones de desplazamiento de los núcleos convectivos, así, los que afectan a la parte noroccidental muestran una dirección de avance del SW al NE, mientras que los que afectan a la provincia de Teruel se desplazan desde el WSW hacia 
el ESE o incluso el E, ayudados además por el efecto atractor de la brisa mediterránea en niveles bajos que afecta a estas zonas más orientales.
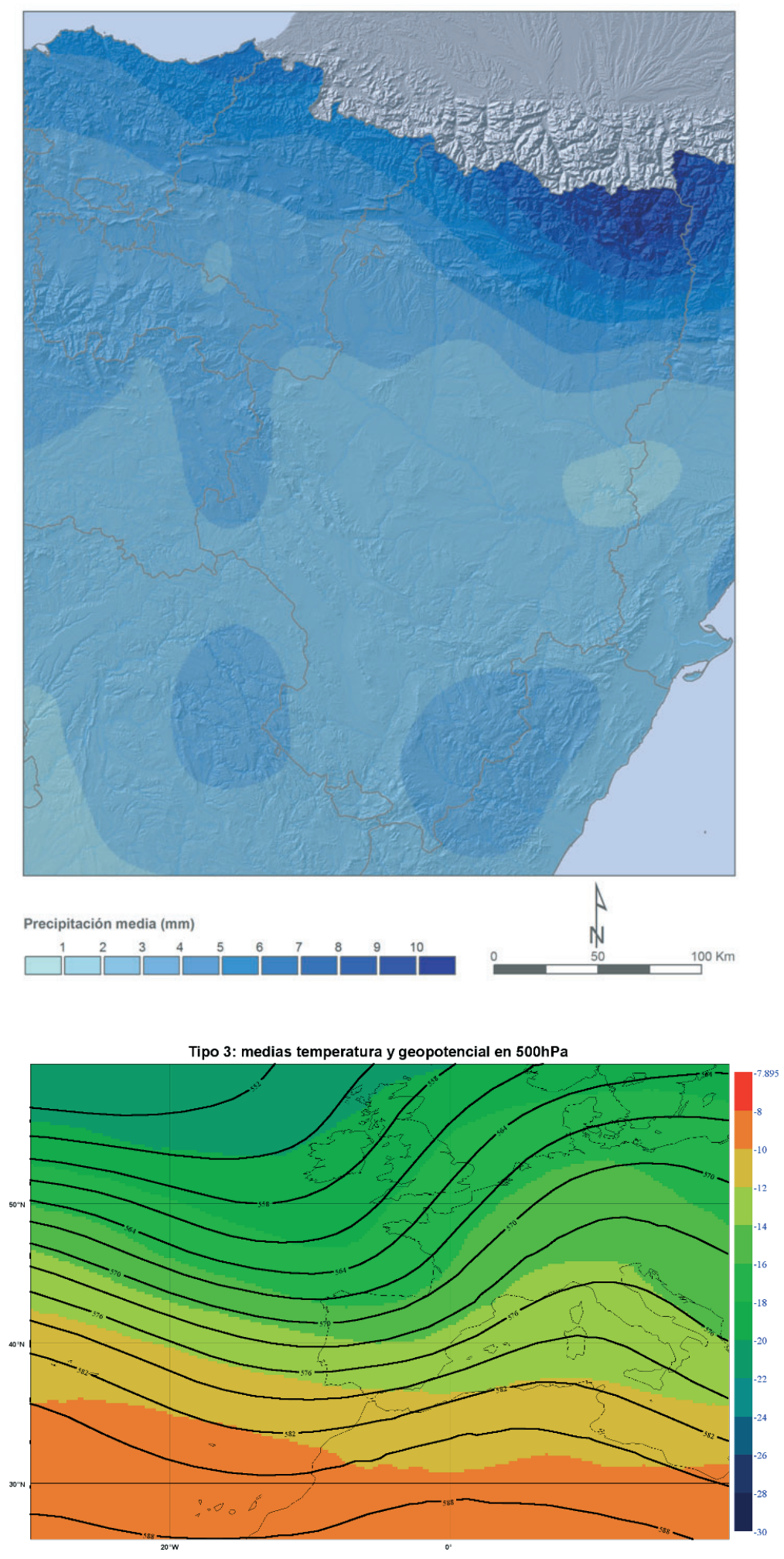

Imagen 3.9. Tipo 3, situación del suroeste con difluencia: mapa de distribución media de las precipitaciones (mapa superior) y promedio de los campos de $T$ y $\mathrm{Z}$ en $500 \mathrm{hPa}$ (inferior). 
En cuanto a la precipitación, también en estas situaciones es más probable que alcance valores mayores en los sitios elevados, siendo destacables las cantidades que pueden producirse en el tercio norte del territorio, especialmente los valores máximos en el Pirineo central, determinados por la mayor latitud, lo cual supone un largo recorrido en el desplazamiento de los sistemas. De cualquier forma, las elevaciones del Sistema Ibérico también responden positivamente al forzamiento, tal y como se identificaba ya en el Tipo 1. Por otra parte, el mínimo relativo de precipitación en el centro de la depresión del Ebro se debe a la sombra orográfica ejercida por la Ibérica.

En el Mapa 3.3 se puede apreciar la elevada densidad de descargas que tiende a producirse en el sureste de la zona, consecuencia de las fuertes convergencias de vientos que se producen, en niveles bajos, entre las brisas mediterráneas que ascienden por los cursos fluviales y los flujos de componente oeste procedentes de la Meseta. Como se ha visto anteriormente, esta es la zona de España en la que más rayos se registran, siendo este tipo de situaciones sus máximas contribuyentes, sin pasar por alto la zona pirenaica en la que también se dan núcleos importantes.

Este tipo presenta una probabilidad de tormenta relativamente grande sobre la Ibérica y el Pirineo, pero es especialmente destacable sobre el núcleo de Gúdar-Maestrazgo. Conviene destacar, no obstante, el desacoplamiento entre máximos de precipitación y de rayos/probabilidad de tormenta, producido porque este tipo de situación puede producir fenómenos convectivos al sur del área de estudio, pero en el extremo norte también se puede corresponder con pasos de frentes o colas de frente que acumulan precipitación en los Pirineos y que apenas afectan al resto del territorio, o precisamente lo hacen en forma de fenómenos convectivos menos generalizados.

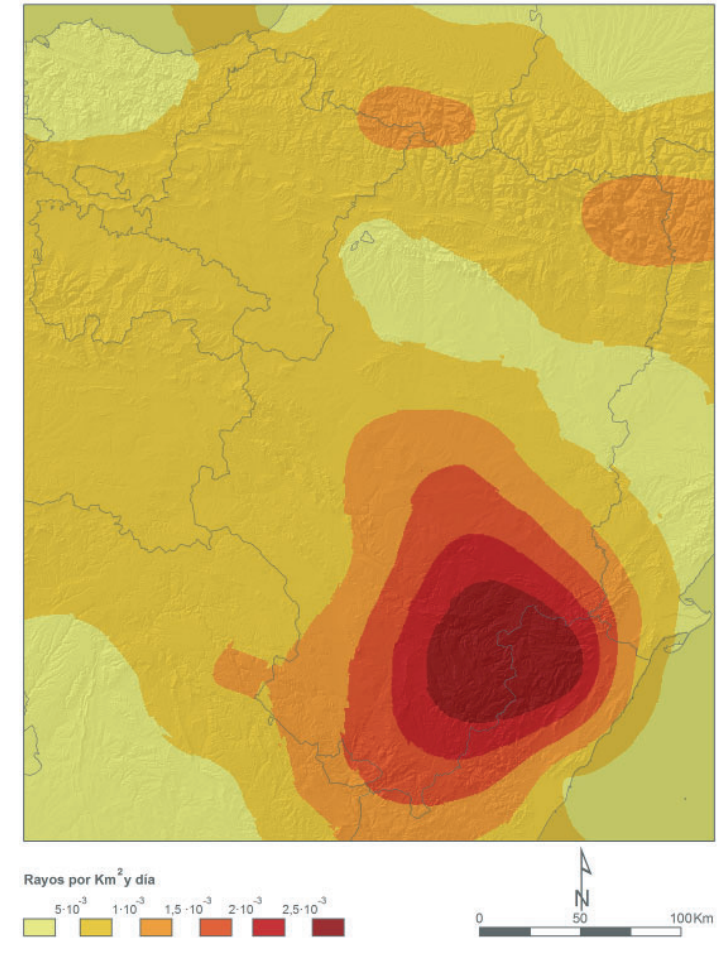

a. Densidad de descargas eléctricas

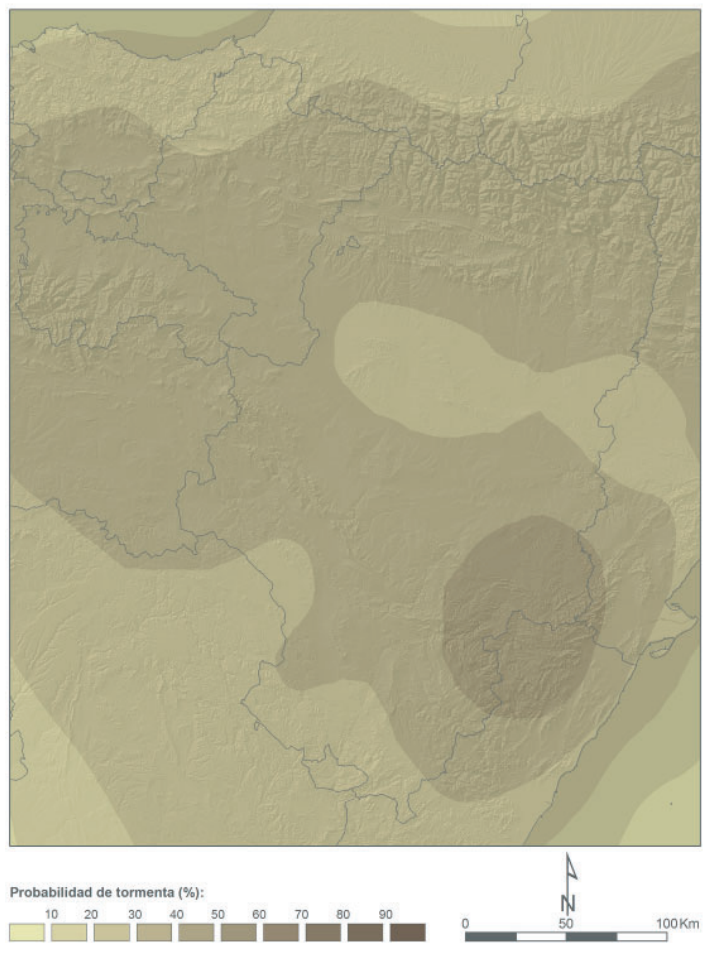

b. Probabilidad de tormentas

Mapa 3.3. Caracterización espacial de la convección en las situaciones del suroeste con difluencia (Tipo 3). 


\subsubsection{Situaciones del suroeste sin difluencia (Tipo 4)}

Aunque por el nombre pueda parecerlo, esta situación no es una mera variación del Tipo 3 anteriormente tratado. Su rasgo diferenciador es que el centro de la zona de bajas presiones, en su traslación hacia el oeste, no cruza sobre el área de estudio sino que lo hace por latitudes más bajas del centro o el sur peninsular. Surge como resultado de agrupar cuatro subtipos (Imagen 3.10) con características menos homogéneas entre sí que en el tipo descrito con anterioridad.

El Subtipo 33 (SW-SW) es el caso más parecido al anterior — aunque se diferencia de él- porque, además de carecer de difluencia, presentar unos geopotenciales medios unos 30 dmg más altos y temperaturas unos $2{ }^{\circ} \mathrm{C}$ más cálidas.
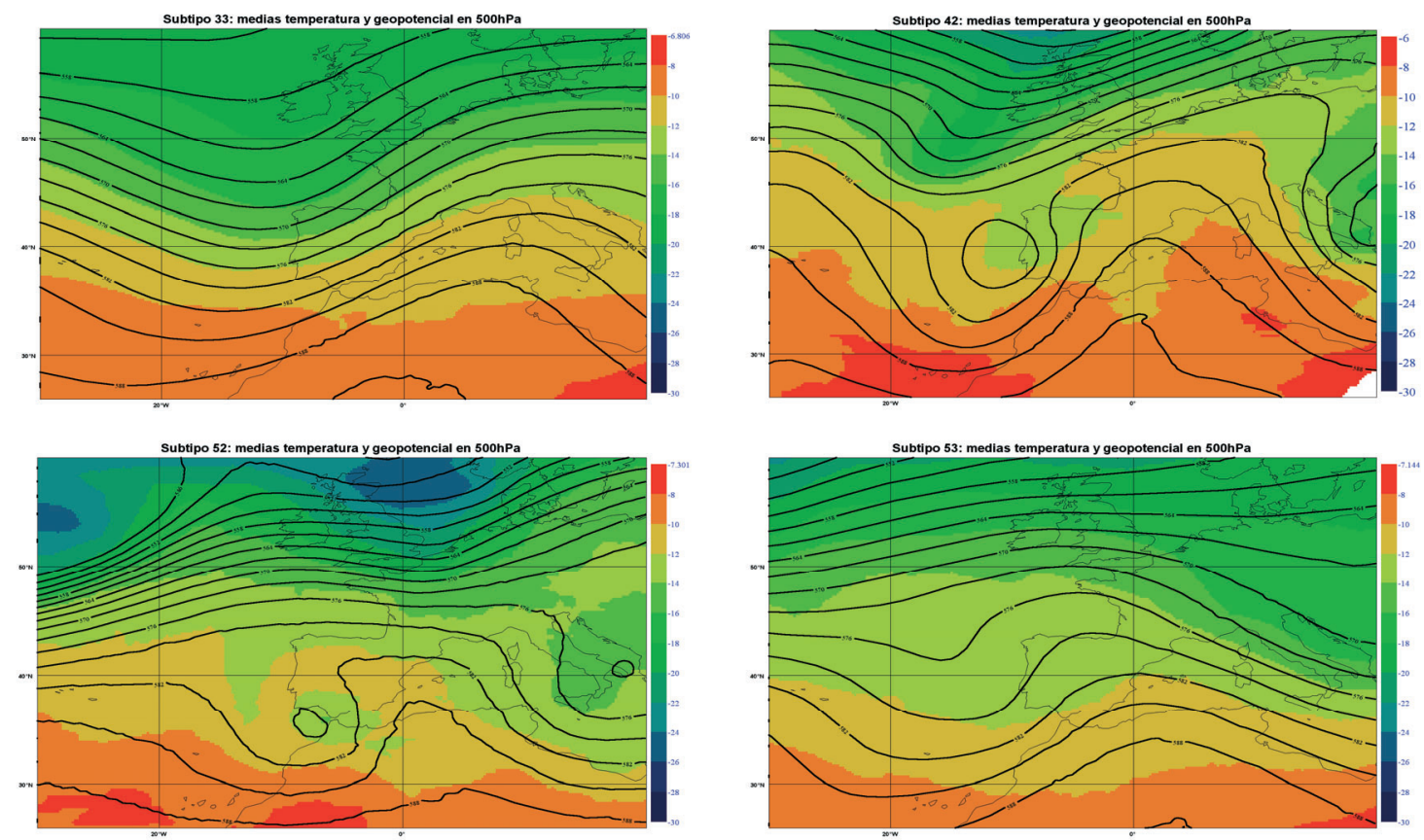

Imagen 3.10. De izquierda a derecha y de arriba abajo: campos de $Z$ y $T$ en $500 \mathrm{hPa}$ de los Subtipos 33 (SW-SW), 42 (W-S), 52 (NW-S) y 53 (NW-SW) del Tipo 4 (situaciones del suroeste sin difluencia).

En el Subtipo 42 (W-S) el centro depresionario cerrado está frente a Lisboa, por lo que el área de estudio va dejando ya de estar afectada por la difluencia, al presentarse las isohipsas muy separadas pero casi paralelas. No obstante, con la precipitación en puertas afectando al sur y centro peninsular, hay que considerar que cuando el sistema en su conjunto se traslade hacia el este, la situación cambiará rápidamente.

En el Subtipo 52 (NW-S) el centro de baja presión todavía se encuentra más al sur (en las inmediaciones del estrecho de Gibraltar), con lo que se acentúan las consideraciones hechas en el Subtipo 42, al estar el área de estudio claramente afectada por la dorsal anticiclónica con flujo zonal poco intenso. Por otra parte, en este subtipo (al igual que en el anterior) la posición de la dorsal traslada la trayectoria de los frentes zonales atlánticos hacia latitudes europeas más altas, mientras la Península Ibérica se ve 
afectada por el entorno de la DANA, lo que dará lugar a menos precipitación, sobre todo en la parte sur de Aragón.

El Subtipo 53 refleja el momento en el que se aproxima por el Atlántico una vaguada con forma de U muy abierta, y con amplitud y longitud de onda reducidas (lo que en el argot meteorológico se denomina como “onda corta”). Al estar alejada la vaguada, el eje de la dorsal se encuentra al oeste de la zona de estudio (en una línea que iría de Asturias a Murcia) y el flujo es convergente (las isohipsas se aproximan según se avanza corriente adelante). Por lo tanto, aunque se esté bajo influencia anticiclónica, es importante tener presente que dinámicamente la existencia de convergencia del flujo en la cola de salida de una dorsal también tiene ciertos efectos potenciadores de la convección, aunque las cantidades de precipitación de este subtipo sean también menores. Esta falta de precipitaciones en los dos últimos subtipos va a dar lugar a que la correspondencia entre los campos de precipitación y actividad eléctrica sea mucho menor en la mitad sur de Aragón.

En los Subtipos 33, 52 y 53 se aprecia una marcada baroclinidad, característica que no había aparecido en las configuraciones vistas hasta ahora, que exhibían una estructura barotrópica. La baroclinidad viene caracterizada por el cruce entre isohipsas e isotermas bajo un fuerte ángulo, lo que determina que las masas de aire de diferentes características térmicas sean fácilmente empujadas por el viento. Esta advección será tanto más fuerte cuanto mayores sean: el gradiente térmico, el ángulo de cruce entre isotermas e isohipsas y la velocidad del viento. El efecto de estas advecciones en distintos niveles puede dar lugar a inestabilizaciones atmosféricas por superposición de masas frías sobre otras cálidas.

El resultado del reagrupamiento origina la configuración del Tipo 4 (situaciones del suroeste sin zona difluente en la parte delantera de la vaguada) mostrada en la Imagen 3.11, que recuerda a la situación del Tipo 3 (situaciones del suroeste con difluencia en la parte delantera de la vaguada) aunque con valores de geopotencial y temperatura ligeramente más altos (isohipsa de $579 \mathrm{dmg}$ e isoterma de $-12{ }^{\circ} \mathrm{C}$ sobre el centro del valle del Ebro). En consecuencia, tanto la dinámica como la inestabilidad térmica se ven algo atenuadas. No obstante, la situación sigue representando una alta probabilidad de chubascos importantes por la posición crítica en la que se encuentran los Subtipos 42 y 52, en los que un ligero desplazamiento hacia el norte del sistema en su conjunto haría que el área de estudio se encontrara bajo la zona de fuerte difluencia. Es, por tanto, una de esas situaciones en las que hay que seguir paso a paso su evolución, pues suele deparar sorpresas.

En cuanto a la distribución de la precipitación, muestra un patrón muy similar al caso anterior (Tipo 3) pero con menores cantidades totales. Tal circunstancia se debe en este caso (Tipo 4) a que la ausencia de difluencia resta intensidad a la convección, unida al hecho, ya comentado, de que la aportación de lluvia de los Subtipos 52 y 53 suele ser reducida.

Algo similar puede decirse para este tipo de situaciones respecto a la disminución de frecuencia e intensidad de la actividad eléctrica mostrada en el Mapa 3.4, en el que también se observa como los núcleos más activos del sureste aparecen ligeramente desplazados hacia el norte, así como el aumento de la probabilidad de tormenta en la vertiente cantábrica de Navarra, consecuencia del efecto de bloqueo ejercido por la 
dorsal anticiclónica. En cualquier caso, aparece una sensible diferencia entre la probabilidad de tormentas (Mapa 3.4a) y la densidad de descargas esperable (Mapa 3.4b), que es mucho mayor en las proximidades de la sierra de Sant Just.
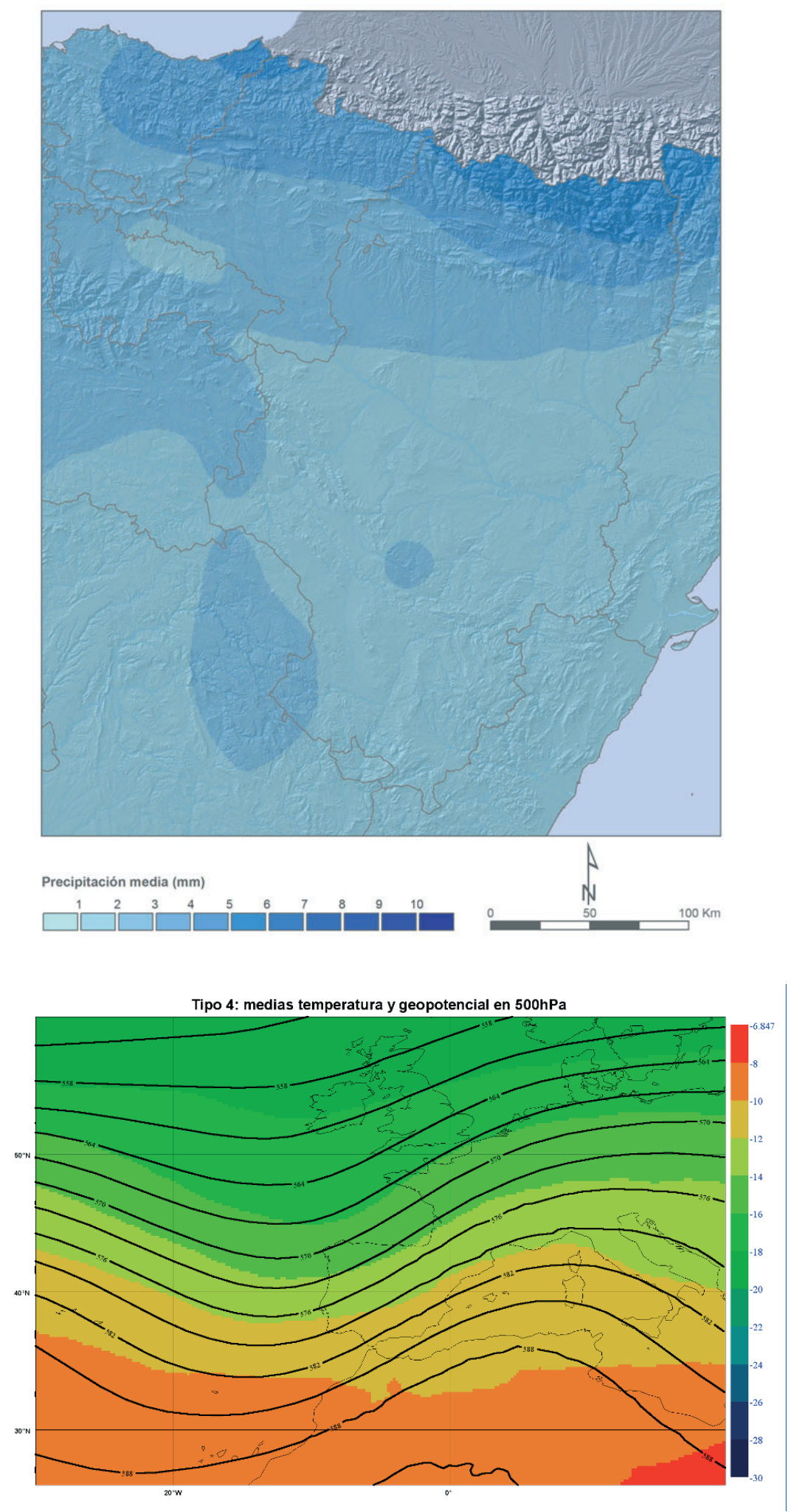

Imagen 3.11. Tipo 4, situación del suroeste sin difluencia: mapa de distribución media de las precipitaciones, imagen superior y promedio de los campos de $\mathrm{T}$ y $\mathrm{Z}$ en $500 \mathrm{hPa}$, inferior. 


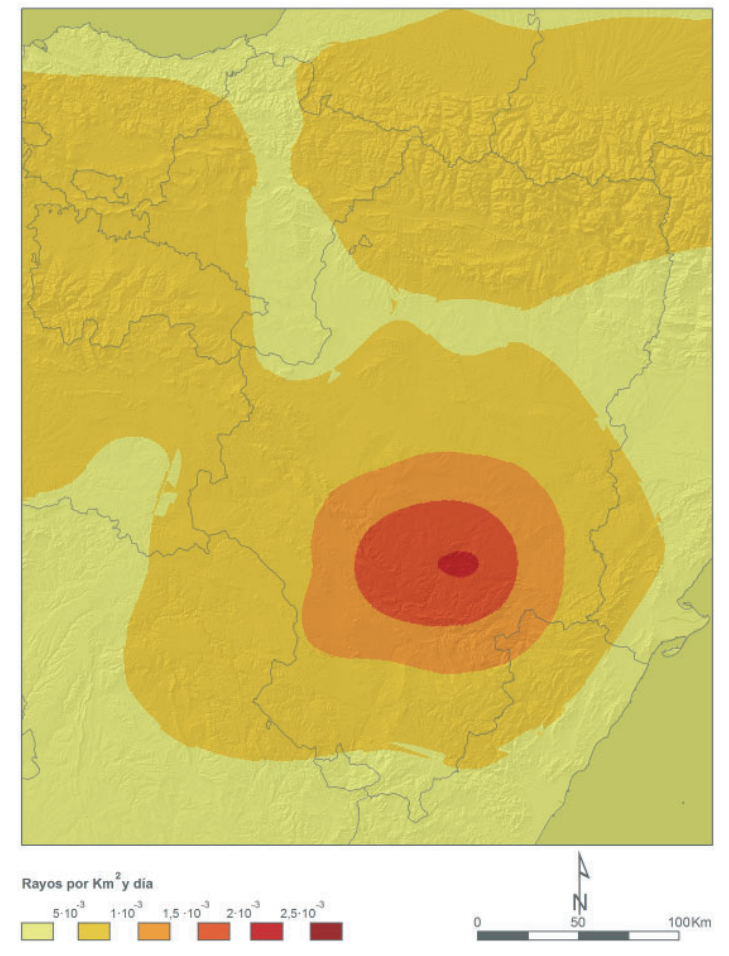

a. Densidad de descargas eléctricas

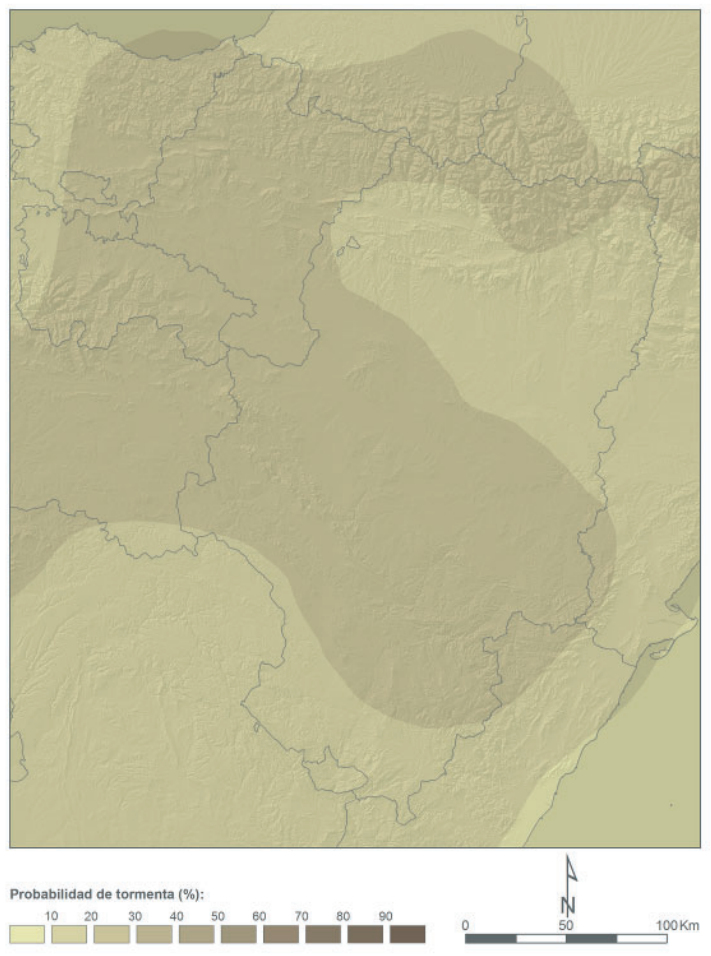

b. Probabilidad de tormentas

Mapa 3.4. Caracterización espacial de la convección en las situaciones del suroeste sin difluencia (Tipo 4).

\subsubsection{Situaciones del oeste (Tipo 5)}

Se trata de aquellos sistemas que afectan a la zona de estudio acercándose desde la horquilla de valores comprendidos entre $250^{\circ}$ y $280^{\circ}$ de la rosa de vientos. Se pretende con ello identificar las masas con claro origen y características marítimas procedentes de latitudes medias del Atlántico. El proceso de asignación de días a subtipos en función del viento en las esquinas superior-izquierda e inferior-derecha del rectángulo que define el área de estudio, junto con el posterior cálculo de los mapas medios de temperatura y geopotencial en 500 hPa discrimina los Subtipos 43 (W-SW) y 44 (W-W) mostrados en la Imagen 3.12.
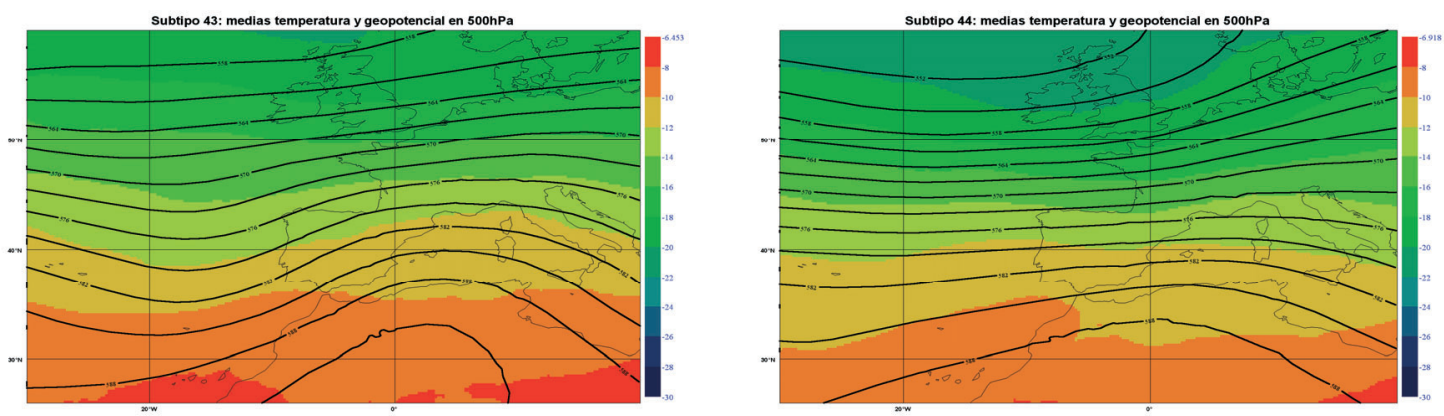

Imagen 3.12. Campos de Z y T en 500 hPa de los Subtipos 43 (W-SW) y 44 (W-W) del Tipo 5 (situaciones del oeste). 
La sutil diferencia del Subtipo 43 (W-SW) respecto al Subtipo 33 (SW-SW) — descrito en el apartado anterior - se da en la mayor zonalidad del flujo general, con la ondulación sinusoidal mucho menos marcada latitudinalmente en el presente caso. Esto determina sistemas nubosos mucho menos activos que una vez dentro de la Península se van resecando progresivamente por agotamiento de la reserva de humedad en su seno como respuesta básicamente a forzamientos orográficos.

El efecto del promediado en el Subtipo $44(\mathrm{~W}-\mathrm{W})$ y en el área de estudio, como caso extremo, determina una configuración totalmente zonal (apenas se intuyen las ondas sinusoidales de Rossby), con gradiente bárico latitudinal constante y barotropía, propia de los flujos húmedos de largo recorrido marino. El valor de la isohipsa estándar es de $576 \mathrm{dmg}$, mientras que la isoterma de $-12{ }^{\circ} \mathrm{C}$ indica la suavidad térmica de influencia marina. La ausencia de curvatura determina que los sistemas nubosos embebidos en la circulación sean de reducidas dimensiones, aunque veloces en su desplazamiento.

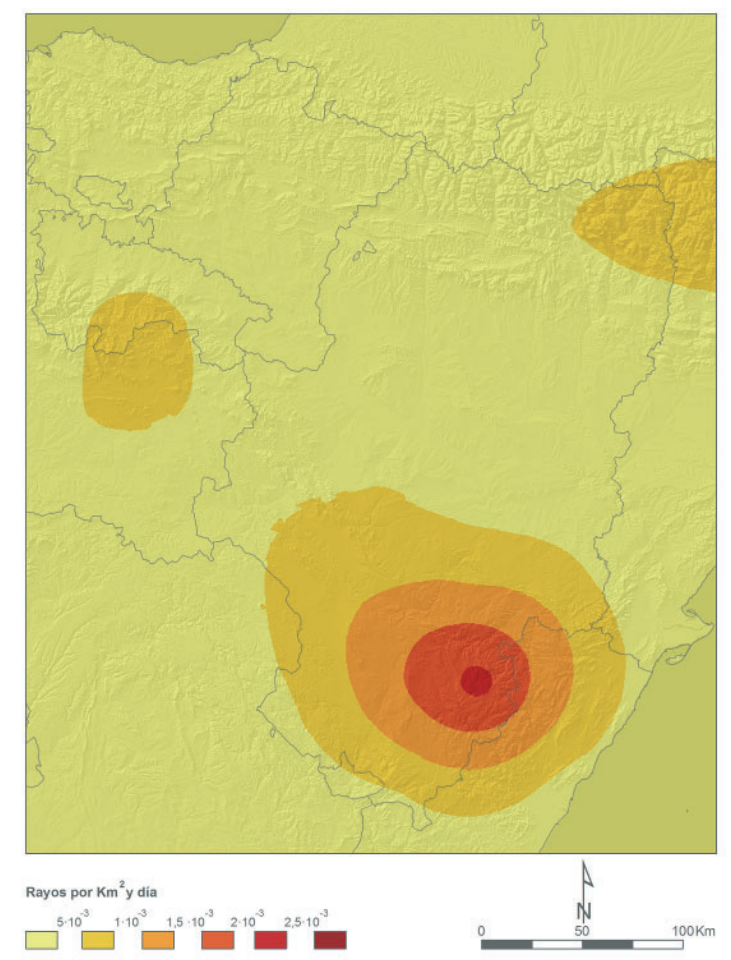

a. Densidad de descargas eléctricas

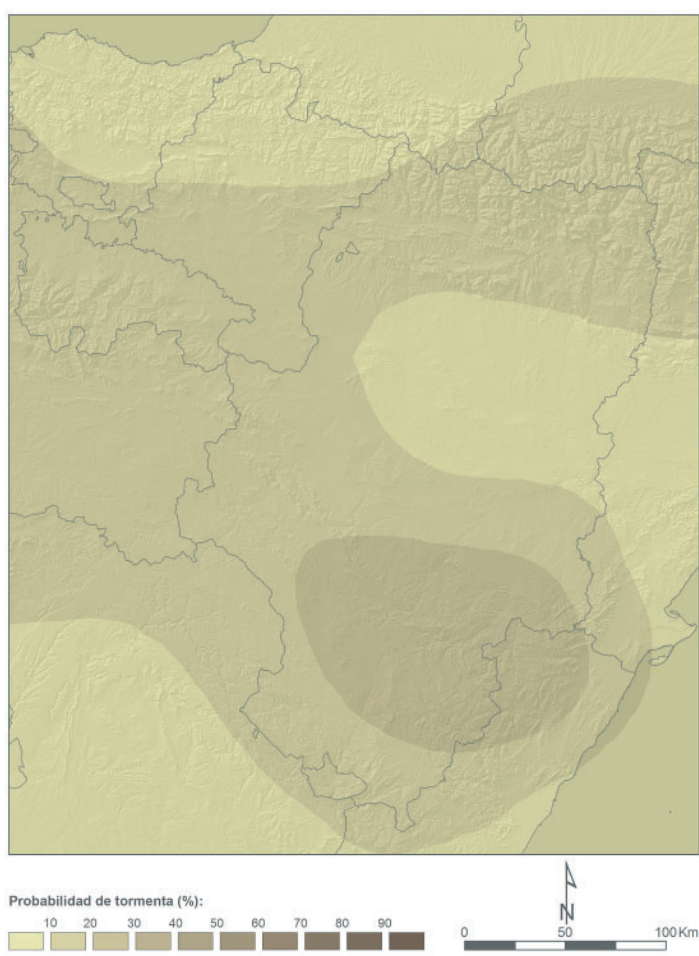

b. Probabilidad de tormentas

Mapa 3.5. Caracterización espacial de la convección en las situaciones del oeste (Tipo 5).

La Imagen 3.13 representa las características medias de la situación de oeste en la que, aunque comparte valores de isotermas e isohipsas con la situación de Tipo 4 (situaciones del suroeste sin difluencia), la ausencia de curvatura determina un régimen de precipitaciones de origen fundamentalmente estratiforme y que, como puede verse en el mapa de precipitación, solo presenta algunos realces en el Pirineo y estribaciones, así como en las sierras de Gúdar y Javalambre, con más carácter convectivo. La ausencia de forzamiento dinámico junto al origen atlántico de la masa de aire visitante, hace que las tormentas que se producen sean poco importantes, concentrándose en aquellas elevaciones montañosas que tienen suficiente entidad en relieve y, sobre todo, ubicación para, incluso con este flujo, inducir al desarrollo de la inestabilidad por ascenso (Mapa 
3.5), con lo que se deduce que la precipitación estratiforme juega un papel importante en este tipo de situaciones.
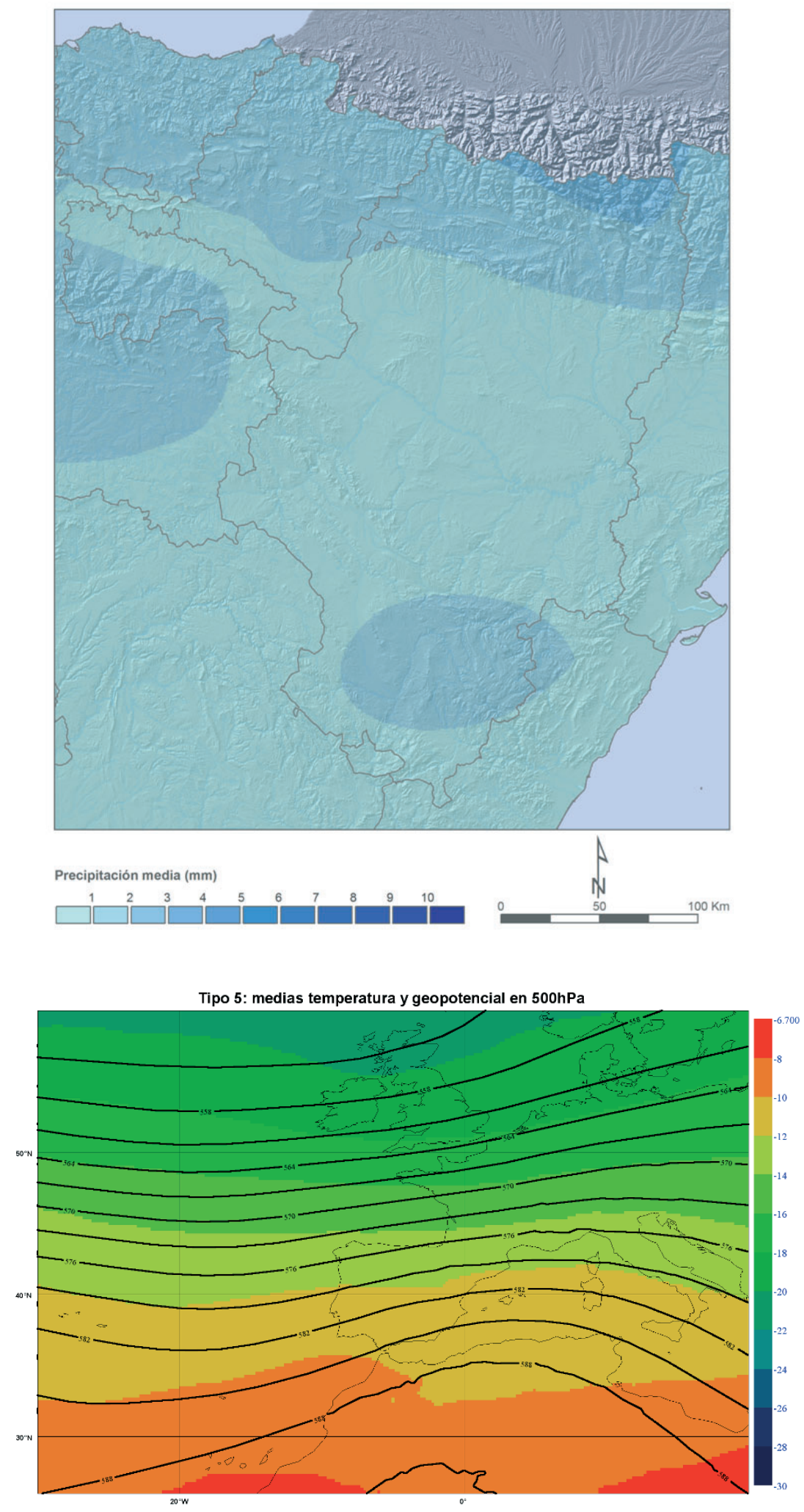

Imagen 3.13. Tipo 5, situación del oeste: mapa de distribución media de las precipitaciones, imagen superior y promedio de los campos de $T$ y $\mathrm{Z}$ en $500 \mathrm{hPa}$, inferior. 


\subsubsection{Situaciones depresionarias entrantes (Tipo 6)}

Todos los subtipos que contribuyen al Tipo 6 se caracterizan por la presencia de una depresión en niveles medio-altos de la atmósfera, aislada de la circulación general de latitudes superiores (DANA). Si bien es cierto que parte de estas DANA pueden ser en realidad depresiones frías, ya que solo se está considerando para esta clasificación el nivel de $500 \mathrm{hPa}$, dada la época del año que abarca la temporada lo más probable es que la mayor parte de estas hipotéticas DANA lo sean en realidad. Estos subtipos son: 36 (SW-E), 46 (W-E), 62 (E-S) y 63 (E-SW). La denominación hace referencia a las etapas en que el nordeste peninsular se ve afectado por la parte delantera del núcleo aislado (Imagen 3.14), de ahí el adjetivo “entrantes”.

En el Subtipo 36 (SW-E) la desconexión de la DANA con el flujo general, aunque existe, no es totalmente efectiva y se percibe por el efecto de acople con la vaguada de latitudes altas desplazándose hacia el este. Llama la atención su importante profundización (menos de $555 \mathrm{dmg}$ en su centro) y su marcado núcleo frío $\left(-22{ }^{\circ} \mathrm{C}\right)$, típicos de épocas otoñales, que con su posición sobre Marruecos deja al área de estudio bajo la zona dorsalizada anterior. Por lo tanto, dependiendo de los basculamientos que puedan producirse, el sur del Sistema Ibérico podría verse afectado por la propia DANA, mientras que los Pirineos podrían recoger algo de precipitación asociada al extremo sur del frente que se sitúa sobre las Islas Británicas y se traslada hacia el este a mayores latitudes.
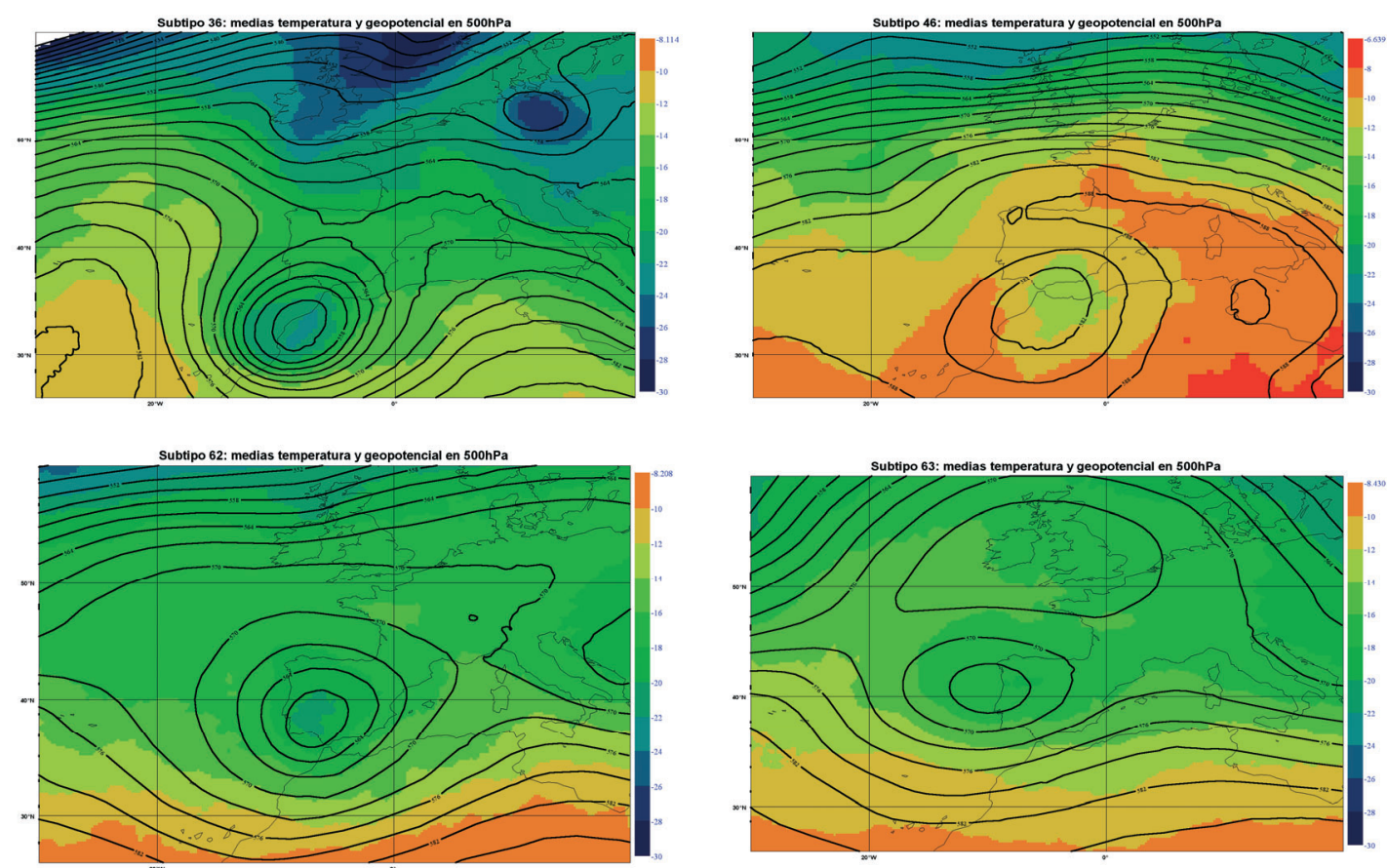

Imagen 3.14. De izquierda a derecha y de arriba a abajo, campos de $Z$ y $T$ en $500 \mathrm{hPa}$ de los Subtipos 36 (SW-E), 46 (W-E), 62 (E-S) y 63 (E-SW) del Tipo 6 (situaciones depresionarias entrantes).

En el Subtipo 46 (W-E) la desconexión de la DANA con la circulación general es completa, encontrándose además totalmente bloqueado su avance por la dorsal 
anticiclónica centrada sobre Túnez. Corresponde a la etapa de oclusión propia del decaimiento del sistema, con los valores de geopotencial aumentando como consecuencia del rellenado bárico y el esquema térmico zonal totalmente roto.

El Subtipo 62 (E-S) representa una DANA que se encuentra ligeramente más al norte que en los subtipos anteriores y que puede acabar afectando directamente al área de estudio si esta se ve trasladada hacia el nordeste, al ser muy escasa la potencia de la dorsal situada al norte. Aunque no es tan profunda como en el Subtipo 36, esta configuración es causa de precipitaciones copiosas y fenómenos convectivos notables.

El Subtipo 63 (E-SW) se diferencia del anterior en la existencia de una marcada dorsal en la vertical de las Islas Británicas, que rompe la continuidad del flujo y fuerza a las depresiones a tomar el camino sur para proseguir en su avance hacia el este, durante el cual la zona de estudio se verá completamente afectada.

El efecto del promediado (Imagen 3.15) muestra una depresión aislada de los flujos zonales, que determina un flujo del suroeste sobre el área de estudio y valores de $576 \mathrm{dmg}$ para el geopotencial y $-12{ }^{\circ} \mathrm{C}$ para la temperatura. A corto plazo y a medida que la depresión se desplace hacia el Mediterráneo, estos flujos del suroeste se verán sustituidos por otros con mayor componente sur, mientras el centro de vorticidad ciclónica se situará sobre la propia zona de estudio.

La distribución de la precipitación (Imagen 3.15) se asemeja a la del Tipo 2 (situaciones del sur) debido al origen semejante de la masa de aire, aunque en este caso las cantidades esperables, de media, son superiores. En esta imagen, en general, las precipitaciones afectan menos a La Rioja, Navarra (salvo la Ribera Baja) y País Vasco debido a que estas zonas quedan bajo la influencia anticiclónica en algunos de los subtipos.

El Mapa 3.6 muestra que la actividad eléctrica registra máximos en la Ibérica zaragozana y parte más noroccidental de la turolense (cuencas del Jalón y Jiloca), afectando menos a otras zonas como los Pirineos, La Rioja, sierras occidentales de Navarra o Guadalajara.

En la zona sur de la provincia de Teruel y en la de Castellón se observan fuertes acumulaciones de precipitación que no están correspondidas por similares acumulaciones de descargas eléctricas, cuyo máximo está claramente desplazado al oeste (Mapa 3.6a). Este desacople se debe a la proximidad al mar de las áreas con máximos de precipitación, lo que determina una fuerte realimentación de humedad en la zona por los flujos de niveles bajos de origen mediterráneo que suelen soplar durante el día en este tipo de situación (como se verá posteriormente en el caso de estudio correspondiente en el Capítulo 6), mientras que el máximo en la actividad convectiva se da allí donde la difluencia es mayor. 

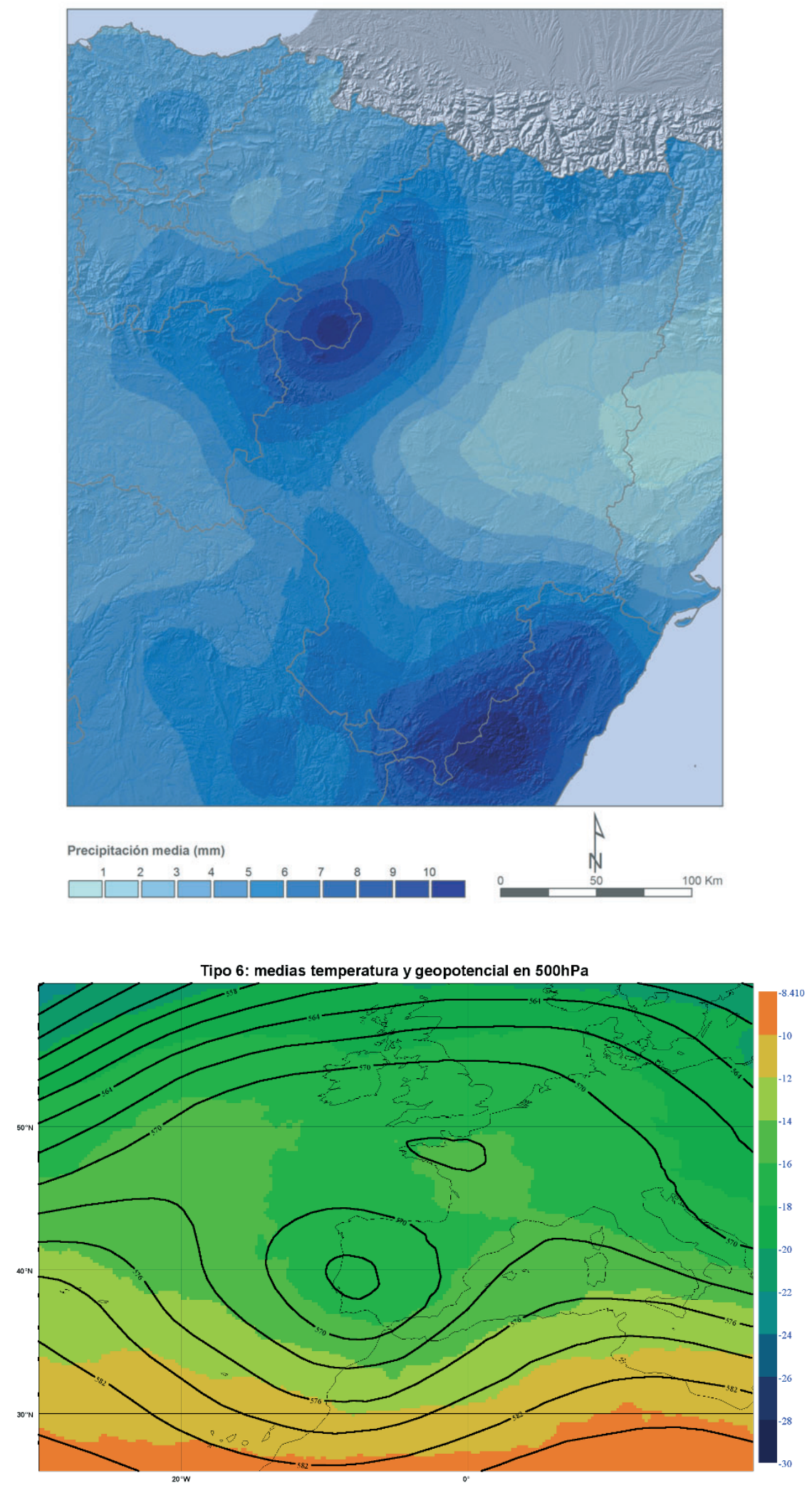

Imagen 3.15. Tipo 6, situación depresionaria entrante: mapa de distribución media de las precipitaciones, imagen superior, y promedio de los campos de Ty Z en $500 \mathrm{hPa}$, inferior. 


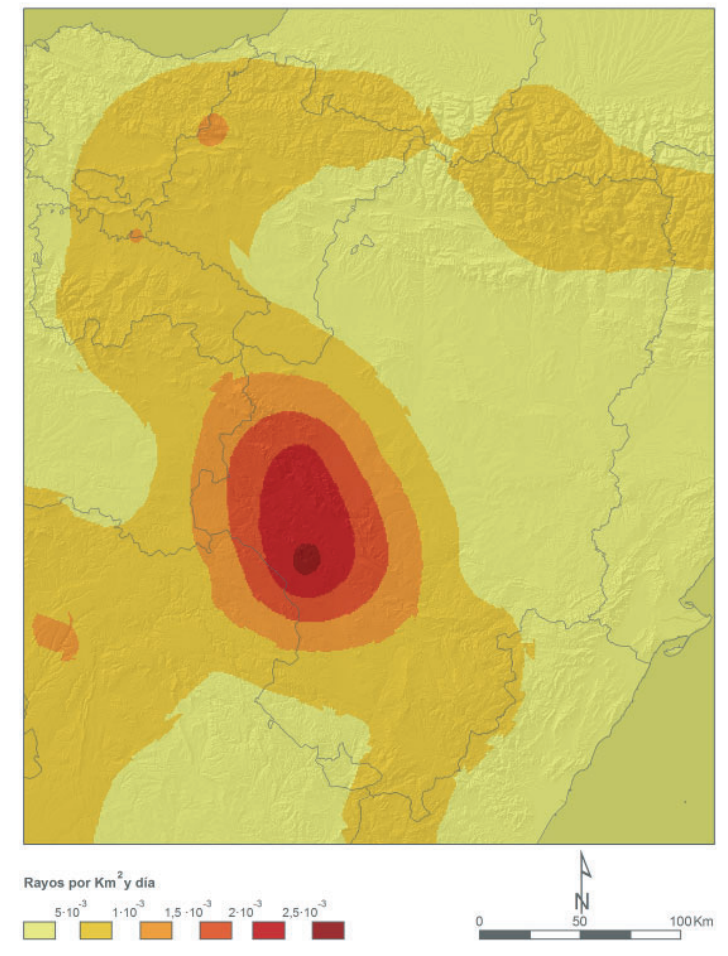

a. Densidad de descargas eléctricas

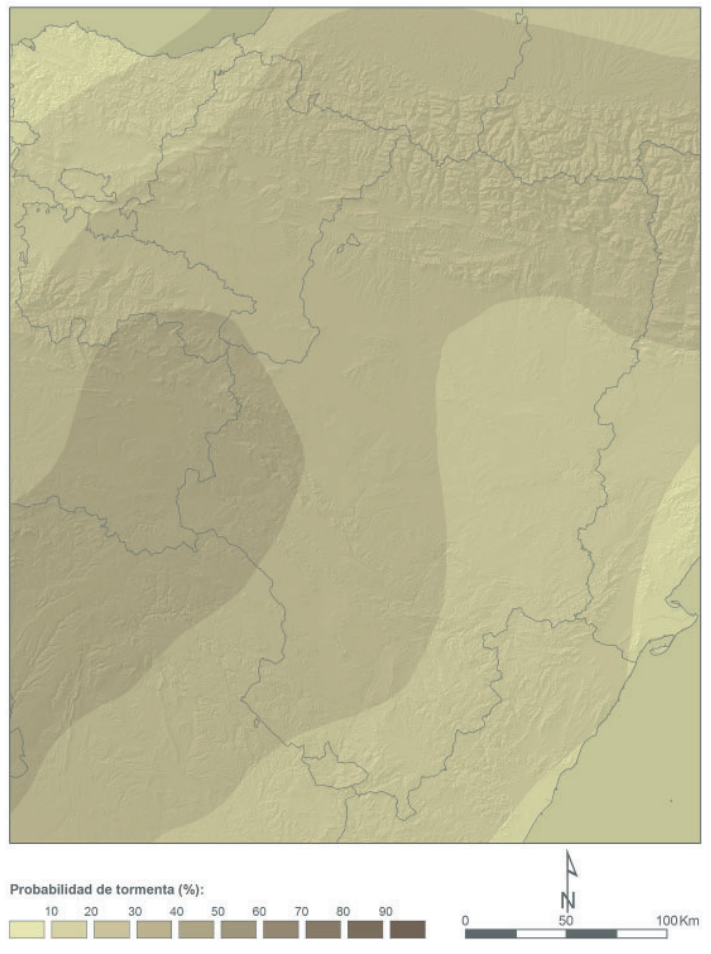

b. Probabilidad de tormentas

Mapa 3.6. Caracterización espacial de la convección en las situaciones depresionarias entrantes (Tipo 6).

\subsubsection{Situaciones depresionarias rebasadas (Tipo 7)}

En este apartado se estudian las circunstancias presentes cuando el área de estudio se ve afectada por la parte posterior de una depresión cerrada o una vaguada profunda con su eje de dirección muy zonal, ambas ya sobre el mar Mediterráneo después de pasar sobre el sur de la península Ibérica. Dicha situación incluye los Subtipos 26 (S-E), 56 (NW-E), 64 (E-W), 65 (E-NW) y 66 (E-E) siendo la característica común a todos ellos, la aparición del flujo de dirección $\mathrm{E}$ en, por lo menos, una de las esquinas del rectángulo que define el área de estudio. Esta circunstancia indica el origen mediterráneo de las masas de aire asociadas a la circulación de retorno de las zonas de bajas presiones cuando se dirigen hacia levante (Imagen 3.16).

El Subtipo 26 (S-E) agrupa los efectos que sobre el área de estudio tiene la traslación hacia el este de depresiones aisladas muy potentes centradas al sur de la Península, Subtipo 36 (SW-E), que previamente se han analizado en el Tipo 6 (situaciones depresionarias entrantes). Dicha configuración (Subtipo 26), puede dar lugar a precipitaciones copiosas en la parte más oriental de la zona de estudio. No obstante, en ocasiones de fuerte flujo en altura, los núcleos pueden propagarse canalizados por la depresión del Ebro hasta alcanzar Navarra y La Rioja —en la parte occidental del área de estudio-, dando lugar mientras tanto a fuertes lluvias de retención orográfica en la vertiente sur del Pirineo. 

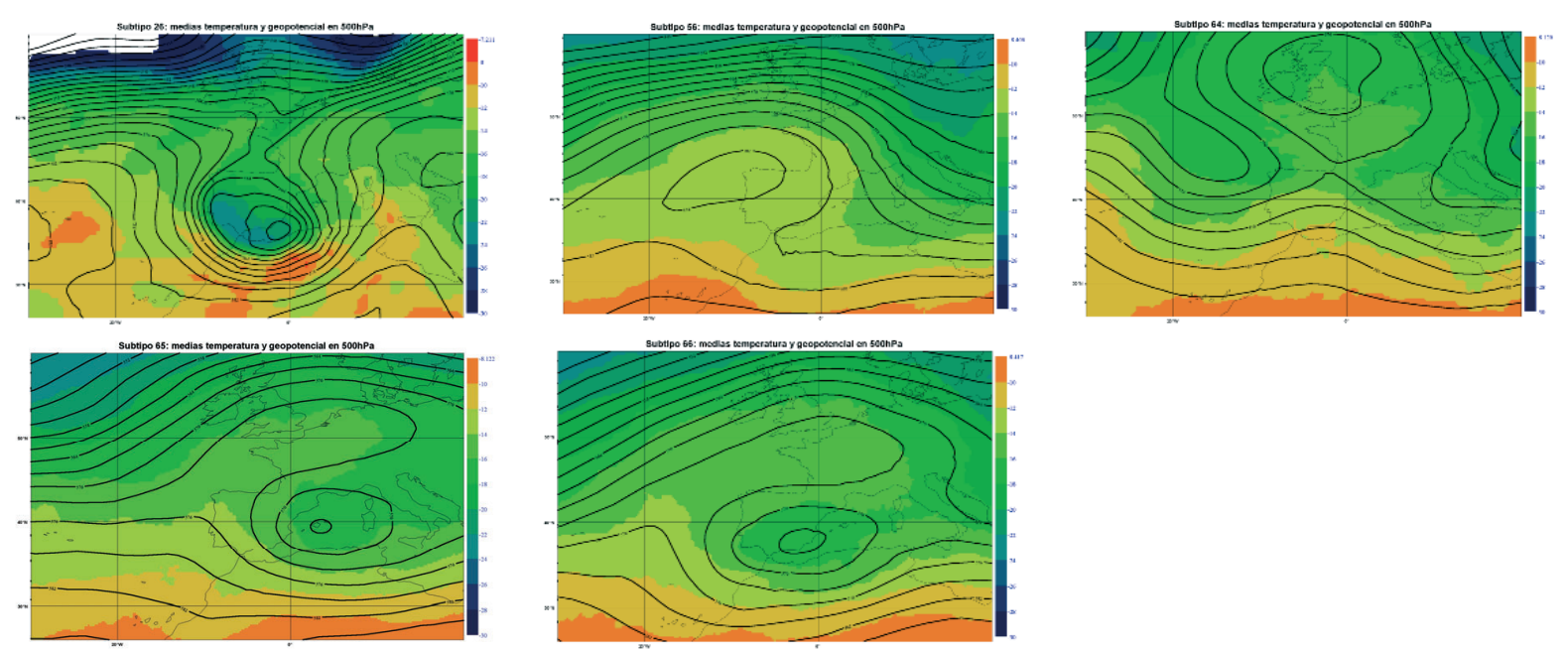

Imagen 3.16. De izquierda a derecha y de arriba abajo, campos de $Z$ y $T$ en $500 \mathrm{hPa}$ de los Subtipos 26 (S-E), 56 (NW-E), 64 (E-W), 65 (E-NW) y 66 (E-E) del Tipo 7.

En el resto de los subtipos se observa la existencia de un anticiclón de bloqueo como elemento regulador del flujo. En el Subtipo 56 (NW-E) el centro de altas presiones está situado al oeste de Finisterre. La vaguada en $\mathrm{V}$ con eje prolongándose desde las islas Baleares hasta el estrecho de Gibraltar puede ser el resultado del avance hacia el este de las situaciones del Tipo 6 o del inicio de una profundización e inestabilización al alcanzar el Mediterráneo las masas de aire de fuerte espesor atmosférico, que tienen su origen en latitudes altas y que bordean el anticiclón por su parte oriental en dirección norte-sur. Cabe resaltar la inmensa dorsal térmica que engloba a la península Ibérica, mientras las masas de aire comentadas refrescan la atmósfera sobre el mar Mediterráneo.

El Subtipo 64 (E-W) muestra una fase posterior al anterior subtipo (56), en el que desde el W y NW una zona de bajas presiones intenta avanzar estrangulando la dorsal anticiclónica, mientras se dibuja una situación conocida con el nombre de "silla de montar" - con su configuración simétrica de zonas de altas y bajas presiones relativas - que puede dar lugar a un tiempo cambiante dados los orígenes distintos de las dos masas de aire que afectan al área de estudio.

Los Subtipos 65 (E-NW) y 66 (E-E) básicamente corresponden a situaciones consecutivas, consecuencia de la influencia de depresiones situadas sobre Baleares o en el mar de Alborán. No obstante no deben ser menospreciadas, pues puede producirse una inestabilización y profundización del sistema como consecuencia del aporte termohídrico del Mediterráneo. Además, es frecuente que la baja, dirigida por el flujo del nordeste de su borde superior, adquiera un movimiento retrógrado; volviendo hacia el oeste y afectando, sobre todo, a la parte más oriental de la zona de estudio. 

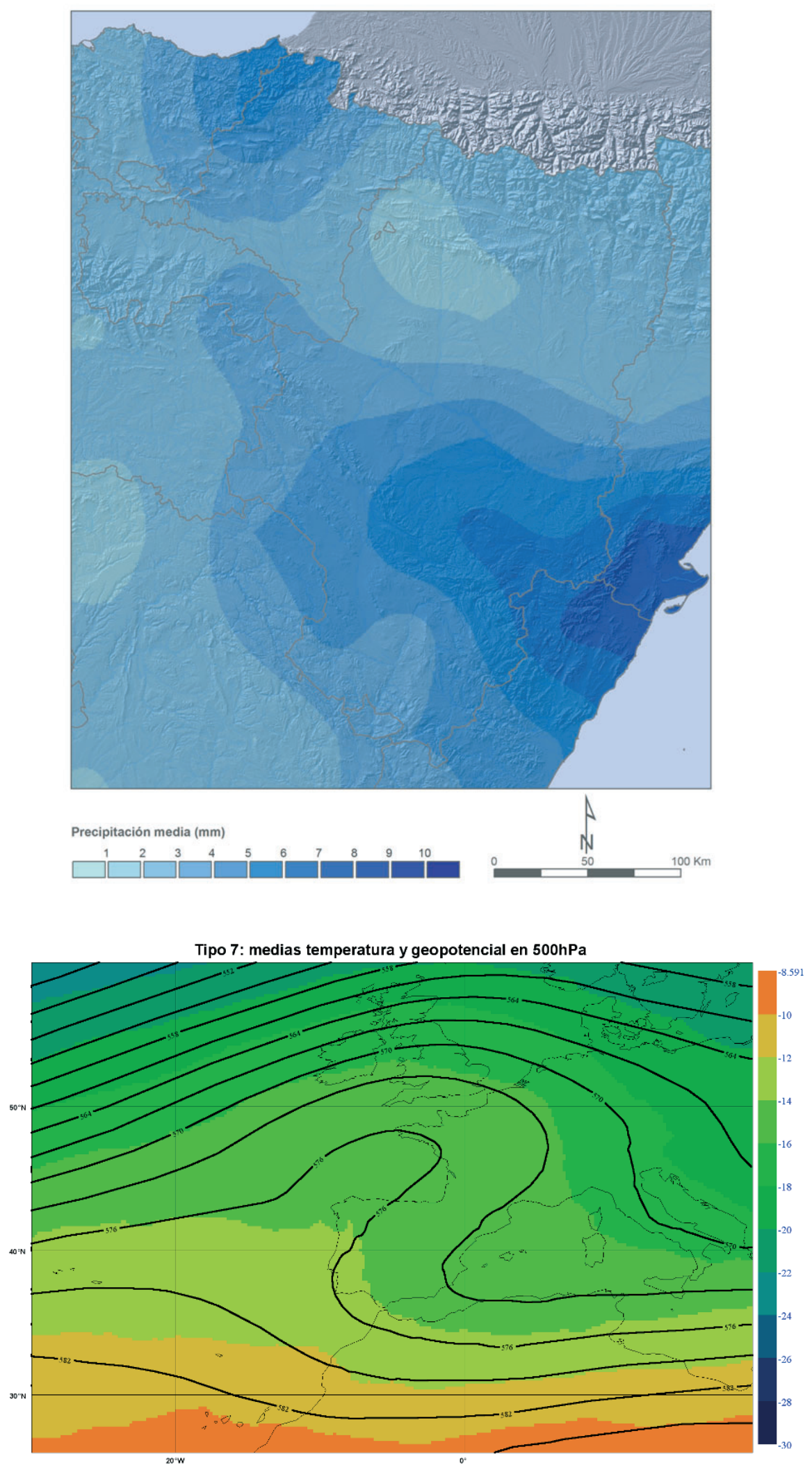

Imagen 3.17. Tipo 7, situación depresionaria rebasada e inclinada: mapa de distribución media de las precipitaciones y promedio de los campos de $\mathrm{T}$ y $\mathrm{Z}$ en $500 \mathrm{hPa}$. 
La situación resultante del proceso de agrupación se muestra en la Imagen 3.17, donde se aprecia que lo más característico es el sistema dorsal-vaguada con sus ejes, muy inclinados en dirección NE al SW y situados uno a cada lado de la Península, canalizando un flujo del nordeste que determina que la parte meridional del área de estudio pueda registrar chubascos de influencia mediterránea, propagándose a lo largo de la depresión del Ebro; mientras que la más septentrional alguna precipitación poco importante advectada desde Francia.

Todo lo comentado respecto a los dos orígenes distintos de los flujos en algunos subtipos tiene reflejo en el campo de la precipitación, que refleja ese doble origen en la forma de un máximo en la vertiente cantábrica navarra y otro más intenso que afecta al delta del Ebro y zonas próximas de la Cordillera Costero-Catalana, con influencia hasta bien tierra adentro a lo largo y ancho de su valle medio. Por el contrario, en la zona pirenaica no se totalizan las cantidades de otros casos, debido a la advección de vorticidad anticiclónica; mientras está patente en la Hoya de Huesca el efecto de "sombra orográfica” generado por el flujo del nordeste sobre los Pirineos.

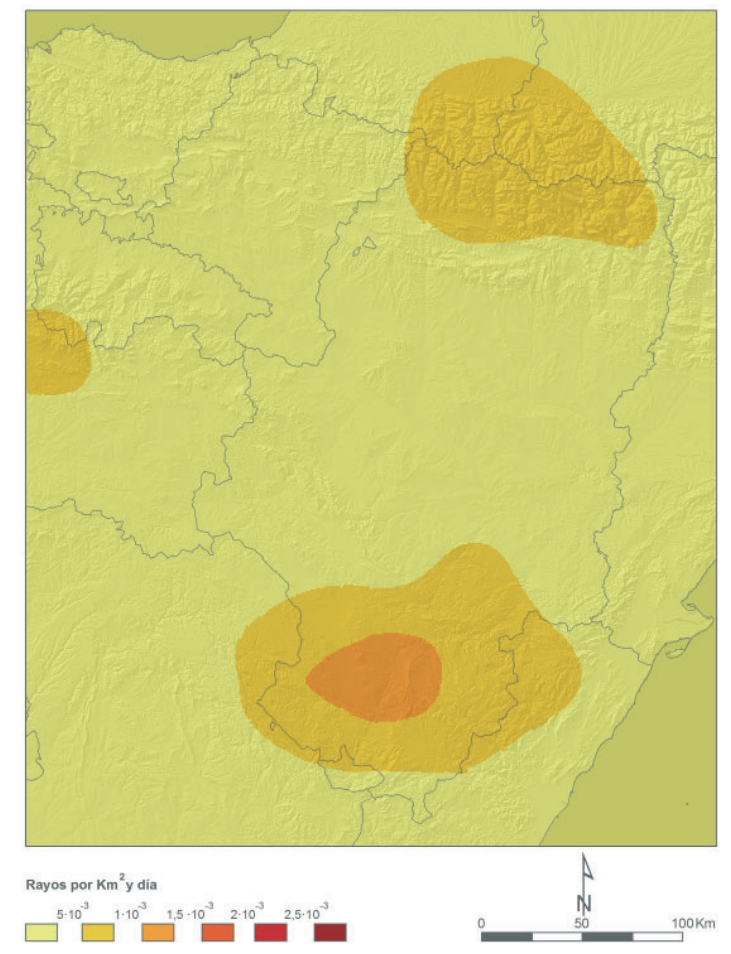

a. Densidad de descargas eléctricas

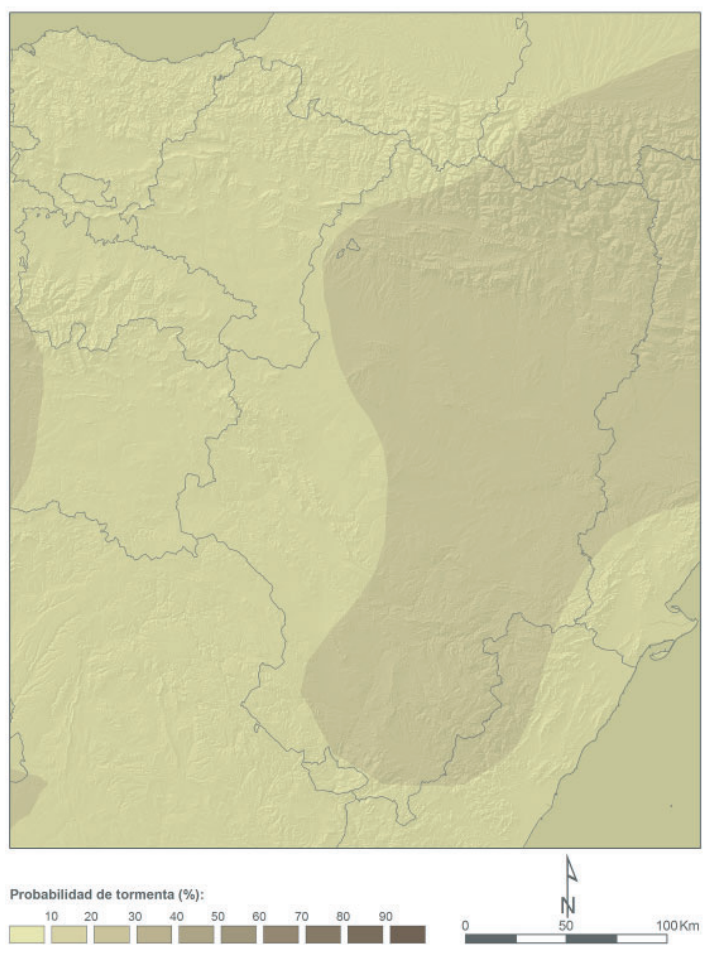

b. Probabilidad de tormentas

Mapa 3.7. Caracterización espacial de la convección en las situaciones depresionarias rebasadas (Tipo 7).

En el Mapa 3.7 lo más representativo es el hecho de que aunque siguen pudiéndose producir tormentas en cualquier parte del territorio, estas —en general- totalizan pocas cantidades de rayos aunque, lógicamente, algo superiores en las montañas al norte y, sobre todo, al sur de Aragón. Como cabía esperar, al encontrarnos bajo la influencia de una dorsal, la actividad eléctrica tiene una intensidad y extensión espacial mucho 
menores, quedando restringida a zonas con orografía muy marcada. Asimismo, la probabilidad de tormentas se halla desplazada hacia el este del área de estudio por la mayor proximidad de la zona a las bajas presiones.

\subsubsection{Situaciones de ondas largas del noroeste (Tipo 8)}

Este tipo de situaciones se caracteriza por la escasa importancia de la precipitación que se recoge mientras perduran, pues son debidas a la influencia del flujo que se aproxima desde el cuarto cuadrante de la rosa de vientos, después del paso de los sistemas convectivos sobre el área de estudio. Detrás de estos, la situación tiene carácter de dorsal por la progresiva llegada de la nueva onda que avanza desde el Atlántico, además de mostrar un carácter seco y frío de las masas de aire que siguen a los centros de bajas presiones. Estos flujos en niveles medios vienen a reforzar en intensidad y duración el viento de los niveles bajos, que tienen una mayor influencia orográfica, como en el caso del cierzo.
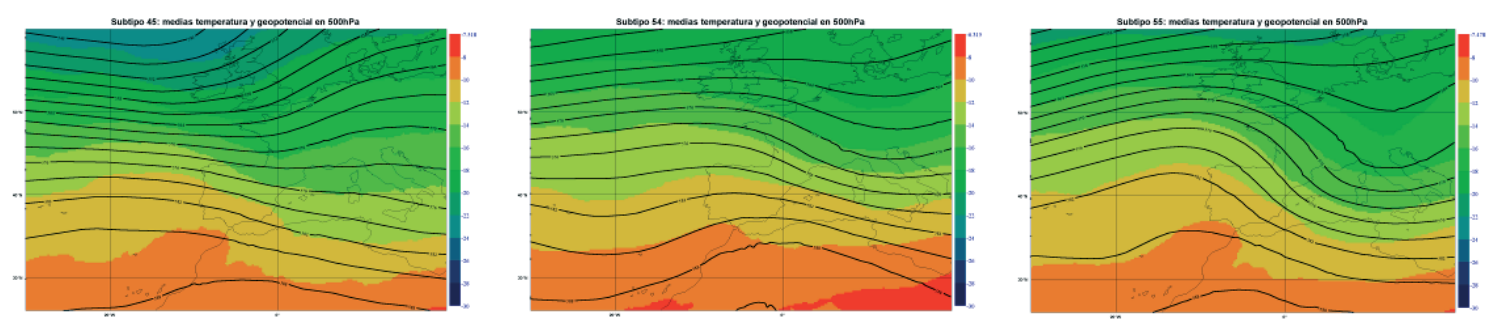

Imagen 3.18. De izquierda a derecha, campos de Z y T en $500 \mathrm{hPa}$ de los Subtipos 45 (W-NW), $54(N W-W)$ y 55 (NW-NW) del Tipo 8 (situaciones de ondas largas del noroeste).

El tipo está integrado por los subtipos 45 (W-NW), 54 (NW-W) y 55 (NW-NW) que, como muestra la Imagen 3.18, presentan poca variación entre sí. Sus campos térmicos presentan el mismo patrón con una ligera traslación latitudinal de la masa fría según el caso. A medida que la dorsal se acerca y la situación se vuelve más subsidente, la dirección del viento va rolando levemente hacia el noroeste mientras su gradiente se mantiene con pocas variaciones.

El promedio de los campos de temperatura y geopotencial en $500 \mathrm{hPa}$ (Imagen 3.19) refleja la similitud entre los tres subtipos componentes y muestra la onda larga del noroeste, con su eje de vaguada rebasado sobre el área de estudio, y fuertemente barotrópica sobre la misma.

La precipitación (Imagen 3.19) con valores muy bajos, prácticamente presenta un campo plano, solo ligeramente realzado en la zona de influencia cantábrica de Navarra. Esta precipitación tiene un carácter absolutamente estratiforme, como se puede corroborar con ayuda del Mapa 3.8.

La actividad eléctrica es muy escasa, solo ligeramente favorecida en algunas zonas montañosas con influencia mediterránea de la Ibérica turolense, especialmente, y del Pirineo más oriental (Mapa 3.8). 

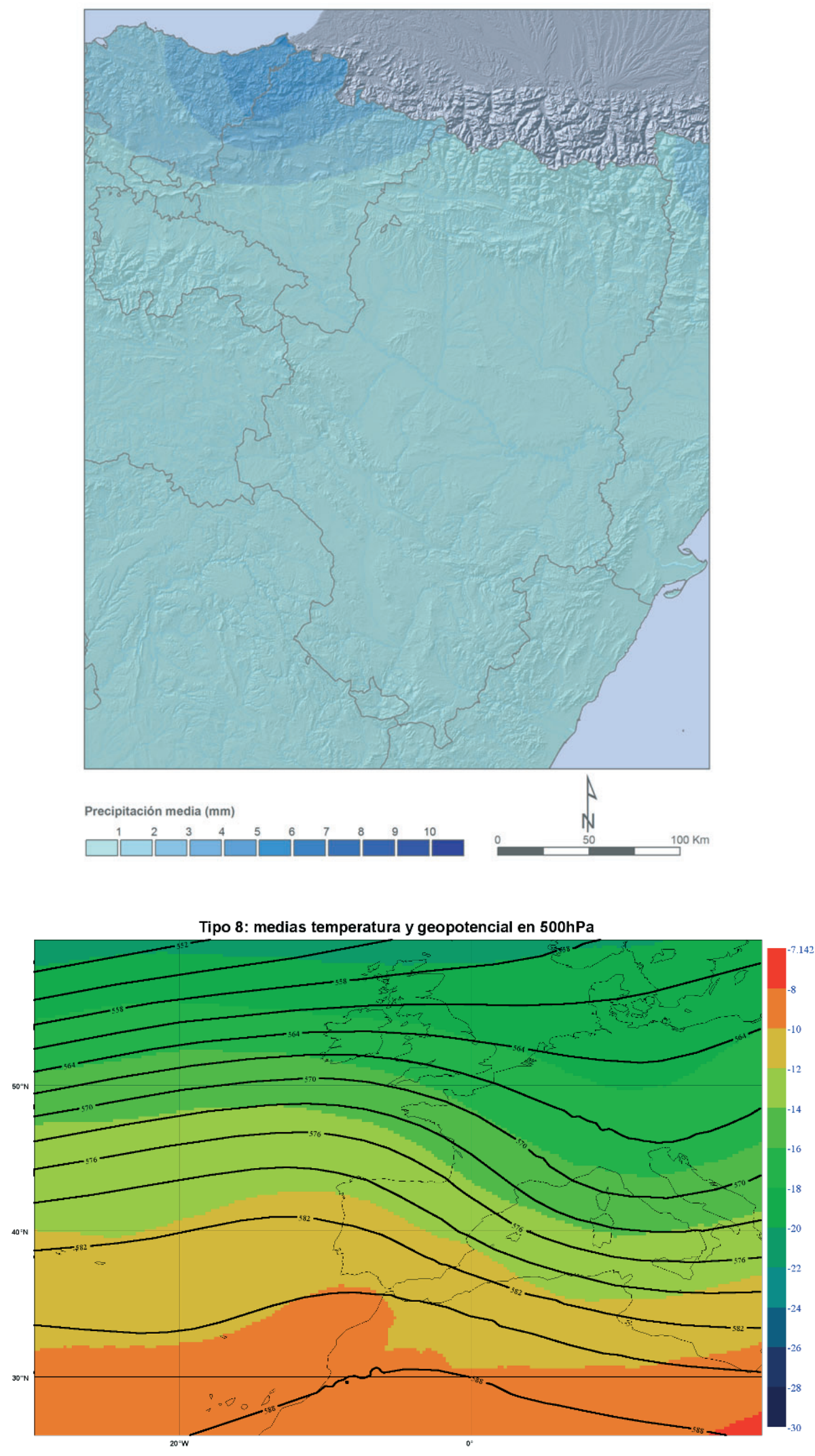

Imagen 3.19. Tipo 8, situación de ondas largas del noroeste: mapa de distribución media de las precipitaciones y promedio de los campos de $T$ y $\mathrm{Z}$ en $500 \mathrm{hPa}$. 


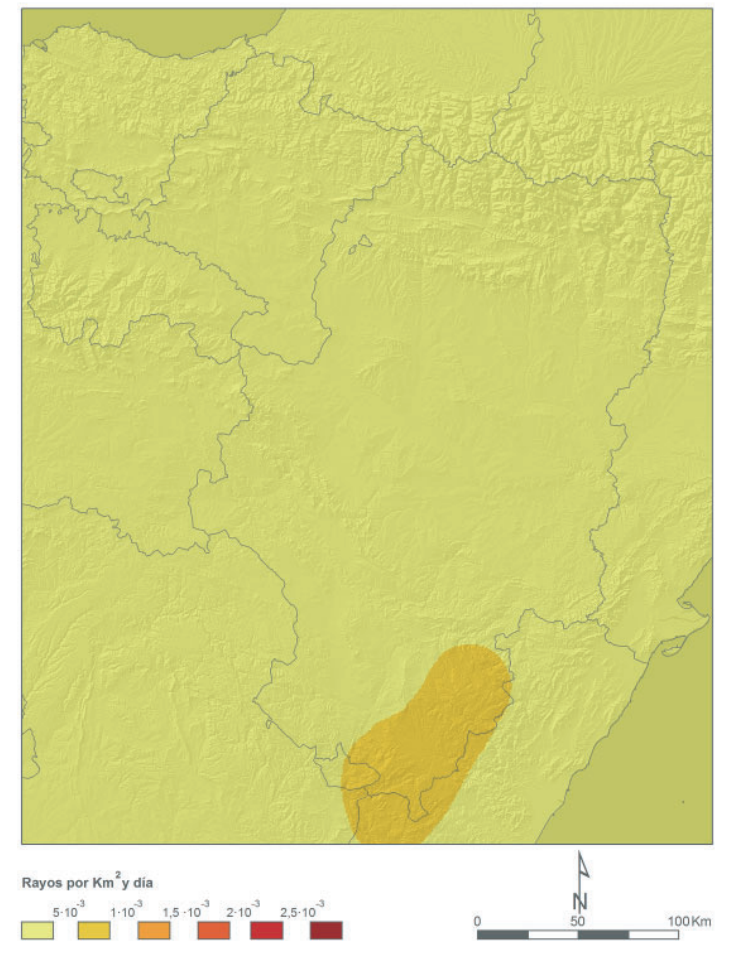

a. Densidad de descargas eléctricas

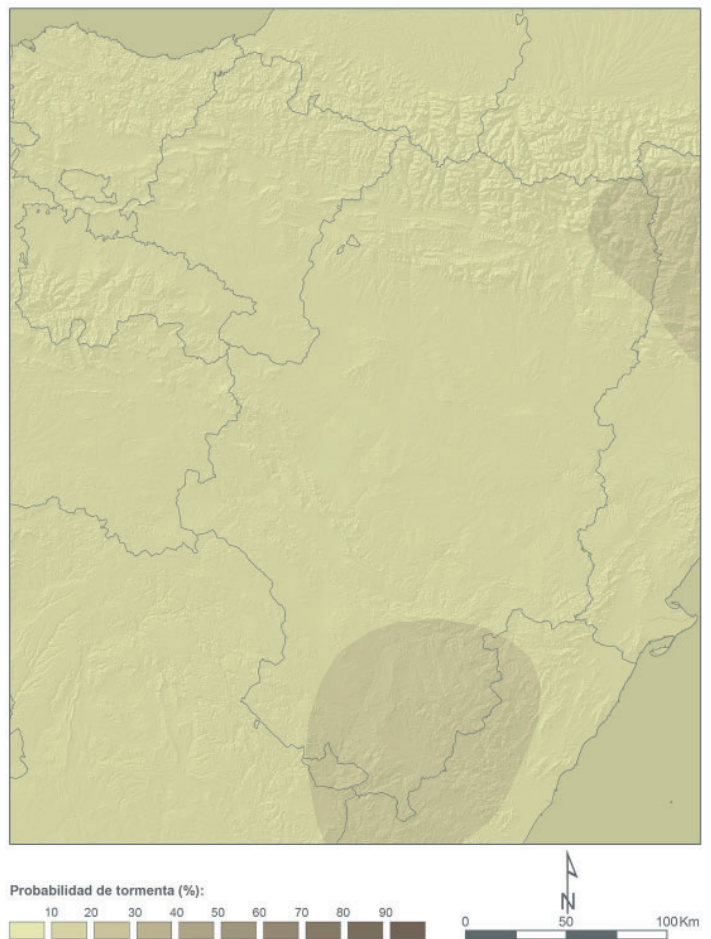

b. Probabilidad de tormentas

Mapa 3.8. Caracterización espacial de la convección en las situaciones de ondas largas del noroeste (Tipo 8).

\subsubsection{Situaciones de oclusiones a vaguadas rebasadas (Tipo 9)}

El Subtipo 25 (S-NW) corresponde a una vaguada en forma de V que ve impedido su avance por la potente dorsal anticiclónica sobre Centroeuropa, con la consecuencia de que el frente frío alcanza progresivamente al frente cálido precedente y retenido, dando lugar a una oclusión. En esta situación, el borde oriental de la Cordillera Cantábrica y los Pirineos occidentales canalizan el flujo hacia el valle del Ebro que se ve afectado por la oclusión. Estas oclusiones pueden dar lugar a precipitaciones caracterizadas por la persistencia más que por la severidad (Imagen 3.20).
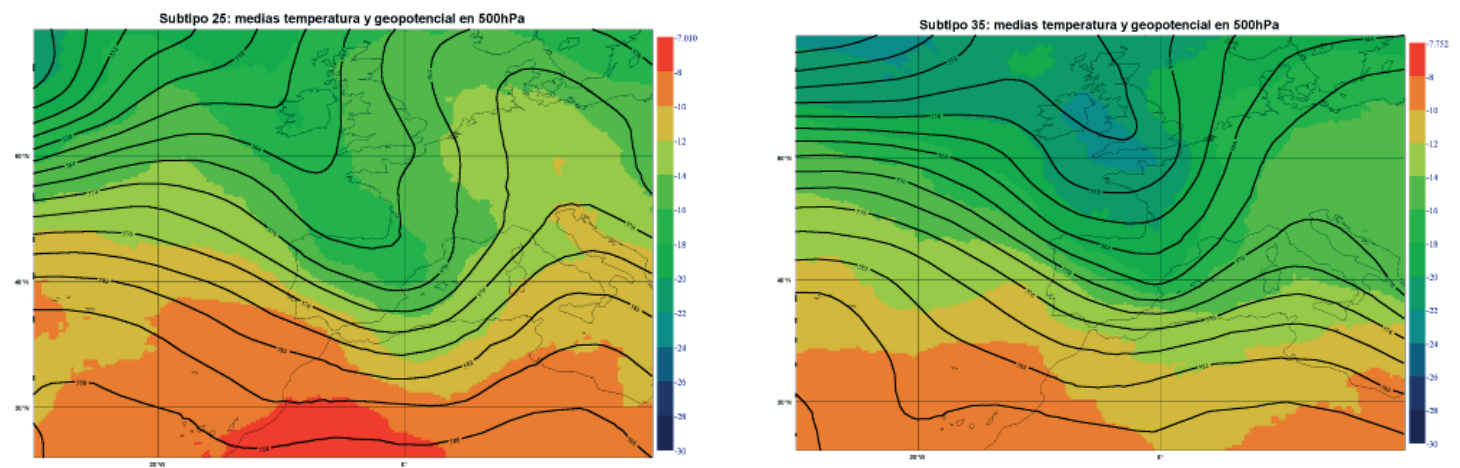

Imagen 3.20. De izquierda a derecha, campos de T y Z en 500 hPa para los Subtipos 25 (S-NW) y 35 (SW-NW) del Tipo 9 (situaciones de oclusiones a vaguadas rebasadas). 
El Subtipo 35 (SW-NW) presenta una situación parecida, aunque con valores más altos en el campo de temperaturas y sobre todo un flujo más zonal, con un mayor carácter marítimo atlántico, en el que el frente no llega prácticamente ocluido, sino que se ocluye sobre la zona de estudio.

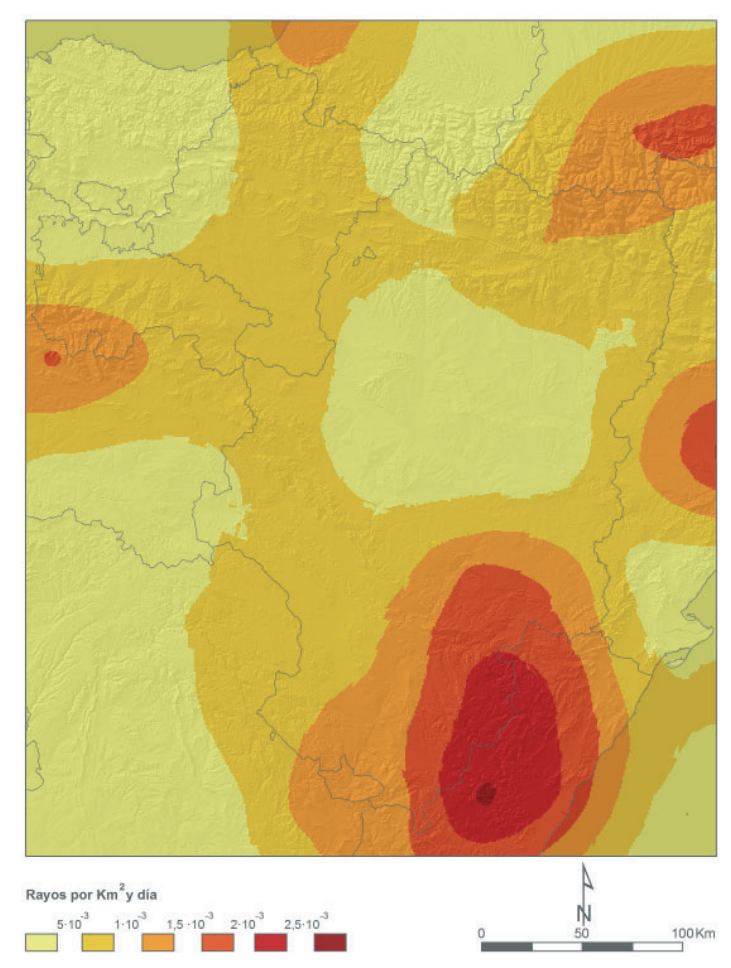

a. Densidad de descargas eléctricas

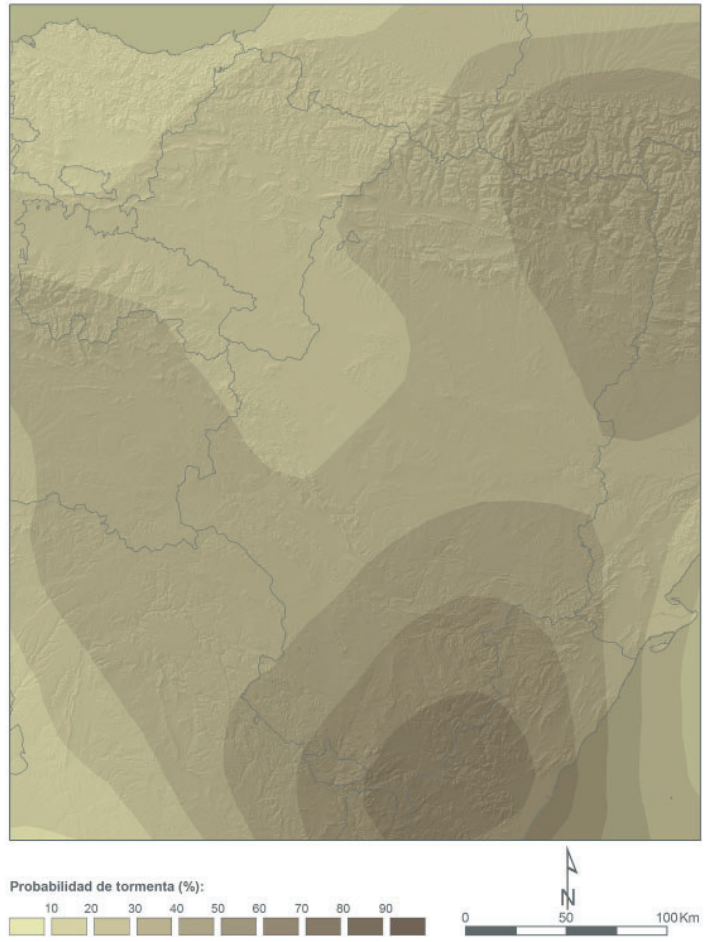

b. Probabilidad de tormentas

Mapa 3.9. Caracterización espacial de la convección en las situaciones de oclusiones a vaguadas rebasadas (Tipo 9).

La Imagen 3.21 muestra el resumen de estas situaciones, debiendo hacerse notar que la oclusión propiamente dicha no tiene por qué deberse a un potente anticiclón de retención, sino que puede ser el resultado del proceso oclusivo normal al que se ven sometidos la mayoría de los frentes asociados a los sistemas depresionarios de latitudes medias. Si su estado determina que se produzca dicha oclusión cuando los frentes se desplazan sobre el área de estudio, esta fácilmente se verá atrapada entre el Sistema Ibérico y los Pirineos, de tal manera que dejará toda su precipitación en la depresión del Ebro, cuyos episodios más intensos pueden durar más de un día. Los sistemas montañosos acumulan las mayores cantidades de precipitación, destacando la cornisa cantábrica por la retención en sus laderas norte y los Pirineos centrales por la retención en las laderas sur. El flujo de componente oeste también afecta al Sistema Ibérico, con episodios en los que se recogen grandes cantidades en los ríos de la margen derecha del Ebro, como el Jalón, Jiloca o Huerva, en los que se acoplan los sistemas nubosos que acaban llevando la precipitación al campo de Zaragoza. 

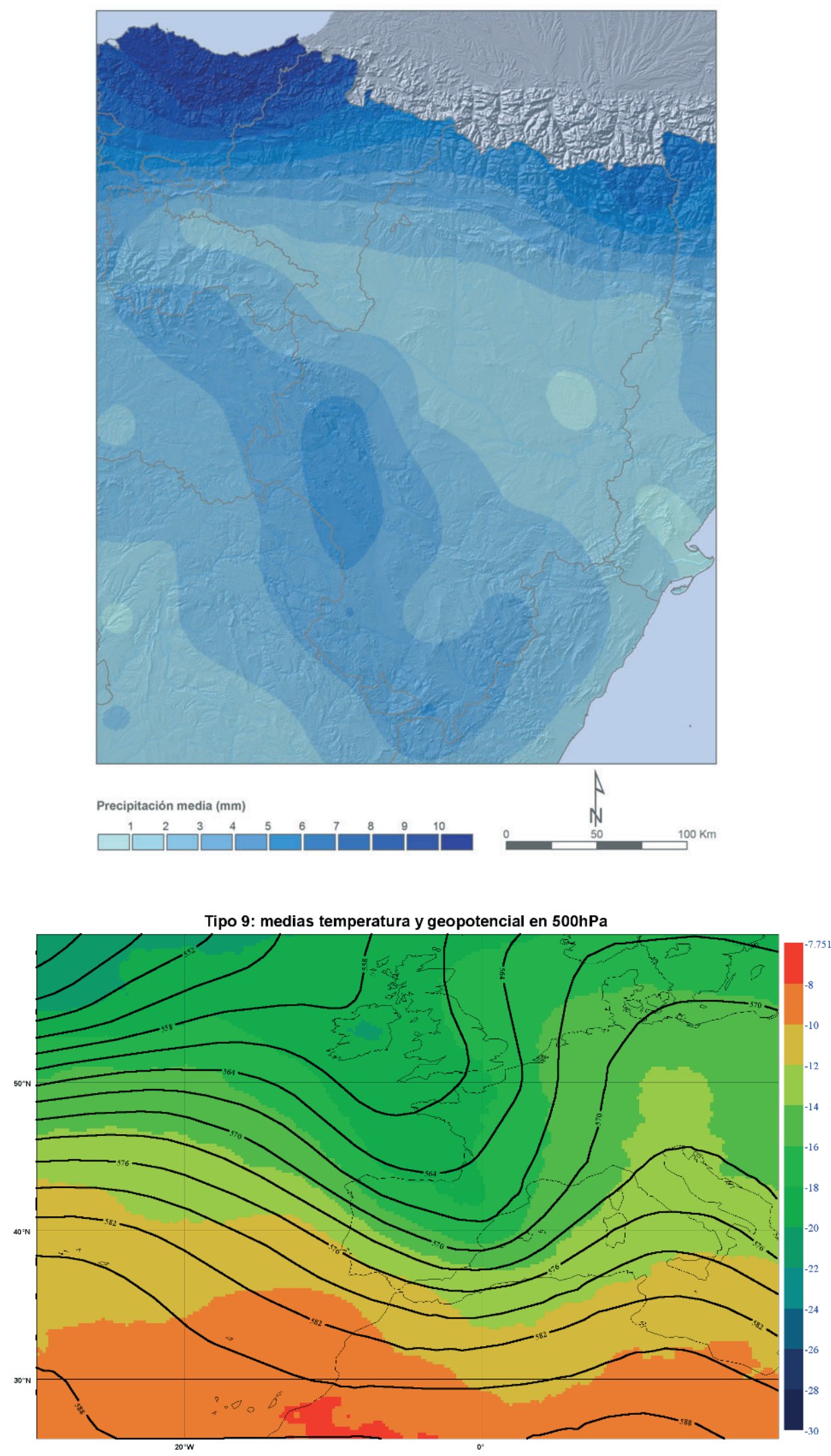

Imagen 3.21. Tipo 9, situación de oclusión a vaguada rebasada: mapa de distribución media de las precipitaciones y promedio de los campos de T y Z en $500 \mathrm{hPa}$. 
La distribución de la densidad de descargas (Mapa 3.9a) muestra similitudes con las situaciones del sur, del suroeste o incluso con las varias etapas del paso de depresiones, debido a que al tratarse de un proceso oclusivo los vientos cambian rápidamente de dirección y presentan cizalladuras muy fuertes. Aunque pueden producirse tormentas en cualquier parte del cuadrante nordeste, son más frecuentes y poseen mayor eficiencia eléctrica las situadas en la zona oriental debido a la influencia mediterránea, muy especialmente sobre la sierra de Javalambre y la cuenca alta del Mijares (Mapa 3.9b). La comparación entre el mapa de la Imagen 3.21 y los Mapas 3.9a y 3.9b discrimina perfectamente la precipitación estratiforme del litoral cantábrico de la predominantemente convectiva sobre los Pirineos y la Ibérica.

\subsection{Distribución temporal}

En la Imagen 3.22 se representa la distribución de frecuencias de las situaciones tipo por mes para el periodo considerado de temporadas 2002-2008, en comparación con el total. Se puede tener una impresión global de las características de todas las situaciones en la Imagen 4.5 del apartado siguiente. Lo primero que cabe destacar es la relativamente baja frecuencia (inferior al $10 \%$ ) de las situaciones consideradas de masa de aire, que revela una elevada importancia de las situaciones dinámicas en la meteorología local. La situación dominante durante todos los meses y en general para toda la temporada es, como cabía esperar, la de ondas largas del noroeste, con una frecuencia del orden del 30 \%. Esta situación, así como la del oeste, que también tiene una frecuencia general y mensual del orden del $20 \%$, está relacionada con situaciones anticiclónicas y por lo tanto predominantemente estables.

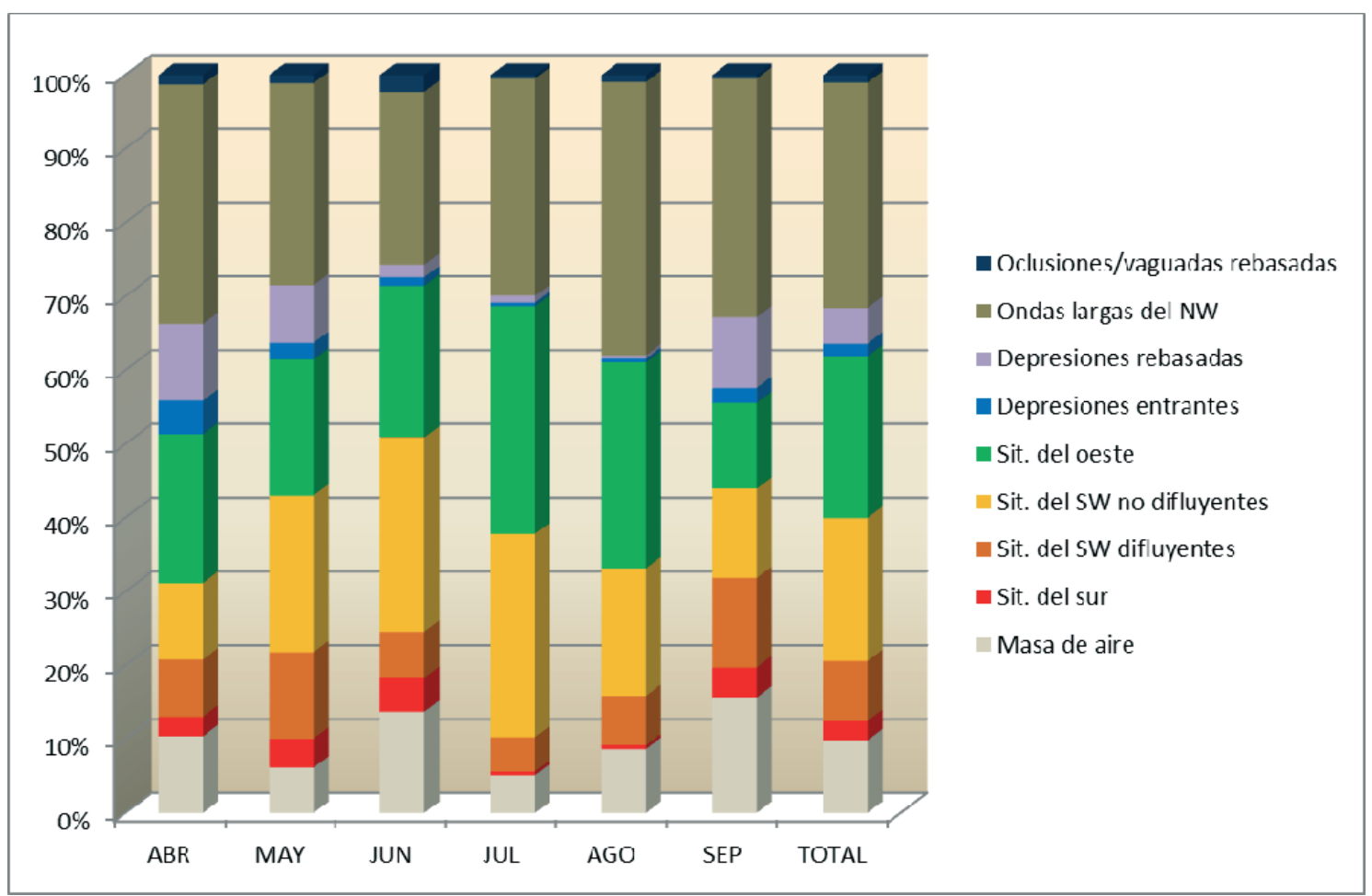

Imagen 3.22. Distribución mensual de frecuencias de situaciones. 
Por otro lado, las situaciones que más precipitación y convección aportan: las del sur, suroeste con difluencia, depresiones entrantes y oclusiones a vaguadas rebasadas tienen, lógica - $\mathrm{y}$ afortunadamente, en bastantes casos - una frecuencia menor, que en total superan con poco el $10 \%$ y que en los meses centrales del verano — cuando la disponibilidad energética es máxima para que estas situaciones produzcan fenómenos de tiempo severo- es inferior a ese umbral. El 35-40 \% restante de los días se clasifica en otras situaciones con un comportamiento intermedio en cuanto a la convección, aunque por lo general de carácter débil, llamando la atención el elevado porcentaje de situaciones del suroeste sin difluencia.

Es igualmente interesante destacar la deriva existente desde situaciones más dinámicas presentes durante los meses primaverales, con una relativamente alta frecuencia de paso de depresiones y situaciones del sur y, sobre todo, del SW con difluencia, hacia la mayor frecuencia de situaciones estáticas en los meses centrales del verano. En septiembre aumenta muy considerablemente la frecuencia de situaciones dinámicas, destacando en particular el acusado aumento de situaciones de depresiones rebasadas que, en realidad, corresponden a bajas presiones formadas sobre el Mediterráneo.

En cualquier caso, la distribución entre temporadas de las frecuencias dista de ser homogénea (Imagen 3.23). En particular, las potencialmente peligrosas situaciones del sur tienen una acusada variabilidad de frecuencia entre unas temporadas y otras, al igual que el paso de depresiones. Otras situaciones, como las del suroeste con o sin difluencia, las del oeste y las oclusiones a vaguadas rebasadas mantienen una frecuencia relativamente estable entre temporadas. Por último, las ondas largas del noroeste, pese a su elevada frecuencia, también pueden presentar variaciones relativas entre temporadas del orden del $100 \%$.

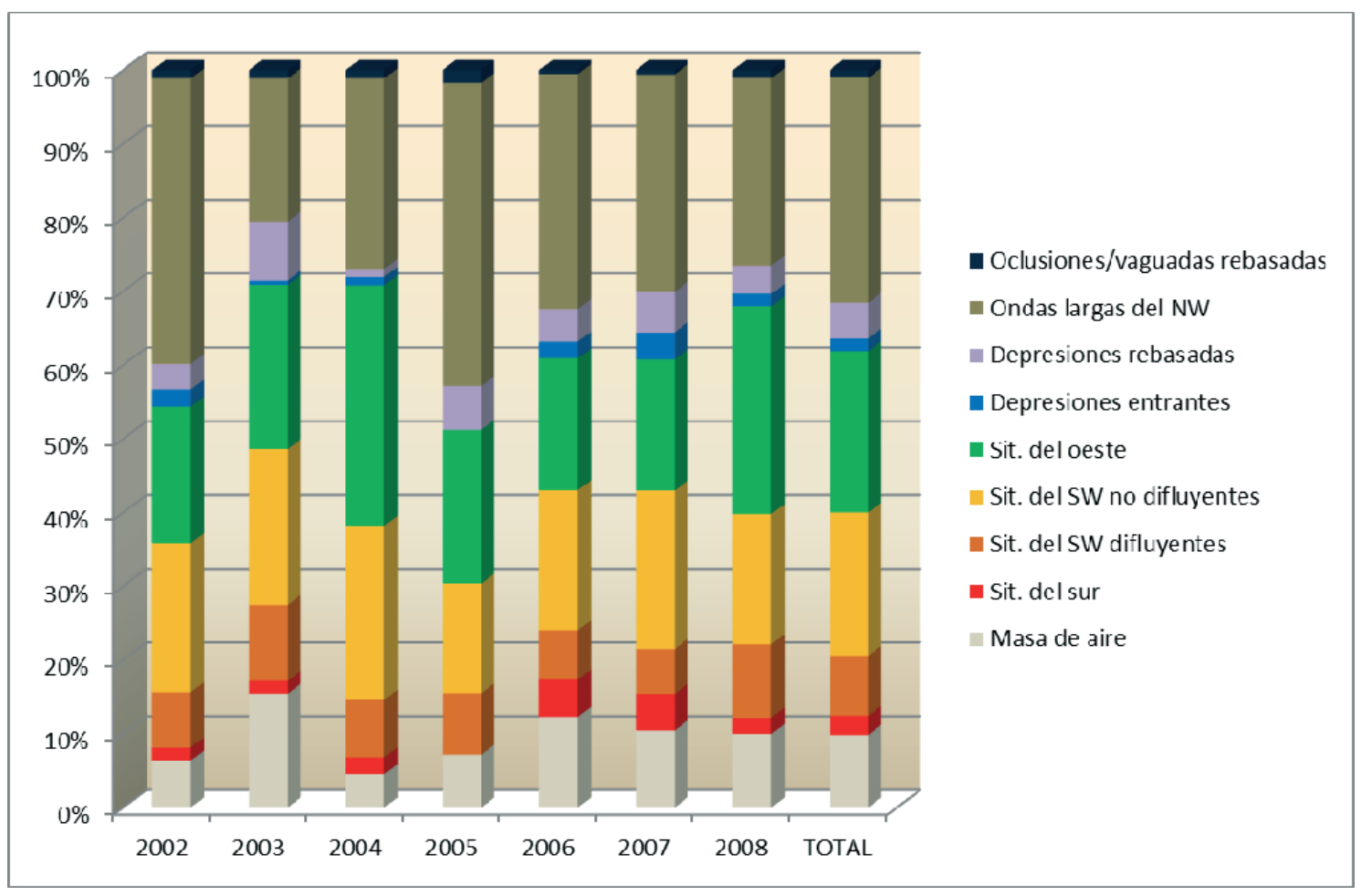

Imagen 3.23. Distribución por temporada de frecuencias de situaciones. 
CARACTERIZACIÓN SINÓPTICA DE LOS PROCESOS CONVECTIVOS...

Obviamente, la dispersión que aparece entre temporadas en número de descargas recibidas (Imagen 2.7 y Mapa 2.4) y en número de días de tormenta (Imagen $2.10 \mathrm{y}$ Mapa 2.6), responde a estas variaciones en la frecuencia de las situaciones. 


\section{ESTUDIO DE LA RELACIỐN ENTRE PRECIPITACIÓN Y ACTIVIDAD ELEECTRICA}

En los capítulos anteriores se ha planteado el problema de discriminar entre la precipitación y la precipitación asociada a la convección (precipitación convectiva frente a la estratiforme). El origen de los datos con los que se trabaja en este estudio no permite discriminar entre ambas, por lo que este capítulo se dedica al estudio en primera aproximación entre la precipitación total y la convectiva, a través del total de precipitación y la producida durante las tormentas, que tampoco es toda la precipitación convectiva, puesto que los chubascos, sin actividad eléctrica, no se pueden contemplar.

\subsection{Medidas de correlación}

Una vez obtenidos los datos de precipitación para cada punto, y analizados territorialmente para el periodo comprendido entre los meses de abril a septiembre de 2002 a 2008, se han relacionado con el estudio de descargas eléctricas ocurridas en el mismo periodo de tiempo. Nótese que en este apartado solo se van a tener en cuenta aquellos puntos que caen sobre el territorio español y se descartarán aquellos que se sitúan sobre el mar o Francia.

Tabla 4.1. Estadísticos descriptivos de cada distribución. Los datos se expresan en descargas eléctricas medias (número de rayos) y precipitación media $(\mathrm{mm})$ por día, y cuadrícula de $0,5^{\circ} \times 0,5^{\circ}$.

\begin{tabular}{|c|c|c|c|}
\hline & Estadístico & Valor & Error típico \\
\hline \multirow{7}{*}{\begin{tabular}{l}
0 \\
0 \\
\multirow{2}{*}{}
\end{tabular}} & Media & 7,60 & 0,17 \\
\hline & Mediana & 0,00 & \\
\hline & Varianza & 1888,81 & \\
\hline & Mínimo & 0,00 & \\
\hline & Máximo & 1732,00 & \\
\hline & Asimetría & 12,08 & 0,01 \\
\hline & Curtosis & 226,72 & 0,02 \\
\hline \multirow{7}{*}{ 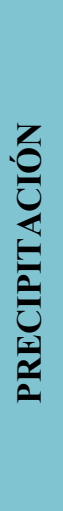 } & Media & 1,52 & 0,02 \\
\hline & Mediana & 0,00 & \\
\hline & Varianza & 21,67 & \\
\hline & Mínimo & 0,00 & \\
\hline & Máximo & 161,00 & \\
\hline & Asimetría & 6,45 & 0,01 \\
\hline & Curtosis & 74,48 & 0,02 \\
\hline
\end{tabular}


Es necesaria la caracterización estadística de ambas variables para conocer su naturaleza y su distribución espacial. Se ha realizado el estudio estadístico para cada cuadrícula de $0,5^{\circ} \times 0,5^{\circ}$ en la que se divide el área de estudio (Tabla 4.1). Los resultados para los datos del estudio muestran una media por cuadrícula de 7,6 rayos y $1,52 \mathrm{~mm}$ de precipitación diarios. Los máximos para una cuadrícula se alcanzan en 1732 descargas eléctricas y $161 \mathrm{~mm}$ de precipitación.

El estadístico utilizado para cuantificar la fuerza de la relación lineal entre dos variables cuantitativas como los rayos y la precipitación es el coeficiente de correlación lineal de Pearson, siempre que ambas variables tengan una distribución normal. Dicho coeficiente oscila entre +1 y -1 . Un valor cercano a 1 en valor absoluto, indica una relación lineal muy fuerte y una correlación próxima a cero indica que no hay relación lineal entre las dos variables. Si los datos no tienen una distribución normal, se calcula un coeficiente de correlación no paramétrico (coeficiente de correlación de Spearman) que tiene el mismo significado e interpretación que el coeficiente de correlación de Pearson y se calcula utilizando el rango de las observaciones (CANAVOS, 2003).

Con el fin de abarcar el estudio correlacional de manera adecuada es necesario, por tanto, determinar en primer lugar si las variables descargas eléctricas y la precipitación siguen una distribución normal o no. Para ello se aplica la prueba de KolmogórovSmirnov a ambas, que es el test de normalidad más extendido en la práctica. Dicho test se basa en la idea de comparar la función de distribución acumulada de los datos observados con una distribución normal, midiendo la máxima distancia entre ambas curvas. Este test de normalidad arroja los resultados mostrados en la Tabla 4.2.

Tabla 4.2. Test de normalidad Kolmogórov-Smirnov para las variables RAYOS Y PCP.

\begin{tabular}{|c|c|c|c|}
\cline { 2 - 4 } \multicolumn{1}{c|}{} & Estadístico & Grados de libertad & Significación \\
\hline RAYOS & 0,435 & 63168 & 0,000 \\
\hline PCP & 0,372 & 63168 & 0,000 \\
\hline
\end{tabular}

La hipótesis nula del test de Kolmogórov-Smirnov asume que la variable a contrastar se distribuye normalmente, frente a la alternativa que niega esta característica. Dado que el grado de significación obtenido (probabilidad de error al rechazar la hipótesis nula) al realizar el test para ambas variables es 0,000 (Tabla 4.2), se rechaza la hipótesis de normalidad para las dos.

Una vez comprobada la no-normalidad de las variables, se descarta el uso del estadístico de correlación habitual para variables continuas (Pearson) y, como se ha comentado al principio de esta sección, es conveniente utilizar el más adecuado para distribuciones no normales, el coeficiente de correlación de Spearman, $\rho$ (rho), que describe la intensidad de relación entre dos conjuntos de variables aleatorias continuas. Los valores resultantes oscilan entre $-1 \mathrm{y}+1$, e indican las asociaciones entre los dos grupos de variables positivas o negativas según el signo. Cuando el resultado es 0 significa que no existe correlación alguna.

El cálculo del coeficiente de correlación de Spearman $(\rho)$ para dos variables X e Y viene dado por: 


$$
\rho=1-\frac{6 \sum D_{i}^{2}}{n\left(n^{2}-1\right)}
$$

donde $D_{i}=\mathrm{r}_{\mathrm{xi}}-\mathrm{r}_{\mathrm{yi}}$ es la diferencia entre los rangos de $\mathrm{X}$ e $\mathrm{Y}$ para $\mathrm{i}=1, \ldots, \mathrm{n}$ siendo $\mathrm{n}$ el número de datos del estudio.

\subsubsection{Correlación mensual}

La correlación por meses se muestra en los datos recogidos en la Tabla 4.3 y la Figura 3.24 , donde se observa que los meses de junio y julio $(0,570$ y 0,575 respectivamente) son aquellos en los que la precipitación está más asociada a las tormentas. Abril es el mes en el que menor correlación aparece con 0,402. El valor de correlación general para los 6 meses considerados es de 0,504, una cifra significativa para el tipo de estudio realizado en el que se busca precisamente esta asociación entre los rayos y la precipitación en los meses del semestre cálido del año.

Tabla 4.3. Correlación precipitación-descargas por meses (abril a septiembre).

\begin{tabular}{|c|c|c|}
\cline { 2 - 3 } \multicolumn{1}{c|}{} & Rho Spearman & núm. de casos \\
\hline GENERAL & 0,504 & 63168 \\
\hline Abril & 0,402 & 8624 \\
\hline Mayo & 0,464 & 10024 \\
\hline Junio & 0,570 & 9800 \\
\hline Julio & 0,575 & 11984 \\
\hline Agosto & 0,546 & 11648 \\
\hline Septiembre & 0,527 & 11088 \\
\hline
\end{tabular}

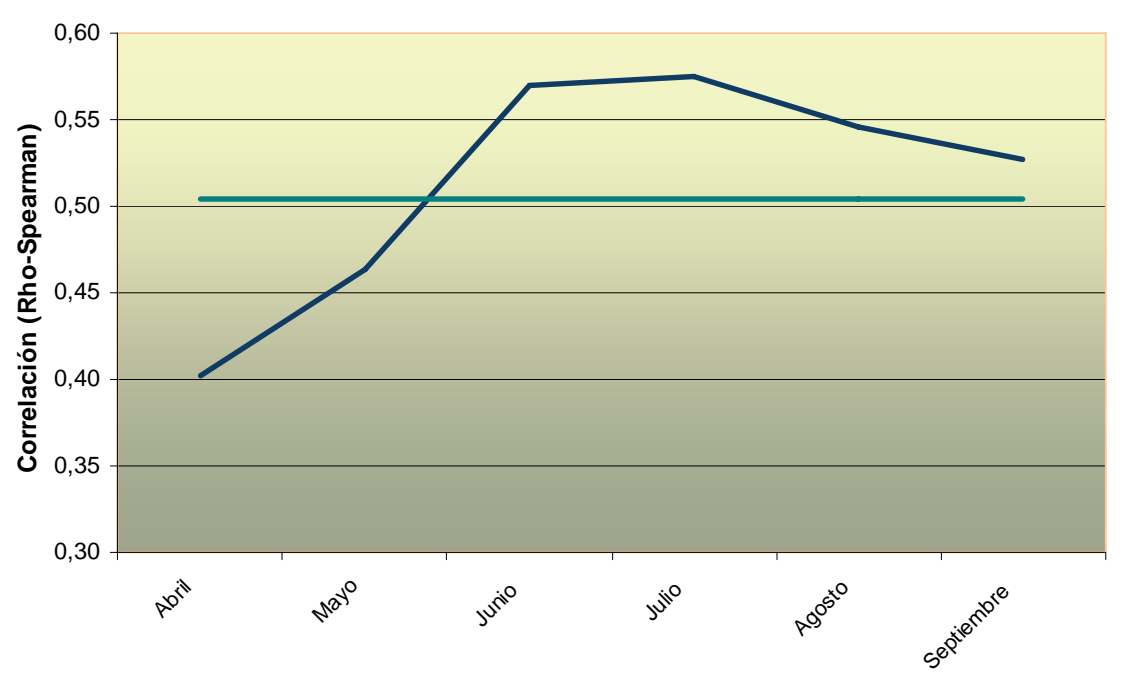

Imagen 3.24. Correlación mensual precipitación-descargas.

Conviene recordar que el Mapa 1.6a mostrado en la introducción hace referencia al porcentaje de precipitación en los meses estivales (junio, julio y agosto) sobre el total anual. En él se observa que, para toda el área de estudio, el porcentaje de lluvia caída sobre el total anual en estos meses (más secos) es tan solo de un $18,75 \% \mathrm{y}$, tras este último análisis, se concluye que esa precipitación está más relacionada con las tormentas, lo que justifica la importancia del papel de la convección. 


\subsubsection{Correlación por situaciones}

Se ha estudiado la relación entre precipitación y descargas eléctricas de manera más profunda, pormenorizándola según los tipos sinópticos establecidos. La Tabla 4.4 aporta unos resultados en general similares a los de la correlación mensual. El tipo sinóptico que mayor correlación muestra son las situaciones del suroeste sin difluencia con un 0,559. Las situaciones de depresiones rebasadas son las que menor relación muestran entre precipitación y descargas con un 0,325 .

El periodo estudiado comprende las temporadas de abril a septiembre de los años 2002 a 2008. Al no tratarse de una serie de años muy larga es necesario destacar que la relación entre las precipitaciones y las descargas por situaciones en estos periodos podría estar condicionada a la cantidad de veces que se han dado estas situaciones. Por ejemplo, tal y como se muestra en la Tabla 4.4, el Tipo 4 (que es el que mayor correlación obtiene) se ha dado un $19,4 \%$ de las veces en total (la tercera más común). Sin embargo, los tipos más habituales han sido el 8 y el 5, que han obtenido una correlación de 0,386 y 0,495 respectivamente. Así que las situaciones sinópticas más comunes del nordeste peninsular no son aquellas en las que hay mayor relación entre rayos y precipitación, lo cual parece lógico, pues existe un alto porcentaje de días con estas situaciones que no son propicias a la aparición de rayos.

Tabla 4.4. Correlación precipitación-descargas por situaciones.

\begin{tabular}{|c|c|r|c|c|}
\hline TIPO & SITUACIONES & n & $\begin{array}{c}\text { Frecuencia } \\
(\%)\end{array}$ & $\begin{array}{c}\text { Rho } \\
\text { Spearman }\end{array}$ \\
\hline \multicolumn{2}{|c|}{ GENERAL } & 63168 & & 0,504 \\
\hline 1 & Masas de aire & 6216 & 9,84 & 0,484 \\
\hline 2 & Situaciones del sur & 1624 & 2,57 & 0,400 \\
\hline 3 & Sit. del SW difluentes & 5152 & 8,16 & 0,523 \\
\hline 4 & Sit. del SW sin difluencia & 12264 & 19,41 & 0,559 \\
\hline 5 & Situaciones del W & 13832 & 21,90 & 0,495 \\
\hline 6 & Depresiones entrantes & 1064 & 1,68 & 0,386 \\
\hline 7 & Depresiones rebasadas & 3080 & 4,88 & 0,325 \\
\hline 8 & Ondas largas del NW & 19264 & 30,50 & 0,386 \\
\hline 9 & Oclus. a vaguadas rebasadas & 672 & 1,06 & 0,396 \\
\hline
\end{tabular}

Posiblemente la clave para entender la correlación entre precipitación y descargas esté relacionada con las circunstancias meteorológicas y los efectos locales que caracterizan a cada situación. Es decir, si los sistemas son estacionarios o móviles, si están influenciados por factores lejanos a la zona de estudio, si es precisa la focalización de las precipitaciones acompañadas de tormenta, o si los obstáculos del terreno son suficientes para generar precipitación orográfica, entre otros.

A efectos de identificar las diferencias y analogías entre los tipos de situaciones y sus manifestaciones asociadas se muestra en la Tabla 4.5 un resumen de sus características principales. Posteriormente se comentan las características de la correlación para cada situación tipo. El análisis de dicha tabla, si se hace de una forma superficial, implica el riesgo de pensar que las distribuciones de descargas y de precipitación son muy parecidas entre sí y que la clasificación establecida no aporta mucho a la hora de discriminar entre las distribuciones espaciales y de intensidad asociadas a cada tipo de situación. No obstante debe puntualizarse que la elevación, orografía, distancia al mar y las características de este, etc. determinan un marco general al cual responden las 
diferentes configuraciones atmosféricas que afectan al área de estudio y dan lugar a las diferencias que se observan. Además, es sabida la gran importancia que estas variaciones locales adquieren en las labores de predicción meteorológica y el partido que el predictor experimentado puede sacar de ellas al relacionar causas y efectos.

En particular, en el Tipo 1 (MA) el coeficiente de correlación es alto por aparecer núcleos tormentosos que suelen ser de reducidas dimensiones y tienen un carácter cuasiestacionario debido a la falta de vectores de desplazamiento importantes. Por lo tanto, su ciclo de vida y meteoros asociados deberían darse prácticamente en el mismo lugar, lo que garantizaría que si se producen precipitación y descargas, estarán fuertemente correlacionadas y no se daría un fenómeno de deslocalización entre ambas. Así se muestra en la Tabla 4.5 donde se comparan los mapas de precipitación, densidades de descargas y la probabilidad de ocurrencia de tormenta. En la Ibérica turolense se observa que existe mayor semejanza entre las distribuciones de precipitación y densidades de descargas que la que se produce con la de ocurrencia de tormentas. Esto se debe a que incluso este tipo de tormentas experimentan un ligero desplazamiento buscando las fuentes de humedad en el Mediterráneo, alcanzando su madurez en las sierras más orientales de Javalambre y Gúdar mostradas en el mapa de densidad de descargas, mientras que el mapa de ocurrencia de rayos (de probabilidad de tormenta) estaría asociado a las pequeñas tormentas de calor propiamente dichas que se dan en los ya mencionados "nidos de tormentas" del nacimiento del Tajo y la sierra de Gúdar. Por el contrario, en el Pirineo las correspondencias entre las tres imágenes son llamativas, así como en las Sierras Exteriores pirenaicas y el resto del Sistema Ibérico.

No obstante, puede darse el caso de que solamente se produzca una de las dos manifestaciones (precipitación o descargas) con correlación nula y las causas habría que buscarlas en el estado particular de las células tormentosas, su fase de desarrollo y en su interacción con el entorno. Un ejemplo de este hecho se da en la vertiente cantábrica de Navarra, donde la abundancia de precipitación no está en correspondencia con las descargas, sin duda debido a la alta frecuencia con la que se produce precipitación estratiforme acumulada por el arrastre de las brisas o por flujos del norte que sortean las alturas pirenaicas por su borde occidental.

En caso de situaciones del sur (Tipo 2), dada la larga extensión de las áreas afectadas por la precipitación, las cantidades recogidas en una zona tienen un carácter mucho más convectivo que las recogidas en otros lugares donde se produce la precipitación con posterioridad, cuando mucha de la actividad convectiva ha decaído y se siguen produciendo precipitaciones de tipo estratiforme con menor actividad eléctrica.

Asimismo, en los casos de situaciones del SW (Tipos 3 y 4) con las tormentas localizadas allí donde desde el punto de vista termodinámico son más esperables, es lógico que exista una alta correlación.

Las del oeste (Tipo 5) podrían estar determinadas por las precisas localizaciones de los obstáculos importantes de tipo orográfico (Moncayo y Gúdar-Javalambre) que inestabilizan por ascenso un flujo del oeste que en los meses de verano no acarrea nunca precipitación.

No es este el caso de las depresiones entrantes (Tipo 6), o incluso en algún subtipo de las rebasadas (Tipo 7) cuyo centro de acción queda demasiado lejos al sur y la 
ocurrencia espacial de las tormentas es más aleatoria quedando desplazados los centros de precipitación y los de descargas.

Por el contrario, en caso de las situaciones del NW (Tipo 8) la ocurrencia de precipitación de tipo convectivo es baja, con lo que el número de descargas es pequeño debido a las propias características de la masa de aire post-tormentosa y seca, por lo que la falta de correspondencia también es clara.

Lo mismo ocurre en cuanto a la deslocalización en las situaciones de oclusión (Tipo 9), pues aunque en este caso sí que se producen cantidades muy importantes tanto de descargas como de precipitaciones, los orígenes de la precipitación convectiva en Teruel son diferentes de la estratiforme que se produce en el área noroccidental.

Tabla 4.5. Representación conjunta de las distribuciones de precipitación, densidad de descargas y número de días de tormenta para cada uno de los tipos de situaciones.

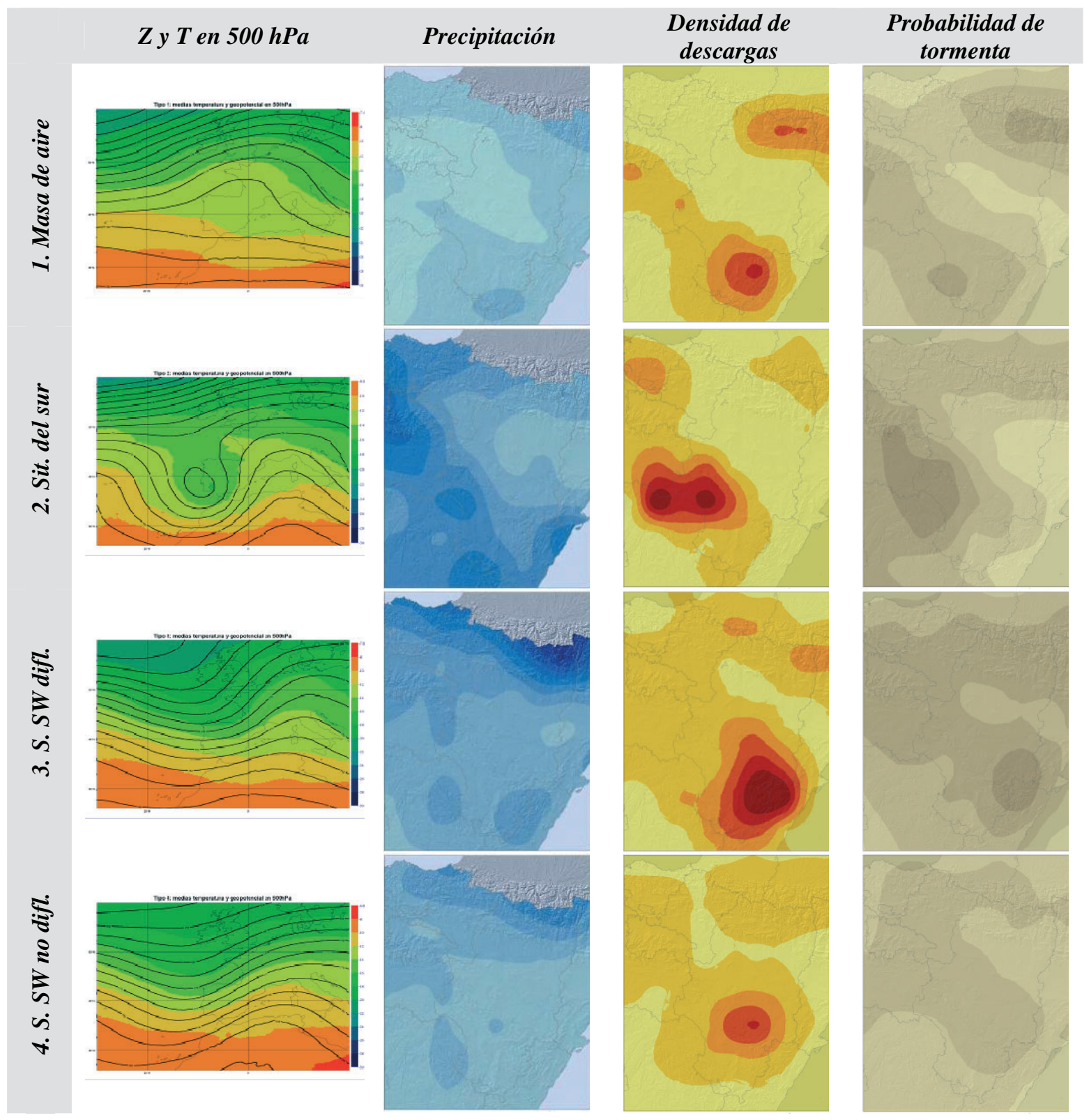




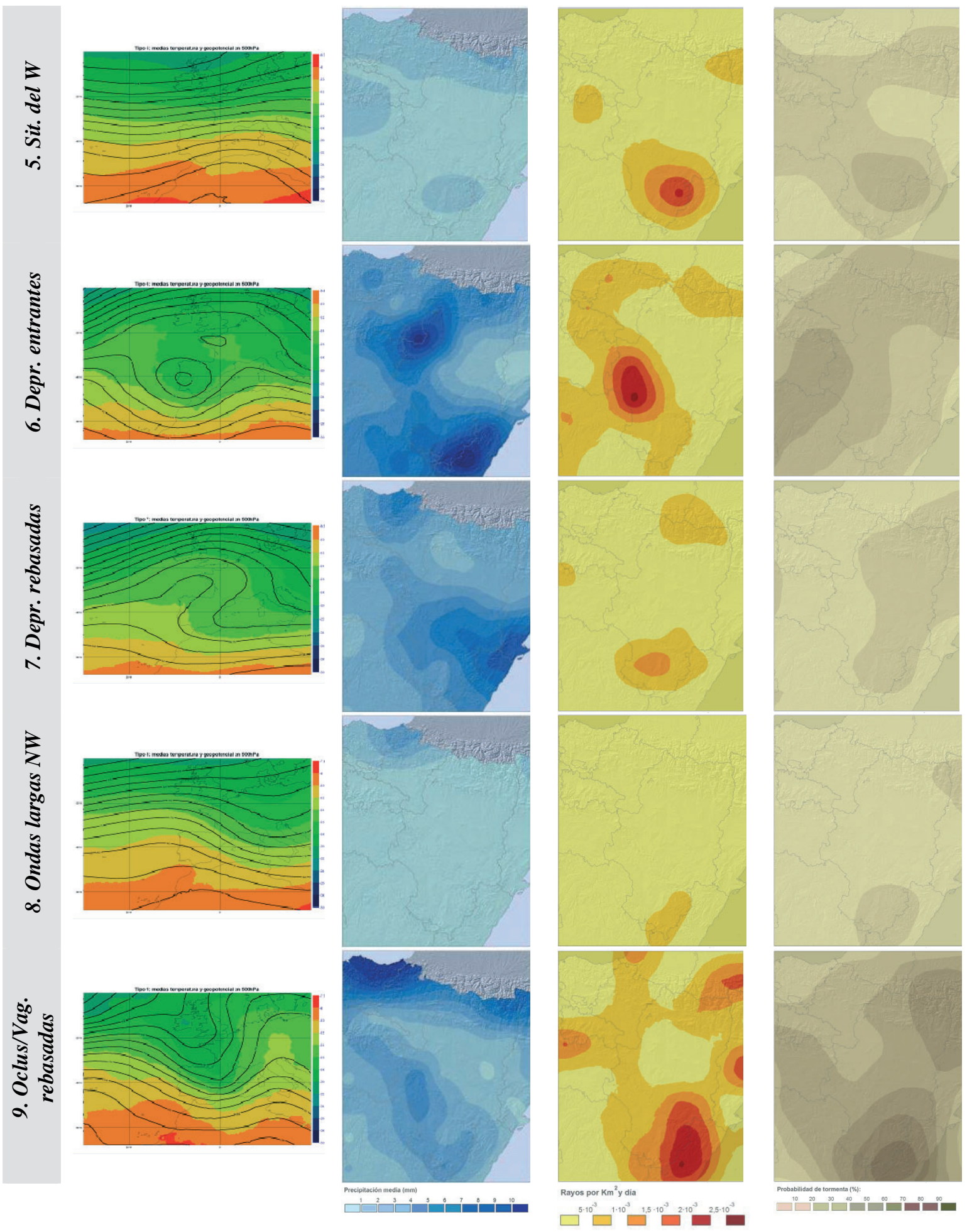

\subsubsection{Correlación geográfica}

Una vez descrita con anterioridad la dependencia de las variables precipitación y descargas, resulta interesante analizar la relación entre ambas a través de al menos un criterio geográfico. 
Para ello se ha llevado a cabo un análisis de conglomerados jerárquico, que se justifica por la distribución geográfica no homogénea de ambas variables (precipitación y rayos), decisivamente influenciada por las características del terreno. Esta clasificación se ha realizado con el software estadístico SPSS 15, que es de uso habitual para el tratamiento de bases de datos, tanto desde el punto de vista de la depuración, como el análisis, clasificación o proyecciones. El proceso comienza con el cálculo de la matriz de distancias entre cada elemento y todos los restantes que configuran la muestra para las variables geográficas consideradas: altitud, latitud, longitud, distancia al Cantábrico y distancia al Mediterráneo. A continuación se buscan los elementos más próximos - es decir, los dos más similares en términos de distancia- y se agrupan en un conglomerado con el fin de obtener una compartimentación adecuada de la zona de estudio (PARDO, 2001).

De las soluciones aportadas por el software se escogió aquella que considera cuatro conglomerados, ya que representa de manera más fiel la distinta influencia de las masas de agua (Cantábrico y Mediterráneo), así como de las cordilleras (Pirineos e Ibérica) y los resultados se muestran en el Mapa 4.1. Hay dos zonas de influencia claramente marítima (cantábrica y mediterránea), y dos zonas de influencia más continental, que se han denominado norte y sur, cuya diferenciación interna seguramente responde a criterios térmicos.

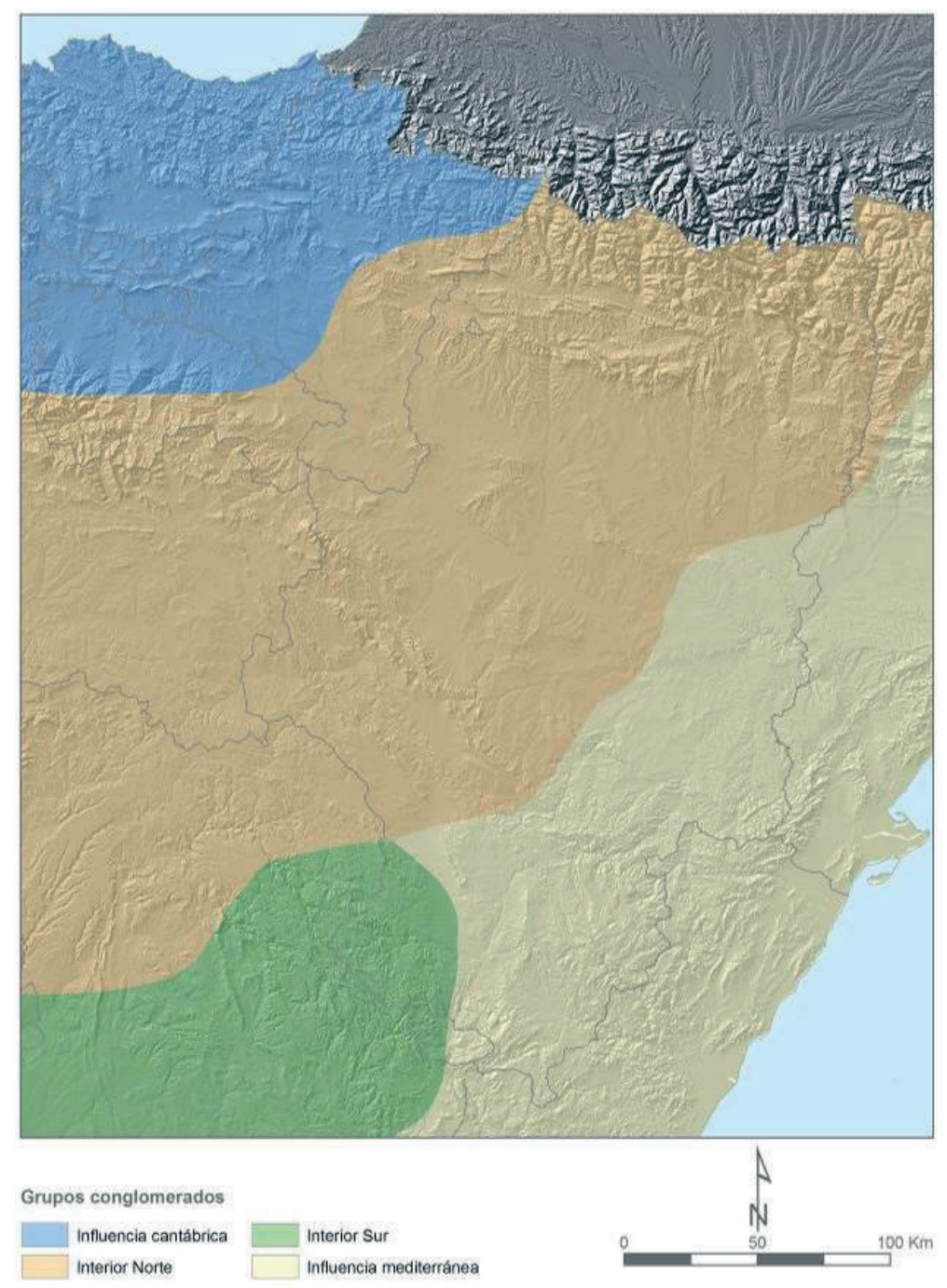

Mapa 4.1. Grupos resultantes del análisis de conglomerados. (Elaboración propia). 
Los resultados de la correlación, mostrados en la Tabla 4.6, señalan una correlación más alta en la zona de influencia mediterránea, especialmente en el este de la provincia de Teruel y su límite con Castellón. Como a priori cabría esperar por la mayor frecuencia de precipitación de origen estratiforme, la zona con menor correlación es la que responde a la influencia cantábrica, aunque las desviaciones con respecto a la media general no son excesivamente altas.

Tabla 4.6. Correlación precipitación-descargas por zonas.

\begin{tabular}{|c|c|r|}
\cline { 2 - 3 } \multicolumn{1}{c|}{} & Rho Spearman & n \\
\hline GENERAL & 0,504 & 63168 \\
\hline Zona 1: Influencia cantábrica & 0,429 & 9024 \\
\hline Zona 2: Interior norte & 0,515 & 30456 \\
\hline Zona 3: Interior sur & 0,509 & 6768 \\
\hline Zona 4: Influencia mediterránea & 0,542 & 16920 \\
\hline
\end{tabular}

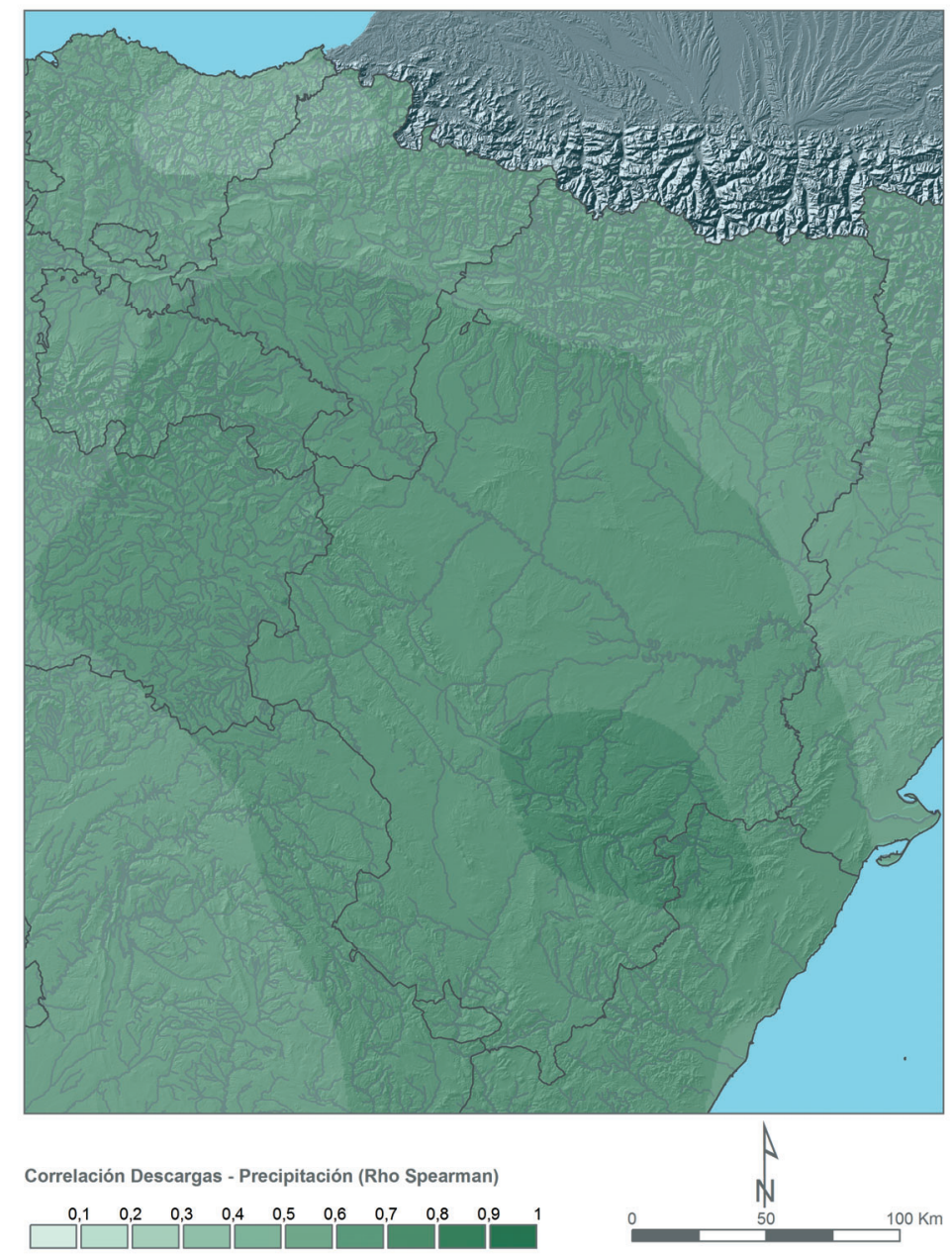

Mapa 4.2. Correlación descargas-precipitación (Rho Spearman). (Elaboración propia).

La representación espacial de la correlación entre precipitación y descargas eléctricas (Mapa 4.2) explica más detalladamente la situación descrita en este capítulo. La correlación de menor intensidad, hasta llegar a cifras poco o nada significativas, se da en el golfo de Vizcaya; esto se debe a que las precipitaciones de esta zona responden en 
mayor medida a otros fenómenos que no son de carácter convectivo. Es inferior a 0,5 en toda la comunidad catalana representada, los Pirineos y las provincias del noroeste y suroeste del área de estudio. La intensidad de la correlación aumenta coincidiendo con el Sistema Ibérico en Soria y Cuenca, el sector central del valle del Ebro y hacia el sur comprendiendo las provincias de Castellón y Teruel. En esta última zona se da la correlación más intensa, superior a 0,6, coincidiendo con el Maestrazgo, donde las precipitaciones del semestre cálido están muy relacionadas con la ocurrencia de descargas eléctricas; área donde (Mapas 1.6a y 1.6b) esta precipitación supone casi dos terceras partes del total anual y, en el caso de la precipitación estival, más de la tercera parte.

\subsection{Medidas de asociación}

Dado que, tal y como se muestra en el Capítulo 2, los valores de la variable precipitación (PRECIPITACION) se obtienen mediante el método de interpolación del Inverso de la Distancia (IDW), asociando al punto central de la cuadrícula de tamaño $0,5^{\circ}$ la media ponderada de todos aquellos registros de precipitación que caen dentro del conjunto de interpolación, mientras que la variable rayos (RAYOS) se obtiene asociando al punto central de la cuadrícula de tamaño $0,5^{\circ}$ el acumulado, y no la media, de todos los rayos que caen dentro de la misma, se ha creído conveniente volver a efectuar un análisis de la relación entre la precipitación y los rayos considerando ambas variables como cualitativas, mediante la categorización de las originales. Como resultado del citado proceso se obtienen las nuevas variables RAYOS_C (variable cualitativa de descargas eléctricas) y PCP_C (variable cualitativa de precipitación), con 3 y 4 categorías respectivamente.

Los criterios para la obtención de las nuevas variables son los siguientes:

- RAYOS C toma valor 0 si RAYOS está dentro del rango $[0,1]$. Es decir, en la cuadrícula no se ha registrado ningún rayo, o a lo sumo 1, que debido a fallos en el sistema de detección de los mismos podría ser un rayo deslocalizado a pesar de las medidas de calidad introducidas a la hora de preparar la base de datos.

- RAYOS_C toma valor 1 si RAYOS está dentro del rango [2, 50]. Este intervalo corresponde a una situación de tormentas débiles, teniendo en cuenta el tamaño de la cuadrícula utilizada (más de $2250 \mathrm{~km}^{2}$ ).

- RAYOS_C toma valor 2 si RAYOS está dentro del rango [51, $\infty$ ). En la cuadrícula caen muchos rayos, correspondientes a tormentas que pueden llegar a ser moderadas o fuertes.

- PCP_C toma valor 0 si PRECIPITACION está dentro del rango [0,0]. En la cuadrícula no se ha registrado precipitación alguna.

- PCP_C toma valor 1 si PRECIPITACION está dentro del rango $(0,3]$. El valor de precipitación asociado al punto central de la cuadrícula varía entre 0 y $3 \mathrm{~mm}$ de media, es decir, precipitaciones, en general, de débiles a moderadas.

- PCP_C toma valor 2 si PRECIPITACION está dentro del rango $(3,10]$; este intervalo puede corresponder a precipitaciones moderadas con una extensión espacial apreciable.

- PCP_C toma valor 3 si PRECIPITACION está dentro del rango $(10, \infty)$. Para tener unos valores medios de esta magnitud en esta categoría puede ser necesaria la presencia de precipitaciones de carácter fuerte. 
Dado que se pueden establecer relaciones de orden entre las categorías de cada una de las nuevas variables obtenidas, las variables cualitativas resultantes son de escala ordinal; de acuerdo a esta característica se calcula el grado de asociación entre las mismas y la dirección de esta. Se dice que dos variables cualitativas están relacionadas positivamente si a valores altos (bajos) de una de ellas le corresponden valores altos (bajos) en la otra, y por el contrario, se dice que están relacionadas negativamente si a valores altos (bajos) de una de ellas le corresponden valores bajos (altos) en la otra (HERNÁNDEZ, 2001).

Mediante el software SPSS 15.0 se obtienen los siguientes resultados:

- Coeficiente de correlación de Spearman $(\rho)$. Es el coeficiente más utilizado a la hora de analizar la asociación entre variables ordinales. Puede variar entre -1 y 1 . Cuanto más próximos estén los valores del mismo a 0 más débil será la relación entre las variables y cuanto más cercanos a 1 (o a -1$)$ sean los valores, mayor será la asociación positiva (negativa) entre las variables.

- Coeficiente d de Somers (d), tiene una interpretación similar al coeficiente de correlación de Spearman, pero además de ser una medida que indica el nivel de asociación entre las variables, también permite, en caso de existir, analizar la dirección de la asociación entre las mismas (SOMERS, 1962).

Al igual que sucede en el apartado anterior con el estudio de la correlación entre la precipitación y las descargas eléctricas, de entre los 91368 registros que forman la base de datos, correspondientes a los 81 puntos centrales de las celdas de $0,5^{\circ}$ que configuran la malla, por cada uno de los 1128 días del período abril-septiembre de 2002 a 2008 que comprende el estudio, se han seleccionado solo 63168 registros, que son aquellos en los que el dato de precipitación está asociado al punto central de una celda que recae sobre territorio español.

Tabla 4.7. Tabla de contingencia de las variables RAYOS_C y PCP_C (\%).

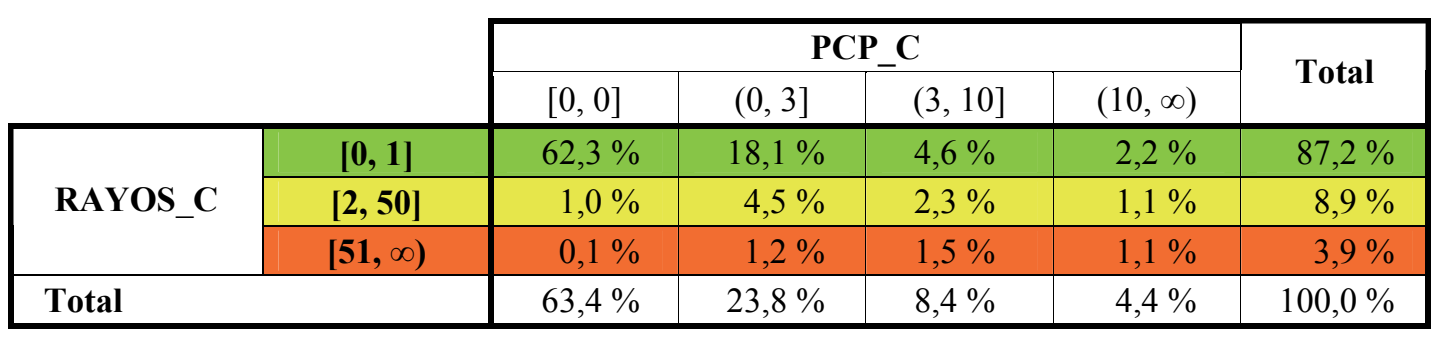

La Tabla 4.7 es una tabla de contingencia entre las variables RAYOS_C y PCP_C, expresando en cada celda el porcentaje de casos presentes en las distintas combinaciones de las categorías de las variables. La mayoría de los casos $(62,3 \%)$ figuran en la celda en que simultáneamente no se ha producido precipitación y los rayos registrados son uno o ninguno, lo cual es lógico puesto que obviamente lo más frecuente es la ausencia de fenómenos convectivos. El resto de la fila corresponde a los casos en los que aunque no se den rayos sí se producen precipitaciones progresivamente importantes, que acumulados al caso anterior totalizan el 87,2 \% de los datos. En la segunda fila, la ocurrencia de hasta 50 rayos por cuadrícula se distribuye de una forma bastante normal en función de la precipitación recogida, destacando tanto el $1 \%$ de casos de ausencia de precipitación, como el 1,1\% en los que se recogen más de $10 \mathrm{~mm}$ 
de precipitación media. Finalmente, la tercera fila muestra que existe una frecuencia similar $(\approx 1 \%)$ del caso en el que para más de 50 rayos por cuadrícula la cantidad de precipitación recogida pueda adquirir cualquier valor, salvo que las tormentas secas en este caso son casi inexistentes $(0,1 \%)$. La proporción de tormentas secas supone, por tanto, algo más del $1 \%$ del total, y su importancia en la generación de incendios forestales es enorme.

Para analizar si se puede rechazar la hipótesis de que las variables RAYOS_C y PCP_C son independientes, se recurre al test de independencia que se recoge en la Tabla 4.8 , donde se observa que el valor del estadístico Chi-cuadrado toma el valor 15 950,929 con una significación cercana al $0 \%$, lo que permite rechazar la hipótesis de independencia para cualquier nivel de significación. Es decir, las variables cualitativas estudiadas no son independientes entre sí (BARÓN ET AL., 2000), lo que hace que tenga sentido abordar el estudio de la asociación entre ambas y la dirección de la misma. Además, para que las probabilidades de la distribución Chi-cuadrado $\left(\chi^{2}\right)$ sean una adecuada aproximación a la distribución del estadístico $\chi^{2}$, no deben tener frecuencias esperadas inferiores a 5 . Como en el presente estudio ninguna casilla tiene una frecuencia esperada inferior a 5 tal y como se muestra en la Tabla 4.8, se puede sostener la robustez de los resultados obtenidos al realizar las pruebas $\chi^{2}$.

Tabla 4.8. Pruebas de Chi-cuadrado.

\begin{tabular}{|l|c|c|c|}
\cline { 2 - 4 } \multicolumn{1}{c|}{} & Valor & Grad. libertad & $\begin{array}{c}\text { Sign. asintótica } \\
\text { (bilateral) }\end{array}$ \\
\hline Chi-cuadrado de Pearson & 15950,929 (a) & 6 & 0,000 \\
\hline Razón de verosimilitudes & 14183,518 & 6 & 0,000 \\
\hline Asociación lineal por lineal & 14396,255 & 1 & 0,000 \\
\hline N. $^{\mathbf{0}}$ de casos válidos & 63168 & \multicolumn{2}{c}{} \\
\cline { 1 - 4 } & &
\end{tabular}

(a) 0 casillas $(0,0 \%)$ tienen una frecuencia esperada inferior a 5 . La frecuencia mínima esperada es 108,54.

Para el estudio de la asociación entre estas variables se obtiene el coeficiente de correlación de Spearman, la medida de concordancia más utilizada con datos ordinales. La Tabla 4.9 muestra los resultados obtenidos del análisis de la asociación entre PCP_C y RAYOS_C para los 63168 casos de este estudio. El valor del coeficiente de correlación rho de Spearman $(\rho)$ es 0,47 , con un error típico asintótico de 0,003 y un $\mathrm{p}$-valor de 0 . Por lo tanto, $\rho$ difiere significativamente de cero para cualquier nivel de significación (se rechaza la hipótesis nula de que $\rho=0$ frente a la alternativa que $\rho \neq 0$ a través de la $t$ de Student ya que el número de casos del estudio así lo permite), por lo que se puede afirmar que existe una asociación moderada y positiva entre las variables (HERNÁNDEZ, 2001).

Tabla 4.9. Medidas simétricas.

\begin{tabular}{|l|c|c|c|c|}
\cline { 2 - 5 } \multicolumn{1}{c|}{} & Valor & $\begin{array}{c}\text { Error típico } \\
\text { asint. (a) }\end{array}$ & $\begin{array}{c}\text { T aproximada } \\
\text { (b) }\end{array}$ & $\begin{array}{c}\text { Signif. } \\
\text { aproximada }\end{array}$ \\
\hline Correlación de Spearman & 0,470 & 0,003 & 133,966 & 0,000 (c) \\
\hline N. ${ }^{\mathbf{0}}$ de casos válidos & 63168 & \multicolumn{2}{c}{} \\
\cline { 1 - 5 } & &
\end{tabular}

(a) Asumiendo la hipótesis alternativa.

(b) Empleando el error típico asintótico basado en la hipótesis nula.

(c) Basada en la aproximación normal. 
Por último, se analizan las medidas direccionales entre ambas variables estudiadas. La Tabla 4.10 recoge los valores de dicho análisis y del mismo se deduce que no es una asociación simétrica, ya que los distintos coeficientes obtenidos para la d de Somers son notablemente distintos unos de otros; 0,411 para el caso simétrico, y 0,294 y 0,678 para los direccionales, y significativos a cualquier nivel, por lo que además de rechazar la hipótesis nula de no existencia de concordancia entre las variables en estudio frente a la alternativa de existencia de la misma, se puede decir que existe entre ellas cierto grado de dependencia.

- Tomando la variable RAYOS_C como dependiente, d de Somers igual a 0,294 indica que el conocimiento de los valores de la variable PCP_C permite reducir la incertidumbre en la predicción del comportamiento de la variable RAYOS_C en un $29,4 \%$.

- Tomando la variable PCP_C como dependiente, d de Somers igual a 0,678 indica que el conocimiento de los valores de la variable RAYOS_C permite reducir la incertidumbre en la predicción del comportamiento de la variable PCP_C en un $67,8 \%$.

Tabla 4.10. Medidas direccionales.

\begin{tabular}{|c|l|l|c|c|c|c|}
\cline { 4 - 6 } \multicolumn{2}{c|}{} & Valor & $\begin{array}{c}\text { Error típico } \\
\text { asint. (a) }\end{array}$ & $\begin{array}{c}\text { T aprox. } \\
\text { (b) }\end{array}$ & $\begin{array}{c}\text { Signif. } \\
\text { aproximada }\end{array}$ \\
\hline \multirow{2}{*}{$\begin{array}{c}\text { Ordinal por } \\
\text { ordinal }\end{array}$} & \multirow{2}{*}{$\begin{array}{c}\text { d de } \\
\text { Somers }\end{array}$} & Simétrica & 0,411 & 0,003 & 92,930 & 0,000 \\
\cline { 3 - 7 } & $\begin{array}{l}\text { RAYOS_C } \\
\text { dependiente }\end{array}$ & 0,294 & 0,003 & 92,930 & 0,000 \\
\cline { 3 - 7 } & $\begin{array}{l}\text { PCP_C } \\
\text { dependiente }\end{array}$ & 0,678 & 0,004 & 92,930 & 0,000 \\
\hline
\end{tabular}

(a) Asumiendo la hipótesis alternativa.

(b) Empleando el error típico asintótico basado en la hipótesis nula.

Así pues se puede concluir que tomando como variable dependiente la precipitación cualitativa (PCP_C) se obtendrán mejores resultados que si, por el contrario, se considera como variable dependiente la actividad eléctrica cualitativa (RAYOS_C), ya que parece lógico suponer que un mayor número de rayos conllevará unas precipitaciones más intensas y mayor cantidad de precipitación, mientras que la presencia de precipitación no tiene por qué conllevar rayos, pues es claro que la precipitación no siempre está vinculada a fenómenos convectivos. De aquí en adelante, se presentarán ambos resultados, pero a efectos de significación solo se estudiará la dependencia de la variable PCP_C frente a RAYOS_C.

\subsubsection{Asociación mensual}

El estudio de la asociación por meses se recoge en la Tabla 4.11 junto con las medidas direccionales. Se observa que los mayores valores de la rho de Spearman se alcanzan en los meses estivales (junio, julio y agosto), siendo el mes de julio el que presenta un valor más alto $(0,555)$. Es decir, es en estos meses cuando hay mayor relación entre las variables PCP_C y RAYOS_C, o dicho de otro modo, la precipitación tiene un carácter más convectivo, mientras que para los meses de abril y mayo es cuando hay menor asociación entre las variables, como indican los menores valores del coeficiente de correlación rho de Spearman. Estos resultados coinciden con los de la correlación entre las variables precipitación y rayos, tratadas como continuas, del apartado 4.1.1. 
Tabla 4.11. Medidas de asociación (rho de Spearman) y direccionales (d de Somers) por meses.

\begin{tabular}{|c|c|c|c|c|c|c|}
\hline & N. ${ }^{\circ} \operatorname{casos}$ & $\rho$ & d simétrica & d RAYOS_C dep. & d PCP_C dep. \\
\hline \multicolumn{2}{|c|}{ Conjunto de datos } & 63168 & 0,470 & 0,411 & 0,294 & 0,678 \\
\hline \multirow{6}{*}{$\sum^{\infty}$} & Abril & 8624 & 0,353 & 0,267 & 0,167 & 0,662 \\
\hline & Mayo & 10024 & 0,422 & 0,347 & 0,235 & 0,664 \\
\hline & Junio & 9800 & 0,534 & 0,483 & 0,373 & 0,687 \\
\hline & Julio & 11984 & 0,555 & 0,516 & 0,401 & 0,725 \\
\hline & Agosto & 11648 & 0,523 & 0,480 & 0,371 & 0,682 \\
\hline & Septiembre & 11088 & 0,491 & 0,422 & 0,298 & 0,725 \\
\hline
\end{tabular}

En la misma Tabla 4.11 se presentan las medidas direccionales por meses. Como se ha indicado anteriormente, la interpretación del coeficiente d de Somers para el caso simétrico es análoga a la de rho de Spearman, ofreciendo una medida de la asociación entre ambas variables. Observando los valores obtenidos, los mayores valores se dan en julio, junio y agosto, y los menores en abril, mayo y septiembre, coincidiendo en el orden ambos coeficientes estudiados.

Si se considera la variable PCP_C como dependiente y se observan los valores del coeficiente d de Somers para los distintos meses del estudio, se comprueba que su rango varía entre 0,662 para el mes de abril y 0,725 para los meses de julio y septiembre, sin que haya mucha variación con respecto al valor medio para el conjunto de los casos: 0,678 , por lo que ambas variables están relacionadas positivamente (a mayor número de rayos, mayor precipitación) y el conocimiento de la variable RAYOS_C permite reducir la incertidumbre en la predicción del comportamiento de la variable PCP_C entre un $66,2 \%$ y un $72,5 \%$. Es decir, en general, durante la temporada de estudio, precipitaciones intensas estarán asociadas a tormentas intensas (y lo mismo sucede en caso de tormentas y precipitaciones débiles) en dos tercios de las ocasiones. En los meses de julio y septiembre, esto es así en tres de cada cuatro casos. Hay un descenso relativo, de no mucha importancia, de esta asociación en agosto, que sin embargo puede ser relevante en la aparición de tormentas secas o con poca precipitación con mayor frecuencia durante ese mes $(\approx 30 \%)$, con la importancia que ello tiene de cara a la aparición de incendios forestales causados por rayo.

\subsubsection{Asociación por situaciones}

Los resultados del análisis de las medidas de asociación y dirección para cada una de las situaciones en las que se han clasificado los casos del estudio se presentan en la Tabla 4.12, obteniéndose una variabilidad notable en los valores que toman los distintos coeficientes para ambas medidas. La rho de Spearman varía entre 0,299 para las depresiones rebasadas y 0,525 para las situaciones del SW sin difluencia, por lo que a pesar de existir una asociación positiva entre ambas variables, el grado de la misma no es ni mucho menos similar para cada uno de los tipos de situaciones considerados. La misma consideración se podría hacer si se analizan los resultados del coeficiente $\mathrm{d}$ de Somers en el caso simétrico, si bien en este caso los valores varían entre 0,227 para las depresiones rebasadas y 0,466 para las situaciones del SW sin difluencia. 
Tabla 4.12. Medidas de asociación y direccionales por situaciones sinópticas.

\begin{tabular}{|c|c|c|c|c|c|c|c|}
\hline & N..$^{\circ}$ casos & $\begin{array}{c}\text { Rho } \\
\text { Spear } \\
\text { categ. }\end{array}$ & $\begin{array}{c}d \\
\text { Simet. }\end{array}$ & $\begin{array}{c}\text { d } \\
\text { RAY_C } \\
\text { dep. }\end{array}$ & $\begin{array}{c}\text { d } \\
\text { PCP_C } \\
\text { dep. }\end{array}$ & $\begin{array}{c}\text { Rho } \\
\text { Spear } \\
\text { cont. }\end{array}$ \\
\hline \multicolumn{2}{|r|}{ Conjunto de datos } & 63168 & 0,470 & 0,411 & 0,294 & 0,678 & 0,504 \\
\hline \multirow{9}{*}{$\stackrel{\varrho}{\equiv}$} & Masas de aire & 6216 & 0,450 & 0,408 & 0,315 & 0,580 & 0,484 \\
\hline & Sit. del sur & 1624 & 0,376 & 0,320 & 0,235 & 0,500 & 0,400 \\
\hline & Sit. del SW difluyentes & 5152 & 0,485 & 0,430 & 0,348 & 0,565 & 0,523 \\
\hline & Sit. del SW sin difluencia & 12264 & 0,525 & 0,466 & 0,354 & 0,682 & 0,559 \\
\hline & Sit. del W & 13832 & 0,463 & 0,409 & 0,292 & 0,681 & 0,495 \\
\hline & Depresiones entrantes & 1064 & 0,360 & 0,301 & 0,218 & 0,487 & 0,386 \\
\hline & Depresiones rebasadas & 3080 & 0,299 & 0,227 & 0,143 & 0,549 & 0,325 \\
\hline & Ondas largas del NW & 19264 & 0,360 & 0,280 & 0,174 & 0,714 & 0,386 \\
\hline & Oclusiones a vaguadas rebasadas & 672 & 0,349 & 0,313 & 0,263 & 0,387 & 0,396 \\
\hline
\end{tabular}

Del estudio del coeficiente d de Somers tomando la variable PCP_D como dependiente se deduce que los valores de dicho coeficiente son muy variables para los diferentes tipos de situaciones sinópticas, siendo 0,387 y 0,714 los valores mínimo y máximo del mismo, correspondientes a los tipos oclusiones a vaguadas rebasadas y ondas largas del NW, respectivamente. La mejor asociación se produce en las ondas largas del NW (apartado 3.3.8). Situaciones con poca convectividad, por lo que el alto valor de la d de Somers refrenda este hecho: pocas descargas (o ninguna) llevan asociadas precipitaciones débiles (o su ausencia). El caso opuesto, el de las oclusiones a vaguadas rebasadas (Apartado 3.3.9) es muy heterogéneo en su comportamiento en el área de estudio. Como se muestra en los Mapas 3.9a y 3.9b y la Imagen 3.2.1, las zonas de mayor actividad eléctrica (Gúdar-Puertos de Beceite) no se corresponden con las de mayor acumulación de precipitación (litoral cantábrico-Pirineos), que es lo que sintéticamente indica este valor de 0,387 de la d de Somers.

\subsubsection{Asociación geográfica}

Se estudian la asociación y la dirección de la misma entre las variables cualitativas PCP_C y RAYOS_C en cada una de las cuatro zonas resultantes del análisis de conglomerados jerárquicos de la zona de estudio desde un punto de vista geográfico (Apartado 4.1.3, Mapa 4.1).

Los resultados, mostrados en la Tabla 4.13, revelan una clara diferencia en los valores del coeficiente rho de Spearman entre cada una de las zonas, alcanzándose el valor mínimo $(0,392)$ para la zona de influencia cantábrica y el valor máximo $(0,505)$ para la zona de influencia mediterránea. Al igual que en los apartados anteriores, si se analizan los valores del coeficiente d de Somers simétrico, el mínimo $(0,320)$ y máximo $(0,451)$ se alcanzan en las mismas zonas que para el coeficiente de correlación rho de Spearman, zona de influencia cantábrica y zona de influencia mediterránea, 
respectivamente. Es decir, se demuestra estadísticamente la impresión de que hay una mayor asociación entre la intensidad de las precipitaciones y de la actividad eléctrica en las zonas mediterráneas que en las de influencia oceánica o, dicho de otro modo, del mayor peso de la convección en las precipitaciones en las zonas de influencia mediterránea.

Tabla 4.13. Medidas de asociación y direccionales por zonas.

\begin{tabular}{|c|c|c|c|c|c|c|}
\hline & & N. ${ }^{\circ} \operatorname{casos}$ & $\rho$ & d simétrica & $\begin{array}{c}\text { d } \\
\text { RAYOS_C } \\
\text { dep. } \\
\end{array}$ & $\begin{array}{c}\text { d } \\
\text { PCP_C } \\
\text { dep. }\end{array}$ \\
\hline & Conjunto de datos & 63168 & 0,470 & 0,411 & 0,294 & 0,678 \\
\hline \multirow{4}{*}{ 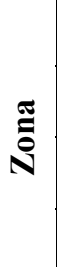 } & Influencia cantábrica & 9048 & 0,392 & 0,320 & 0,214 & 0,636 \\
\hline & Interior norte & 30537 & 0,484 & 0,426 & 0,311 & 0,678 \\
\hline & Interior sur & 6786 & 0,485 & 0,423 & 0,301 & 0,711 \\
\hline & Influencia mediterránea & 16965 & 0,505 & 0,450 & 0,330 & 0,705 \\
\hline
\end{tabular}

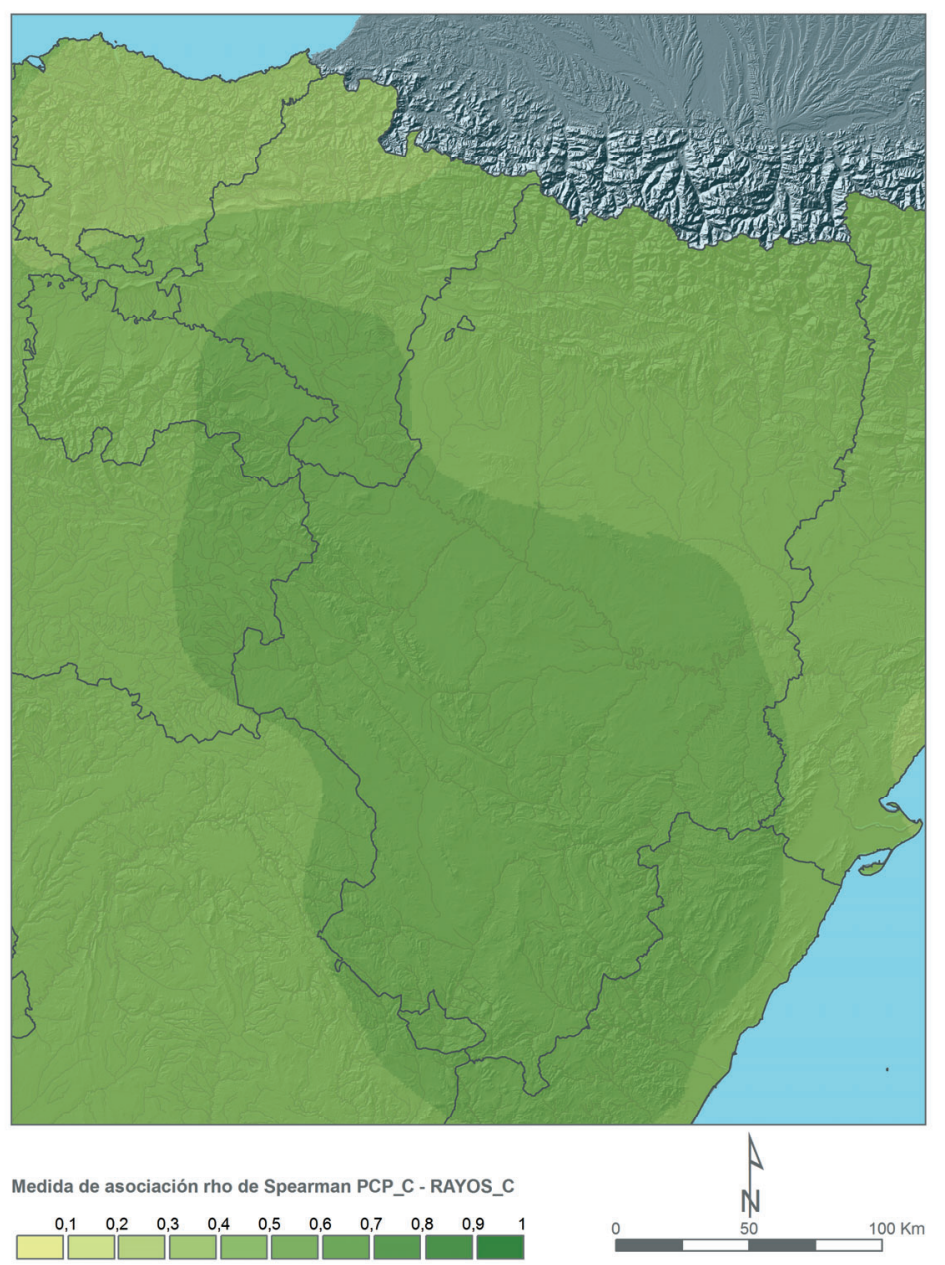

Mapa 4.3. Asociación (rho de Spearman) entre PCP_C y RAYOS_C. (Elaboración propia). 
Del estudio de los distintos coeficientes que toma la d de Somers, considerando la variable PCP_C como dependiente, se puede afirmar que es en la zona interior sur donde el conocimiento de la variable RAYOS_C va a ayudar más a reducir la incertidumbre de estimación de la variable PCP_C ya que alcanza el valor más alto $(0,711)$, similar al que se alcanza en la zona de influencia mediterránea $(0,705)$, mientras que es en la zona de influencia cantábrica donde hay una menor precisión en la estimación de la variable PCP_C ya que el valor del citado coeficiente alcanza el valor mínimo de las cuatro zonas $(0, \overline{6} 36)$.

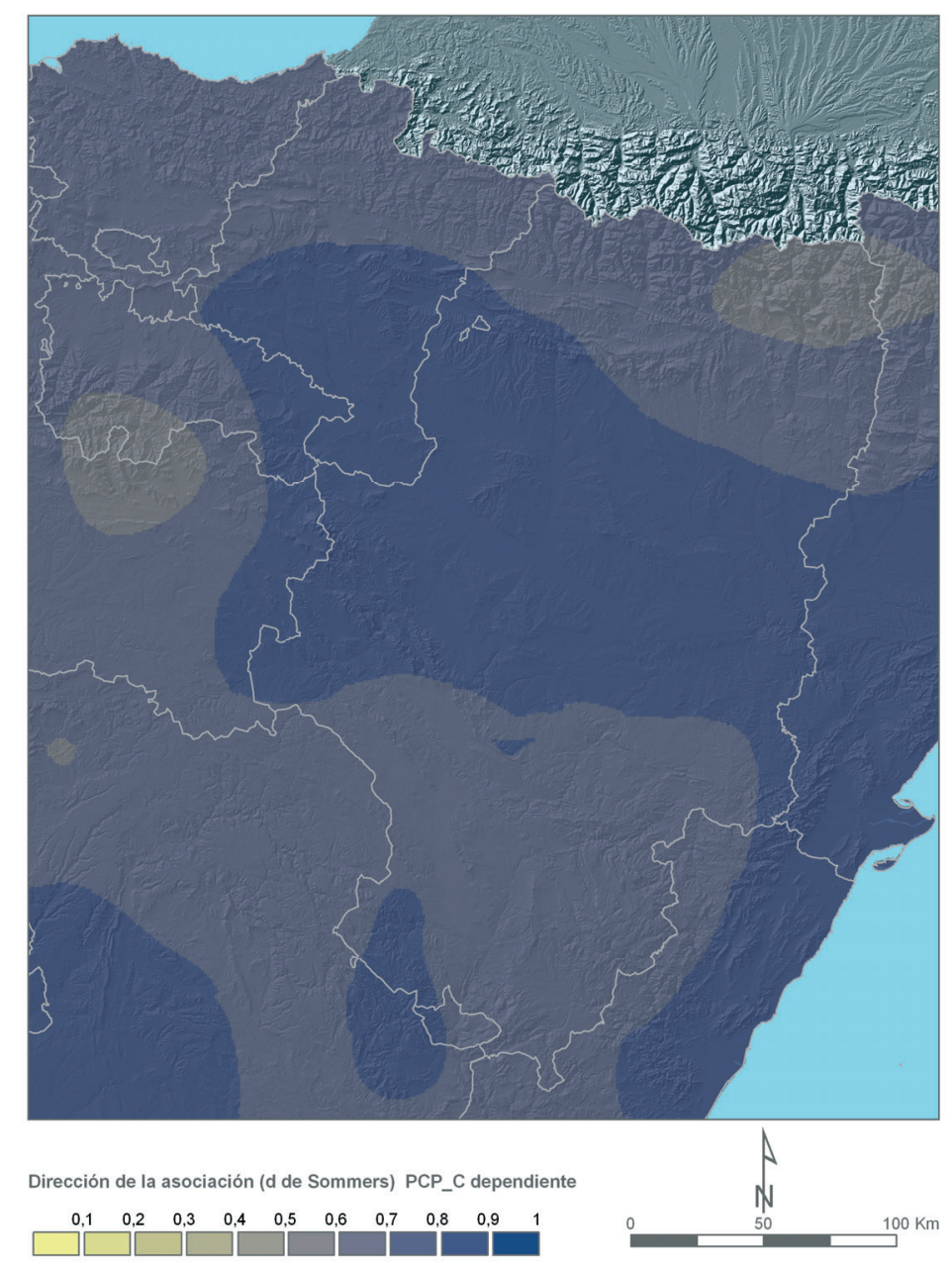

Mapa 4.4. Dirección de la asociación (d de Somers) tomando PCP_C como dependiente.

(Elaboración propia).

La representación espacial de la asociación (rho de Spearman) entre la precipitación y la actividad eléctrica cualitativa que se muestra en el Mapa 4.3 revela el área de los dos tercios inferiores de la depresión del Ebro y la Ibérica aragonesa como la zona en que precipitación y descargas están más asociados durante el semestre cálido. Sin embargo, la representación espacial de la dirección de la misma tomando como variable dependiente (de la actividad eléctrica) la precipitación cualitativa, mostrada en el Mapa 4.4, matiza este hecho. En este caso es en la depresión del Ebro y el litoral mediterráneo donde la asociación es mayor. La Ibérica turolense queda, casi en su totalidad, excluida de la zona de máximos ( $\sin$ que esto haga olvidar el hecho de los altos valores en cualquier parte del territorio considerado) debido a la alta intensidad de los fenómenos 
eléctricos. En el área con mayor número de días de tormenta, la Ribagorza, esta asociación es aún menor. Es decir, en el interior de la depresión del Ebro y en el litoral mediterráneo es donde la observación de una gran cantidad de rayos puede hacer pensar que se estén produciendo grandes cantidades de precipitación. En las zonas de actividad convectiva más frecuente, puede haber muchas descargas sin que ello implique necesariamente que la precipitación es intensa. 


\section{SISTEMATIZACIÓN DE LAS CAUSAS DE LOS PROCESOS CONVECTIVOS}

\subsection{Metodología}

Según los resultados anteriores, desde el punto de vista estadístico se reduce la incertidumbre en la predicción de descargas en un $29,4 \%$ si se conoce la precipitación, mientras que al predecir la precipitación se llega a reducir su incertidumbre en un $67,8 \%$ si se conocen las descargas.

A esta falta de simetría se une el hecho de que los modelos numéricos de predicción presentan salidas para los campos de precipitación convectiva, estratiforme y total. Es además conocido que los campos de precipitación suelen presentar serias limitaciones para su representación correcta, sobre todo precisamente en caso de la precipitación de tipo convectivo. La pequeña escala de los procesos físicos y termodinámicos involucrados puede ser más reducida que el tamaño de la rejilla de cálculo del modelo, lo que determina que dichos procesos a nivel de meso o microescala tengan que ser introducidos como rutinas externas al proceso del resto de las variables.

Este procedimiento de representar los procesos relacionados con el cambio de estado del agua entre los estados de vapor, líquido o sólido y su caída a la superficie se conoce como parametrización de la precipitación. Por el reducido tamaño de las células convectivas suele haber deficiencias en su seguimiento y análisis, que lógicamente influyen en los resultados. Además, la servidumbre de mantener en el ordenador un tiempo de cálculo reducido determina que muchas de estas formulaciones utilicen esquemas sencillos, que solo incorporan una pequeña parte del conocimiento que se posee sobre los procesos involucrados.

Posteriormente debe acoplarse la precipitación al modelo de predicción en su conjunto, pero dado que las variables del entorno tienen una fuerte influencia en las distintas fases del proceso, los resultados en ocasiones no son precisos. Por ejemplo, es sobradamente conocido que las acumulaciones de precipitaciones convectivas intensas son infravaloradas por los modelos numéricos.

A partir de esta realidad, el problema se suele abordar mediante la incorporación al proceso predictivo de modelos conceptuales que aporten la información añadida que ayude al predictor a modular los resultados suministrados por los modelos numéricos. Lógicamente, este conjunto de algoritmos adicionales se puede integrar y ejecutar en las máquinas de cálculo.

\subsubsection{Del modelo}

Dentro de este planteamiento se ha venido procediendo a calcular un factor que informe sobre la probabilidad de ocurrencia de rayos, es decir, la localización de tormentas productoras de descargas eléctricas mediante la cuantificación de ascensos en la atmósfera, aunque la correspondencia entre la potencia de estos ascensos y el número de descargas no tiene por qué darse siempre. 
El problema se aborda considerando las variables que a nivel de mesoescala se cree que tienen influencia en la ocurrencia de tormentas en la zona de interés. Como variables se elige un conjunto de campos básicos o derivados con los que normalmente se trabaja cuando se estudian aspectos relacionados con la inestabilidad atmosférica, tomando como referencia los estudios realizados previamente con la misma fuente de datos (ÁlvareZ ET AL., 2005). Estos campos son productos de modelos de predicción y se encuentran disponibles en el entorno McIDAS como salidas de modelos numéricos operativos de AEMET. Se ha venido trabajando con INMH-0.5 (actualmente HINR-0.48) para la escala sinóptica y HINR-0.2 (actualmente INMH-0.16) para la escala meso-beta, considerando solamente la ventana espacial utilizada en el actual estudio y realizándose los cálculos para las $17 \mathrm{~h}$ oficiales.

Variables consideradas a escala sinóptica (Hirlam-0.5):

- Advección diferencial de vorticidad geostrófica 300/500 hPa (ADVG)

- Advección de espesores en 1000 hPa (AESP)

- Divergencia del vector Q de Hoskins: 500, 850 hPa (DIVQ)

- Índice de inestabilidad Total de Totales en 500 hPa (TT)

- Convergencia de humedad en 925 hPa (CONH)

Variables consideradas a escala meso-beta (Hirlam-0.2):

- Convergencia del campo superficial de viento (CONW)

- Presión en superficie (PSL)

Tabla 5.1. Estadísticos descriptivos de las variables independientes.

\begin{tabular}{|c|c|c|c|c|c|c|c|}
\hline & $\begin{array}{c}\text { ADVG } \\
\left(\mathbf{s}^{-2}\right)\end{array}$ & $\begin{array}{r}\text { AESP } \\
(\mathbf{K} / \mathbf{h}) \\
\end{array}$ & $\begin{array}{c}\text { DIVQ } \\
(\mathrm{uQ})\end{array}$ & $\begin{array}{c}\text { TT } \\
\left({ }^{\circ} \mathrm{C}\right) \\
\end{array}$ & $\begin{array}{c}\mathrm{CONH} \\
\left(\mathrm{g} \cdot \mathrm{kg}^{-1} / 6 \mathrm{~h}\right)\end{array}$ & $\begin{array}{c}\text { CONW } \\
\left(\mathrm{s}^{-1}\right)\end{array}$ & $\begin{array}{c}\text { PSL } \\
(\mathbf{h P a})\end{array}$ \\
\hline Media & 0,164 & $-0,103$ & $-0,536$ & 47,313 & $-1,190$ & $-0,001$ & 0,562 \\
\hline $\begin{array}{l}\text { Error típico } \\
\text { de la media }\end{array}$ & 0,021 & 0,007 & 0,031 & 0,010 & 0,008 & 0,001 & 0,004 \\
\hline Mediana & 0,000 & 0,100 & $-0,600$ & 46,600 & $-1,000$ & $-0,030$ & 0,800 \\
\hline Varianza & 39,014 & 4,871 & 87,350 & 9,215 & 5,563 & 0,199 & 1,473 \\
\hline Mínimo & $-205,200$ & $-22,400$ & $-108,899$ & 39,200 & $-11,700$ & $-2,000$ & $-10,000$ \\
\hline Máximo & 196,799 & 12,667 & 127,099 & 58,000 & 8,200 & 2,500 & 5,800 \\
\hline Asimetría & $-0,920$ & $-1,118$ & 0,195 & 0,678 & $-0,363$ & 0,407 & $-1,238$ \\
\hline $\begin{array}{l}\text { Error típico } \\
\text { de asimetría }\end{array}$ & 0,008 & 0,008 & 0,008 & 0,008 & 0,008 & 0,008 & 0,008 \\
\hline Curtosis & 153,546 & 5,482 & 9,415 & $-0,490$ & 0,292 & 1,149 & 3,199 \\
\hline $\begin{array}{l}\text { Error típico } \\
\text { de curtosis }\end{array}$ & 0,016 & 0,016 & 0,016 & 0,016 & 0,016 & 0,016 & 0,016 \\
\hline $\begin{array}{l}\text { Número de } \\
\text { casos }\end{array}$ & 91368 & 91368 & 91368 & 91368 & 91368 & 91368 & 91368 \\
\hline
\end{tabular}


Los estadísticos descriptivos de las siete variables consideradas en el estudio se muestran en la Tabla 5.1. Hay que señalar que a la variable CONW se le realiza un cambio de escala, multiplicándola por 10000 , debido a que el orden de magnitud en el que se mueve es muy pequeño.

\subsubsection{Del análisis estadístico}

El objetivo del presente estudio es estimar la ocurrencia o no de tormenta a partir de los valores adquiridos por un conjunto de variables meteorológicas conocidas: índice Total de Totales (TT), Convergencia de Humedad (CONH), Convergencia de Vientos (CONW), Advección Diferencial de Vorticidad Geostrófica (ADVG), Divergencia del Vector Q (DIVQ), Tendencia de la Presión (PSL) y Advección de Espesores (AESP).

El modelo empleado para esta estimación es la regresión logística binaria (RODRÍGUEZ ET AL., 2009), por ser adecuado para expresar la relación entre una variable dependiente (ocurrencia de tormenta) y un conjunto de variables independientes (variables meteorológicas mencionadas en el párrafo anterior). En este caso, se ha transformado la variable dependiente en una variable dicotómica que toma el valor 0 o 1 según sea la ausencia/presencia de tormenta en cada una de las celdas de tamaño $0,5^{\circ}$ de latitud y longitud de la rejilla que abarca el área de estudio.

El modelo de regresión logística se define como:

$$
P_{i}=\frac{1}{1+e^{-z}} \mathrm{z}=\beta_{0}+\beta_{1} \mathrm{X}_{1}+\beta_{2} \mathrm{X}_{2}+\ldots+\beta_{\mathrm{n}} \mathrm{X}_{\mathrm{n}}
$$

Donde $\mathrm{P}_{\mathrm{i}}$ es la probabilidad de ocurrencia de tormenta, $\mathrm{z}$ la combinación de las variables independientes con sus coeficientes de regresión $(\beta), X_{i}$ el valor de cada variable independiente y $e$ la base del logaritmo natural. De entre las posibilidades de modelos de regresión logística binaria se aplica el modelo logit:

$$
\log \left(\frac{p}{1-p}\right)=\mathrm{x}^{\mathrm{T}} \beta
$$

Siendo $\mathrm{x}^{\mathrm{T}}$ el vector de las variables explicativas y $\beta$ el vector de los parámetros (VILAR ET AL., 2007). A la hora de aplicar la regresión logística se emplea el método de "pasos hacia delante Wald", con punto de corte para la clasificación 0,3. Este valor se elige porque de toda la población del estudio, de más de 90000 casos, hubo tormenta aproximadamente en el $30 \%$ de ellos.

Antes de construir el modelo es conveniente comprobar que las variables consideradas no sean innecesarias o redundantes y que, como consecuencia de ello, no aporten información. Cuando las variables independientes tienen mucha relación entre sí, el modelo no puede distinguir qué parte de la variable dependiente es explicada por una $\mathrm{u}$ otra variable. Este factor se conoce como multicolinealidad. Para estudiar la incidencia de este fenómeno en los datos se han aplicado diagnósticos de colinealidad propios de la técnica de regresión multivariante (VILAR ET AL., 2007): 
- Coeficiente de tolerancia: indicador de la independencia de una variable respecto de otras. Es el porcentaje de esa variable que no es explicada por las otras variables independientes. Por debajo de 0,1 se considera que la multicolinealidad es alta.

- Factor de Inflación de la Varianza (FIV): es el valor recíproco de la tolerancia (1/Tolerancia), siempre mayor que 1. Es un indicador del aumento de la varianza del coeficiente de regresión de la variable. Cuanto mayor sea este factor mayor será la multicolinealidad. Valores mayores de 30 indican un serio problema de multicolinealidad y los mayores de 15 , un posible inconveniente.

- Autovalores, índice de condición y proporción de la varianza de los coeficientes de regresión asociada a cada valor propio: los autovalores indican cuántas dimensiones distintas hay entre las variables independientes. Cuando varios sean próximos a 0 , las variables estarán altamente correlacionadas. El índice de condición es la raíz cuadrada de la ratio entre el máximo autovalor y cada autovalor sucesivo. Cuanto mayor sea el índice, mayor dependencia entre las variables implicadas. Un valor mayor de 15 indica un posible problema y mayor de 30 un gran problema con la multicolinealidad de las variables consideradas.

Además, se explora el grado de correlación entre las variables independientes mediante coeficientes de correlación no paramétricos de Spearman. Aquellas variables que presentan entre sí una correlación superior a 0,7 se excluyen del modelo.

Por último, para el desarrollo de la ecuación de regresión se selecciona aleatoriamente el $70 \%$ de los casos, mientras que para la validación del mismo, se utiliza el $30 \%$ restante de la muestra considerada en el estudio.

\subsection{Atribución general de causas}

Antes de proceder a realizar la regresión logística, se analiza la existencia o no de multicolinealidad entre las variables independientes, tal y como se ha comentado en el Apartado 5.1.2, para lo que es necesario calcular los coeficientes de correlación bivariada no paramétrica de Spearman de las mismas. En la Tabla 5.2 se presentan los resultados de la matriz de correlación para el conjunto de los datos, donde se observa que la correlación entre los pares de variables es siempre significativa al $1 \%$ de nivel de significación. Ahora bien, ninguno de los coeficientes de correlación es lo suficientemente alto (el más alto no llega a 0,4 en valor absoluto) como para causar problemas importantes de multicolinealidad.

Los resultados se corroboran adicionalmente mediante cinco criterios: el análisis del factor de inflación de la varianza (FIV), el coeficiente de tolerancia, autovalores, índice de condición y proporción de la varianza de los coeficientes de regresión asociada a cada valor propio (descritos en el Apartado 5.1.2), obteniéndose unos resultados que confirman la ausencia de multicolinealidad de las variables independientes incluidas en el estudio. Así pues, se puede afirmar que —a priori- ninguna de las variables consideradas es innecesaria o redundante, por lo que todas ellas serán incluidas en el estudio de la regresión logística que se presenta a continuación. 
Tabla 5.2. Correlaciones bivariadas no paramétricas de Spearman de las variables independientes.

\begin{tabular}{|c|c|c|c|c|c|c|c|c|c|}
\hline & & & $\begin{array}{c}\text { ADVG } \\
\left(\mathrm{s}^{-2}\right)\end{array}$ & $\begin{array}{l}\text { AESP } \\
(\mathbf{K} / \mathbf{h})\end{array}$ & $\begin{array}{c}\text { DIVQ } \\
\text { (uQ) }\end{array}$ & $\begin{array}{c}\mathrm{T} \\
\left({ }^{\circ} \mathrm{C}\right) \\
\end{array}$ & $\begin{array}{c}\text { CONH } \\
\left(g^{*} \mathrm{~kg}^{-1} / 6 \mathrm{~h}\right)\end{array}$ & $\begin{array}{c}\text { CONW } \\
\left(\mathrm{s}^{-1}\right)\end{array}$ & $\begin{array}{c}\text { PSL } \\
(\mathrm{hPa})\end{array}$ \\
\hline \multirow{14}{*}{ 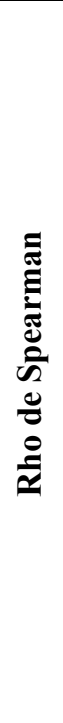 } & \multirow{2}{*}{ ADVG } & $\rho$ & 1,00 & 0,07 & $-0,01$ & 0,02 & $-0,02$ & $-0,02$ & 0,03 \\
\hline & & Sig. & & 0,00 & 0,00 & 0,00 & 0,00 & 0,00 & 0,00 \\
\hline & \multirow{2}{*}{ AESP } & $\rho$ & 0,07 & 1,00 & $-0,36$ & 0,28 & $-0,29$ & 0,11 & 0,25 \\
\hline & & Sig. & 0,00 & & 0,00 & 0,00 & 0,00 & 0,00 & 0,00 \\
\hline & \multirow{2}{*}{ DIVQ } & $\rho$ & $-0,01$ & $-0,36$ & 1,00 & $-0,16$ & 0,31 & $-0,16$ & $-0,08$ \\
\hline & & Sig. & 0,00 & 0,00 & & 0,00 & 0,00 & 0,00 & 0,00 \\
\hline & \multirow{2}{*}{ TT } & $\rho$ & 0,02 & 0,28 & $-0,16$ & 1,00 & $-0,37$ & 0,15 & $-0,06$ \\
\hline & & Sig. & 0,00 & 0,00 & 0,00 & & 0,00 & 0,00 & 0,00 \\
\hline & \multirow{2}{*}{ CONH } & $\rho$ & $-0,02$ & $-0,29$ & 0,31 & $-0,37$ & 1,00 & $-0,36$ & $-0,07$ \\
\hline & & Sig. & 0,00 & 0,00 & 0,00 & 0,00 & & 0,00 & 0,00 \\
\hline & \multirow{2}{*}{ CONW } & $\rho$ & $-0,02$ & 0,11 & $-0,16$ & 0,15 & $-0,36$ & 1,00 & 0,22 \\
\hline & & Sig. & 0,00 & 0,00 & 0,00 & 0,00 & 0,00 & . & 0,00 \\
\hline & \multirow{2}{*}{ PSL } & $\rho$ & 0,02 & 0,25 & $-0,08$ & $-0,06$ & $-0,07$ & 0,22 & 1,00 \\
\hline & & Sig. & 0,00 & 0,00 & 0,00 & 0,00 & 0,00 & 0,00 & \\
\hline
\end{tabular}

La construcción del modelo con las siete variables anteriores a partir del método "pasos hacia delante Wald" (dentro de las opciones de regresión logística en el programa SPSS), que contrasta la entrada basándose en la significación del estadístico de puntuación y contrasta la eliminación basándose en la probabilidad del estadístico de Wald, con una muestra del $70 \%$ de los casos y un punto de corte en la clasificación de 0,3, da como resultado 7 modelos, incorporando progresivamente desde la primera a la séptima de las variables consideradas para explicar la ocurrencia o no de tormenta. De entre estos siete modelos, y puesto que el porcentaje de acierto global de todos ellos está comprendido entre el $85,2 \%$ y el $85,8 \%$, se opta por seleccionar aquel que optimice la clasificación correcta de ocurrencia de tormenta y que, a su vez, tenga en cuenta el principio de parsimonia, también llamado navaja de Ockham, por el cual cuando se tienen dos modelos en las mismas condiciones y de la aplicación de estos se obtienen los mismos resultados, el modelo más simple tiene más posibilidades de ser el correcto frente al complejo.

De acuerdo a lo anterior, se selecciona el modelo 3, que únicamente considera 3 de las 7 variables. En la Tabla 5.3 se presentan los resultados de la regresión logística del modelo seleccionado. Las variables incluidas en el mismo han sido TT, CONH y CONW, y por este orden (la primera variable en ser considerada es el TT, luego CONH y por último CONW). Para comprobar si estas tres variables son significativas (los coeficientes asociados a cada una de ellas en la ecuación del modelo son distintos de cero) o no, hay que fijarse en el estadístico de Wald, que es una prueba de significación estadística que contrasta la hipótesis nula de que los coeficientes de cada una de las variables $(\beta)$ son iguales a cero frente a la hipótesis alternativa, que sostiene que son distintos de cero. En la Tabla 5.3 se muestra el estadístico de Wald para cada variable, así como su significación. Como para las tres variables la significación del estadístico de Wald es 0,000, o dicho de otra manera, la probabilidad de error al descartar la hipótesis nula de que los coeficientes de las variables en el modelo de regresión logística son nulos es muy próxima a 0 , se puede concluir que las tres variables son significativas y deben introducirse en la ecuación del modelo. 
Tabla 5.3. Variables en la ecuación de regresión logística para el modelo seleccionado.

\begin{tabular}{|c|l|r|r|r|r|r|r|}
\cline { 3 - 8 } \multicolumn{2}{c|}{} & \multicolumn{1}{c|}{ B } & \multicolumn{1}{c|}{ E.T. } & \multicolumn{1}{c|}{ Wald } & \multicolumn{1}{c|}{ Gr.lib. } & \multicolumn{1}{c|}{ Sign. } & \multicolumn{1}{c|}{$\operatorname{Exp(B)}$} \\
\hline \multirow{4}{*}{ Paso 3 } & TT & 0,439 & 0,005 & 7580,156 & 1 & 0,000 & 1,552 \\
\cline { 2 - 9 } & CONH & $-0,121$ & 0,006 & 369,261 & 1 & 0,000 & 0,886 \\
\cline { 2 - 9 } & CONW & 0,473 & 0,033 & 207,232 & 1 & 0,000 & 1,605 \\
\cline { 2 - 8 } & Constante & $-23,596$ & 0,251 & 8831,209 & 1 & 0,000 & 0,000 \\
\hline
\end{tabular}

Para finalizar con la explicación de los resultados presentados en la Tabla 5.3, se analiza

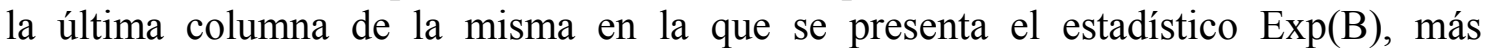
conocido por el término inglés "odds ratio". Es una medida para entender mejor la interpretación de los coeficientes $\beta$ de la ecuación de regresión logística. El modelo logístico puede ser escrito en término de la probabilidad de ocurrencia de un evento (en este caso es la aparición de tormenta), que se define como la relación entre la probabilidad de que el evento ocurra y la probabilidad de que el evento no ocurra. Entonces $\operatorname{Exp}\left(\beta_{\mathrm{i}}\right)$ indica cuántas veces cambian las probabilidades cuando la i-ésima variable independiente aumenta en una unidad, permaneciendo constantes el resto de variables independientes. Si $\beta_{\mathrm{i}}$ es positivo, $\operatorname{Exp}\left(\beta_{\mathrm{i}}\right)$ será mayor que 1 , lo que significa que las oportunidades de ocurrencia aumentan; si $\beta_{\mathrm{i}}$ es negativo, $\operatorname{Exp}\left(\beta_{\mathrm{i}}\right)$ será menor que 1 , lo que significa que las oportunidades disminuyen cuando la variable independiente en cuestión es aumentada. Cuando $\beta_{\mathrm{i}}$ es cero, el factor se iguala a 1, lo que lleva a una no alteración de las unidades. De acuerdo a esta explicación y aplicándolo al estudio, los coeficientes de las variables TT y CONW son positivos, por lo que cuando los valores de estas variables aumenten, aumentará la probabilidad de ocurrencia de tormentas (siempre que el resto de las variables independientes se mantengan constantes). Por el contrario, el coeficiente de $\mathrm{CONH}$ es negativo, puesto que lo que se representa es la expresión físico-matemática de la divergencia de humedad. Es decir, al aumentar el valor de CONH (divergencia de humedad), la probabilidad de ocurrencia de tormenta disminuirá, o dicho de otra forma, a mayores concentraciones de humedad en una zona, mayores probabilidades de ocurrencia de fenómenos tormentosos en dicha zona si se mantienen constantes el resto de las variables independientes. Todos estos resultados son cualitativamente coincidentes con la física de los procesos atmosféricos y, a priori, no aportan mucho; sin embargo, el siguiente análisis cuantitativo sí supone una aportación relevante.

Los valores de $\operatorname{Exp}(B)$ de la Tabla 5.3 indican que para la variable TT se obtiene un valor de 1,552, es decir, con el aumento de una unidad del TT y no habiendo variación en las variables CONH y CONW, la posibilidad de ocurrencia de tormenta aumenta en 1,552 veces, o sea un 55,2\%. La explicación para el resto de las variables es análoga. Un aumento de una unidad en la variable $\mathrm{CONH}$ (recuérdese que en realidad es la divergencia) implica que la ocurrencia de tormenta es del 0,886 , o sea la probabilidad de tormenta es un $11,4 \%$ menor. Para la variable CONW el aumento de una unidad supone un $60,5 \%$ más de posibilidades de ocurrencia de tormenta, aunque respecto a esta variable hay que recordar que se le ha aplicado un cambio de escala (se ha multiplicado por 10000 ya que se movía en rangos de valores por debajo de la diezmilésima de unidad), por lo que ese efecto de aumento de una unidad no se puede producir en la realidad, cuyos valores son muchísimo más bajos.

Con las estimaciones de los parámetros mostrados en la Tabla 5.3 la ecuación de regresión logística para este modelo es la siguiente: 


$$
p=\frac{1}{1+e^{-\left(-23,596+0,439^{*} T T-0,121^{*} \mathrm{CONH}+0,423^{*} \mathrm{CONW}\right)}}
$$

Donde $\mathrm{p}$ es la probabilidad de ocurrencia de tormenta. Así pues, si la probabilidad obtenida es mayor o igual que 0,3 (que es el valor considerado como regla de discriminación) se considera que se puede producir tormenta, mientras que si por el contrario dicha probabilidad es inferior a 0,3 se descarta dicha posibilidad. Aplicando la ecuación anterior a los datos del estudio se obtiene la Tabla 5.4, que presenta los resultados de la clasificación para la muestra de entrenamiento ( $70 \%$ de los datos) y para la muestra de validación (30\% restante). El porcentaje global de acierto del modelo es de un $85,7 \%$; la no ocurrencia de tormenta se clasifica correctamente en un $91,0 \%$, mientras que la ocurrencia de tormenta presenta un porcentaje de acierto del $50,6 \%$. La muestra de validación tiene un porcentaje de acierto global del 85,6 \%.

Tabla 5.4. Tabla de clasificación para el conjunto de los datos.

\begin{tabular}{|c|c|c|c|c|c|c|c|}
\hline \multirow{4}{*}{\multicolumn{2}{|c|}{ Observado }} & \multicolumn{6}{|c|}{ Pronosticado } \\
\hline & & \multicolumn{3}{|c|}{$\begin{array}{c}\text { Muestra de } \\
\text { entrenamiento (70 \%) }\end{array}$} & \multicolumn{3}{|c|}{$\begin{array}{c}\text { Muestra de } \\
\text { validación (30\%) }\end{array}$} \\
\hline & & \multicolumn{2}{|c|}{ TORMENTA } & \multirow{2}{*}{$\begin{array}{l}\text { Porcentaje } \\
\text { correcto }\end{array}$} & \multicolumn{2}{|c|}{ TORMENTA } & \multirow{2}{*}{$\begin{array}{l}\text { Porcentaje } \\
\text { correcto }\end{array}$} \\
\hline & & Sí & NO & & Sí & NO & \\
\hline \multirow{2}{*}{ TORMENTA } & Sí & 4212 & 4111 & 50,6 & 1826 & 1718 & 51,5 \\
\hline & NO & 5052 & 50773 & 91,0 & 2193 & 21483 & 90,7 \\
\hline \multicolumn{2}{|c|}{ Porcentaje global } & & & 85,7 & & & 85,6 \\
\hline
\end{tabular}

Por último, y para completar el estudio, una vez obtenida la tabla de clasificación para el conjunto de los datos (Tabla 5.4), se calculan los índices de precisión del modelo obtenido. Los índices mostrados se calculan a raíz de los resultados obtenidos en la citada tabla, de acuerdo a unas fórmulas que a continuación se definen (LÓPEZ ET AL., 2008) y (JOLLIFEE ET AL., 2003). Se presenta la Tabla 5.5 para facilitar la comprensión sobre cómo se definen y calculan cada uno de los índices de precisión mostrados.

Tabla 5.5. Definición de los índices de precisión empleados.

\begin{tabular}{|c|c|c|c|}
\hline \multirow{2}{*}{ Observado } & \multicolumn{3}{|c|}{ Pronosticado } \\
\cline { 2 - 4 } & $\mathrm{Si}$ & No & Total \\
\hline $\mathrm{Si}$ & $\mathrm{a}$ & $\mathrm{b}$ & $\mathrm{a}+\mathrm{b}$ \\
\hline No & $\mathrm{c}$ & $\mathrm{d}$ & $\mathrm{c}+\mathrm{d}$ \\
\hline Total & $\mathrm{a}+\mathrm{c}$ & $\mathrm{b}+\mathrm{d}$ & $\mathrm{a}+\mathrm{b}+\mathrm{c}+\mathrm{d}$ \\
\hline
\end{tabular}

False alarm ratio (FAR, proporción de falsas alarmas), es la proporción de predicciones de ocurrencia que no se han observado.

$$
F A R=\frac{c}{a+c}
$$

Frequency of hits (POH, frecuencia de aciertos), complementario de FAR.

$$
\mathrm{POH}=\frac{a}{a+c}
$$


Hit rate $(\mathrm{H}$, tasa de aciertos), es la proporción de ocurrencias que fueron correctamente pronosticadas.

$$
\mathrm{H}=\frac{a}{a+b}
$$

Frequency of misses (FOM, frecuencia de errores), es el complementario de $\mathrm{H}$.

$$
\mathrm{FOM}=\frac{b}{a+b}
$$

False alarm rate (F, probabilidad de falsa detección), es la proporción de no ocurrencias que fueron incorrectamente predichas.

$$
\mathrm{F}=\frac{c}{c+d}
$$

Probability of null event (PON, probabilidad de evento nulo), es el complementario de F.

$$
\mathrm{PON}=\frac{d}{c+d}
$$

Detection failure ratio (DFR, tasa de fallo en la detección), es la proporción de ocurrencias no pronosticadas.

$$
\mathrm{DFR}=\frac{b}{b+d}
$$

Frecuency of correct null events (FOCN, frecuencia de eventos nulos correctos), es el complementario de DFR.

$$
\mathrm{FOCN}=\frac{d}{b+d}
$$

Heidke's Skill Score (HSS, tasa de aciertos de Heidke), es la proporción de predicciones que podrían resultar correctas al azar.

$$
\mathrm{HSS}=\frac{2 *((a * d)-c)}{((a+b) *(c+d))+((a+c) *(c+d))}
$$

Critical success index (CSI, índice crítico de aciertos), es la probabilidad condicional de un acierto siempre que el acontecimiento haya sido pronosticado, observado, o ambas cosas.

$$
\mathrm{CSI}=\frac{a}{a+b+c}
$$

El rango de valores que pueden alcanzar cada uno de los índices anteriormente presentados es de 0 a 1, ambos inclusive, a excepción del Heidkés Skill Score en el que el rango de valores que puede tomar está entre -1 y 1 , ambos inclusive. Lo ideal sería que los índices $\mathrm{POH}, \mathrm{H}, \mathrm{PON}, \mathrm{FOCN}$ y CSI estuvieran lo más próximos a $1 \mathrm{y}$, por el contrario, los índices FAR, FOM, F y DFR (que son los complementarios de POH, H PON y FOCN, respectivamente) presentaran valores próximos a 0 , lo cual significaría que el modelo de predicción es muy satisfactorio. En el caso del HSS, valores próximos 
a -1 o 1 indicarían una predicción casi perfecta, mientras que valores cercanos al cero indicarían que el modelo obtenido no es un buen modelo de predicción.

Los índices de precisión obtenidos para el conjunto de los datos se presentan en la Tabla 5.6, tomando como base de cálculo los resultados presentados en la Tabla 5.4. De lo anterior, se puede concluir que el modelo obtenido es moderadamente satisfactorio ya que si bien obtiene solo un 0,315 de CSI y un 0,436 de HSS, en lo que respecta a los índices $\mathrm{POH}$ y $\mathrm{H}$ está cerca del 0,5 (0,455 y 0,506 respectivamente). Por el contrario se obtienen muy buenos resultados (por encima de 0,9) en los índices PON y FOCN, más concretamente 0,910 y 0,925 respectivamente. En cualquier caso, el hecho de buscar resultados a la resolución de una cuadrícula de la rejilla de $0,5^{\circ}$ hace que haya muchas probabilidades y un error de predicción en una cuadrícula adyacente a otras en las que se ha predicho correctamente penaliza mucho los resultados globales.

Tabla 5.6. Índices de precisión para el conjunto de los datos.

\begin{tabular}{|l|c|c|}
\hline \multicolumn{1}{|c|}{ Índice de Precisión } & $\begin{array}{c}\text { Muestra de } \\
\text { entrenamiento }\end{array}$ & $\begin{array}{c}\text { Muestra de } \\
\text { validación }\end{array}$ \\
\hline False alarm ratio (FAR) & 0,545 & 0,546 \\
\hline Frequency of hits (POH) & 0,455 & 0,454 \\
\hline Hit rate (H) & 0,506 & 0,515 \\
\hline Frecuency of misses (FOM) & 0,494 & 0,485 \\
\hline False alarm rate (F) & 0,090 & 0,093 \\
\hline Probability of null event (PON) & 0,910 & 0,907 \\
\hline Detection failure ratio (DFR) & 0,075 & 0,074 \\
\hline Frecuency of correct null events (FOCN) & 0,925 & 0,926 \\
\hline Heidkés skill score index (HSS) & 0,436 & 0,438 \\
\hline Critical Success Index (CSI) & 0,315 & 0,318 \\
\hline
\end{tabular}

\subsection{Atribuciốn de causas para cada tipo sinốptico}

De manera análoga a la regresión logística para el conjunto de los datos, se ha repetido el mismo análisis utilizando el mismo método de regresión logística (pasos hacia delante Wald) y con el mismo punto de corte para clasificar $(0,3)$ para cada una de las situaciones sinópticas en las que se dan los datos de partida. Así pues se han obtenido nueve modelos específicos y distintos, de modo que puedan dar una orientación sobre los campos a los que se debería prestar más atención en cada tipo de situación y sobre la predecibilidad de las tormentas en cada caso. 
A continuación se presentan los resultados obtenidos en cada uno de los análisis, si bien por brevedad solo se presentan la tabla resumen de las variables incluidas en el modelo seleccionado, la ecuación de regresión logística y la tabla de clasificación para cada tipo de situación. Es importante añadir que las variables aparecen tanto en la tabla resumen como en la ecuación de regresión logística por el orden de entrada de cada una de ellas en el modelo. Así, por ejemplo, en las situaciones de masa de aire (Tabla 5.7) el orden de introducción de las variables en el modelo es TT, CONW, PSL y CONH (Total de Totales, Convergencia de Vientos, Tendencia de la Presión y Convergencia de Humedad, respectivamente).

A la vista de cada una de las tablas que se presentan a continuación resulta interesante analizar cómo el diferente carácter, tanto térmico como dinámico, de las distintas situaciones sinópticas determina tanto las variables introducidas en cada modelo, como el peso de las mismas. Por ejemplo, en el caso de las situaciones de masas de aire, Tabla 5.7, es la variable TT (con su carácter puramente térmico) la que tiene especial relevancia, mientras que en las situaciones depresionarias entrantes y oclusiones y vaguadas rebasadas (Tabla 5.17 y Tabla 5.23) son los aspectos hídricos (CONH) los más influyentes.

Al final del capítulo se adjunta una tabla resumen con los índices de calidad obtenidos para cada uno de los nueve modelos (Tabla 5.25).

\subsubsection{Situaciones de masa de aire (Tipo 1)}

Tabla 5.7. Variables en la ecuación de regresión logística para las situaciones de masa de aire (Tipo 1).

\begin{tabular}{|c|l|r|r|r|r|r|r|}
\cline { 2 - 8 } \multicolumn{2}{c|}{} & \multicolumn{1}{c|}{ B } & \multicolumn{1}{c|}{ E.T. } & \multicolumn{1}{c|}{ Wald } & \multicolumn{1}{c|}{ gl } & \multicolumn{1}{c|}{ Sig. } & \multicolumn{1}{c|}{$\operatorname{Exp(B)}$} \\
\hline \multirow{3}{*}{ Paso 4 } & TT & 0,450 & 0,018 & 637,112 & 1 & 0,000 & 1,569 \\
\cline { 2 - 9 } & CONW & 1,424 & 0,120 & 140,894 & 1 & 0,000 & 4,152 \\
\cline { 2 - 9 } & PSL & $-0,266$ & 0,039 & 46,448 & 1 & 0,000 & 0,766 \\
\cline { 2 - 9 } & CONH & $-0,112$ & 0,024 & 22,216 & 1 & 0,000 & 0,894 \\
\cline { 2 - 9 } & Constante & $-23,730$ & 0,887 & 715,335 & 1 & 0,000 & 0,000 \\
\hline
\end{tabular}

La ecuación obtenida para las situaciones de masa de aire es:

$$
p=\frac{1}{1+e^{-\left(-23,730+0,450^{*} T T+1,424^{*} C O N W-0,266^{*} P S L-0,112^{*} C O N H\right)}}
$$

Tabla 5.8. Tabla de clasificación para las situaciones de masa de aire (Tipo 1).

\begin{tabular}{|c|c|c|c|c|c|c|c|}
\hline \multirow{4}{*}{\multicolumn{2}{|c|}{ Observado }} & \multicolumn{6}{|c|}{ Pronosticado } \\
\hline & & \multicolumn{3}{|c|}{$\begin{array}{c}\text { Muestra de } \\
\text { entrenamiento }(70 \%)\end{array}$} & \multicolumn{3}{|c|}{$\begin{array}{c}\text { Muestra de } \\
\text { validación (30\%) }\end{array}$} \\
\hline & & \multicolumn{2}{|c|}{ TORMENTA } & \multirow{2}{*}{$\begin{array}{l}\text { Porcentaje } \\
\text { correcto }\end{array}$} & \multicolumn{2}{|c|}{ TORMENTA } & \multirow{2}{*}{$\begin{array}{l}\text { Porcentaje } \\
\text { correcto }\end{array}$} \\
\hline & & Sí & NO & & Sí & $\mathrm{NO}$ & \\
\hline \multirow{2}{*}{ TORMENTA } & SÍ & 556 & 455 & 55,0 & 243 & 196 & 55,4 \\
\hline & $\mathrm{NO}$ & 632 & 4670 & 88,1 & 276 & 1963 & 87,7 \\
\hline \multicolumn{2}{|c|}{ Porcentaje global } & & & 82,8 & & & 82,4 \\
\hline
\end{tabular}




\subsubsection{Situaciones del sur (Tipo 2)}

Tabla 5.9. Variables en la ecuación de regresión logística para las situaciones de sur (Tipo 2).

\begin{tabular}{|l|l|r|r|r|r|r|r|}
\cline { 3 - 8 } \multicolumn{2}{c|}{} & \multicolumn{1}{c|}{ B } & \multicolumn{1}{c|}{ E.T. } & \multicolumn{1}{c|}{ Wald } & gl & \multicolumn{1}{c|}{ Sig. } & Exp(B) \\
\hline \multirow{4}{*}{ Paso 3 } & TT & 0,310 & 0,027 & 129,614 & 1 & 0,000 & 1,364 \\
\cline { 2 - 8 } & AESP & $-0,333$ & 0,049 & 45,858 & 1 & 0,000 & 0,717 \\
\cline { 2 - 8 } & CONH & $-0,196$ & 0,035 & 31,212 & 1 & 0,000 & 0,822 \\
\cline { 2 - 8 } & Constante & $-16,643$ & 1,354 & 151,035 & 1 & 0,000 & 0,000 \\
\hline
\end{tabular}

Ecuación de regresión logística para las situaciones de sur:

$$
p=\frac{1}{1+e^{-\left(-16,643+0,310^{*} T T-0,333^{*} A E S P-0,196^{*} \mathrm{CONH}\right)}}
$$

Tabla 5.10. Tabla de clasificación para las situaciones de sur (Tipo 2).

\begin{tabular}{|c|c|c|c|c|c|c|c|}
\hline \multirow{4}{*}{\multicolumn{2}{|c|}{ Observado }} & \multicolumn{6}{|c|}{ Pronosticado } \\
\hline & & \multicolumn{3}{|c|}{$\begin{array}{c}\text { Muestra de } \\
\text { entrenamiento }(70 \%)\end{array}$} & \multicolumn{3}{|c|}{$\begin{array}{c}\text { Muestra de } \\
\text { validación }(30 \%)\end{array}$} \\
\hline & & \multicolumn{2}{|c|}{ TORMENTA } & \multirow{2}{*}{$\begin{array}{l}\text { Porcentaje } \\
\text { correcto }\end{array}$} & \multicolumn{2}{|c|}{ TORMENTA } & \multirow{2}{*}{$\begin{array}{l}\text { Porcentaje } \\
\text { correcto }\end{array}$} \\
\hline & & SÍ & NO & & SÍ & NO & \\
\hline \multirow{2}{*}{ TORMENTA } & SÍ & 228 & 127 & 64,2 & 85 & 64 & 57,0 \\
\hline & $\mathrm{NO}$ & 219 & 1062 & 82,9 & 108 & 456 & 80,9 \\
\hline \multicolumn{2}{|c|}{ Porcentaje global } & & & 78,9 & & & 75,9 \\
\hline
\end{tabular}

\subsubsection{Situaciones del suroeste con difluencia (Tipo 3)}

Tabla 5.11. Variables en la ecuación de regresión logística para las situaciones de SW difluentes (Tipo 3).

\begin{tabular}{|l|l|r|r|r|r|r|r|}
\cline { 3 - 8 } \multicolumn{2}{c|}{} & \multicolumn{1}{c|}{ B } & \multicolumn{1}{c|}{ E.T. } & \multicolumn{1}{c|}{ Wald } & \multicolumn{1}{c|}{ gl } & \multicolumn{1}{c|}{ Sig. } & \multicolumn{1}{c|}{$\operatorname{Exp(B)}$} \\
\hline \multirow{4}{*}{ Paso 3 } & TT & 0,325 & 0,013 & 591,389 & 1 & 0,000 & 1,384 \\
\cline { 2 - 8 } & CONH & $-0,098$ & 0,016 & 39,665 & 1 & 0,000 & 0,907 \\
\cline { 2 - 8 } & AESP & 0,119 & 0,020 & 36,863 & 1 & 0,000 & 1,126 \\
\cline { 2 - 8 } & Constante & $-17,342$ & 0,668 & 673,372 & 1 & 0,000 & 0,000 \\
\hline
\end{tabular}

Ecuación de regresión logística para las situaciones de suroeste difluyentes:

$$
p=\frac{1}{1+e^{-\left(-17,342+0,325^{*} T T-0,098^{*} \mathrm{CONH}+0,119^{*} \mathrm{AESP}\right)}}
$$


Tabla 5.12. Tabla de clasificación para las situaciones de SW difluentes (Tipo 3).

\begin{tabular}{|c|c|c|c|c|c|c|c|}
\hline \multirow{4}{*}{\multicolumn{2}{|c|}{ Observado }} & \multicolumn{6}{|c|}{ Pronosticado } \\
\hline & & \multicolumn{3}{|c|}{$\begin{array}{c}\text { Muestra de } \\
\text { entrenamiento }(70 \%)\end{array}$} & \multicolumn{3}{|c|}{$\begin{array}{c}\text { Muestra de } \\
\text { validación }(30 \%)\end{array}$} \\
\hline & & \multicolumn{2}{|c|}{ TORMENTA } & \multirow{2}{*}{$\begin{array}{l}\text { Porcentaje } \\
\text { correcto }\end{array}$} & \multicolumn{2}{|c|}{ TORMENTA } & \multirow{2}{*}{$\begin{array}{c}\text { Porcentaje } \\
\text { correcto }\end{array}$} \\
\hline & & SÍ & NO & & SÍ & NO & \\
\hline \multirow{2}{*}{ TORMENTA } & SÍ & 1028 & 415 & 71,2 & 462 & 155 & 74,9 \\
\hline & $\mathrm{NO}$ & 1125 & 2671 & 70,4 & 478 & 1118 & 70,1 \\
\hline \multicolumn{2}{|c|}{ Porcentaje global } & & & 70,6 & & & 71,4 \\
\hline
\end{tabular}

\subsubsection{Situaciones del suroeste sin difluencia (Tipo 4)}

Tabla 5.13. Variables en la ecuación de regresión logística para las situaciones de SW sin difluencia (Tipo 4).

\begin{tabular}{|l|l|r|r|r|r|r|r|}
\cline { 3 - 8 } \multicolumn{2}{c|}{} & \multicolumn{1}{c|}{ B } & \multicolumn{1}{c|}{ E.T. } & \multicolumn{1}{c|}{ Wald } & \multicolumn{1}{c|}{ gl } & \multicolumn{1}{c|}{ Sig. } & \multicolumn{1}{c|}{$\operatorname{Exp(B)}$} \\
\hline \multirow{4}{*}{ Paso 4 } & TT & 0,446 & 0,011 & 1683,896 & 1 & 0,000 & 1,562 \\
\cline { 2 - 8 } & CONH & $-0,092$ & 0,012 & 63,112 & 1 & 0,000 & 0,912 \\
\cline { 2 - 8 } & CONW & 0,410 & 0,066 & 38,405 & 1 & 0,000 & 1,507 \\
\cline { 2 - 8 } & PSL & $-0,095$ & 0,023 & 17,852 & 1 & 0,000 & 0,909 \\
\cline { 2 - 8 } & Constante & $-23,713$ & 0,544 & 1899,338 & 1 & 0,000 & 0,000 \\
\hline
\end{tabular}

Ecuación de regresión logística para las situaciones de suroeste sin difluencia:

$$
p=\frac{1}{1+e^{-\left(-23,713+0,446^{*} T T-0,092^{*} \mathrm{CONH}+0,410^{*} \mathrm{CONW}-0,095^{*} P S L\right)}}
$$

Tabla 5.14. Tabla de clasificación para las situaciones de SW sin difluencia (Tipo 4).

\begin{tabular}{|c|c|c|c|c|c|c|c|}
\hline \multirow{4}{*}{\multicolumn{2}{|c|}{ Observado }} & \multicolumn{6}{|c|}{ Pronosticado } \\
\hline & & \multicolumn{3}{|c|}{$\begin{array}{c}\text { Muestra de } \\
\text { entrenamiento }(70 \%)\end{array}$} & \multicolumn{3}{|c|}{$\begin{array}{c}\text { Muestra de } \\
\text { validación }(30 \%)\end{array}$} \\
\hline & & \multicolumn{2}{|c|}{ TORMENTA } & \multirow{2}{*}{$\begin{array}{l}\text { Porcentaje } \\
\text { correcto }\end{array}$} & \multicolumn{2}{|c|}{ TORMENTA } & \multirow{2}{*}{$\begin{array}{l}\text { Porcentaje } \\
\text { correcto }\end{array}$} \\
\hline & & Sí & NO & & SÍ & NO & \\
\hline \multirow{2}{*}{ TORMENTA } & SÍ & 1483 & 872 & 63,0 & 659 & 367 & 64,2 \\
\hline & $\mathrm{NO}$ & 1536 & 8524 & 84,7 & 636 & 3662 & 85,2 \\
\hline \multicolumn{2}{|c|}{ Porcentaje global } & & & 80,6 & & & 81,2 \\
\hline
\end{tabular}

\subsubsection{Situaciones del oeste (Tipo 5)}

Tabla 5.15. Variables en la ecuación de regresión logística para las situaciones del W (Tipo 5).

\begin{tabular}{|l|l|r|r|r|r|r|r|}
\cline { 2 - 8 } \multicolumn{2}{c|}{} & \multicolumn{1}{c|}{ B } & \multicolumn{1}{c|}{ E.T. } & \multicolumn{1}{c|}{ Wald } & \multicolumn{1}{c|}{ gl } & \multicolumn{1}{c|}{ Sig. } & \multicolumn{1}{c|}{$\operatorname{Exp(B)}$} \\
\hline \multirow{3}{*}{ Paso 4 } & TT & 0,477 & 0,012 & 1519,807 & 1 & 0,000 & 1,611 \\
\cline { 2 - 8 } & CONW & 0,842 & 0,071 & 139,569 & 1 & 0,000 & 2,321 \\
\cline { 2 - 8 } & PSL & $-0,264$ & 0,027 & 97,140 & 1 & 0,000 & 0,768 \\
\cline { 2 - 8 } & ADVG & $-0,025$ & 0,004 & 41,482 & 1 & 0,000 & 0,975 \\
\cline { 2 - 8 } & Constante & $-25,286$ & 0,610 & 1719,029 & 1 & 0,000 & 0,000 \\
\hline
\end{tabular}


Ecuación de regresión logística para las situaciones del oeste:

$$
p=\frac{1}{1+e^{-\left(-25,286+0,477^{*} T T+0,842^{*} C O N W-0,264^{*} P S L-0,025^{*} A D V G\right)}}
$$

Tabla 5.16. Tabla de clasificación para las situaciones del W (Tipo 5).

\begin{tabular}{|c|c|c|c|c|c|c|c|}
\hline \multirow{4}{*}{\multicolumn{2}{|c|}{ Observado }} & \multicolumn{6}{|c|}{ Pronosticado } \\
\hline & & \multicolumn{3}{|c|}{$\begin{array}{c}\text { Muestra de } \\
\text { entrenamiento }(70 \%)\end{array}$} & \multicolumn{3}{|c|}{$\begin{array}{c}\text { Muestra de } \\
\text { validación }(30 \%)\end{array}$} \\
\hline & & \multicolumn{2}{|c|}{ TORMENTA } & \multirow{2}{*}{$\begin{array}{l}\text { Porcentaje } \\
\text { correcto }\end{array}$} & \multicolumn{2}{|c|}{ TORMENTA } & \multirow{2}{*}{$\begin{array}{l}\text { Porcentaje } \\
\text { correcto }\end{array}$} \\
\hline & & SÍ & NO & & SÍ & NO & \\
\hline \multirow{2}{*}{ TORMENTA } & SÍ & 577 & 896 & 39,2 & 263 & 370 & 41,5 \\
\hline & $\mathrm{NO}$ & 762 & 11728 & 93,9 & 343 & 5068 & 93,7 \\
\hline \multicolumn{2}{|c|}{ Porcentaje global } & & & 88,1 & & & 88,2 \\
\hline
\end{tabular}

\subsubsection{Situaciones depresionarias entrantes (Tipo 6)}

Tabla 5.17. Variables en la ecuación de regresión logística para las situaciones depresionarias entrantes (Tipo 6).

\begin{tabular}{|l|l|r|r|r|r|r|r|}
\cline { 3 - 9 } \multicolumn{2}{c|}{} & \multicolumn{1}{c|}{ B } & \multicolumn{1}{c|}{ E.T. } & \multicolumn{1}{c|}{ Wald } & \multicolumn{1}{c|}{ gl } & \multicolumn{1}{c|}{ Sig. } & \multicolumn{1}{c|}{$\operatorname{Exp(B)}$} \\
\hline \multirow{4}{*}{ Paso 3 } & CONH & $-0,390$ & 0,053 & 54,764 & 1 & 0,000 & 0,677 \\
\cline { 2 - 9 } & TT & 0,203 & 0,035 & 33,904 & 1 & 0,000 & 1,225 \\
\cline { 2 - 9 } & AESP & $-0,320$ & 0,065 & 23,876 & 1 & 0,000 & 0,726 \\
\cline { 2 - 8 } & Constante & $-11,907$ & 1,756 & 45,992 & 1 & 0,000 & 0,000 \\
\hline
\end{tabular}

Ecuación de regresión logística para las situaciones depresionarias entrantes:

$$
p=\frac{1}{1+e^{-\left(-11,907-0,390^{*} C O N H+0,203^{*} T T-0,320^{*} \text { AESP }\right)}}
$$

Tabla 5.18. Tabla de clasificación para las situaciones depresionarias entrantes (Tipo 6).

\begin{tabular}{|c|r|r|r|r|r|r|r|}
\hline \multirow{2}{*}{ Observado } & \multicolumn{6}{|c|}{ Pronosticado } \\
\cline { 2 - 8 } & \multicolumn{3}{|c|}{$\begin{array}{c}\text { Muestra de } \\
\text { entrenamiento }(70 \%)\end{array}$} & \multicolumn{3}{c|}{$\begin{array}{c}\text { Muestra de } \\
\text { validación (30 \%) }\end{array}$} \\
\cline { 2 - 8 } & & $\begin{array}{r}\text { TORMENTA } \\
\text { SÍ }\end{array}$ & NO & $\begin{array}{c}\text { Porcentaje } \\
\text { correcto }\end{array}$ & $\begin{array}{r}\text { TORMENTA } \\
\text { SÍ }\end{array}$ & NO & $\begin{array}{c}\text { Porcentaje } \\
\text { correcto }\end{array}$ \\
\hline \multirow{2}{*}{ TORMENTA } & SÍ & 120 & 96 & 55,6 & 49 & 38 & 56,3 \\
\cline { 2 - 8 } & NO & 119 & 755 & 86,4 & 44 & 318 & 87,8 \\
\hline \multicolumn{2}{|l|}{ Porcentaje global } & & & 80,3 & & & 81,7 \\
\hline
\end{tabular}




\subsubsection{Situaciones depresionarias rebasadas (Tipo 7)}

Tabla 5.19. Variables en la ecuación de regresión logística para las situaciones depresionarias rebasadas (Tipo 7).

\begin{tabular}{|c|l|r|r|r|r|r|r|}
\cline { 2 - 9 } \multicolumn{2}{c|}{} & \multicolumn{1}{c|}{ B } & \multicolumn{1}{c|}{ E.T. } & \multicolumn{1}{c|}{ Wald } & \multicolumn{1}{c|}{ gl } & \multicolumn{1}{c|}{ Sig. } & \multicolumn{1}{c|}{ Exp(B) } \\
\hline \multirow{3}{*}{ Paso 4 } & TT & 0,496 & 0,029 & 288,909 & 1 & 0,000 & 1,642 \\
\cline { 2 - 9 } & CONH & $-0,191$ & 0,037 & 27,108 & 1 & 0,000 & 0,826 \\
\cline { 2 - 9 } & PSL & $-0,261$ & 0,077 & 11,417 & 1 & 0,001 & 0,770 \\
\cline { 2 - 9 } & CONW & 0,597 & 0,213 & 7,868 & 1 & 0,005 & 1,817 \\
\cline { 2 - 8 } & Constante & $-26,691$ & 1,466 & 331,593 & 1 & 0,000 & 0,000 \\
\hline
\end{tabular}

Ecuación de regresión logística para las situaciones depresionarias rebasadas:

$$
p=\frac{1}{1+e^{-\left(-26,691+0,496^{*} T T-0,191^{*} \mathrm{CONH}-0,261^{*} P S L+0,597^{*} \mathrm{CONW}\right)}}
$$

Tabla 5.20. Tabla de clasificación para las situaciones depresionarias rebasadas (Tipo 7).

\begin{tabular}{|c|c|c|c|c|c|c|c|}
\hline \multirow{4}{*}{\multicolumn{2}{|c|}{ Observado }} & \multicolumn{6}{|c|}{ Pronosticado } \\
\hline & & \multicolumn{3}{|c|}{$\begin{array}{c}\text { Muestra de } \\
\text { entrenamiento }(70 \%)\end{array}$} & \multicolumn{3}{|c|}{$\begin{array}{c}\text { Muestra de } \\
\text { validación }(30 \%)\end{array}$} \\
\hline & & \multicolumn{2}{|c|}{ TORMENTA } & \multirow{2}{*}{$\begin{array}{c}\text { Porcentaje } \\
\text { correcto }\end{array}$} & \multicolumn{2}{|c|}{ TORMENTA } & \multirow{2}{*}{$\begin{array}{l}\text { Porcentaje } \\
\text { correcto }\end{array}$} \\
\hline & & SÍ & NO & & SÍ & NO & \\
\hline \multirow{2}{*}{ TORMENTA } & SÍ & 134 & 125 & 51,7 & 52 & 57 & 47,7 \\
\hline & NO & 161 & 2693 & 94,4 & 64 & 1169 & 94,8 \\
\hline \multicolumn{2}{|c|}{ Porcentaje global } & & & 90,8 & & & 91,0 \\
\hline
\end{tabular}

\subsubsection{Situaciones de ondas largas del noroeste (Tipo 8)}

Tabla 5.21. Variables en la ecuación de regresión logística para las situaciones de ondas largas del NW (Tipo 8).

\begin{tabular}{|l|l|r|r|r|r|r|r|}
\cline { 3 - 8 } \multicolumn{2}{c|}{} & \multicolumn{1}{c|}{ B } & \multicolumn{1}{c|}{ E.T. } & \multicolumn{1}{c|}{ Wald } & \multicolumn{1}{c|}{ gl } & \multicolumn{1}{c|}{ Sig. } & \multicolumn{1}{c|}{ Exp(B) } \\
\hline \multirow{3}{*}{ Paso 4 } & TT & 0,472 & 0,012 & 1592,700 & 1 & 0,000 & 1,604 \\
\cline { 2 - 8 } & CONH & $-0,144$ & 0,020 & 52,307 & 1 & 0,000 & 0,866 \\
\cline { 2 - 8 } & CONW & 0,653 & 0,089 & 53,442 & 1 & 0,000 & 1,920 \\
\cline { 2 - 8 } & DIVQ & $-0,023$ & 0,004 & 32,408 & 1 & 0,000 & 0,977 \\
\cline { 2 - 8 } & Constante & $-25,653$ & 0,584 & 1928,164 & 1 & 0,000 & 0,000 \\
\hline
\end{tabular}

Ecuación de regresión logística para las situaciones de noroeste:

$$
p=\frac{1}{1+e^{-\left(-25,653+0,472^{*} T T-0,144^{*} C O N H+0,653^{*} C O N W-0,023^{*} D I V Q\right)}}
$$


Tabla 5.22. Tabla de clasificación para las situaciones de ondas largas del NW (Tipo 8).

\begin{tabular}{|c|c|c|c|c|c|c|c|}
\hline \multirow{4}{*}{\multicolumn{2}{|c|}{ Observado }} & \multicolumn{6}{|c|}{ Pronosticado } \\
\hline & & \multicolumn{3}{|c|}{$\begin{array}{c}\text { Muestra de } \\
\text { entrenamiento }(70 \%)\end{array}$} & \multicolumn{3}{|c|}{$\begin{array}{c}\text { Muestra de } \\
\text { validación }(30 \%)\end{array}$} \\
\hline & & \multicolumn{2}{|c|}{ TORMENTA } & \multirow{2}{*}{$\begin{array}{l}\text { Porcentaje } \\
\text { correcto }\end{array}$} & \multicolumn{2}{|c|}{ TORMENTA } & \multirow{2}{*}{$\begin{array}{l}\text { Porcentaje } \\
\text { correcto }\end{array}$} \\
\hline & & SÍ & NO & & SÍ & NO & \\
\hline \multirow{2}{*}{ TORMENTA } & SÍ & 333 & 646 & 34,0 & 138 & 260 & 34,7 \\
\hline & NO & 475 & 18244 & 97,5 & 195 & 7573 & 97,5 \\
\hline \multicolumn{2}{|c|}{ Porcentaje global } & & & 94,3 & & & 94,4 \\
\hline
\end{tabular}

\subsubsection{Situaciones de oclusiones a vaguadas rebasadas (Tipo 9)}

Tabla 5.23. Variables en la ecuación de regresión logística para las situaciones de oclusiones a vaguadas rebasadas (Tipo 9).

\begin{tabular}{|l|l|r|r|r|r|r|r|}
\cline { 3 - 9 } \multicolumn{2}{c|}{} & \multicolumn{1}{c|}{ B } & \multicolumn{1}{c|}{ E.T. } & \multicolumn{1}{c|}{ Wald } & gl & \multicolumn{1}{c|}{ Sig. } & \multicolumn{1}{c|}{$\operatorname{Exp(B)}$} \\
\hline \multirow{4}{*}{ Paso 4 } & CONH & $-0,308$ & 0,055 & 31,949 & 1 & 0,000 & 0,735 \\
\cline { 2 - 9 } & TT & 0,196 & 0,033 & 36,301 & 1 & 0,000 & 1,217 \\
\cline { 2 - 9 } & AESP & 0,293 & 0,072 & 16,772 & 1 & 0,000 & 1,341 \\
\cline { 2 - 9 } & CONW & 0,672 & 0,255 & 6,941 & 1 & 0,008 & 1,958 \\
\cline { 2 - 8 } & Constante & $-10,961$ & 1,673 & 42,942 & 1 & 0,000 & 0,000 \\
\hline
\end{tabular}

Ecuación de regresión logística para las situaciones de oclusiones a vaguadas rebasadas:

$$
p=\frac{1}{1+e^{-\left(-10,961-0,308^{*} C O N H+0,196^{*} T T+0,293^{*} A E S P+0,672^{*} C O N W\right)}}
$$

Tabla 5.24. Tabla de clasificación para las situaciones de oclusiones a vaguadas rebasadas (Tipo 9).

\begin{tabular}{|c|c|c|c|c|c|c|c|}
\hline \multirow{4}{*}{\multicolumn{2}{|c|}{ Observado }} & \multicolumn{6}{|c|}{ Pronosticado } \\
\hline & & \multicolumn{3}{|c|}{$\begin{array}{c}\text { Muestra de } \\
\text { entrenamiento }(70 \%)\end{array}$} & \multicolumn{3}{|c|}{$\begin{array}{c}\text { Muestra de } \\
\text { validación }(30 \%)\end{array}$} \\
\hline & & \multicolumn{2}{|c|}{ TORMENTA } & \multirow{2}{*}{$\begin{array}{l}\text { Porcentaje } \\
\text { correcto }\end{array}$} & \multicolumn{2}{|c|}{ TORMENTA } & \multirow{2}{*}{$\begin{array}{l}\text { Porcentaje } \\
\text { correcto }\end{array}$} \\
\hline & & SÍ & $\mathrm{NO}$ & & SÍ & $\mathrm{NO}$ & \\
\hline \multirow{2}{*}{ TORMENTA } & SÍ & 184 & 48 & 79,3 & 67 & 19 & 77,9 \\
\hline & $\mathrm{NO}$ & 181 & 268 & 59,7 & 69 & 136 & 66,3 \\
\hline \multicolumn{2}{|c|}{ Porcentaje global } & & & 66,4 & & & 69,8 \\
\hline
\end{tabular}

En general, puede afirmarse que las situaciones más dinámicas y en las que la convección puede aparecer en cualquier punto del área de estudio (del suroeste con difluencia y de oclusiones a vaguadas rebasadas), se pueden predecir peor, de acuerdo con los valores alcanzados por el porcentaje global de acierto según el modelo de 
regresión logística (del orden del $70 \%$ ). Por el contrario, las que poseen un carácter menos convectivo (ondas largas del noroeste y depresiones rebasadas), alcanzan una predecibilidad del orden del $90 \%$ o superior, presentándose unos valores generales del orden del $80 \%$ para el resto.

Pero, sin embargo, si la atención no se fija en el porcentaje global de acierto, sino en la capacidad de predecir la presencia o ausencia de tormenta, porcentajes correctos de "tormenta sí" o "tormenta no", la situación es diferente. Especialmente en el caso de "tormenta sí" el porcentaje de acierto es más alto en situaciones potencialmente más inestables (del sur y suroeste y de oclusiones a vaguadas rebasadas), llegando a ser del orden del $70 \%$. Por el contrario, es más difícil predecir que va a haber tormenta en una situación a priori más estable (situaciones del oeste $u$ ondas largas del NW), con porcentajes de acierto en la predicción de aparición de tormenta del orden del $30 \%-40 \%$.

Tabla 5.25. Índices de precisión para cada tipo de situación sinóptica.

\begin{tabular}{|l|c|c|c|c|c|c|c|c|c|}
\hline $\begin{array}{l}\text { Índice de } \\
\text { precisión }\end{array}$ & Tipo 1 & Tipo 2 & Tipo 3 & Tipo 4 & Tipo 5 & Tipo 6 & Tipo 7 & Tipo 8 & Tipo 9 \\
\hline FAR & 0,532 & 0,490 & 0,523 & 0,509 & 0,569 & 0,498 & 0,552 & 0,586 & 0,507 \\
\hline POH & 0,468 & 0,510 & 0,477 & 0,491 & 0,431 & 0,502 & 0,448 & 0,414 & 0,493 \\
\hline H & 0,550 & 0,642 & 0,712 & 0,630 & 0,392 & 0,556 & 0,477 & 0,347 & 0,779 \\
\hline FOM & 0,450 & 0,358 & 0,288 & 0,370 & 0,608 & 0,444 & 0,523 & 0,653 & 0,221 \\
\hline F & 0,119 & 0,171 & 0,296 & 0,153 & 0,061 & 0,136 & 0,052 & 0,025 & 0,337 \\
\hline PON & 0,881 & 0,829 & 0,704 & 0,847 & 0,939 & 0,864 & 0,948 & 0,975 & 0,663 \\
\hline DFR & 0,089 & 0,107 & 0,134 & 0,093 & 0,071 & 0,113 & 0,046 & 0,033 & 0,123 \\
\hline FOCN & 0,911 & 0,893 & 0,866 & 0,907 & 0,929 & 0,887 & 0,954 & 0,967 & 0,877 \\
\hline HSS & 0,445 & 0,471 & 0,402 & 0,468 & 0,385 & 0,455 & 0,438 & 0,368 & 0,397 \\
\hline CSI & 0,338 & 0,397 & 0,400 & 0,381 & 0,258 & 0,358 & 0,301 & 0,233 & 0,432 \\
\hline
\end{tabular}

En la Tabla 5.25 se muestran los índices de precisión para cada uno de los modelos que caracterizan cada uno de los tipos de situaciones sinópticas. Se pueden hacer algunas consideraciones sobre los índices más difundidos. Buena parte del resto derivan de estos o son análogos:

\section{Hit rate $(\mathrm{H})$}

Se presentan valores medios ligeramente superiores a 0,5 , destacando la bondad en la predicción de las situaciones del SW con difluencia y las oclusiones a vaguadas rebasadas con valores superiores a 0,7 , mientras que las situaciones del $\mathrm{W}$ y ondas largas del NW apenas alcanzan valores superiores a 0,3 , probablemente porque en estas situaciones las tormentas son extremadamente poco frecuentes, aleatorias y dispersas en el espacio, al tratarse de flujos que avanzan desde el cuarto cuadrante durante la época estival. 
False alarm rate $(\mathrm{F})$

En general se obtienen valores aceptables (inferiores a 0,2), a excepción de las situaciones del SW difluyentes y, sobre todo, las oclusiones a vaguadas rebasadas, en las que claramente se produce sobrepredicción de la convección, pues esta no ocurre en todos los puntos de grid del área de estudio, a pesar de ser situaciones en las que la convección se produce de manera más o menos generalizada.

Critical success index (CSI)

Los valores obtenidos están en la misma línea que los del hit rate $(\mathrm{H})$, siendo los mejores (en torno a 0,4 ) los correspondientes a las situaciones del SW con difluencia y oclusiones a vaguadas rebasadas, mientras que por el contrario los valores más bajos (en torno a 0,2 ) son los correspondientes a las ondas largas del $\mathrm{NW}$, por razones análogas a las citadas anteriormente. 



\section{CASOS DE ESTUDio}

Como complemento a la descripción de situaciones se analiza brevemente un ejemplo de cada uno de los 9 tipos de situaciones establecidos, bien sea por sus características extremas o por su permanencia en el recuerdo de los profesionales o incluso de la memoria colectiva. Sin embargo, aparte de esta consideración, los casos analizados han sido elegidos evitando las fáciles interpretaciones o las ocasiones en los que el modelo ha sido capaz de ajustarse al análisis y predecir con precisión los hechos, pues se trata de dar una visión eminentemente operativa del proceso predictivo.

Los campos presentados para cada caso van a limitarse a la situación con las predicciones $\mathrm{H}+3$ de la pasada de las $12 \mathrm{Z}$ del modelo HINR 0.16, es decir predicciones para las 15 horas del día analizado, representando gráficamente las salidas con la aplicación Metview. Dado que lo que se pretende es describir la situación con la mayor precisión posible, se ha utilizado este modelo de mayor resolución espacial. Además, como se ha indicado anteriormente, con la elección de esta pasada y alcance de predicción, podemos utilizar el archivo histórico almacenado en el proceso de predicción diaria, que consta de un alto número de campos meteorológicos derivados específicos y más elaborados que nos permiten analizar la situación desde un punto de vista complementario. Por motivos de espacio, salvo en un caso a modo de ejemplo, no se representen gráficamente estos campos derivados.

Asimismo, se ha interpolado la precipitación 07-07 Z procedente de los datos de la red climatológica complementaria de AEMET y se han representado directamente las descargas eléctricas producidas en el intervalo de 06-06 Z, en ambos casos desde las 07 o las 06 horas solares del día de la fecha a las 07 o 06 horas solares del día siguiente.

Con el fin de hacer más perceptibles los comentarios, pero manteniendo limitada la documentación suministrada, en cada caso se va a mostrar una imagen con un conjunto de campos:

- Geopotenciales y temperaturas en el nivel de $500 \mathrm{hPa}$ como representativos de los niveles atmosféricos medios a escala sinóptica, con las isohipsas trazadas en dmg (decámetros geopotenciales) adaptando el intervalo según los casos para mostrar la importancia de los flujos.

- Temperatura y vectores de viento en $850 \mathrm{hPa}$ como representativos de los niveles atmosféricos bajos a escala meso-beta, con isotermas de 0,5 en $0,5^{\circ} \mathrm{C}$ y valores de viento según la escala adjunta.

- Presión a nivel del mar (PSL) y los vectores de viento en superficie a escala sinóptica y ampliado a escala meso-beta, con isobaras trazadas de 1 en 1 en hPa y valores de viento según la escala adjunta.

- Mapa compuesto con el índice de inestabilidad Total de Totales (TT), con isolíneas de $1^{\circ}$ en $1^{\circ} \mathrm{C}$ y convergencia de humedad en $925 \mathrm{hPa}$ con isolíneas de $\mathrm{g} \cdot \mathrm{kg}^{-1} \cdot \mathrm{m}^{-1}$, en continuo para las divergencias y a trazos para las convergencias.

- Mapa conjunto de la precipitación y descargas correspondientes al día del episodio, presentadas y coloreadas según intervalos horarios de 4 en 4 horas para apreciar la evolución espacio-temporal de las señales de convección. 
Además, se hace también referencia a los campos de advección diferencial de espesores $500 / 1000 \mathrm{hPa}$, la advección de vorticidad relativa en niveles altos, así como las circulaciones ageostróficas transversales al flujo (vector Q) y la advección térmica en $925 \mathrm{hPa}$ (que puede ayudar a explicar con mayor claridad cómo el campo de viento advecta los campos térmicos es ese nivel), aunque no se representan gráficamente por motivos de extensión y comodidad del texto, más que en el ejemplo de la situación del tipo 4 (situaciones del SW sin difluencia), para dar una idea de su formato y de la información que aportan. 


\section{Caso de estudio del tipo 1 (situaciones de masa de aire): 11 de junio de 2004}

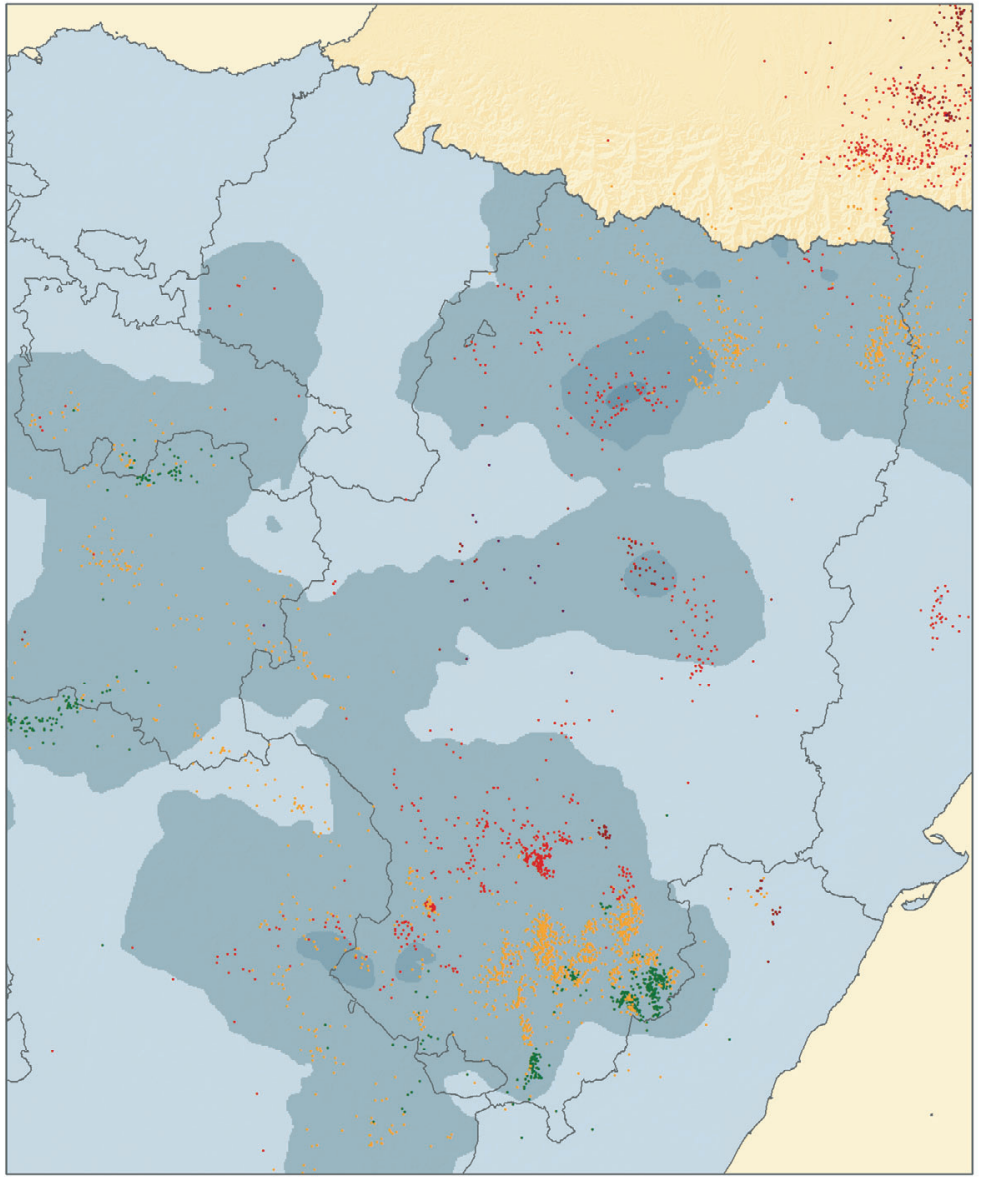

Número de rayos por intervalo horario desde las 06:00 TUC a las 05:59 TUC del día siguiente: 06:00-08:59 09:00-11:59 12:00-14:59 15:00-17:59 18:00-20:59 21:00-23:59 00:00-02:59 03:00-05:59

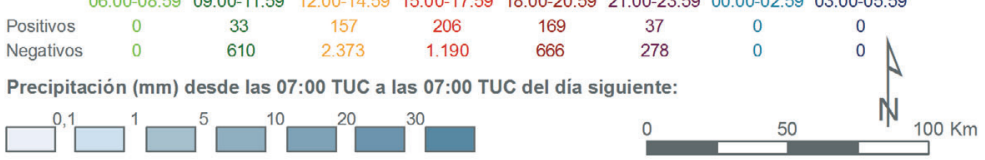

Precipitación (PCP) en 24 h (07-07 Z) y Descargas eléctricas (06-06 Z)

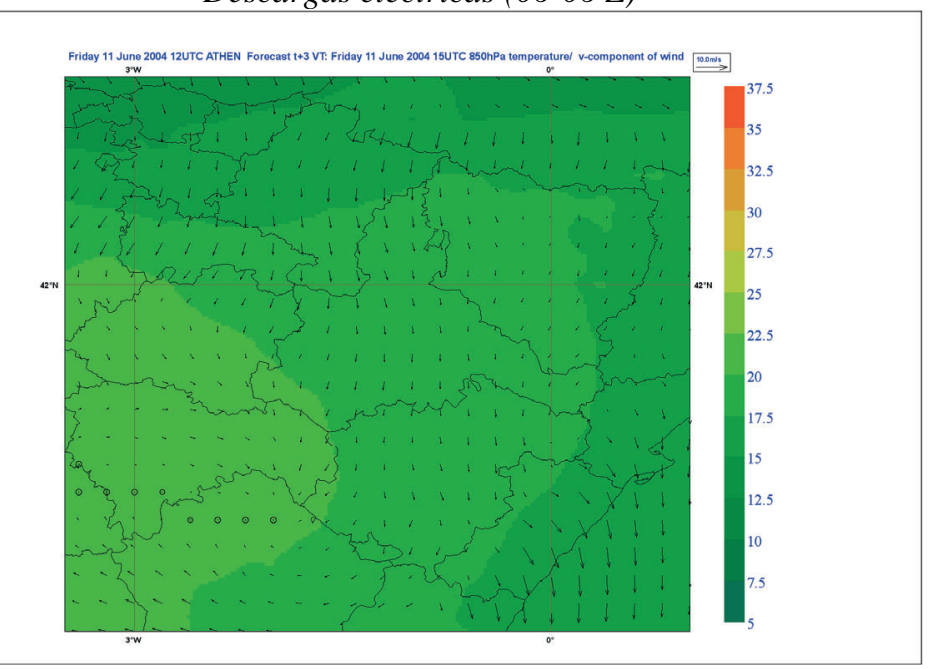

850 hPa: Temperatura(T) y Viento(W) (15 Z)

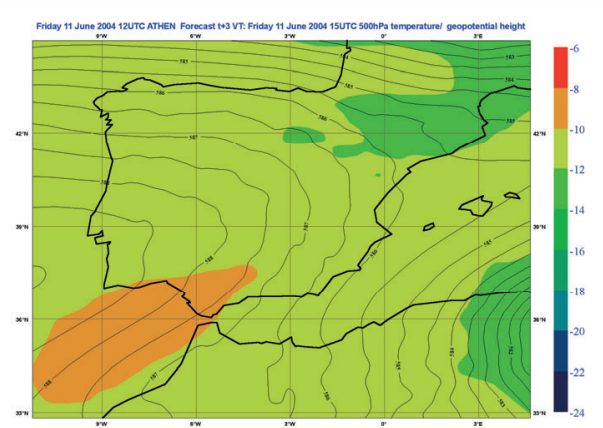

500 hPa: Geopotencial (Z) y Temperatura (T) (15 Z)

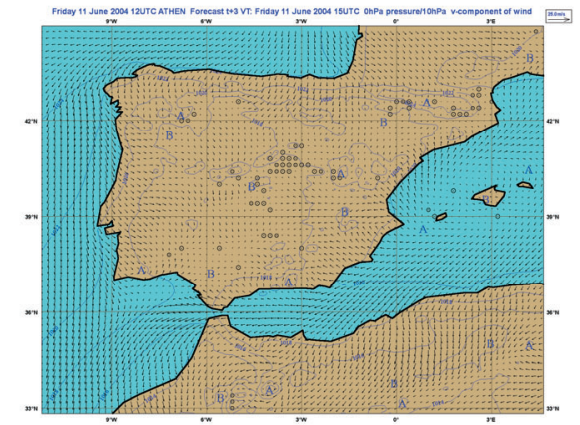

Superficie: Presión (PSL), Viento (W) (15 Z)

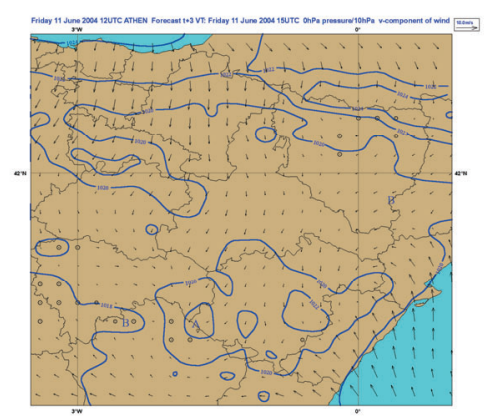

Detalle de presión (PSL) y Viento en superficie (W) $(15 \mathrm{Z})$

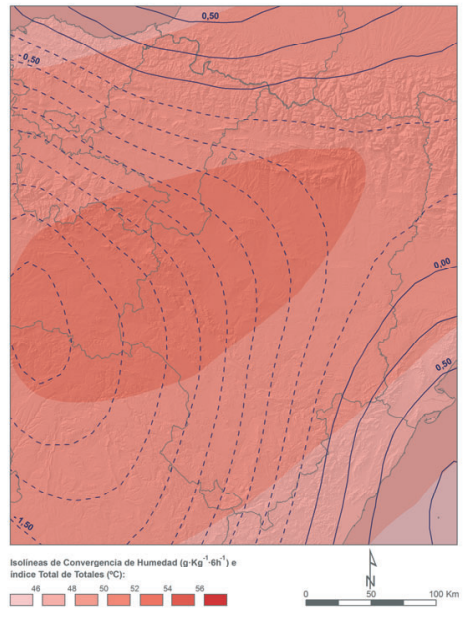

Convergencia de Humedad (en $925 \mathrm{hPa}$ ) e Índice Total de Totales (TT) (15 Z)

Imagen 6.1. Caso de estudio de situación tipo 1 (masa de aire): 11 de junio de 2004. 
Comentarios a la situación de masa de aire:

La topografía de $500 \mathrm{hPa}$ (Imagen 6.1) representa una de las muchas posibles configuraciones sinópticas que caracteriza una situación de masa de aire autóctona, determinada por un potente anticiclón que va extendiendo su radio de acción sobre la península Ibérica tras el paso de una depresión que tiene su centro sobre la vertical de Túnez. En este caso, el intervalo de las isohipsas es de 0,5 en 0,5 dmg, con lo que se ve que el gradiente es escaso, con la isolínea de 586 dmg sobre el río Ebro.

En $850 \mathrm{hPa}$, mientras los Pirineos centrales cortan el flujo del viento de componente norte dejando a la provincia de Huesca a resguardo, este remonta las menores alturas de la divisoria en Navarra y alcanza el Ebro e incluso el Sistema Ibérico. Las temperaturas son altas, con $5{ }^{\circ} \mathrm{C}$ de gradiente entre Pirineos $\left(22^{\circ} \mathrm{C}\right)$ y la Ibérica $\left(27^{\circ} \mathrm{C}\right)$.

En superficie, existen altas presiones al norte de los Pirineos (superiores a $1024 \mathrm{hPa}$ ) por retención de la masa de aire, mientras que en el valle del Ebro se dibuja la zona de bajas presiones a sotavento de la cordillera que, dejando dos zonas con altas presiones relativas $(1022 \mathrm{hPa})$ en los mayores relieves del Sistema Ibérico, enlaza con la baja de tipo térmico que orla la Península y alcanza valores inferiores a $1018 \mathrm{hPa}$ sobre la vertical de Madrid. El viento en superficie, en la mitad occidental, sopla de componente norte, lógicamente debilitado por el rozamiento, ascendiendo incluso el somontano ibérico acoplado a los cauces de la margen derecha del Ebro y acercándose a las alturas de los llanos turolenses. Sin embargo, con los cielos despejados y ayudados por el viento del NW en $850 \mathrm{hPa}$, en el Mediterráneo se han desarrollado las brisas costeras del SE que ascienden hacia las alturas de Teruel. Se forman, por lo tanto, importantes zonas de convergencia de masas de aire de orígenes distintos que son la causa principal del desarrollo de los núcleos tormentosos, que se siguen produciendo hasta mitad de la tarde. Este proceso no es exclusivo de la zona analizada sino que se produce en todos aquellos lugares donde las convergencias, calentamientos diferenciales altos entre zonas continuas, cursos de agua, etc. proporcionan las condiciones iniciales suficientes para el inicio de la convección, por lo que suelen tener carácter repetitivo a lo largo del verano. El modelo ha sido capaz de captar estas convergencias con un núcleo sobre Guadalajara y Soria de $-2.25 \mathrm{~g} \cdot \mathrm{kg}^{-1} \cdot \mathrm{m}^{-1}$, pero su radio de acción se extiende a prácticamente todo el territorio. Se observan máximos de convergencia de humedad en área de la Ibérica tanto en 925 como en 850 hPa (no presentado por mostrar similar configuración).

La representación del índice Total de Totales, que caracteriza la inestabilidad mediante la consideración de las condiciones termohídricas en las capas inferiores respecto a la temperatura en las capas superiores, muestra valores superiores a $48^{\circ} \mathrm{C}$ en prácticamente todo el territorio con un núcleo central superior a $50^{\circ} \mathrm{C}$, que caracterizaría un entorno favorable para el desarrollo de las tormentas esperables como de débiles a moderadas.

En el mapa de precipitación y descargas se pueden observar los conglomerados de impactos que se producen en las zonas elevadas ya mencionadas, pero también unas tormentas desarrolladas junto el río Ebro a final de la tarde al encontrar humedad suficiente para la reactivación de algunos núcleos.

Se observa claramente lo ya comentado sobre la buena correspondencia espacial entre precipitación y descargas, por el escaso desplazamiento de las tormentas. 
Caso de estudio del tipo 2 (situaciones del sur): 3 de septiembre de 2004

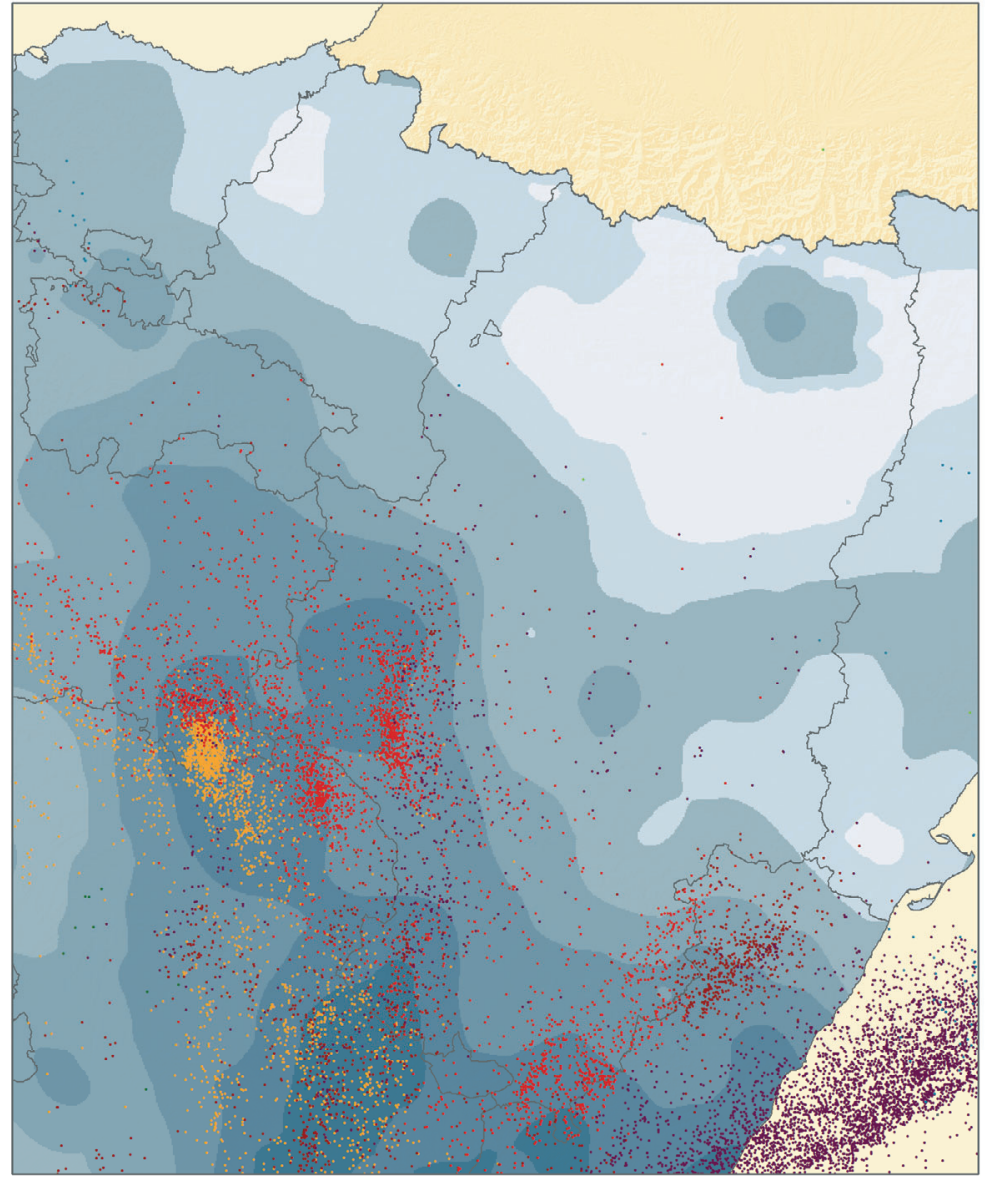

Número de rayos por intervalo horario desde las 06:00 TUC a las 05:59 TUC del día siguiente:

06:00-08:59 09:00-11:59 12:00-14:59 15:00-17:59 18:00-20:59 21:00-23:59 00:00-02:59 03:00-05:59

$\begin{array}{llllccccc}\text { Positivos } & 63 & 21 & 365 & 529 & 245 & 904 & 213 & 0 \\ \text { Negativos } & 279 & 84 & 2.383 & 3.066 & 2.664 & 4.594 & 1.464 & 0\end{array}$ Precipitación (mm) desde las 07:00 TUC a las 07:00 TUC del día siguiente:

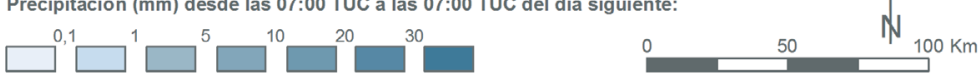

Precipitación (PCP) en 24 h (07-07 Z) y Descargas eléctricas (06-06 Z)

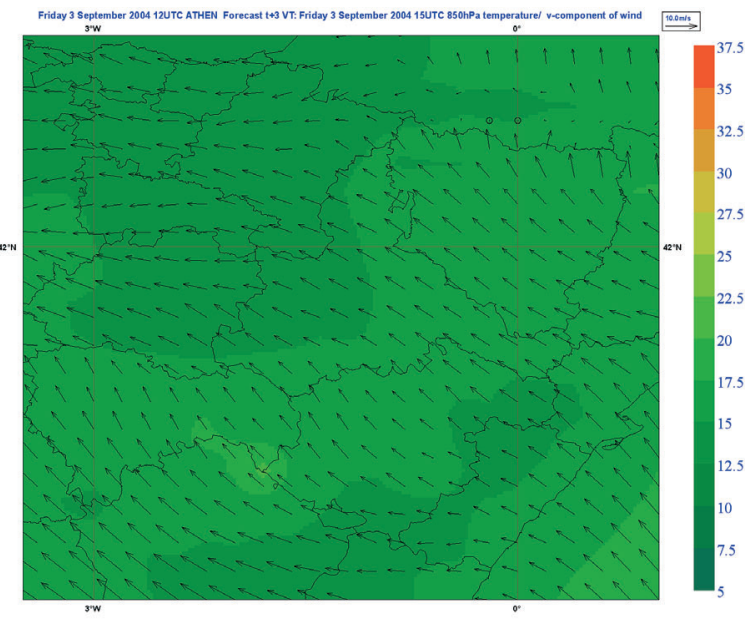

850 hPa: Temperatura (T) y Viento (W) (15 Z)

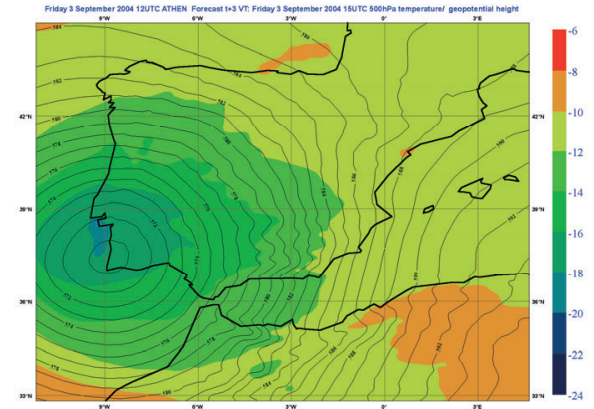

500 hPa: Geopotencial (Z) y Temperatura (T) $(15 \mathrm{Z})$

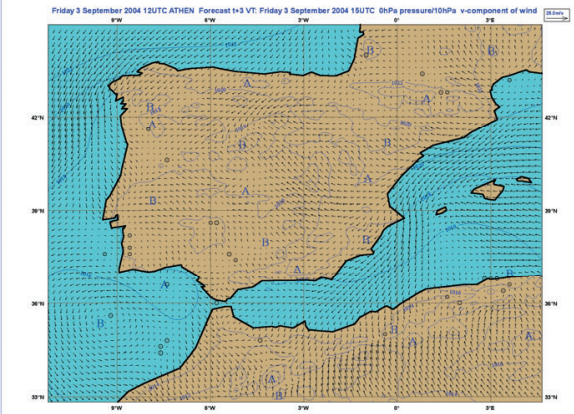

Superficie: Presión (PSL), Viento (W) (15 Z)

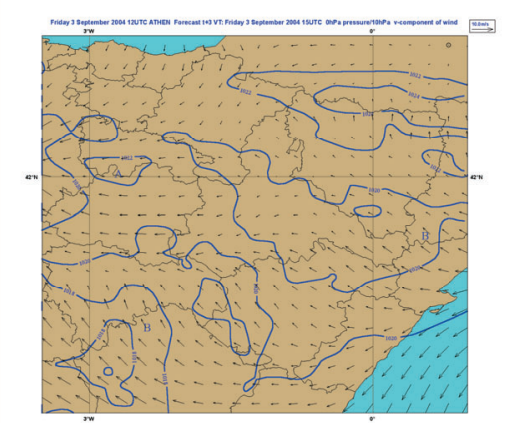

Detalle de Presión (PSL) y Viento (W) en superficie (15 Z)

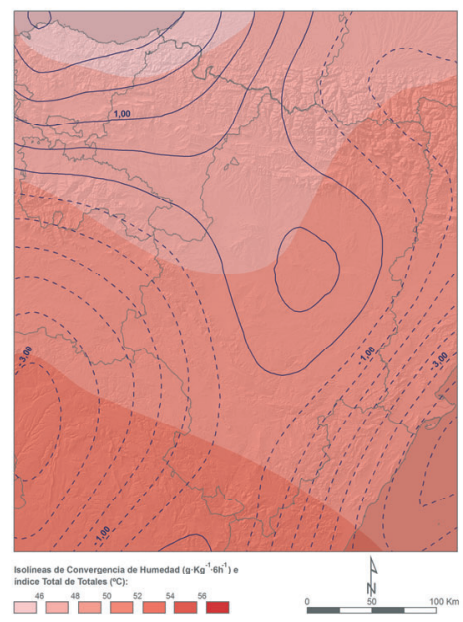

Convergencia de Humedad (Hr) en $925 \mathrm{hPa}$ e Índice Total de Totales (TT) (15 Z)

Imagen 6.2. Caso de estudio de situación tipo 2 (del sur): 3 de septiembre de 2004. 
Comentarios a la situación del sur:

En la topografía de $500 \mathrm{hPa}$, una depresión aislada con centro de $570 \mathrm{dmg}$ en la vertical del cabo de San Vicente, lleva asociado un núcleo frío con temperaturas inferiores a $-18{ }^{\circ} \mathrm{C}$. Sobre el área de estudio se proyecta un flujo de componente sur que rola al SE en la parte norte del territorio. Es interesante notar como este flujo acusa la influencia del Sistema Ibérico dibujando, incluso en este nivel, un incipiente dipolo bárico con la curvatura anticiclónica a barlovento y la ciclónica a sotavento de las principales alturas de dicha cordillera, mientras que al encontrar los Pirineos pierde su intensidad al abrirse en abanico. Sobre el área de estudio hay geopotenciales de 586 dmg y temperaturas de $-11^{\circ} \mathrm{C}$. La advección de espesores 500/1 000 muestra valores altos en toda la zona mientras que la advección de vorticidad y las circulaciones ageostróficas (no mostradas) no parecen relevantes.

En niveles bajos, a $850 \mathrm{hPa}$ se observa como una fuerte corriente advectiva avanza desde el Mediterráneo aportando humedad. Este transporte (no mostrado) no es exclusivo del valle del Ebro sino que se desarrolla en toda la fachada mediterránea buscando el centro de la zona de bajas presiones en este nivel situado unos $150 \mathrm{~km}$ al sur de la posición del centro en niveles medios. Las temperaturas son altas sobre el área de estudio en este nivel.

En superficie, el centro de bajas presiones relativas, inferiores a $1014 \mathrm{hPa}$, se encuentra sobre Sevilla, mientras que frente a Cádiz aparece una zona de altas presiones, lo que indica que el sistema se encuentra en su fase de madurez y con poco desplazamiento hacia el este. Sobre el área de estudio, bajas presiones en el valle y ligeramente más altas en las zonas montañosas, pero esta vez producidas por el flujo de componente sur. El viento en la mitad sur del territorio muestra en este caso una marcada componente este que asciende con facilidad a la Meseta, mostrando claras convergencias en las zonas limítrofes de las provincias de Soria, Guadalajara, Cuenca y Teruel.

Cuantitativamente, en el mapa de convergencias/divergencias de humedad se aprecia perfectamente una zona con valores de convergencia de $-3 \mathrm{~g} \cdot \mathrm{kg}^{-1} \cdot \mathrm{m}^{-1}$. También aparece otra importante banda próxima a la costa mediterránea con valores similares o incluso superiores. Por el contrario, en el centro y noroeste del área de estudio aparecen divergencias. La comparación con la imagen de descargas y precipitación muestra que esta variable discrimina perfectamente la zona influenciada por la actividad convectiva. De hecho es un campo de diagnóstico y pronóstico que siempre debe ser tenido en cuenta en las labores cotidianas de predicción. Asimismo el índice Total de Totales apunta al suroeste como la zona potencialmente más peligrosa, con valores que disminuyen hacia el norte. El mapa de precipitación y descargas muestra los intensos ramales que, naciendo en la zona de convergencias, se trasladan hacia el norte y noroeste siguiendo la ligera curvatura del flujo conductor de niveles medios y con estructura de "trenes convectivos". Además, debido a la casi nula traslación del centro de todo el sistema hacia el este, los sucesivos ramales se mantienen paralelos entre sí mientras se desplazan ligeramente hacia el levante. También se nota que a medida que se acerca la noche son desviados por el atractor mediterráneo que los alimenta y mantiene con fuerte actividad hasta bien después de la puesta del sol. En este caso en concreto, la correlación precipitación-descargas también es bastante alta en el sur (a pesar de la poca correlación que en general aparece en este tipo de situaciones), aunque en el norte no coinciden. 
Caso de estudio del tipo 3 (situaciones del SW con difluencia): 1 de agosto de 2005
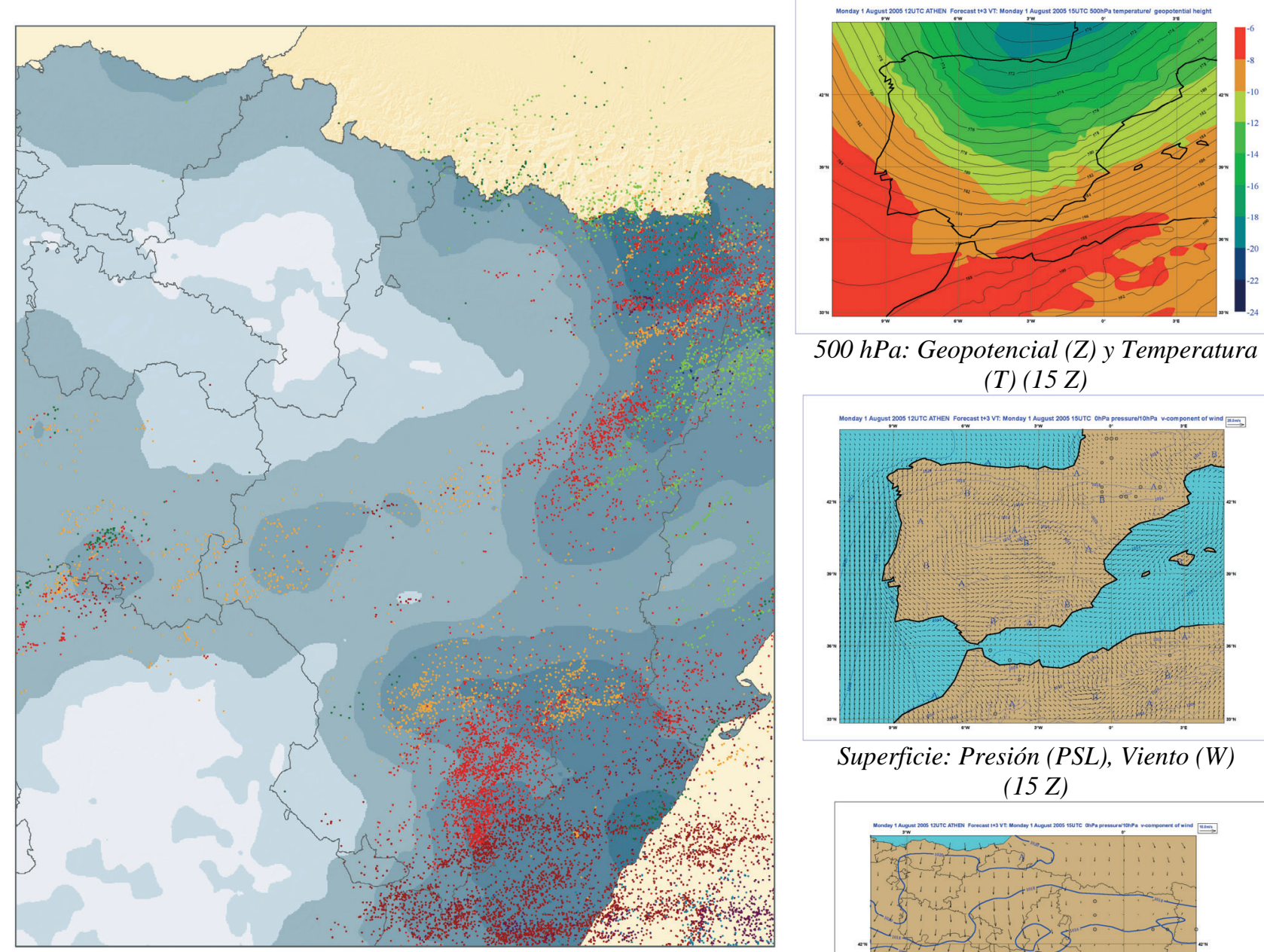

500 hPa: Geopotencial (Z) y Temperatura (T) $(15 \mathrm{Z})$

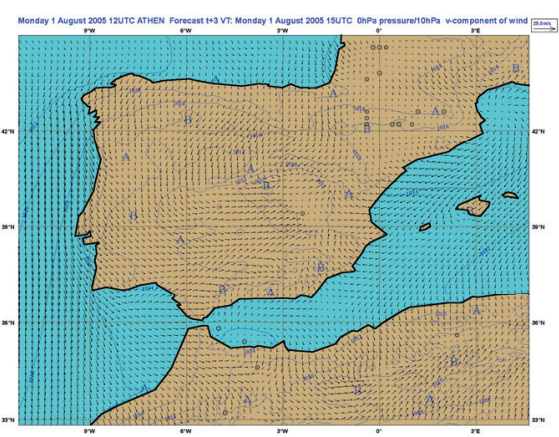

Superficie: Presión (PSL), Viento (W) (15 Z)

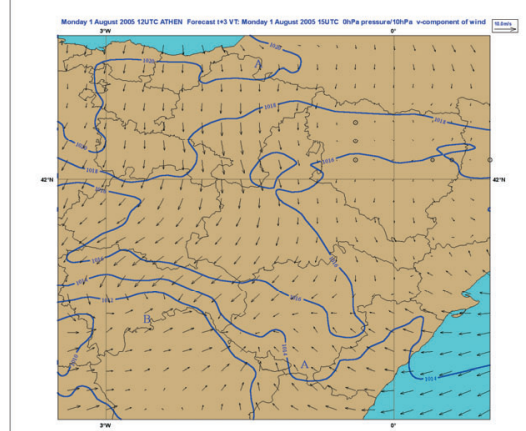

Detalle de Presión (PSL) y Viento (W) en superficie (15 Z)

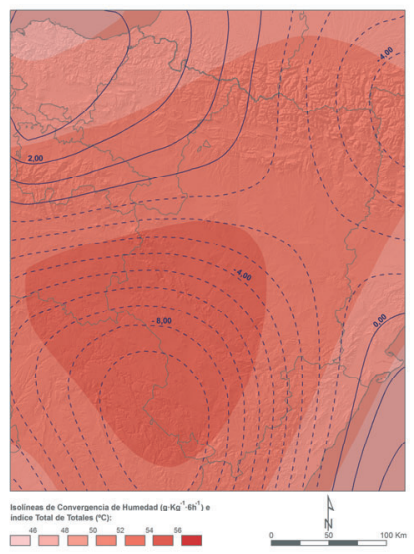

Convergencia de humedad (Hr) en $925 \mathrm{hPa}$ e Índice Total de Totales (TT) (15 Z)

Imagen 6.3. Ejemplo de situación tipo 3 (del SW con difluencia): 1 de agosto de 2005. 
Comentarios a la situación del suroeste con difluencia:

En 500 hPa una vaguada con forma de U abierta se desplaza por el mar del Norte, alcanzando a la Península bajo su radio de acción. El eje de la vaguada se puede dibujar mediante una línea hipotética entre Vizcaya y Salamanca. Sobre al área de estudio el flujo es del SW, con una ligera curvatura ciclónica, una difluencia muy ligera y la isolínea de 575 dmg situada sobre el centro de la zona, mientras que la corriente en chorro de la parte delantera de la vaguada se sitúa sobre el área de estudio. La distribución térmica a escala sinóptica coincide con la de geopotenciales, con un marcado gradiente de unos $10^{\circ} \mathrm{C}$ en la distancia que separa el mar Cantábrico del Mediterráneo. A menor escala se notan las ondulaciones de las isotermas más cálidas, que son la causa de los desarrollos convectivos que se producirán dentro de la escala meso-beta por efectos de advección térmica.

En niveles bajos, un importante flujo de componente norte sobre la mitad occidental del área de interés va a converger con el flujo del suroeste procedente de la Meseta sur y el flujo de levante de origen mediterráneo a lo largo de una amplia zona que se extiende linealmente sobre las provincias de Guadalajara y Teruel entre las latitudes de $40^{\circ}$ y $41^{\circ}$. Por contra, en las provincias de Huesca y Lérida, el flujo mediterráneo que asciende Ebro arriba, gira anticiclónicamente hacia las cumbres pirenaicas y determina un segundo núcleo de convergencias en esas zonas. Cuantitativamente, se dan valores de $-3 \mathrm{~g} \cdot \mathrm{kg}^{-1} \cdot \mathrm{m}^{-1}$ en la zona de Teruel y de $-3 \mathrm{~g} \cdot \mathrm{kg}^{-1} \cdot \mathrm{m}^{-1}$ en la de Huesca y Lérida. Por el contrario, sobre La Rioja y Navarra aparecen divergencias.

Aparece un núcleo cálido con fuerte gradiente térmico en las cercanías de los Montes Universales, encrucijada funcional de flujos y cabecera de importantes ríos atlánticos y mediterráneos. La ligera advección de este núcleo cálido, junto con las ondulaciones de niveles superiores, dará lugar a la importante actividad convectiva mientras en el resto de la zona esa advección es negativa y actúa como inhibidor (no mostrado).

En superficie el patrón de viento sigue pautas semejantes, determinado por una distribución de isobaras típica de estos casos, cuando el dipolo orográfico solamente está insinuado por la curvatura anticiclónica, sin cerrar, de las isobaras sobre Pirineos e Ibérica. Sin embargo, la isobara de 1016 hPa contornea con precisión la diferencia de elevación entre dichas zonas y el valle del Ebro mediante una serie de sucesivos zigzag, para después continuar por la Meseta norte, llegar hasta la costa portuguesa y contornear la Península, a la par que dibuja la baja térmica estival, que en este caso tiene su centro sobre La Mancha.

Las cantidades de precipitación recogidas son importantes, adoptando formas lineales en concordancia con los largos regueros de descargas que indican que los núcleos tormentosos en estado maduro van generando otros nuevos en sus inmediaciones que los sustituyen cuando decaen, mediante la modificación de las condiciones del entorno, lo que da continuidad al sistema convectivo en su conjunto.

Asimismo se aprecia como, ayudadas por la difluencia presente en niveles medios, las trayectorias seguidas por las tormentas en el norte se dirigen hacia el NE, mientras que sobre Teruel su recorrido tiene una marcada componente zonal del $\mathrm{W}$, hacia las fuentes de humedad mediterránea. 


\section{Caso de estudio del tipo 4 (situaciones del SW sin difluencia): 8 de julio de 2002}

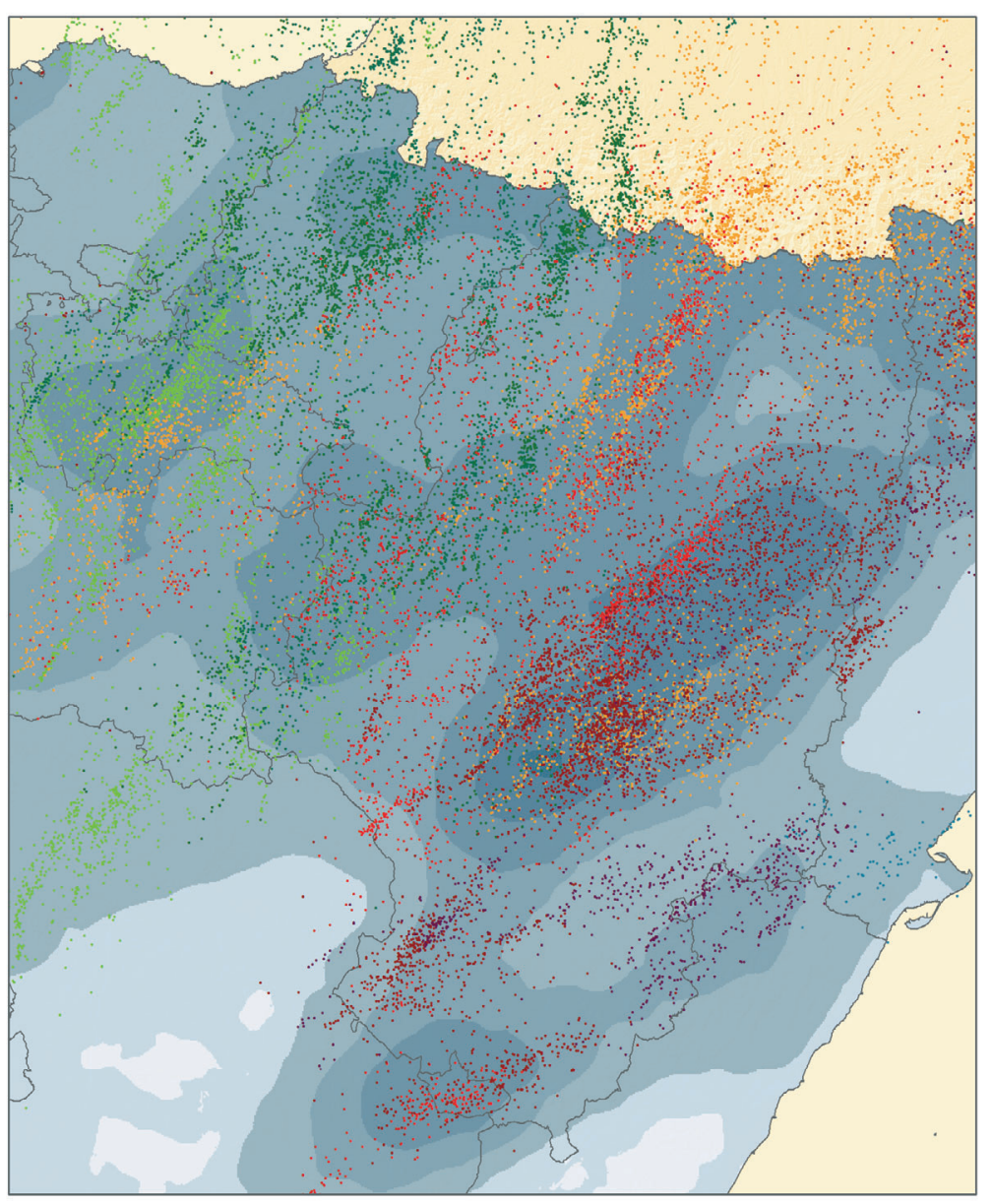

Número de rayos por intervalo horario desde las 06:00 TUC a las 05:59 TUC del día siguiente: 06:00-08:59 09:00-11:59 12:00-14:59 15:00-17:59 18:00-20:59 21:00-23:59 00:00-02:59 03:00-05:59 $\begin{array}{lllllllll}\text { Positivos } & 362 & 426 & 1.070 & 846 & 1.407 & 400 & 8 & 0\end{array}$ Negativos $\quad 5.448 \quad 7.458$

Precipitación ( $\mathrm{mm}$ ) desde las 07:00 TUC a las 07:00 TUC del día siguiente: $\square^{0,1} \square^{5} \square^{10} \square^{20} \square^{30}$

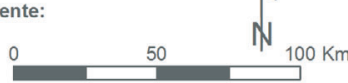

Precipitación (PCP) en 24 h (07-07 Z) y Descargas eléctricas (06-06 Z)

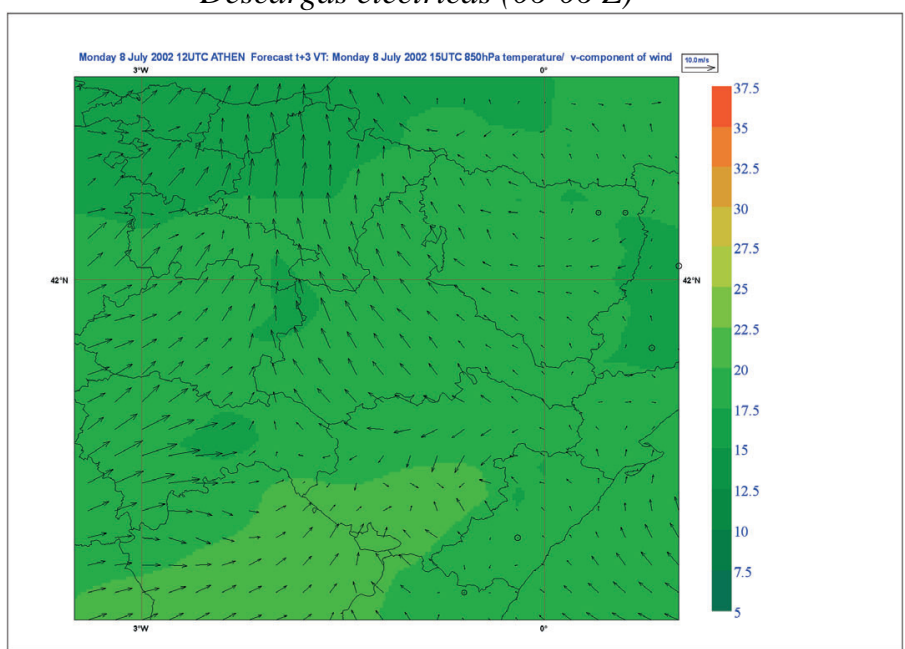

850 hPa: Temperatura (T) y Viento (W) (15 Z)

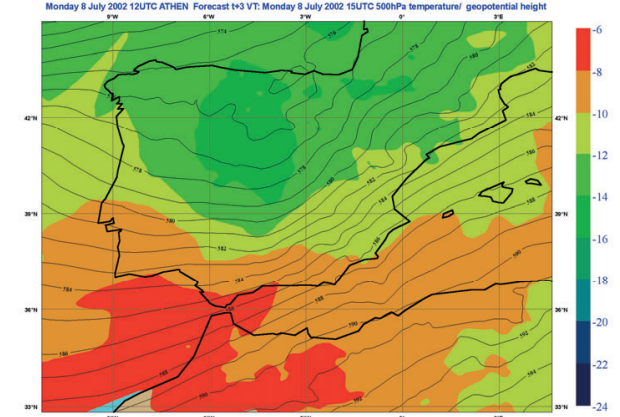

500 hPa: Geopotencial (Z) y Temperatura (T) (15 Z)

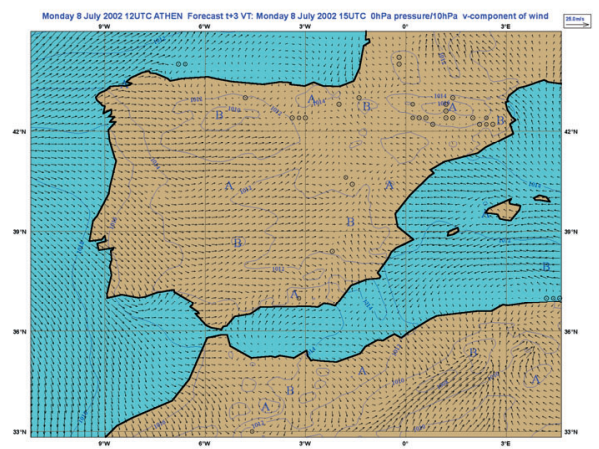

Superficie: Presión (PSL), Viento (W) (15 Z)

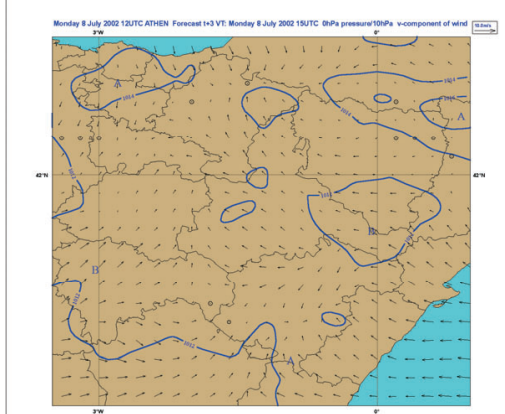

Detalle de Presión (PSL) y Viento (W) en superficie (15 Z)

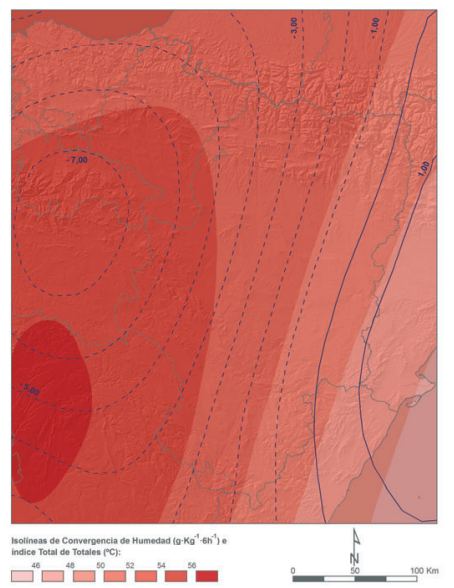

Convergencia de humedad ( $\mathrm{Hr}$ ) en $925 \mathrm{hPa}$ e Índice Total de Totales (TT) (15 Z)

Imagen 6.4. Ejemplo de situación tipo 4 (del suroeste sin difluencia): 8 de julio de 2002. 
Comentarios a la situación del suroeste sin difluencia:

En los niveles medios de la atmósfera se encuentra, dentro del flujo general del suroeste, embebida una pequeña ondulación de onda corta con eje de vaguada sobre la línea imaginaria que va desde Vizcaya hasta Salamanca, mientras que el eje de dorsal precedente se sitúa en ese momento sobre el noroeste de Navarra. Este tipo de situaciones son sumamente peligrosas de cara a las labores de predicción meteorológica, pues además de poder pasar desapercibidas por su pequeño tamaño, suelen venir acompañadas de unos efectos que no están en concordancia con su tamaño. Conviene recordar este punto y no subestimar su importancia por sus reducidas dimensiones. La isohipsa que mejor muestra la forma sinusoidal es la de $576 \mathrm{dmg}$, existiendo un núcleo cerrado de $575 \mathrm{dmg}$. La situación lleva asociado un embolsamiento frío de valores inferiores a $-14^{\circ} \mathrm{C}$. También las circulaciones ageostróficas muestran fuertes núcleos que afectan a toda la zona de estudio, mientras que la advección térmica diferencial entre superficie y los niveles medios, aunque positiva no da valores tan altos. Por su parte la advección relativa de vorticidad positiva entre niveles medios y altos muestra valores moderados que alternan de negativos a positivos según avanza el sistema hacia el nordeste (Imagen 6.5).

El campo de presiones muestra que, dentro de una situación general de bajas presiones, los valores más bajos asociados a la perturbación que se acerca en esos momentos se encuentran sobre la provincia de León con valores de $1010 \mathrm{hPa}$, mientras que sobre el valle del Ebro existe una baja térmica relativa que contrasta con las altas presiones pirenaicas. En niveles bajos es notoria la línea de convergencia existente desde Guipúzcoa hasta Guadalajara, pasando por la divisoria entre Álava y Navarra, La Rioja y la divisoria provincial entre Soria y Zaragoza. Al sur de Teruel se encuentra otra zona de convergencias. En superficie existe total correspondencia con el nivel de $850 \mathrm{hPa}$, lo que indica la potencia de espesor de las masas que convergen. El mapa correspondiente refleja que los máximos valores de convergencia de humedad de $-7 \mathrm{~g} \cdot \mathrm{kg}^{-1} \cdot \mathrm{m}^{-1}$ se encuentran centrados sobre Soria y La Rioja, extendiendo su radio de acción a todo el centro y oeste del territorio, mientras que la inestabilidad térmica representada por el índice TT muestra elevados valores en torno a $56{ }^{\circ} \mathrm{C}$ distribuidos de forma semejante. La advección térmica en niveles bajos es poco importante, sobre todo en la mitad oriental (Imagen 6.5).

Las descargas se desarrollan en la parte delantera de la vaguada barriendo de SSW a NNE toda la extensión del territorio mientras los sucesivos núcleos convectivos se van trasladando lentamente hacia levante como indica el color asignado a los distintos intervalos horarios. Al no existir prácticamente difluencia sobre la zona en los niveles medios, las trayectorias seguidas por los distintos ramales de precipitación son prácticamente paralelas entre sí. Nuevamente la ubicación de la precipitación está en correspondencia con las descargas, lo cual concuerda con los valores de correlación (Tabla 4.4) y de asociación (Tabla 4.12), que daban los valores máximos para este tipo de situación.

Para esta situación concreta se muestran gráficamente (Imagen 6.5) algunos de los campos derivados mencionados anteriormente como los que normalmente se usan en la predicción operativa y que no se muestran para todos los tipos de situaciones por razones de longitud de este trabajo. Estos campos son: vector Q (circulaciones ageostróficas), advección térmica en $925 \mathrm{hPa}$, advección de vorticidad relativa en 
niveles altos y advección diferencial de espesores entre 500 y 1000 hPa. A algunos de ellos ya se ha hecho referencia anteriormente. Tanto la advección de espesores 500/1 000 como la de vorticidad y las circulaciones ageostróficas muestran claros núcleos que afectan a toda la zona de estudio.
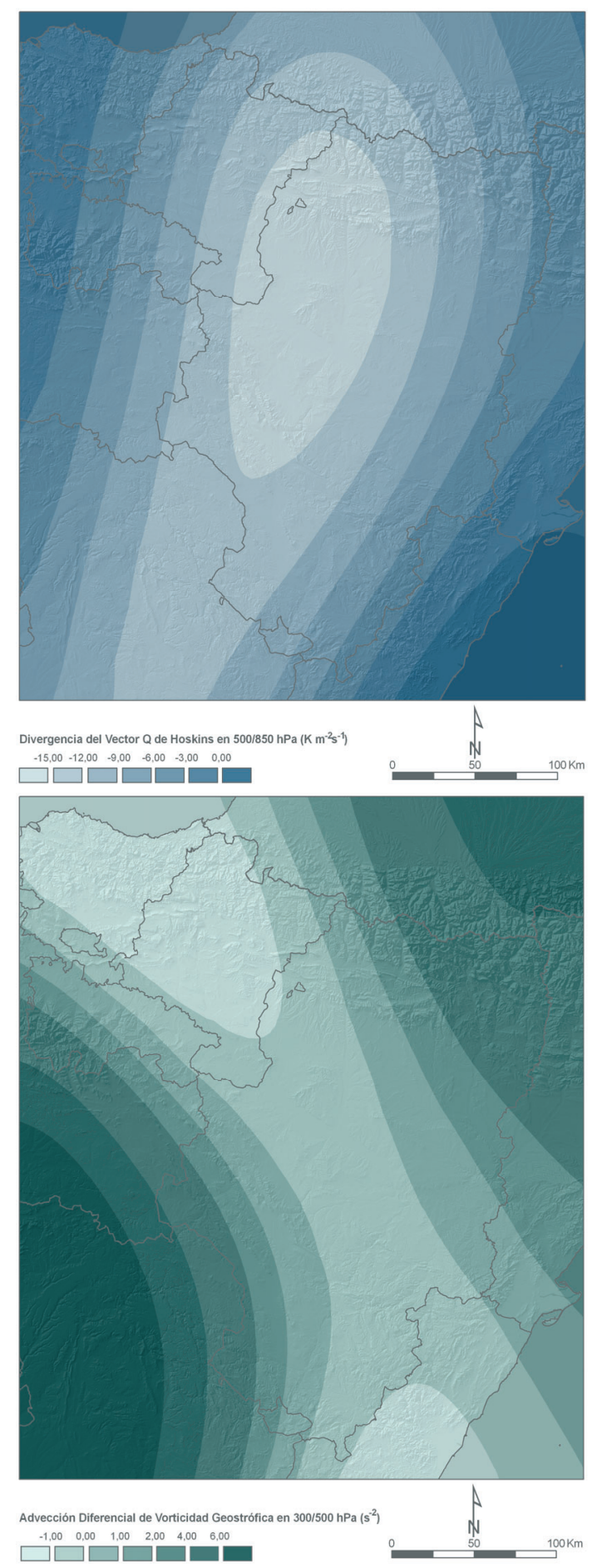
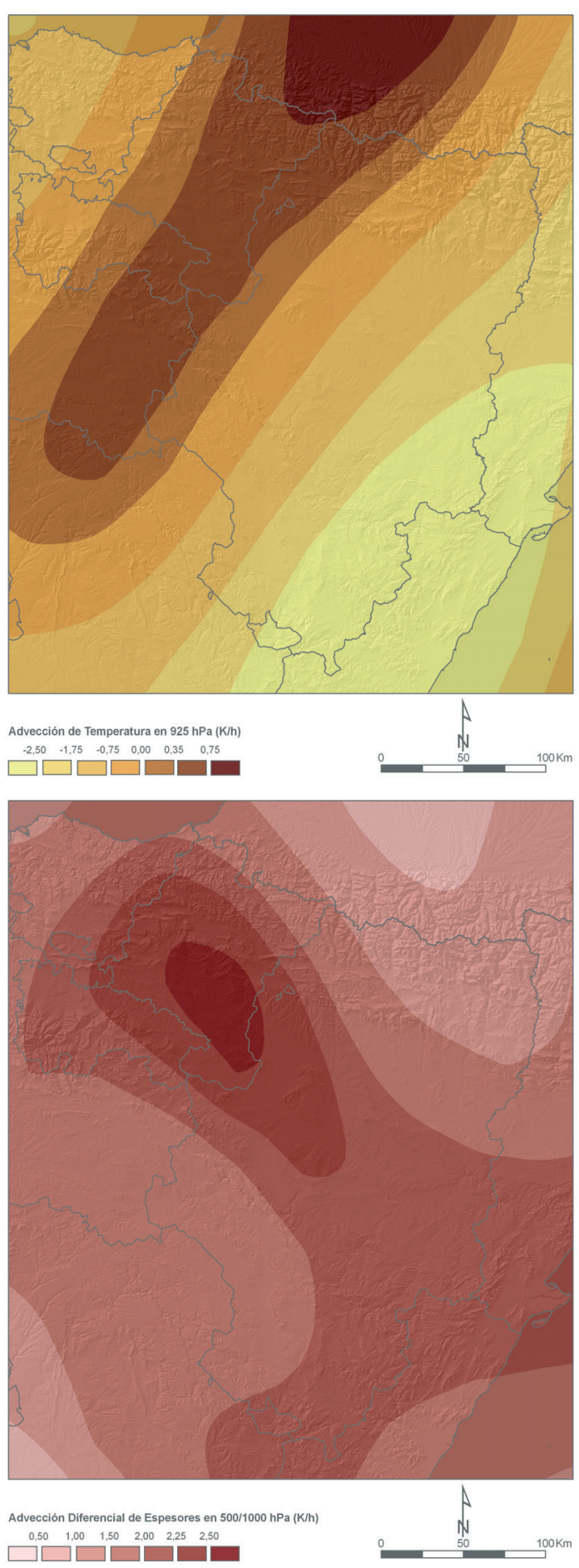

Imagen 6.5. Para el día 8 de julio de 2002, de izquierda a derecha y de arriba abajo:

$1^{\circ}$ : Vector $Q(u Q)$ (que representa las circulaciones ageostróficas). $2^{\circ}$ : Advección Térmica (ADVT925) en 925 hPa.

3a: Advección Diferencial de Vorticidad Relativa (ADVVR300 - ADVVR500) en altura. 4: Advección Diferencial de Espesores 500/1 000 hPa (ADVZ550 - ADVZ1000). 


\section{Caso de estudio del tipo 5 (situaciones del oeste): 16 de julio de 2004}

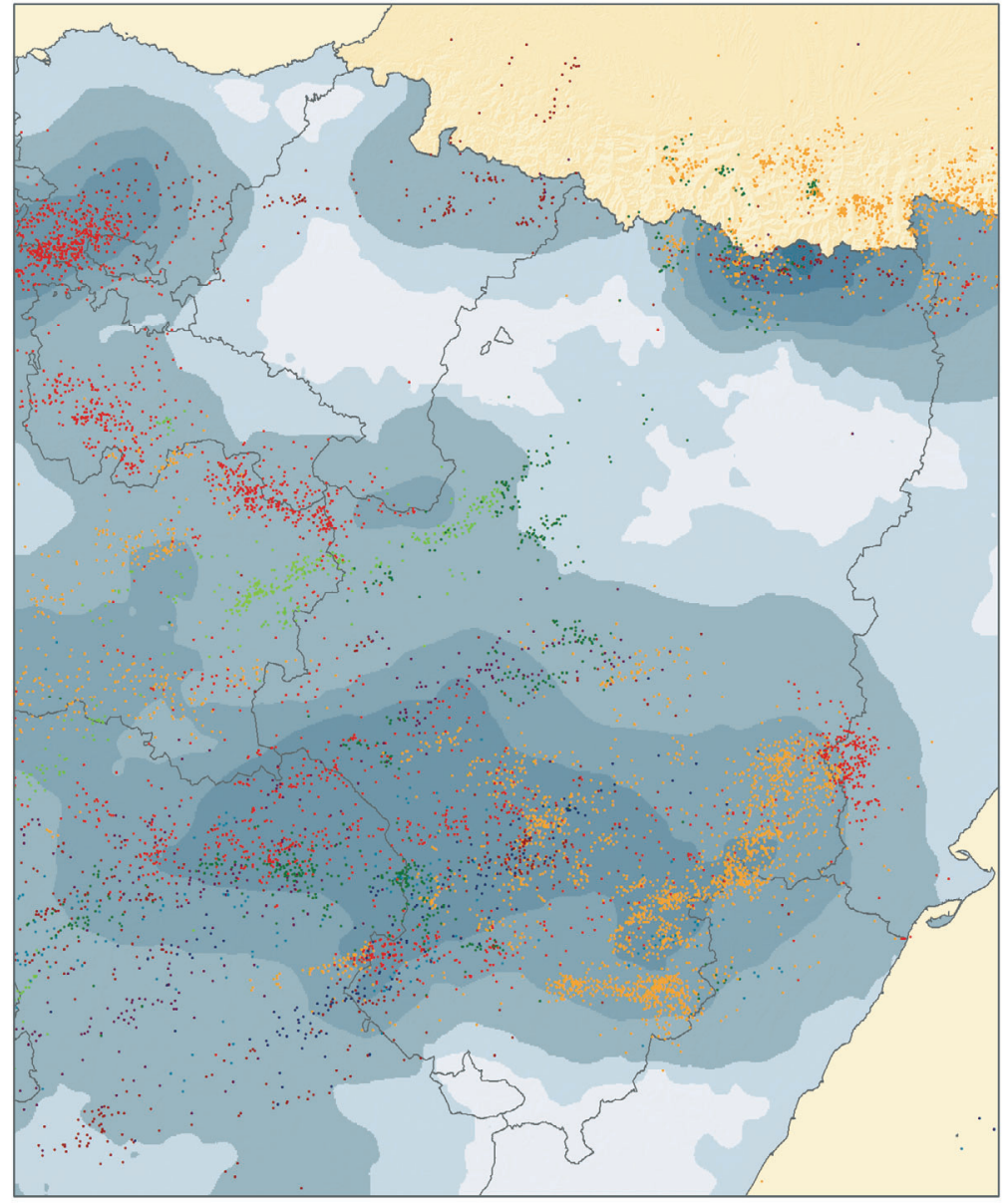

Número de rayos por intervalo horario desde las 06:00 TUC a las 05:59 TUC del día siguiente: 06:00-08:59 09:00-11:59 12:00-14:59 15:00-17:59 18:00-20:59 21:00-23:59 00:00-02:59 03:00-05:59 $\begin{array}{lllllllll}\text { Positivos } & 21 & 33 & 470 & 364 & 147 & 60 & 47 & 29\end{array}$ $\begin{array}{lllllll}\text { Negativos } & 474 & 688 & 4.167 & 2.975 & 904 & 340\end{array}$

Precipitación (mm) desde las 07:00 TUC a las 07:00 TUC del dia siguiente:
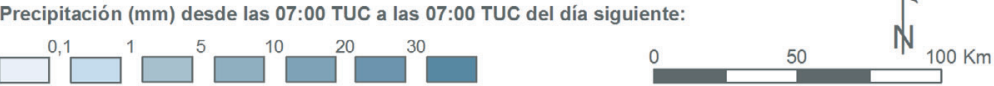

Precipitación (PCP) en 24 h (07-07 Z) y Descargas eléctricas(06-06 Z)

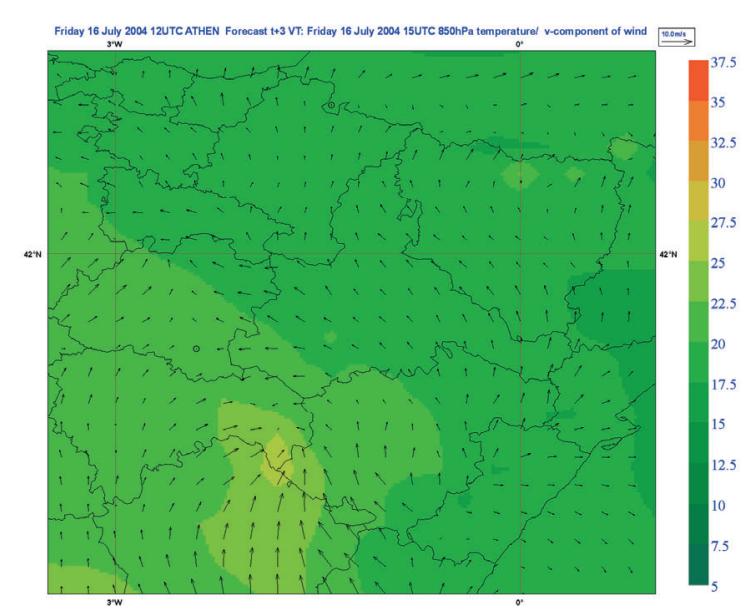

850 hPa: Temperatura (T) y viento (W) (15 Z)

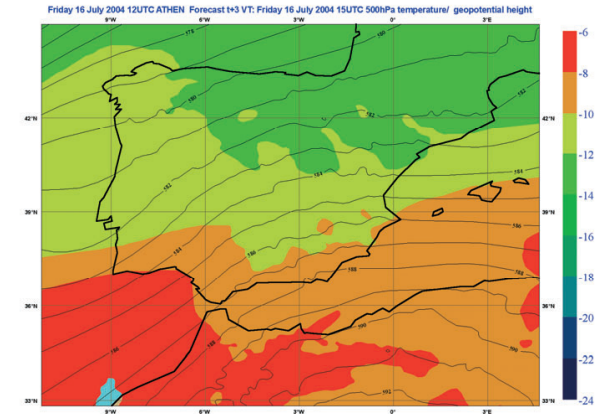

500 hPa: Geopotencial (Z) y temperatura (T) (15 Z)

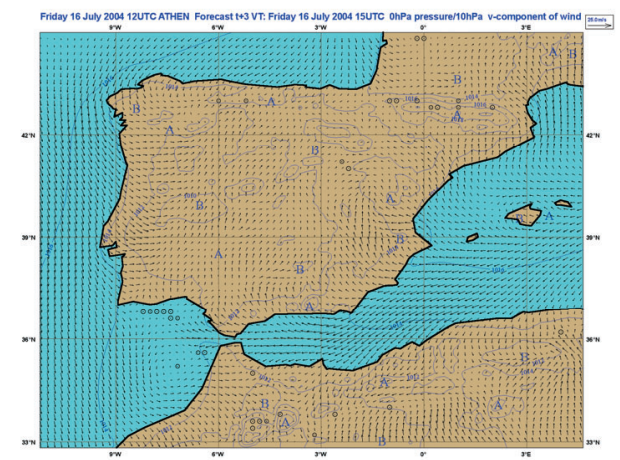

Superficie: Presión (PSL), Viento (W) (15 Z)

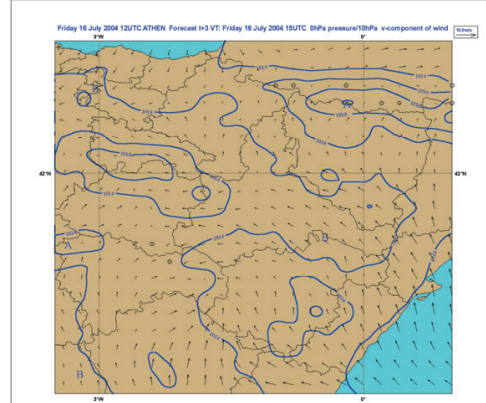

Detalle de Presión (PSL) y Viento (W) en superficie (15 Z)

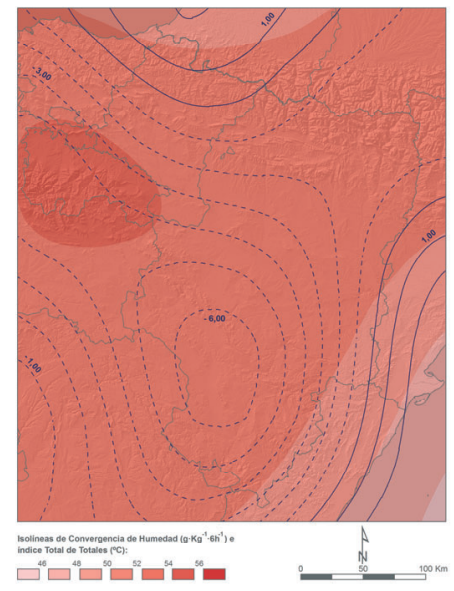

Convergencia de humedad ( $\mathrm{Hr}$ ) en $925 \mathrm{hPa}$ e Índice Total de Totales (15 Z)

Imagen 6.6. Caso de estudio de situación tipo 5 (del oeste): 16 de julio de 2004. 
Comentarios a la situación del oeste:

El ejemplo elegido muestra unos efectos ligeramente superiores en la mitad sur de la zona que los que se han obtenido como valores medios para este tipo de situaciones, pero refleja bien el avance de los núcleos convectivos propios de una situación de ponientes.

En $500 \mathrm{hPa}$ una onda larga se acerca desde el Atlántico con suave dorsal sobre la Meseta y curvatura ciclónica frente a Portugal. Sobre la zona de interés se sitúa la isohipsa de $582 \mathrm{dmg}$, con temperaturas en torno a $-12{ }^{\circ} \mathrm{C}$ distribuidas en su conjunto de una forma zonal pero con perturbaciones asociadas a los sistemas convectivos que se acercan. Los campos dinámicos centrados en niveles medios (los habituales que se analizan) en este caso solo dan valores ligeramente positivos en la parte más occidental y montañosa de la zona, mientras que en la oriental son neutros o negativos (no presentados).

La precipitación empieza a primeras horas de la mañana y se produce durante toda la jornada con los valores más importantes en las zonas cantábrica, pirenaica y en áreas de la Ibérica riojana occidental y el centro de Teruel.

En niveles medios y superficie el flujo es del sureste, que converge con el que se aproxima desde el suroeste en la zona de barlovento del Sistema Ibérico, como es típico de este tipo de configuraciones sinópticas y que también se refleja en la representación de los índices de inestabilidad. La mitad oriental está bajo la influencia del flujo del sur, mientras que en Huesca se encamina hacia Pirineo.

Las temperaturas en $850 \mathrm{hPa}$ presentan valores elevados, en torno a $25^{\circ} \mathrm{C}$, lo que junto con la temperatura en $500 \mathrm{hPa}$, determina un índice TT del orden de $56^{\circ} \mathrm{C}$, que es un valor elevado y que vaticina las tormentas que se producirán finalmente. La advección térmica en niveles bajos es positiva en la mitad occidental, como corresponde a una masa de aire de origen atlántico (no presentado), mientras que la convergencia de humedad es muy fuerte se aprecia en el nivel de $925 \mathrm{hPa}$.

Salvo la zona pirenaica, toda la Península se encuentra bajo la influencia de las bajas presiones, distinguiéndose dos centros relativos de $1010 \mathrm{hPa}$, uno en la parte norte de Extremadura y otro centrado sobre La Rioja y Soria. La posición relativa sobre la vertical de los centros de bajas presiones en superficie, adelantados con respecto a los de los niveles medios, indica que se trata de un sistema joven que se encuentra en sus primeras etapas de desarrollo. La distribución de las descargas adopta la configuración zonal propia del sistema pero no se observa continuidad espacial en las mismas, sino que están asociadas a los diferentes núcleos convectivos que pasan sucesivamente sobre el territorio y descargan sin duda influidos por la orografía, pero también por su propia estructura interna.

Este tipo de situaciones es muy frecuente y no en todos los casos se produce tanta precipitación y descargas sino que, frecuentemente, quedan reflejadas por un aumento de la nubosidad con escasos o nulos fenómenos tormentosos en su seno, por lo que normalmente carecen de características adversas y por el contrario suelen ser muy apreciadas por humedecer y refrescar el ambiente veraniego. 
Caso de estudio del tipo 6 (situaciones depresionarias entrantes): 6 de septiembre de 2004

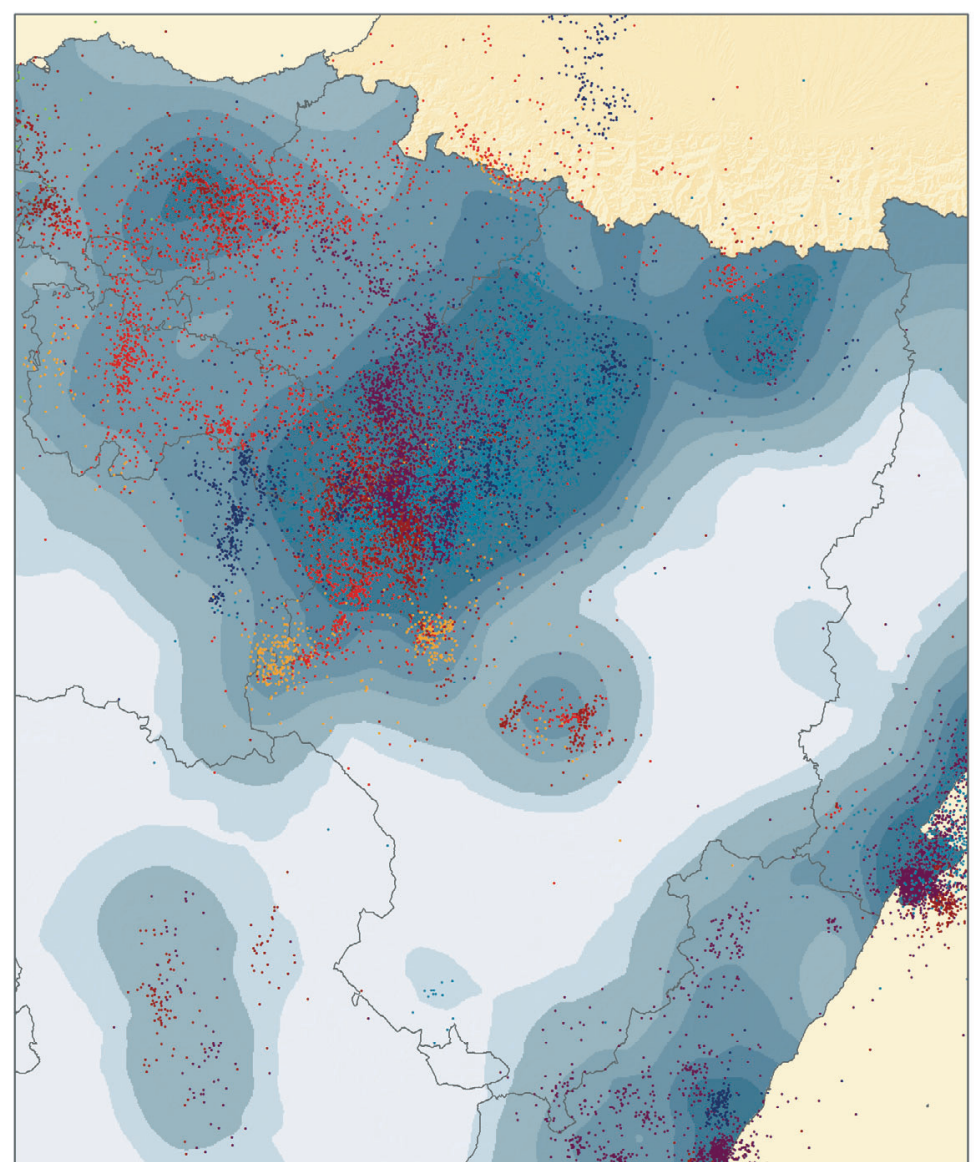

Número de rayos por intervalo horario desde las 06:00 TUC a las 05:59 TUC del día siguiente:

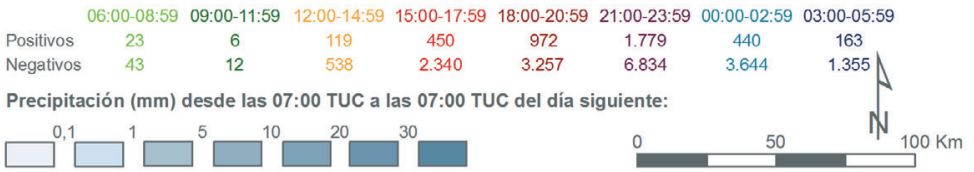

Precipitación (PCP) en 24 h (07-07 Z) y Descargas eléctricas (06-06 Z)

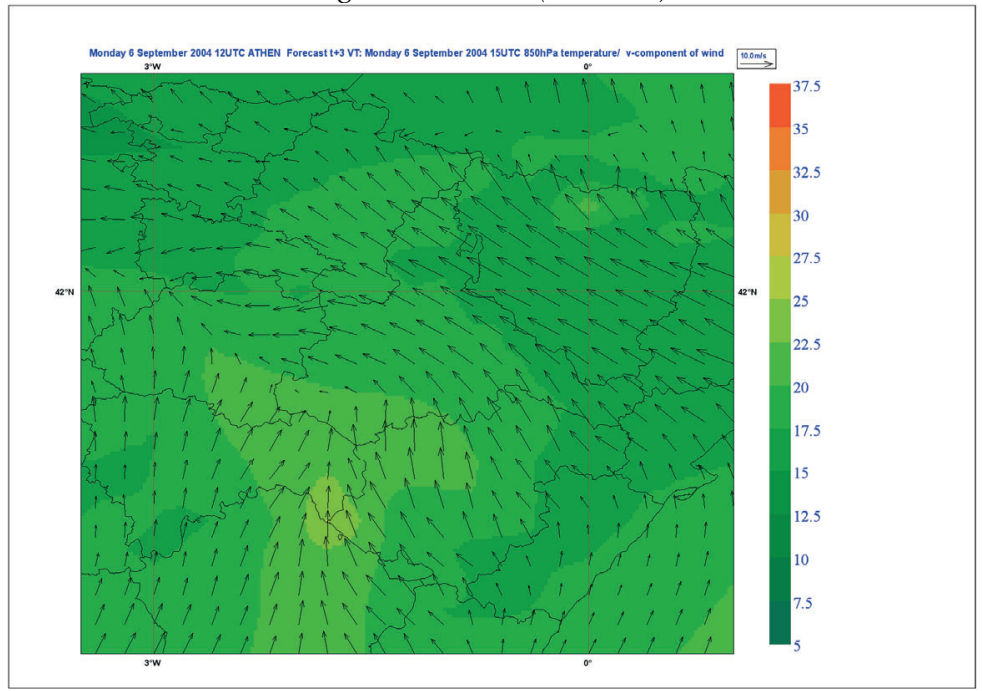

850 hPa: Temperatura (T) y viento (W) (15 Z)

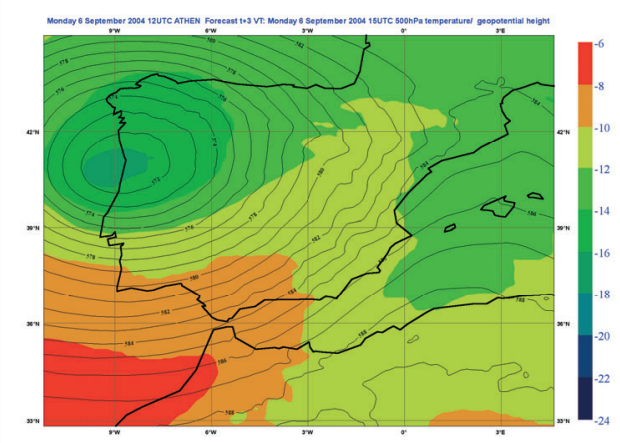

500 hPa: Geopotencial (Z) y Temperatura (T) $(15 \mathrm{Z})$

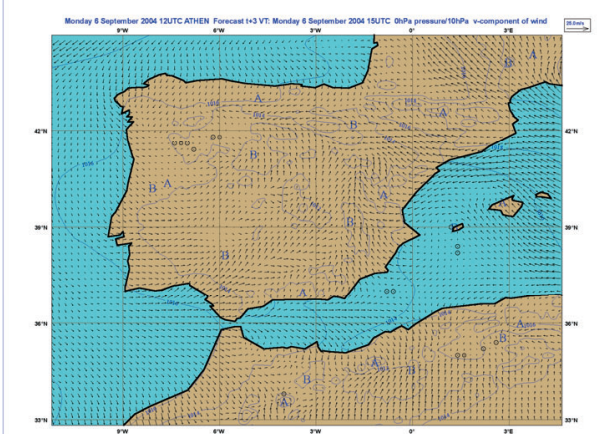

Superficie: Presión (PSL), Viento (W) (15 Z)

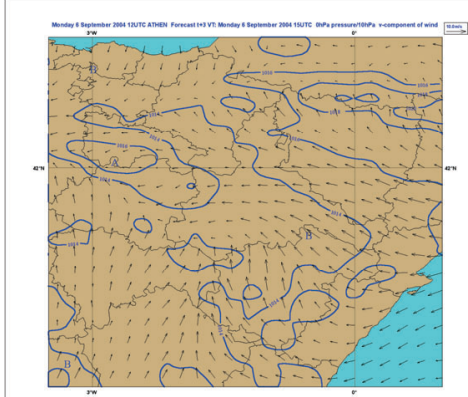

Detalle de Presión (PSL) y Viento en superficie (W) $(15 \mathrm{Z})$

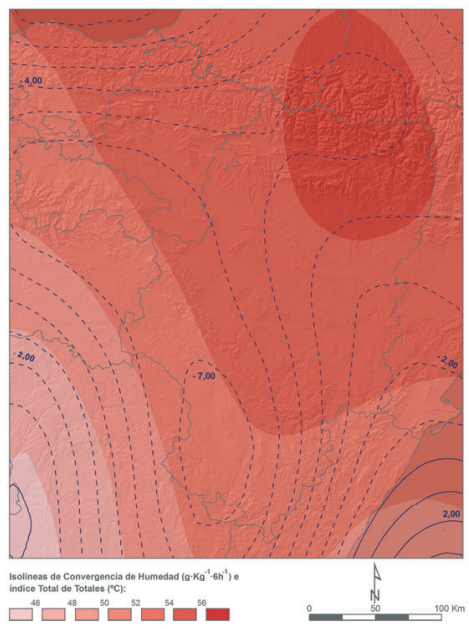

Convergencia de humedad (Hr) en $925 \mathrm{hPa}$ e Índice Total de Totales (15 Z)

Imagen 6.7. Ejemplo de situación tipo 6 (depresión entrante): 6 de septiembre de 2004. 
Comentarios a la situación depresionaria entrante:

El centro del sistema que se aproxima se encuentra situado sobre Oporto, con valores inferiores a $576 \mathrm{dmg} \mathrm{y}-16^{\circ} \mathrm{C}$. Su parte delantera proyecta sobre el área de estudio un flujo de componente sur que arrastra una lengua cálida de unos $-12{ }^{\circ} \mathrm{C}$ con origen en latitudes más bajas. Claramente se puede trazar un eje de vaguada de orientación zonal situado sobre la depresión del Ebro que va a ser el causante de la focalización de la precipitación en dicha zona debido a la fuerte curvatura ciclónica, que a su vez lleva asociada una fuerte advección de la misma, así como unas altas circulaciones no geostróficas en la mitad occidental de la zona de estudio. Por lo tanto, el sistema muestra unas características dinámicas muy marcadas. La configuración cerrada de las isohipsas induce a pensar en un avance lento del sistema, con el eje de la dorsal sobre Baleares.

El flujo de componente sur que existe sobre el Mediterráneo occidental se canaliza en la depresión del Ebro mediante un potente chorro advectivo de baja cota tal y como se observa en la topografía de $850 \mathrm{hPa}$. Este flujo afecta a todo el territorio de estudio, pero se prolonga hasta la Cordillera Cantábrica, aportando gran cantidad de humedad que junto con las temperaturas de hasta $25^{\circ} \mathrm{C}$ crea las condiciones propicias para que los sistemas convectivos no solo sean severos, sino también muy efectivos en la producción de precipitación. A su vez la advección calida en niveles bajos (no presentada) es positiva en la parte occidental y el Mediterráneo; dado que en $500 \mathrm{hPa}$ la temperatura es algo más baja que lo normal, la advección diferencial 500/1 000 hPa (no mostrada) es relativamente positiva sobre la mayor parte de la zona.

Los valores más elevados del índice TT se dan en la mitad norte, centrándose sobre Pirineos y la zona de convergencia de humedad, con valores de $-7 \mathrm{~g} \cdot \mathrm{kg}^{-1} \cdot \mathrm{m}^{-1}$, afecta especialmente al Sistema Ibérico, por lo que en este caso este campo no explica adecuadamente las fortísimas precipitaciones que se producen en las Bardenas y el valle del Ebro y que como se ha indicado tienen su origen en causas dinámicas presentes en los niveles medios y altos.

En superficie, la isobara de $1012 \mathrm{hPa}$ adopta la forma propia de los sistemas convectivos intensos, con una parte ciclónica sobre el valle del Ebro y otra trasera anticiclónica envolviendo el aire frío y seco que se desploma desde niveles altos arrastrado por la ingente precipitación. También en la zona del litoral levantino se observa un dipolo de bajas y altas presiones similar y que sería el responsable de la precipitación en esa zona, así como de la baja precipitación en la Ibérica turolense por encontrarse bajo la influencia de las altas presiones relativas.

La precipitación más importante adquiere una estructura globular con lento avance hacia el nordeste, al igual que los otros núcleos más modestos. Aunque en conjunto este tipo de situaciones es de las que más baja correlación presenta entre precipitación y descargas, en este caso extremo tampoco es especialmente alta, sino todo lo contrario, sin duda debido a la gran potencia de los sistemas convectivos.

Este día sigue siendo muy recordado entre los aficionados al ciclismo pues la precipitación afectó al recorrido de una etapa de la Vuelta Ciclista a España, causando efectos devastadores en el pelotón y en la propia carretera, lo que obligó a modificar su trazado y la convirtió en una auténtica odisea. 


\section{Caso de estudio del tipo 7 (situaciones depresionarias rebasadas): 7 de septiembre de 2006}

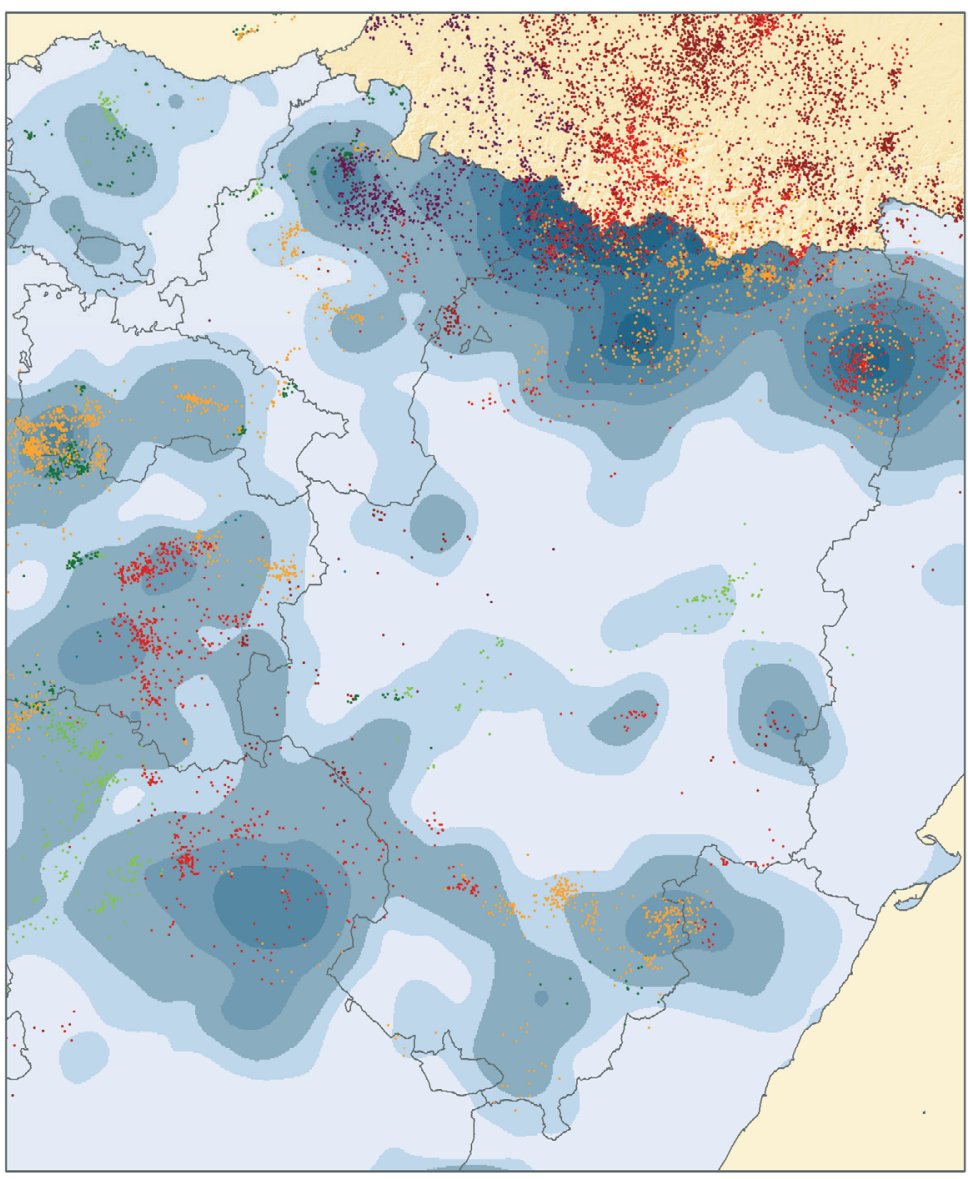

Número de rayos por intervalo horario desde las 06:00 TUC a las 05:59 TUC del día siguiente:

06:00-08:59 09:00-11:59 12:00-14:59 15:00-17:59 18:00-20:59 21:00-23:59 00:00-02:59 03:00-05:59

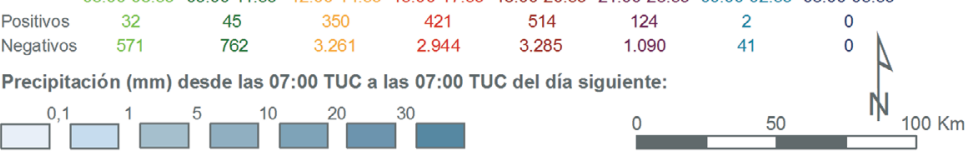

Precipitación (PCP) en 24 h (07-07 Z) y Descargas eléctricas (06-06 Z)

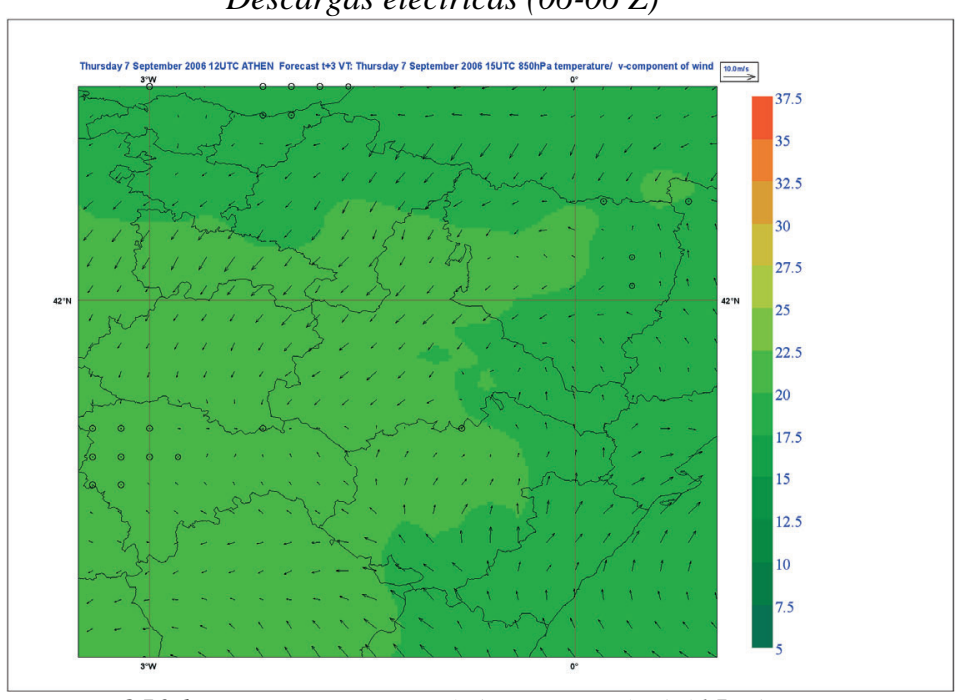

850 hPa: Temperatura (T) y Viento (W) (15 Z)

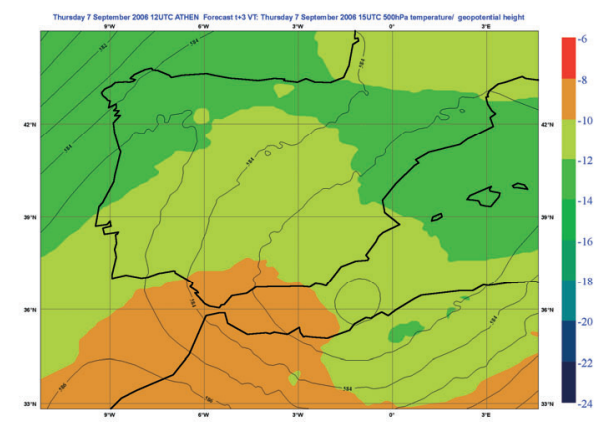

500 hPa: Geopotencial (Z) y temperatura (T) (15 Z)

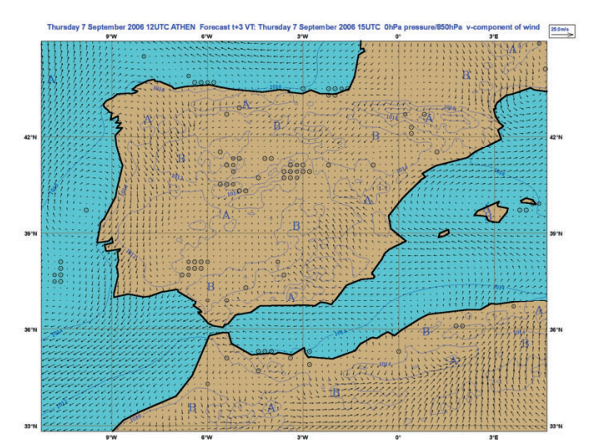

Superficie: Presión (PSL), Viento (W) (15 Z)

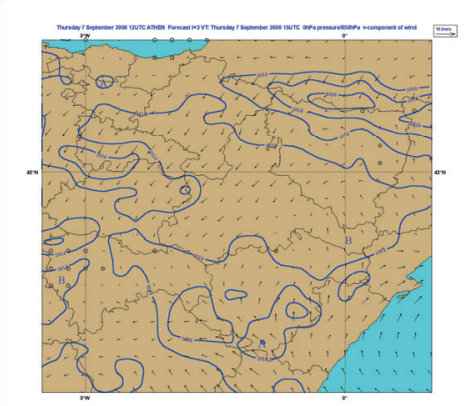

Detalle de Presión (PSL) y Viento (W) en superficie (15 Z)

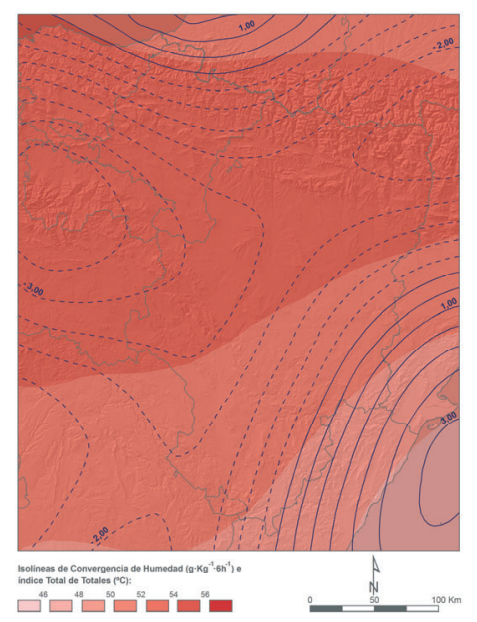

Convergencia de humedad (Hr) en $925 \mathrm{hPa}$ e Índice Total de Totales (15 Z)

Imagen 6.8. Ejemplo de situación tipo 7 (depresión rebasada): 7 de septiembre de 2006. 
Comentarios a la situación depresionaria rebasada:

En este caso la baja cerrada ya ha alcanzado la zona del mar de Alborán y toda el área de estudio se encuentra bajo la influencia del flujo del nordeste asociado a la parte trasera de la misma marcada por las isohipsas de 584 y 585 dmg y temperaturas en torno a $-14{ }^{\circ} \mathrm{C}$. Mientras la depresión se encuentra sobre la zona, la advección diferencial de giro ciclónico en niveles altos es prácticamente nula por tratarse de una depresión madura con una configuración concéntrica en todos los niveles que no está desplazada en la horizontal. Además, en su progresión hacia el Mediterráneo, la parte posterior presenta curvatura anticiclónica, con lo que sobre la zona siguen existiendo valores negativos o nulos. Por otra parte, las únicas condiciones favorables para las circulaciones ageostróficas se localizan sobre Pirineos, Navarra, La Rioja e Ibérica más occidental, asociadas a un corto paquete de viento (jet streak) del chorro en niveles altos del nordeste.

El mapa de $850 \mathrm{hPa}$ refleja que mientras en la parte occidental del territorio soplan vientos del noroeste, la zona litoral se halla bajo la influencia de la parte delantera del centro de bajas presiones y presenta vientos de componente sur; a la par, en Huesca las intensidades son muy bajas. Las temperaturas muestran valores alrededor de $22{ }^{\circ} \mathrm{C}$.

Las convergencias de humedad son ligeras y se encuentran centradas en la parte occidental del área de estudio, mientras que los vientos de origen mediterráneo no se introducen tierra adentro.

En superficie, las bajas presiones que abarcan la depresión del Ebro quedan bordeadas por las zonas de altas presiones en los sistemas montañosos, las cuales, ayudadas por el factor orográfico, van a dar origen a la focalización de las descargas eléctricas que se puede observar.

Quizá lo más llamativo sea ver en los mapas de 500 y 850 hPa como las temperaturas más frescas están instaladas sobre toda la zona, tanto en niveles bajos como medios y altos. En estas condiciones la diferencia de temperaturas en la vertical no presenta valores elevados, lo que determina una menor inestabilidad, como se ve en los valores relativamente bajos del índice TT, que indican convección de débil a moderada.

Las tormentas adoptan una distribución espacial dispersa y con poco recorrido propio de esta situación, aunque esta es una situación en la que se puede apreciar las trayectorias norte a sur que siguen los núcleos convectivos o, más frecuentemente, de nordeste a suroeste, que como se sabe es contraria a la usual de avance desde el suroeste a nordeste. Asimismo, la zona más activa es la zona pirenaica en la que se extiende la actividad, que tiene su origen en la vertiente francesa, pues nuevamente la mole pirenaica se opone al flujo y las laderas en la parte francesa también tienen un carácter retentivo, lo que hace que las máximas concentraciones de descargas se den en territorio francés.

En este caso sí que aparecen descargas dispersas asociadas a zonas con poca o nula precipitación, concordante con la baja correlación entre ambas que se ha constatado para este tipo de situaciones. 
Caso de estudio del tipo 8 (ondas largas del noroeste): 18 de agosto de 2005

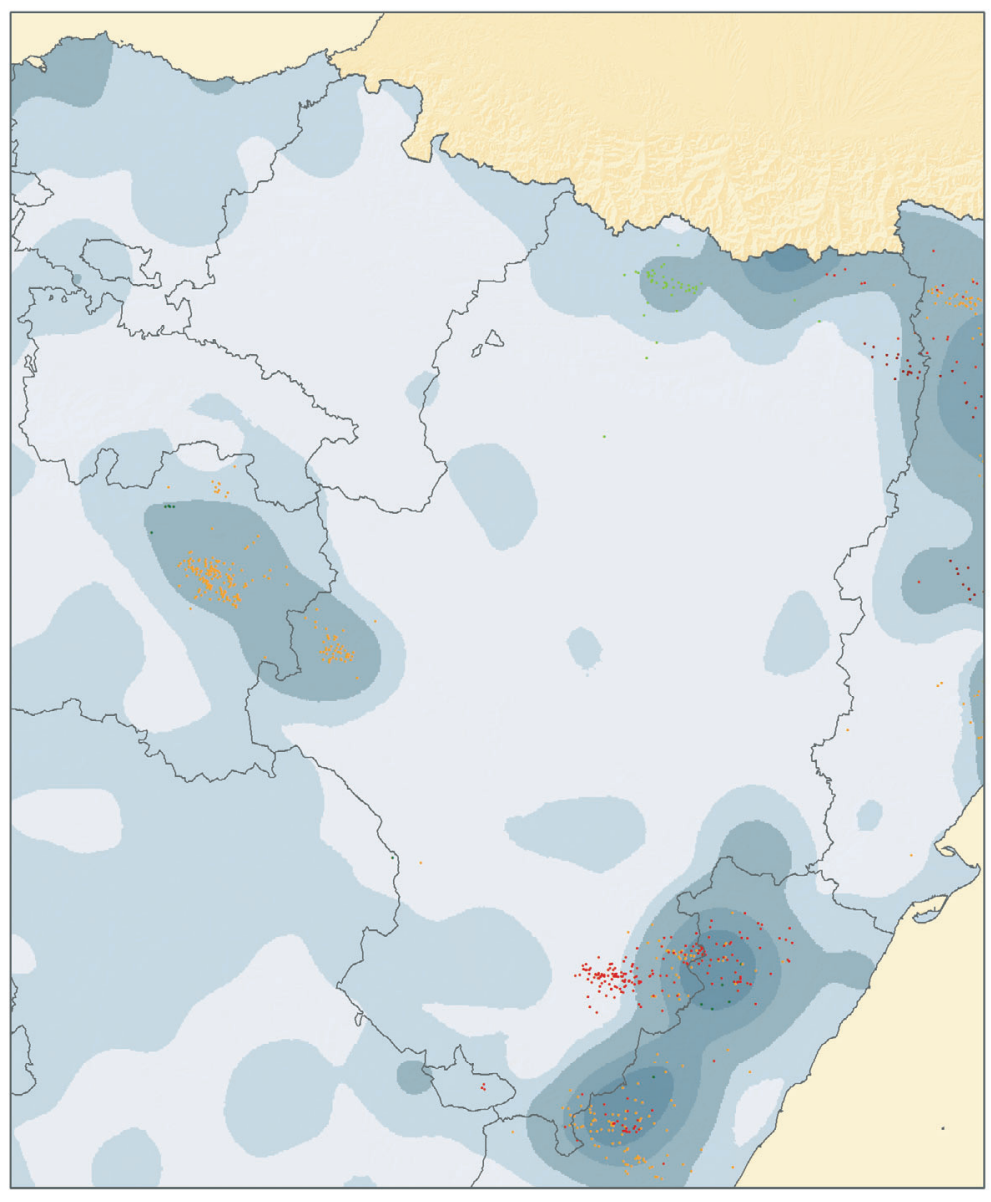

Número de rayos por intervalo horario desde las 06:00 TUC a las 05:59 TUC del día siguiente:

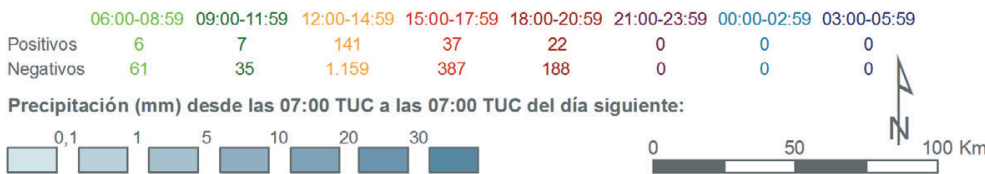

Precipitación (PCP) en 24 h (07-07 Z) y Descargas eléctricas (06-06 Z)

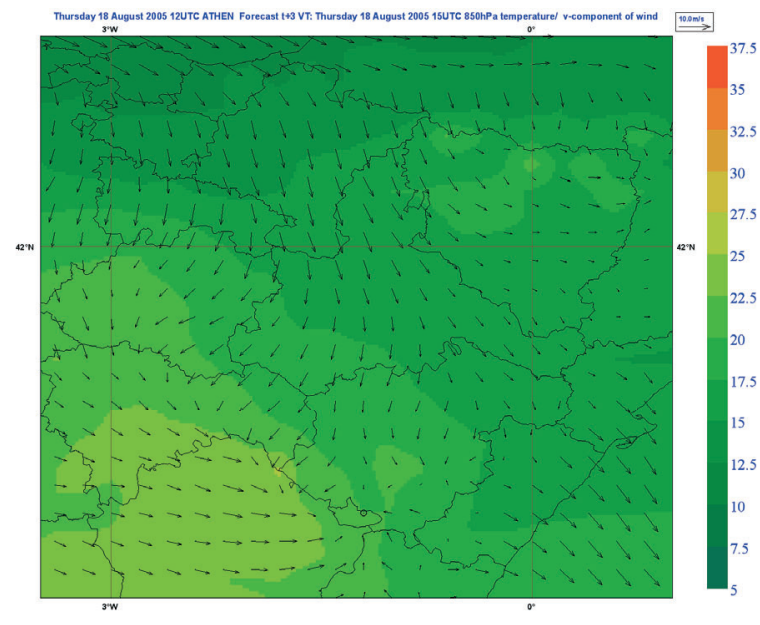

850 hPa: Temperatura (T) y Viento (W) (15 Z)

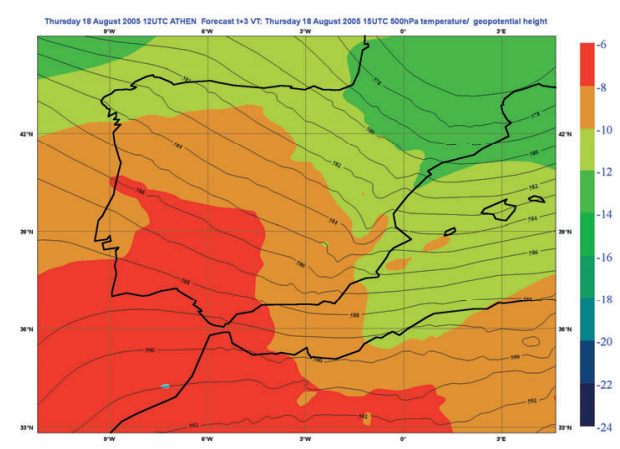

500 hPa: Geopotencial (Z) y Temperatura (T) $(15 \mathrm{Z})$

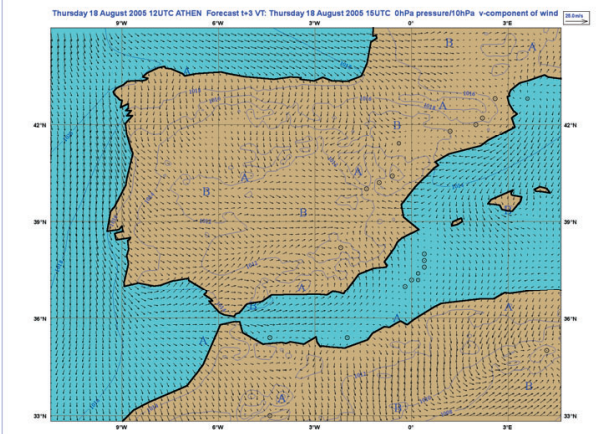

Superficie: Presión (PSL), Viento (W) (15 Z)

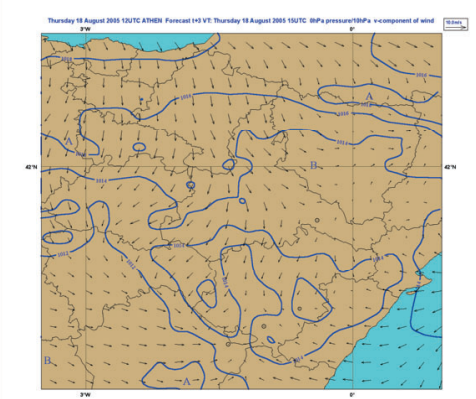

Detalle de Presión (PSL) y Viento (W) en superficie (15 Z)

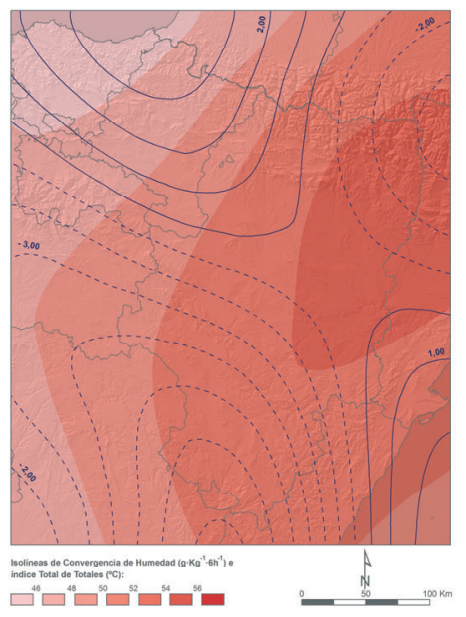

Convergencia de humedad (Hr) en $925 \mathrm{hPa}$ e Índice Total de Totales (15 Z)

Imagen 6.9. Ejemplo de situación tipo 8 (onda larga del noroeste):18 de agosto de 2005. 
Comentarios a la situación de onda larga del noroeste:

Es el tipo de situación más frecuente. Incluso a nivel popular se conocen los rasgos meteorológicos que las acompañan. Aunque en invierno no suelen ser demasiado apreciadas debido a que los vientos fuertes asociados aumentan la sensación fría del ambiente, durante el verano suelen representar un respiro dentro de los días de fuerte canícula del centro del verano. La experiencia demuestra que suelen tener una duración de unos cuatro días y se establecen sobre la zona tras el paso de los sistemas convectivos, aportando frescor y la ventilación para aliviar las jornadas precedentes.

La topografía de $500 \mathrm{hPa}$ se caracteriza por la presencia de un flujo de largo recorrido proveniente del cuarto cuadrante, aunque en ocasiones también llega desde el NNE, dependiendo de la circulación en la parte trasera del centro de bajas presiones precedente. En el caso de estudio, la isohipsa de $580 \mathrm{dmg}$ y la isoterma de $-10^{\circ} \mathrm{C}$ pasan sobre el centro de la zona de estudio. Los tres campos de tipo termodinámico que se analizan presentan valores fuertemente negativos en estas situaciones como puede deducirse de los campos presentados en este ejemplo.

Esta dirección del flujo se mantiene igual en todos los niveles inferiores produciéndose un fuerte acoplamiento con la orografía mediante apantallamientos y redireccionamientos en las zonas montañosas, seguidos de fuertes canalizaciones en valles de prácticamente cualquier dimensión. Así, mientras en zonas altas se mantiene el viento del norte, en el valle del Ebro sopla de aproximadamente dirección NW, y en el valle del Jalón sopla del NNE adaptándose al relieve. El dipolo bárico doble con altas presiones en Pirineos e Ibérica y bajos valores en la depresión del Ebro se encarga de mantener temporal y espacialmente el flujo, alcanzando la desembocadura del Ebro y adentrándose sin dificultad mar adentro.

Es un flujo divergente, seco y subsidente, lo que determina una advección térmica muy negativa y la práctica ausencia de nubosidad y precipitaciones. Solamente se dan algunos chubascos esporádicos en zonas con relieves prominentes como el Moncayo, Pirineos o los ramales ibérico-béticos más próximos al litoral mediterráneo, consecuencia de la interacción de la nubosidad de características ondulatorias con dichos relieves.

Solamente en el sur de Teruel se producen convergencias con los ponientes que soplan en la Meseta o incluso con el régimen de brisas que se establece en la costa. En cuanto a los índices térmicos de inestabilidad, como el TT, sus valores son solo moderados debido al menor contraste de temperaturas en la vertical. Solo en la parte central y oriental del Pirineo, a resguardo del flujo que aquí no llega a mezclar las distintas capas en altura, se dan valores más altos que explicarían los chubascos, que aunque de poca importancia, se dan allí. La trayectoria de estas tormentas sigue lógicamente la dirección del flujo y en ocasiones alcanzan las Sierras Exteriores de los Pirineos.

No obstante, no debe confundirse esta situación con el régimen exclusivamente nocturno y por tanto transitorio, propio de las brisas de ladera y valle, que se establece muchas noches veraniegas en los valles fluviales, y que aunque también vienen a tener un carácter refrescante y coinciden en su dirección en algunos casos, carecen de la circulación del noroeste en altura que caracteriza la situación estudiada. 


\section{Caso de estudio del tipo 9 (oclusiones a vaguadas rebasadas): 29 de julio de 2004}

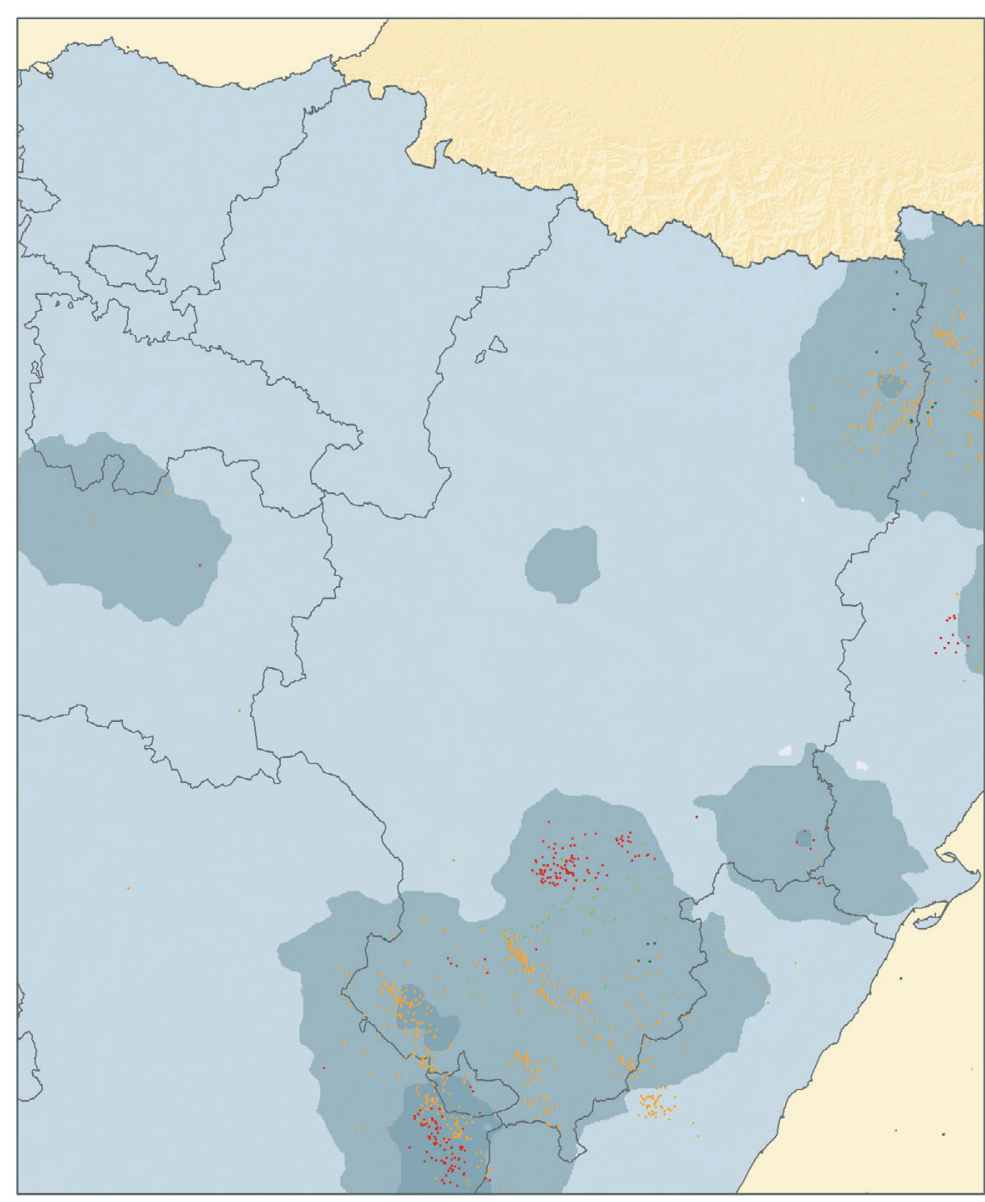

Número de rayos por intervalo horario desde las 06:00 TUC a las 05:59 TUC del día siguiente: 06:00-08:59 09:00-11:59 12:00-14:59 15:00-17:59 18:00-20:59 21:00-23:59 00:00-02:59 03:00-05:59

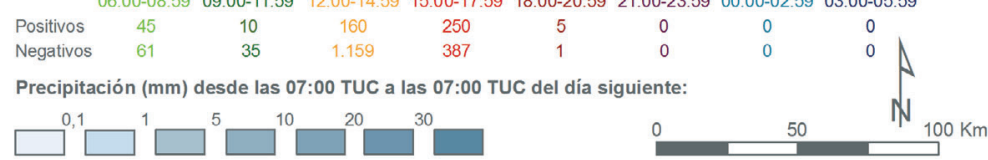

Precipitación (PCP) en 24 h (07-07 Z) y Descargas eléctricas (06-06 Z)

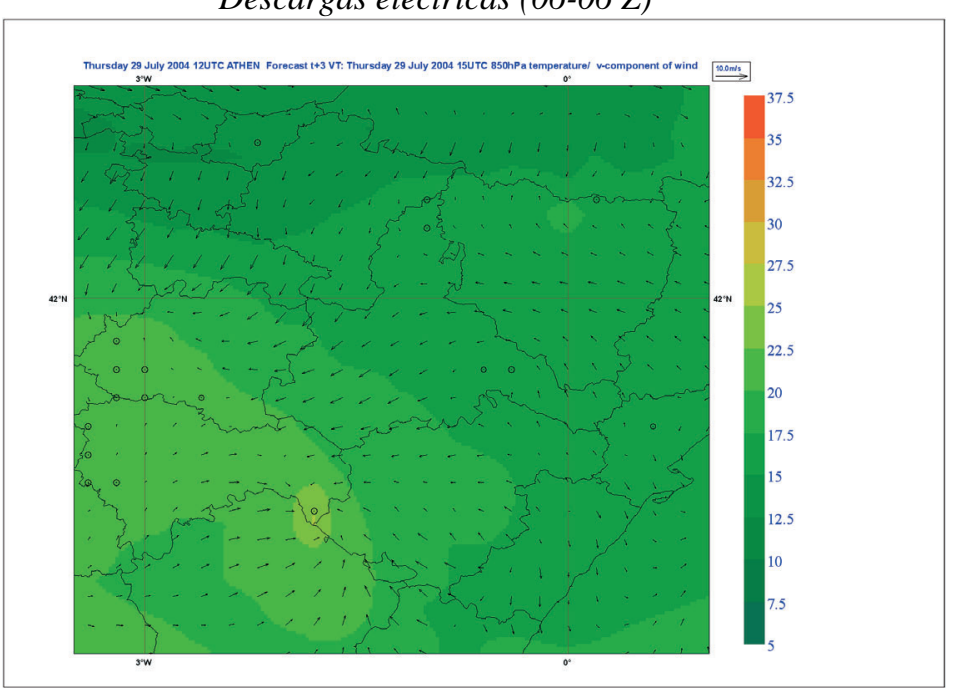

850 hPa: Temperatura (T) y viento (W) (15 Z)

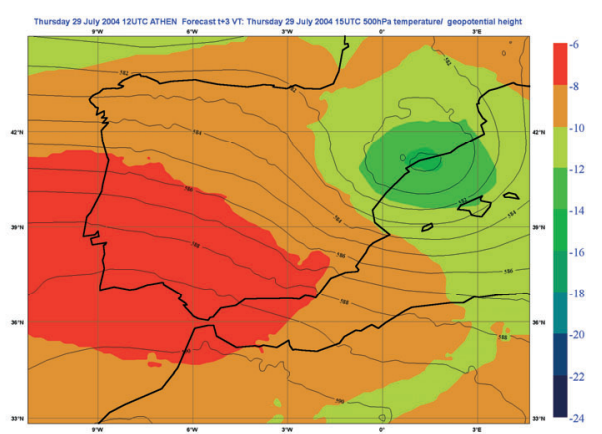

500 hPa: Geopotencial (Z) y Temperatura (T) (15 Z)

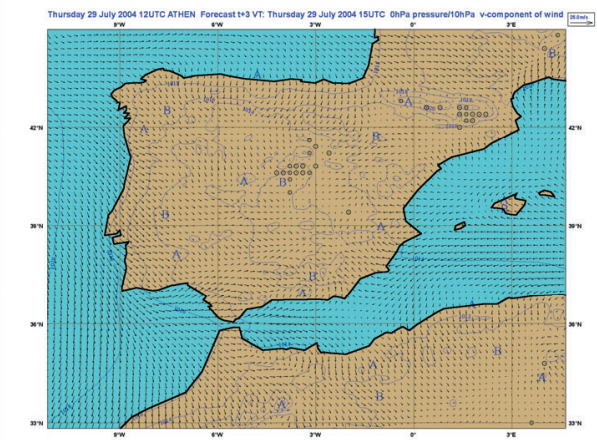

Superficie: Presión (PSL), Viento (W) (15 Z)

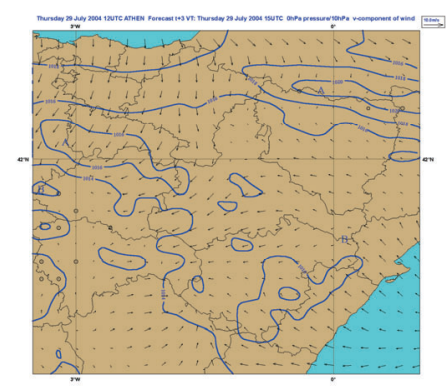

Detalle de Presión (PSL) y Viento (W) en superficie (15 Z)

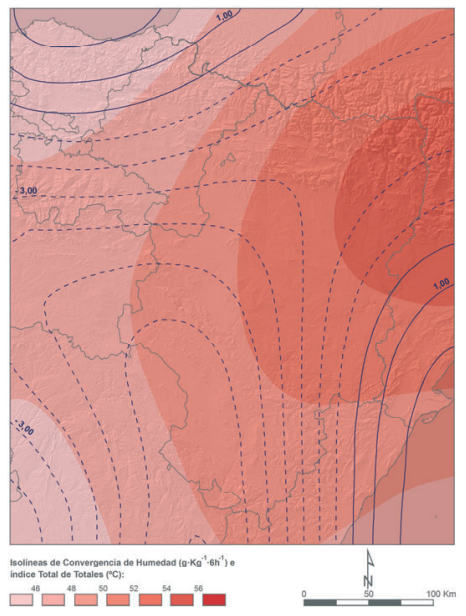

Convergencia de humedad (Hr) en $925 \mathrm{hPa}$ e Índice Total de Totales (15 Z)

Imagen 6.10. Ejemplo de situación tipo 9 (oclusión a vaguada rebasada):29 de julio de 2004. 
Comentarios a la situación de oclusiones a vaguadas rebasadas:

Como se ha comentado en la descripción general de este tipo de situaciones, está participada por varios de los tipos analizados y tiene por principal característica que en determinadas ocasiones los sistemas actuantes se ocluyen sobre la zona de estudio dando lugar a precipitaciones que son más copiosas, por acumulación, de lo que cabría esperar en un principio. No se trata, en cualquier caso, de situaciones especialmente frecuentes.

En el caso de estudio el centro de bajas presiones en altura, de dimensiones reducidas, se sitúa al norte del delta del Ebro, con valores inferiores a $580 \mathrm{dmg}$ y $-14{ }^{\circ} \mathrm{C}$ de temperatura en la topografía de $500 \mathrm{hPa}$, mostrando vientos de componente norte en la parte posterior occidental y flujos del sur en la parte oriental.

Los campos dinámicos en niveles medios y altos son los propios de sistemas depresionarios muy evolucionados y, por lo tanto, la advección de vorticidad presenta valores negativos o muy bajos en casi toda la zona y, respecto a las circulaciones transversales al flujo, solamente la parte más al sur y sobre el Sistema Ibérico se encuentra influenciada por las mismas al encontrarse a la derecha de la zona de salida de un máximo de viento que cruza sobre la Península y puede apreciarse en la topografía de $500 \mathrm{hPa}$.

Estas diferencias quedan muy claras en el nivel bajo de $850 \mathrm{hPa}$ : en las provincias más occidentales hay flujos de componente norte, mientras en las restantes el flujo es mayoritariamente del $\mathrm{E}$, de tal forma que las convergencias de flujo, aunque no son especialmente intensas, están extendidas sobre prácticamente toda la zona.

Un patrón similar se repite en el mapa de superficie debido a la situación de las cuñas anticiclónicas relativas en las zonas de montaña dentro de un marco general mesoescalar de bajas presiones y al desarrollo sin dificultad de los flujos marinos que soplan desde el litoral.

El índice TT muestra sus máximos valores en la zona nororiental, en la que el embolsamiento de niveles medio-altos se superpone sobre los valores del orden de $20{ }^{\circ} \mathrm{C}$ que se dan en $850 \mathrm{hPa}$. A su vez, la advección diferencial de espesores es máxima en la zona turolense influenciada por los valores en torno a $25^{\circ} \mathrm{C}$ que se dan en ella, aunque las advecciones térmicas en niveles bajos son negativas en toda la zona.

Integrando todo lo visto hasta ahora en los diferentes tipos, el carácter de la precipitación en la parte occidental es diferente del que se produce en el levante: esta última presenta algunas características de tipo convectivo, mientras que la del poniente tiene un carácter mucho más estratiforme, como queda reflejado en la distribución de las descargas eléctricas.

Este diferente carácter de los tipos de precipitaciones asociadas según las zonas consideradas es lo que determina que la correlación entre descargas eléctricas y cantidades de precipitación acumulada sea el más bajo de todos los tipos establecidos en la clasificación. 



\section{CONCLUSIONES}

La calidad de los modelos numéricos para la predicción del tiempo es progresivamente mayor. Este avance permite la mejora de la predicción de fenómenos como los convectivos que, por su naturaleza, pueden ser muy intensos y localizados en el tiempo y en el espacio. Como muestra de ello, este trabajo se basa en buena parte en resultados procedentes de campos de análisis y predicciones de modelos numéricos. Sin embargo, limitar la comprensión de los fenómenos atmosféricos, por ejemplo, en el caso de la predicción meteorológica, a los resultados que ofrecen los modelos numéricos puede reducir la comprensión de los procesos y hacer perder la perspectiva de los mismos. Así, sin que ello represente en absoluto un menosprecio a los productos de los modelos numéricos, una visión más conceptual y general sobre el desarrollo de la convección puede aportar un extra, puesto que los modelos conceptuales constituyen otra herramienta ampliamente empleada por el colectivo de personas dedicadas a las tareas de predicción, en las que cada uno de ellos sirve para sintetizar el conocimiento de un conjunto de situaciones meteorológicas con características similares. Además estos modelos suelen incorporar no solo características sinópticas, sino que también incorporan razonamientos de tipo mesoescalar para la zona de aplicación. Es en este punto donde los resultados obtenidos adquieren su principal valor, como herramienta de de clasificación y síntesis de los “tipos de tiempo” en la zona de estudio.

Además de la finalidad concreta y aplicada para la predicción meteorológica, el estudio de la distribución espacial de los fenómenos convectivos y su clasificación según el tipo de situación tiene validez en sí misma, puesto que aporta una climatología de elementos que normalmente o no se tienen en cuenta, o se consideran de forma parcial y a partir de datos poco consistentes.

En este sentido, se puede concluir que los máximos de actividad tormentosa en España se dan en el interior del cuadrante nordeste peninsular, el área de estudio de este trabajo. Los máximos absolutos son diferentes según se trate de la densidad de rayos que caen en la superficie o del número de días de tormenta. En el primer caso, el máximo está en un ramal de la sierra de Gúdar, en el Maestrazgo turolense, que lleva el adecuado nombre de sierra del Rayo y su valor es superior a 3 rayos por $\mathrm{km}^{2}$ y temporada (abrilseptiembre). Sin embargo, por número de días de tormenta, el máximo se da en el Pirineo oriental aragonés, en las Sierras Interiores del Sobrarbe y la Ribagorza (también la catalana), con valores de 35 días por temporada. Es decir, grosso modo, hay tormenta en esa zona uno de cada seis días entre abril y septiembre, valores que aumentan a más de uno de cada cuatro días en julio y agosto.

La mayor cantidad de rayos se produce entre las 15 y las 18 h UTC, aunque este hecho general presenta variaciones según la época del año, así como también la zona donde se localizan los máximos. En general, puede hablarse de un desplazamiento de los máximos de las zonas occidentales del área de estudio durante la primavera a la zona puramente mediterránea a comienzos del otoño.

Aparecen, sin embargo, más diferencias en el número de días de tormenta por zonas y por meses, aunque en general, los máximos se dan en junio, julio y agosto. La variabilidad entre temporadas, tanto en densidad de rayos como en número de días de 
tormenta, es mayor en la Ibérica occidental (Soria, La Rioja, Moncayo) y en la depresión del Ebro.

Durante la aquí denominada temporada cálida, el porcentaje de precipitación recogida con respecto al total anual es ampliamente superior al 50 \% en la Ibérica, buena parte de la depresión del Ebro y el Pirineo oriental. En áreas de la Ibérica turolense y el Pirineo catalán más occidental, la precipitación estrictamente estival es superior a la tercera parte del total anual. Se produce la aparente paradoja de que las zonas teóricamente más mediterráneas tienen su máximo de precipitación en verano. Por tanto, es consecuente pensar que la convección juega un papel determinante en este resultado. Dada la imposibilidad, comentada a lo largo del trabajo, de discriminar entre precipitación convectiva y estratiforme a partir de los datos de origen, se ha procedido a estudiar la correlación y la asociación que hay para cada punto de rejilla del área de estudio entre precipitación y rayos. La correlación es muy alta, superior a 0,5 en general, alcanzando sus valores máximos en junio y julio. Como podría esperarse, esta correlación es mayor en el área de influencia mediterránea y bastante menor en la zona de influencia cantábrica.

El estudio de la asociación entre la precipitación y los rayos, tratando ambos como variables cuantitativas, arroja resultados similares. Por meses, la asociación máxima se da en junio y julio y aparece, además, un resultado interesante: la probabilidad máxima de tormentas secas o con muy poca precipitación ronda el $30 \%$ y se da en el mes de agosto, lo cual es relevante de cara a la aparición de incendios forestales originados por rayo. Otro resultado interesante del estudio de la asociación es la dirección de la misma: es más acertado colegir que se están produciendo precipitaciones intensas a partir de grandes densidades de rayos que lo contrario, especialmente en la depresión del Ebro y el litoral mediterráneo. Este hecho puede ser de utilidad en las labores de vigilancia meteorológica.

Este trabajo incluye una clasificación sinóptica de las situaciones que se presentan durante la temporada cálida. Los métodos para realizar una clasificación sinóptica son prácticamente infinitos (YARNAL, 1993) y no puede decirse que exista un método universalmente aceptable. En este caso, se ha pretendido realizar una clasificación sencilla, definida a partir de unos criterios subjetivos basados en la experiencia y que sacase el máximo partido de las bases de datos disponibles, tanto de salidas de modelos numéricos, como de descargas y de precipitación. No obstante esta sencillez, los resultados obtenidos del agrupamiento de situaciones resisten con coherencia los análisis posteriores realizados empleando consideraciones puramente meteorológicas, no solo en el aspecto dinámico que es lógico que quede bien definido al ser el viento la variable empleada, sino que también muestran claras coherencias con las consideraciones térmicas en los distintos niveles atmosféricos y que tanta importancia tienen en el tipo y cantidad de precipitaciones recogidas en el área de estudio debido a sus particulares características geográficas y orográficas.

Como resultado de sucesivos procesos de reagrupamiento ha quedado restringido a 9 el número de tipos de situaciones del estudio, aunque para aquellos profesionales interesados en una más estricta catalogación se han mantenido los 26 subtipos que inicialmente surgen del proceso clasificatorio. 
Para cada uno de estos nueve tipos se ha realizado un estudio pormenorizado de cada uno de los aspectos mencionados anteriormente: densidad media de descargas, probabilidad de tormenta, precipitación media y medidas de correlación y de asociación entre precipitación y rayos, así como consideraciones sobre su frecuencia mensual media y por temporada. Se ha podido discriminar a través de esta clasificación cuáles son aquellas situaciones más propensas al desarrollo de tormentas (las situaciones del sur, las del suroeste con difluencia y las situaciones de oclusiones a vaguadas rebasadas), en cuáles existe una mejor correlación y asociación entre precipitación y rayos - o dicho de otro modo, en cuáles es la precipitación más convectiva en general- (las del suroeste con o sin difluencia) y además, para cada una de ellas, se ha logrado representar espacialmente las zonas donde es más probable que se desarrolle la actividad convectiva, que presentan grandes variaciones entre unas y otras situaciones.

Para dotar a este estudio de una mayor profundidad y utilidad práctica, se ha realizado un modelo de regresión logística general y para cada situación que identifique cuáles son los campos derivados de los modelos numéricos que mejor explican las situaciones y, por ello, en los que conviene fijarse más a la hora de realizar una predicción. En general, estos campos son el índice total de totales, las convergencias de humedad en $925 \mathrm{hPa}$ y la convergencia de vientos en superficie. Para cada situación varían los campos más relevantes para explicarla, aunque el índice total de totales suele ser el más importante en la mayoría de ellos. Este análisis ha permitido identificar las situaciones con mayor o menor predecibilidad. Se puede afirmar que, en general, atendiendo al porcentaje global de acierto, es más fácil acertar una predicción en aquellas situaciones con carácter menos convectivo y más difícil hacerlo en las más dinámicas. Sin embargo, considerando la capacidad de predecir con mayor precisión espacial la aparición de tormenta, esta es mayor en situaciones más inestables y menor en situaciones a priori más estables.

El trabajo incluye casos de estudio para cada una de las situaciones, con el objetivo de ilustrar mejor las características de cada una de ellas. La elección de los ejemplos ha sido cuasi aleatoria, solo incluyendo algún caso que trae algún recuerdo particular pero desde luego sin buscar la facilidad de las explicaciones o el buen ajuste del modelo numérico en el que se basan las interpretaciones.

A pesar del carácter técnico de la publicación, se ha procurado dotar al texto de una sencillez de léxico que permita el seguimiento del mismo por cualquier persona que posea unos conocimientos meteorológicos elementales. Aunque se ha evitado en general la utilización de formulación de carácter físico-matemático, muchos de los conceptos utilizados tienen su fundamentación en dichos desarrollos y para explicar aquellos conceptos que pueden resultar algo menos habituales a algún tipo de lectores menos especializados se ha procurado dar una explicación de tipo descriptivo lo más asequible posible. 



\section{BIBLIOGRAFÍA}

AEMET-IM (2011). Atlas Climático Ibérico. Agencia Estatal de Meteorología e Instituto de Meteorología, Madrid.

Allmaras, R. R., R. E. Burwell, W. E. LARson y R. F. Holt (1966). Total porosity and random roughness of the interrow zone as influenced by tillage. USDA Conservation Research Report, 7, 1-14.

Álvarez, E. y F. CORTÉs (2007). Modelo de colaboración entre administraciones públicas para la lucha contra los incendios forestales en la Comunidad Autónoma de Aragón (España). $4^{\text {th }}$ International Wildland Fire Conference, Wildfire 2007, Sevilla.

Álvarez, E. (2000). Climatología de descargas eléctricas (año 1999). Documento disponible en línea en: www0.inm.es/cmt/zara/int/descarga/rayos99/pagerayos99.html (consulta julio de 2010).

Álvarez, E. (2001). Climatología de descargas eléctricas (año 2000). Documento disponible en línea en: www0.inm.es/cmt/zara/int/descarga/rayos00/pagerayos00.html (consulta julio de 2010).

Álvarez, E., C. DE LA Fuente y A. GARCíA (2005). Índice meteorológico de riesgo de incendios forestales para Aragón. Serie monografías (Ministerio de Medio Ambiente), Nota Técnica del CMT en Aragón, La Rioja y Navarra, n. ${ }^{\circ}$ 4, Instituto Nacional de Meteorología. Centro de Publicaciones, Ministerio de Medio Ambiente, Madrid.

Álvarez, E., F. Espejo, F. Cortés y C. LAFragüEta (2009). Characteristics of convective processes in inland NE Spain. $5^{\text {th }}$ European Conference on Severe Storms, ECSS 2009, Landshut (Alemania).

Barón, F. J. y F. TÉLlez (2004). Apuntes de Bioestadística. Universidad de Málaga. Documento disponible en línea en: www.bioestadistica.uma.es/baron/apuntes/ficheros/ cap01.pdf (consulta de junio de 2011).

BuisÁn, S. y F. ESPEJO (2009). Convective activity and severe weather in the Teruel Province: description, episodes and possible future trends. $1^{\text {st }}$ Spain-China Symposium on Geophysical \& Geochemichal Geosystems, SG3, Zaragoza.

BuisÁN, S., F. EsPejo, G. SANZ, F. CoRTÉS y C. LAFRAGÜETA (2009). Characterization of the convective activity in the Eastern Iberian Range, Spain. $30^{\text {th }}$ International Conference on Alpine Meteorology, ICAM 2009, Rastatt (Alemania).

Canavos, G. C. (2003). Probabilidad y Estadística: aplicaciones y métodos. Ed. McGraw Hill, Madrid.

ConesA, A. (2003). Tornado de Valdealgorfa (Teruel) de 23 de julio de 2003. Documento disponible en línea en: www0.inm.es/cmt/zara/int/tormentas/tornado3/ valde.htm (consulta de julio de 2010).

ConesA, A. (2004). Tornado de Corbalán (Teruel) de 28 de agosto de 2004. Documento disponible en línea en: www0.inm.es/cmt/zara/int/tormentas/tornado2/ TORNADO DE CORBALAN.htm (consulta de julio de 2010).

CuAdrat, J. M., R. SERrano y M. A. SAz (2010). Clasificación climática de la Cuenca del Ebro. Confederación Hidrográfica del Ebro. Sin publicar. 
EsPeJo, F. (2007). “Granizo y convección severa”, en LóPEz, F., M. CABRERA, J. M. Cuadrat (Coord.). Atlas Climático de Aragón. Departamento de Medio Ambiente, Gobierno de Aragón, Zaragoza.

ESPEJO, F. y R. SANZ (2001). El tornado del 28 de agosto de 1999 en la Sierra del Rayo (Teruel). 5. ${ }^{\circ}$ Simposio Nacional de Predicción, INM, Madrid. (También disponible en línea en: www0.inm.es/cmt/zara/int/index.html).

Espejo, F. y E. Álvarez (2007). Characterization of the evolution of convective processes in the Ebro Basin (NE Spain). $4^{\text {th }}$ European Conference on Severe Storms, ECSS 2007, Trieste (Italia).

FreXeiro, S. (2009). Population density in Spain. Documento disponible en línea en: http://es.wikipedia.org/wiki/Archivo:EspDens2.jpg (consulta de agosto de 2010).

HERNÁNDEZ, B. (2001). Técnicas estadísticas de investigación social. Editorial Díaz de Santos, Madrid.

Jolliffe, I. T. y D. B. Stephenson (2003). Forecast Verification. A Practitioner's Guide in Atmospheric Science. Wiley, Chichester.

Lafragüeta, C., F. Cortés, F. Espejo y E. Álvarez (2009). Estudio comparado de dos episodios de incendios forestales originados por rayo en Aragón. 5. ${ }^{\circ}$ Congreso Forestal Español, SECF, Ávila.

LÓPEZ, L. y J. L SÁNCHEz (2008). Discriminant methods for radar detection hail. Atmospheric Research, 93, 358-368.

ORLANSKI, I. (1975). A rational subdivision of scales for atmospheric processes. Bulletin of the American Meteorological Society, 56 (5), 527-530.

PARDO, A. y M. A. RuIz (2001). SPSS 10.0 Guía para el análisis de datos. Universidad Autónoma de Madrid, Madrid.

PeÑA, J. L. y M. V. LOZANo (2004). “Las unidades del relieve aragonés”, en PeÑA, J. L., L. A. LONGARES y M. SÁnCHEZ. Geografía Física de Aragón. Aspectos Generales y Temáticos, 3-14. Universidad de Zaragoza, Zaragoza.

PÉrez, F. (2004). Cooperación entre las redes de rayos de España y Portugal. 28 ${ }^{\text {th }}$ Jornadas Científicas de la Asociación Meteorológica Española, AME, Badajoz.

PÉREZ, F. (2005). El valor de la información sobre electricidad atmosférica. La evolución de la red de rayos. Ambienta, 49, 57-63.

PÉrez, F. y C. ZANCAJO (2008). Los niveles de la actividad eléctrica atmosférica en España. 30. ${ }^{\circ}$ Jornadas Científicas de la Asociación Meteorológica Española, AME, Zaragoza.

PÉREZ, F. (2009). Sistemas de localización y detección de rayos. Material Didáctico. Curso selectivo para ingreso en Cuerpo Superior de Meteorólogos del Estado. AEMET, Madrid.

PÉReZ, F. y C. ZanCAjo (2010). Regímenes tormentosos en la Península Ibérica durante la década 2000-2009. Boletín de la AME, 28, 28-35.

REQuenA, R. y F. EsPejo (2007). Tornado de Arnedo (La Rioja) de 30 de abril de 2007. Documento disponible en línea en: www0.inm.es/cmt/zara/int/index.html (consulta de julio de 2010). 
Riosalido, R., F. Elizaga, O. Carretero y F. M. Martín (1998). Climatología satélite de sistemas convectivos de mesoescala en las proximidades de la Península Ibérica. Aplicación a la predicción de lluvias torrenciales. Nota Técnica del STAP, n. ${ }^{\circ}$ 29, Instituto Nacional de Meteorología. Centro de Publicaciones, Ministerio de Medio Ambiente, Madrid.

Riosalido, R., J. Ferraz, E. Álvarez, A. Cansado, F. Martín, F. Elizaga, A. MARTín, J. L. CAMACHO y A. Mestre (1998). Estudio meteorológico de la situación del 7 de agosto de 1996 (Biescas). Serie monografías (Ministerio de Medio Ambiente), Nota Técnica del STAP, n. ${ }^{\circ} 26$ y Nota Técnica del CMT en Aragón, La Rioja y Navarra, n. ${ }^{\circ}$ 1, Instituto Nacional de Meteorología. Centro de Publicaciones, Ministerio de Medio Ambiente, Madrid.

Rodríguez, J. R., M. Gómez, M. F. Álvarez, J. L. Marcos, I. Ruiz y F. Castedo (2009). Modelización de la probabilidad espacial de ocurrencia de incendios forestales por rayo en la provincia de León. 5. ${ }^{\circ}$ Congreso Forestal Español, SECF, Ávila.

SOMMERS, R. H. (1962). A new asymmetric measure of association for ordinal variables. American Sociological Review, 27, 799-811.

StOrch, H. y F.W. ZWIERS (1999). Statistical Analysis in Climatic Research. Cambridge University Press, Cambridge.

Vilar, L., I. Gómez, M. P. MARTín y F. J. MARTínez (2007). Análisis comparativo de diferentes métodos para la obtención de modelos de riesgo humano de incendios forestales. $4^{\text {th }}$ International Wildland Fire Conference, Wildfire 2007, Sevilla.

VICENTE, S. M. y M. A. SAZ (2002). Cartografía de precipitaciones y temperaturas en el valle medio del Ebro mediante la utilización de diferentes técnicas estadísticas. Geographicalia, 42, 73-92.

Vicente, S. M., M. A. Saz y J. M. Cuadrat (2003). Comparative analysis of interpolation methods in the middle Ebro Valley (Spain): application to annual precipitation and temperature. Climate Research, 24, 161-180.

YARNAL, B. (1993). Synoptic Climatology in Environmental Analysis: a primer. Belhaven Press, London. 



\section{GLOSARIO DE ABREVIATURAS Y UNIDADES}

ADVG: Advección diferencial de vorticidad geostrófica 300/500 hPa.

ADVVR: Advección de Vorticidad Relativa.

AEMET: Agencia Estatal de Meteorología.

AESP: Advección de espesores en $1000 \mathrm{hPa}$.

ALDF: Advanced Lightning Direction Finding.

B: Coeficientes de las ecuaciones de regresión logística.

C.A.: Comunidad Autónoma.

C.H.: Confederación Hidrográfica.

CC.AA.: Comunidades Autónomas.

Chi-cuadrado $\left(\chi^{2}\right)$ : Estadístico para evaluar la hipótesis de dependencia de poblaciones de datos.

CONH: Convergencia de humedad en $925 \mathrm{hPa}$.

CONW: Convergencia del campo superficial de viento.

CSI: Índice crítico de aciertos.

$\mathbf{C}_{\mathbf{V}}$ : Coeficiente de variación.

DANA: Depresión aislada en niveles altos.

DFR: Tasa de fallo en la detección. Direcciones de procedencia del viento en la rosa de dieseis direcciones.

DIVQ: Divergencia del vector Q $(500,850 \mathrm{hPa})$.

E: Este.

ENE: Este-Noreste.

ESE: Este-Sureste.

F: Probabilidad de falsa detección.

FAR: Proporción de falsas alarmas.

FIV: Factor de Inflación de la Varianza.

FOCN: Frecuencia de eventos nulos correctos.

FOM: Frecuencia de errores.

GPS: Global Positioning System.

GRIB_API: Aplicación informática para tratamiento y representación de datos meteorológicos en formato binario en retícula desarrollada por el Centro Europeo de Predicción a Medio Plazo.

H: Tasa de aciertos.

H+: Alcance de predicción (en horas).

HINR: Modelo HIRLAM de muy alta resolución.

HIRLAM: High Resolution Limited Area Model.

HR: humedad relativa.

HSS: tasa de aciertos de Heidke.

IDW: Inverse Distance Weighting. Método de interpolación según el inverso del cuadrado de la distancia.

IMPACT: Improved Position Accuracy Technology.

INMH: Modelo HIRLAM de alta resolución.

M.A.: Masa de aire.

McIDAS: Man Computer Interactive Data Access System.

Metview: Aplicación informática para tratamiento y representación de datos meteorológicos desarrollada por el Centro Europeo de Predicción a Medio Plazo.

N: Norte. 
NE: Noreste.

NNE: Nor-Noreste.

NNW: Nor-Noroeste.

NW: Noroeste.

PAS.: Pasada.

PCP: Precipitación.

PCP_C: Variable cualitativa de precipitación.

$\mathbf{P}_{\mathbf{i}}$ : Probabilidad de ocurrencia.

POH: Frecuencia de aciertos.

PON: Probabilidad de evento nulo.

PSL: Presión en superficie.

Q: Vector Q de Hoskins (representa las circulaciones ageostróficas transversales al flujo).

RAYOS: Número de rayos.

RAYOS_C: Variable cualitativa de descargas eléctricas.

S: Sur.

SE: Sureste.

Sig.: Nivel de significación estadística.

SIG (GIS, ArcGIS): Sistema de Información Geográfico.

SPSS 15.0: Paquete de software para tratamiento estadístico de bases de datos.

SSE: Sur-Sureste.

SSW: Sur-Suroeste.

SW: Suroeste.

T: Temperatura.

TT: Índice Total de Totales de inestabilidad en $500 \mathrm{hPa}$.

UTC, Z: Tiempo Universal Coordinado, hora del meridiano de Greenwich.

W: Oeste.

WNW: Oeste-Noroeste.

WSW: Oeste-Suroeste.

Z: Altura de geopotencial.

$* * * * * * * * * * * * * * * * * * * * * * * * * * * * * * * * * * * * * * * * * * * * * * *$

d: coeficiente de correlación de Somers

dmg: decámetro geopotencial

g: gramo

h: hora

hPa: hectopascal

$\mathrm{K}$ : Kelvin

kg: kilogramo

$\mathrm{m} / \mathrm{s}$ : metro por segundo

mgp: metro geopotencial

mm: altura de precipitación en milímetros (equivalente a litros por metro cuadrado)

${ }^{\circ} \mathrm{C}$ : grado Celsius

s: segundo

uQ: unidades de Vector $Q$

$\rho:$ coeficiente de correlación de Spearman

$\sigma:$ desviación típica o estándar

$\Sigma$ : sumatorio 